\title{
Leber's hereditary optic neuropathy: an interaction between two genomes?
}

Citation for published version (APA):

Spruijt, L. (2008). Leber's hereditary optic neuropathy: an interaction between two genomes? [Doctoral Thesis, Maastricht University]. Maastricht University. https://doi.org/10.26481/dis.20080227ls

Document status and date:

Published: 01/01/2008

DOI:

10.26481/dis.20080227ls

Document Version:

Publisher's PDF, also known as Version of record

\section{Please check the document version of this publication:}

- A submitted manuscript is the version of the article upon submission and before peer-review. There can be important differences between the submitted version and the official published version of record.

People interested in the research are advised to contact the author for the final version of the publication, or visit the DOI to the publisher's website.

- The final author version and the galley proof are versions of the publication after peer review.

- The final published version features the final layout of the paper including the volume, issue and page numbers.

Link to publication

\footnotetext{
General rights rights.

- You may freely distribute the URL identifying the publication in the public portal. please follow below link for the End User Agreement:

www.umlib.nl/taverne-license

Take down policy

If you believe that this document breaches copyright please contact us at:

repository@maastrichtuniversity.nl

providing details and we will investigate your claim.
}

Copyright and moral rights for the publications made accessible in the public portal are retained by the authors and/or other copyright owners and it is a condition of accessing publications that users recognise and abide by the legal requirements associated with these

- Users may download and print one copy of any publication from the public portal for the purpose of private study or research.

- You may not further distribute the material or use it for any profit-making activity or commercial gain

If the publication is distributed under the terms of Article $25 \mathrm{fa}$ of the Dutch Copyright Act, indicated by the "Taverne" license above, 
Leber's Hereditary Optic Neuropathy: an interaction between two genomes? 
Omslag

Foto: $\quad$ Gemaakt door fotograaf Hannes Wallrafen, "De boom" Honduras 2001@. www. wallrafen.nl.

Ontwerp: Francis van der Lubbe

Printing: Benda drukkers v.o.f., Nijmegen

ISBN: $\quad$ 978-90-9022826-6

The studies presented in this thesis were financially supported by: Mitocircle, SOON, ANVVB. 


\title{
Leber's Hereditary Optic Neuropathy: an interaction between two genomes?
}

\author{
Proefschrift \\ ter verkrijging van de graad van doctor \\ aan de Universiteit Maastricht, \\ op gezag van de Rector Magnificus, \\ Prof. mr. G.P.M.F. Mols \\ volgens het besluit van het College van Decanen \\ in het openbaar te verdedigen op \\ woensdag 27 februari 2008 om 16.00 uur
}

door

Liesbeth Spruijt

geboren op 18 juli 1970 te Amersfoort 
Promotor:

Copromotoren:

Manuscriptcommissie:
Prof. dr.C.T.R.M. Schrander-Stumpel

Dr. H.J.Smeets

Dr. C.E.M. de Die-Smulders

Prof. dr. F. Hendrikse (voorzitter)

Dr. C. Faber

Prof. dr. N.V. Knoers-Slobbe (Katholieke Universiteit Nijmegen) Prof dr. J.P. Fryns (Katholieke Universiteit Leuven)

Prof. dr. A. Bergen ( 101 Amsterdam) 


\section{Contents}

General introduction and aims of the study

Introduction to mitochondrial disorders and LHON in particular

Chapter $1 \quad$ Mitochondria

Chapter 2 Leber's Hereditary optic neuropathy. Encyclopedia of Life Science. John Wiley \& Sons, Ltd: Chichester (2007), United Kingdom doi: 10.1002/9780470015902. a0005541.

Clinical phenotype

Chapter 3 Influence of mutation type on clinical expression of Leber hereditary optic neuropathy. Am J Ophthalmol 2006;

$141(4): 676-682$

Chapter $4 \quad$ Cardiac involvement in adults with Leber's hereditary optic neuropathy. Submitted

Biochemical phenotype

Chapter 5 A simplified and reliable assay for complex I in human blood lymphocytes. JImmunol Methods 2007; 326 (7-2):76-82.

Chapter 6 Complex I activity in circulating lymphocytes in Leber hereditary optic neuropathy (LHON) mutation carriers. Submitted

\section{Mitochondrial DNA mutations and modifying variants}

Chapter 7 Additional mitochondrial DNA mutations may explain extra-ocular involvement in LHON.

Am J Med Genet 2006; 140(13):1478-1481.

Chapter 8 A novel MELAS-associated ND1 mutation causing LHON and spastic dystonia. Arch Neurol 200764 (6):890-893. 
Chaper 10 Identification of an X-chromosomal locus and haplotype modulating the phenotype of a mtDNA disorder. Am J Hum Genet 2005,17:1086-1091.

\section{General Discussion}

Summary

Samenvatting

Dankwoord

Curriculum vitae

Publicaties 


\section{List of Abbreviations}

$\begin{array}{ll}\text { AIF } & \text { Apoptosis inducing factor } \\ \text { ATP } & \text { Adenosine triposphate } \\ \text { CS } & \text { Citrate synthase } \\ \text { COQ } & \text { Coenzyme Q } \\ \text { CI } & \text { Complex I } \\ \text { ERG } & \text { Electronretinografie } \\ \text { MRI } & \text { Magnetic resonance imaging } \\ \text { VEP } & \text { Visual evoked potentials } \\ \text { ETC } & \text { Electron transport chain } \\ \text { FADH2 } & \text { Flavin adenine dinucleotide } \\ \text { LHON } & \text { Leber's Hereditary Optic Neuropathy } \\ \text { MELAS } & \text { Mitochondrial myopathy, encephalopathy, lactic acidosis, } \\ \text { mfERG } & \text { and stroke-like episodes } \\ \text { MRI } & \text { Multifocal electro-retinography } \\ \text { MTATP6 } & \text { Magnetic resonance imaging } \\ \text { MTCOI } & \text { Mitochondrial ATPase 6 } \\ \text { MTCYB } & \text { Mitochondrial cytochrome I gen } \\ \text { MEDNA } & \text { Mitochondrial encoded cytochromoe B gen } \\ \text { MTND1 } & \text { Mitochondrial DNA } \\ \text { NADH } & \text { Mitochondrial encoded NADH dehydrogenase I gen } \\ \text { NPL } & \text { Nicotinamide adenine dinucleotide } \\ \text { OXPHOS } & \text { Nonparametric linkage } \\ \text { PGD } & \text { Oxidative phosphorylation } \\ \text { PVEP } & \text { Preimplantation genetic diagnosis } \\ \text { RGC } & \text { Pattern-reversal visual evoked potentials (PVEP) } \\ \text { RINO } & \text { Retinal ganglion cells } \\ \text { SOD2 } & \text { NADH: Rotenone insensitive coenzyme Q reductase } \\ \text { VEP } & \text { Superoxide dismutase 2 gene } \\ & \end{array}$




\section{General introduction and aims of the study}

Leber's hereditary optic neuropathy (LHON) is a mitochondrial inherited disorder that characteristically presents with a (sub) acute painless, impaired vision in previous healthy persons predominantly in the second and third decade. The penetrance of the disease is not complete and males are for a yet unexplained reason, predominantly affected. It becomes more and more clear that the clinical expression is more variable than was initially thought. The pathogenesis of LHON is in spite of many years of research still unsolved. In the Netherlands there is a long history of studies in LHON families, which was initiated in 1963 by the ophthalmologist Anthony Van Senus (1900-1976). His work has contributed to, and has been referred to in many studies because of the unique completeness of his cohort. He described 352 cases from 27 large LHON families. In the early nineties the detection of mutations in the mitochondrial DNA as the cause of LHON brought the knowledge about this disease an important step further. Later, Dr Roelof Jan Oostra (Interuniveritair Oogheelkundig Instituut, Amsterdam) expanded on the previous work of van Senus by im. plementing this genetic information that became available, in the LHON pedigrees.

1-6 His particular focus was the definition of the genotype-phenotype correlation in the large pedigrees and he investigated the involvement of the X-chromosome in the expression of this disorder. We continued with the information collected by van Senus and Oostra and the information we received by contacting LHON patient interest groups. Furthermore, we had access to the molecular data of LHON patients, which were gathered since 1998 in the DNA laboratory of the Department of Clinical Genetics in Maastricht. Some of the patients who became symptomatic only recently could be traced back to ancient pedigrees with a common ancestor of before the year 1600 . The medical records of patients were reviewed, new patients clinically investigated and new DNA and biochemical tests were performed. Through international cooperation with several European and American LHON research groups, of which the group of Prof.dr. Patrick Chinnery was the most important, we could extend the patient group even more. 


\section{Aims and Outline of this thesis}

The main aims of this study were (1) to characterize the clinical and biochemical expression of LHON in affected families and (2) to identify genetic factors that might explain the incomplete penetrance and variable expression of LHON.

Our approach was:

1. Collection of families and clinical evaluation of individual patients. An overview of the clinical presentation of LHON patients is given in Chapter 3. An evaluation, specifically of the cardiac system is given in Chapter 4.

2. Characterization of the biochemical phenotype in lymphocytes of LHON patients. A method to measure complex I in circulating lymphocytes was optimized (Chapter 5) and the complex I activity was determined in LHON patients carrying one of the three primary mutations, in order to investigate if a specific biochemical phenotype could be determined (Chapter 6).

3. Screening of the complete mtDNA for additional mutations in LHON patients with specific clinical features. This was performed in a patient with LHON and additional extra-ocular involvement (Chapter 7 ) and in a family with LHON and dystonia (Chapter 8).

4. Examine the influence of the mtDNA background on the clinical expression of LHON in a large LHON population (Chapter 9).

5. Screening of X-chromosomal candidate genes for modifying mutations. We attempted to identify a modifier gene involved in the clinical expression of LHON by traditional parametric analysis in families focussing on the $\mathrm{X}$-chromosome (Chapter 10$)$.

6. Performing a total genome scan in the families, in which $\mathrm{X}$-linked inheritance is excluded by means of non-parametric analysis and positional-candidate gene approach. 


\section{Introduction to mitochondrial disorders and LHON in particular}

$\begin{array}{ll}\text { Chapter } 1 & \text { Mitochondria } \\ & 1.1 \text { Structure and mitochond } \\ & 1.2 \text { Oxidative phosphoryl } \\ \text { Chapter } 2 & \\ & \text { LHON } \\ & 2.1 \text { History } \\ & 2.2 \text { Clinical aspects } \\ & 2.3 \text { Epidemiology } \\ & 2.4 \text { Genetics } \\ & 2.5 \text { Modifier genes } \\ & 2.6 \text { Pathogenesis } \\ & 2.7 \text { Biochemistry } \\ & 2.8 \text { Treatment options } \\ & 2.9 \text { Genetic counselling }\end{array}$

Adapted from:

L. Spruijt. Leber's Hereditary Optic Neuropathy.

In Encyclopedia of Life Science. John Wiley \& Sons, Ltd: Chichester (2007), United Kingdom doi: 10.1002/ 9780470015902.a0005541. 
Chapter

\section{Mitochondria}




\subsection{Structure and mitochondrial DNA}

Mitochondria are double-membrane cytoplasmic organelles that are required for many cellular processes and synthesis of compounds that are essential for cellular function, including compounds needed for protein, fatty acid, pyrimidine, carbohydrate metabolism and apoptosis. One of the most important processes is the oxidative phosphorylation resulting in the production of cellular energy in the form of adenosine triphosphate (ATP). Each nucleated human cell can contain hundreds to several thousands of mitochondria, depending on the cell type and its metabolic needs and each mitochondrion contains 2 to 10 copies of the mitochondrial DNA (mtDNA). MtDNA is a circular, double-stranded molecule of 16.569 base pairs (bp) in length. Mitochondrial DNA encodes for 13 proteins, which are essential subunit components of the oxidative phosphorylation (OXPHOS) enzymatic complexes (Complex I, III, IV and V). Complex I consists of at least 36 nuclear encoded and 7 mitochondrial encoded subunits. The mitochondrial encoded genes are in complex I: mitochondrial encoded NADH dehydrogenase I gene (MTND1), MTND2, MTND3, MTND4, MTND4L, MTND5, MTND6; in complex III: mitochondrial encoded cytochrome B gene (MTCYB), in complex IV: mitochond rial cytochrome I gene (MTCO1), $\mathrm{MTCO}_{2}, \mathrm{MTCO}_{3}$ and in complex V: mitochondrial ATPase 6 gene(MTATP6) and MTATP8. All other mitochondrial proteins are encoded in the nucleus and transported to the mitochondrion. Mutations in any of these genes can cause a mitochondrial disorder. In LHON in mainly mutations in the ND genes of complex I are present.?

There are 24 genes in the mtDNA that contribute to the local protein synthesis of the 13 structural genes, 2 rRNAs and 22 tRNA's. Mitochondrial genes are replicated, transcribed, and translated within the mitochondrial matrix, and these processes are catalyzed by enzymes generated as products of nuclear genes and imported into the mitochondria. 7 The OXPHOS system is in this way under dual genetic control of the mitochondrial and nuclear DNA. Mitochondrial disorders affect more than 1 in 8000 of the population and this makes it one of the most common inherited metabolic diseases. ${ }^{8}$ There are now more than 400 diseases recognized as mitochondrial disorders. Neurological diseases, cardiomyopathy, skeletal myopathy, and multisystemic involvement dominate the clinical picture of these disorders.

\subsection{Oxidative phosphorylation}

The production of cellular energy in the form of ATP is a result of the OXPHOS in the electron transfer chain (ETC) of the mitochondria. In the ETC, electrons are shuttled with the 
help of two specific cofactors: coenzyme $\mathrm{O}$ (ubiquinone, CoQ) and cytochrome $\mathrm{c}$ (cyt c). Complex I catalyses electron transfer from NADH to ubiquinol $\left(\mathrm{COOH}_{2}\right) . \mathrm{CoO} 1$ reduction is linked to proton translocation, which adds to the generation of an electrochemical gradient across the membrane. From ubiquinol two electrons are transferred to complex III (ubiquinol:-ferricytochrome c oxidoreductase). ${ }^{9}$ Ubiquinol is also produced by complex II, in a path parallel to that of complex I. Complex II transfers electrons from flavin adenine dinucleotide $\left(\mathrm{FADH}_{2}\right)$ to $\mathrm{CoO}$. Complex III thus receives thus electrons by both complex I and II in two independent paths. Complex III transfers two electrons from FADH 2 to cytochrome $c$, which than shuttles the electrons to complex IV. Finally the electrons are transferred to oxygen resulting in phosphorylation of ADP to ATP and water by the ATPase. ${ }^{10,11}$ (figure 1) The structure and function of the ETC its protein components are important and have been extensively studied. This knowledge is vital to understand the underlying pathogenic mechanisms in LHON and other mitochondrial diseases. ${ }^{12}$

Figure 1

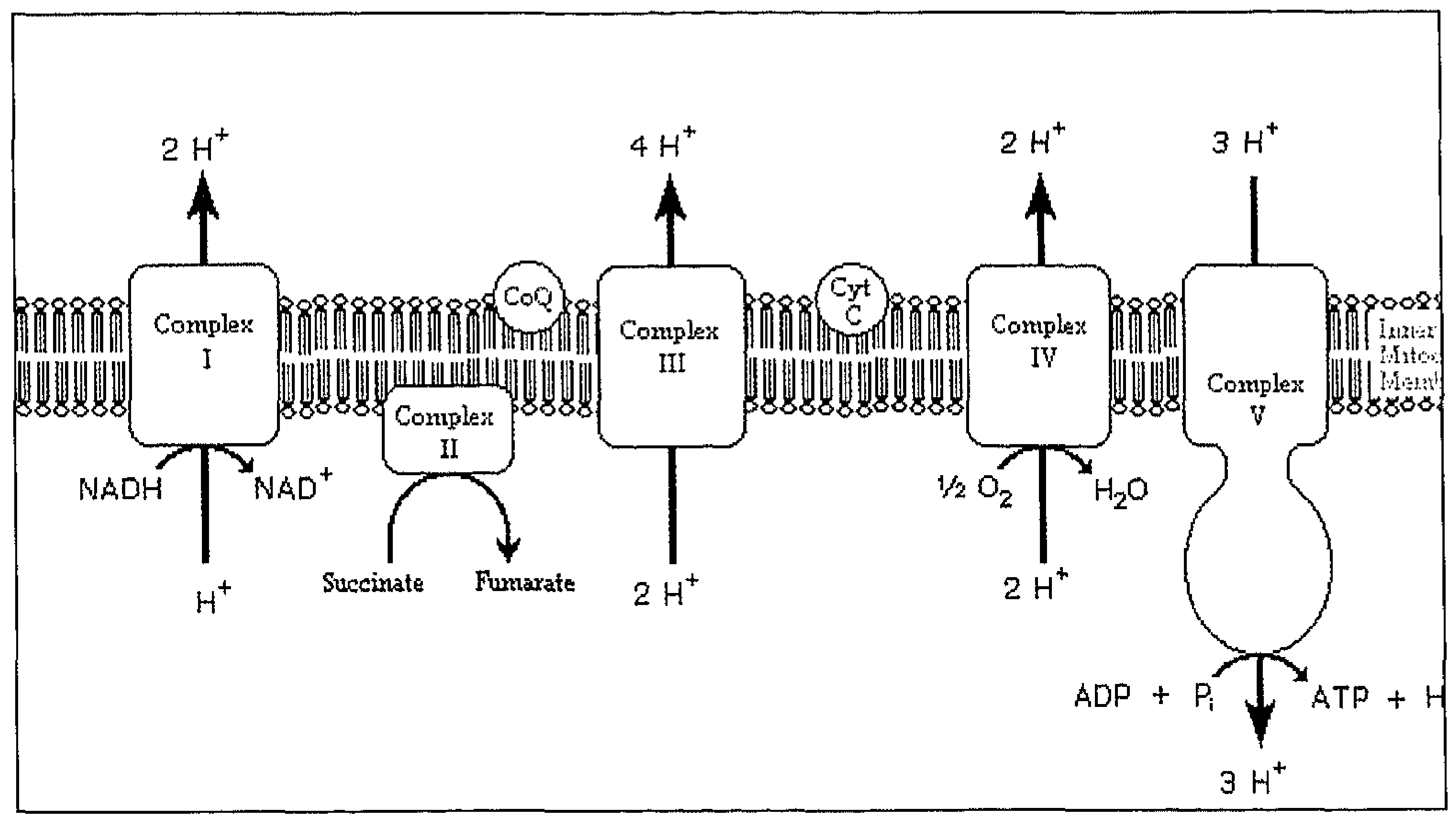

The electron transport chain (ETC) located in the inner mitochondrial membrane. A cascade of biochemical reactions transporting electrons through the five complexes resulting in the production of ATP. The Metabolic Pathways of Biochemistry. http://www.gwu.edu/ mpb/index.html Copyright 1998 Karl J. Miller 
Chapter 2

LHON 


\subsection{History}

Theodor Karl Gustav von Leber (1840-1917), a German ophthalmologist, described in 1871 an inherited form of blindness that since than has been designated Leber's Hereditary Optic Neuropathy (LHON). ${ }^{3}$ This disease has been given several other names, for example Leber's (acute) optic neuropathy, Leber's (optic) atrophy, Leber's disease and Leber's syndrome I. Patients in the Netherlands use the name "Leber's Optic Atrophy" (LOA). LHON should be distinguished from other ophthalmological diseases also described by von Leber, like Leber's congenital amaurosis (LCA) ${ }^{14}$, a congenital autosomal recessive form of blindness; Leber's idiopathic stellate neuroretinitis15; and Leber's miliary aneurysms (a form of unilateral $(95 \%)$ exudative retinopathy occurring in children before puberty, causing so-called amaurotic cat's eyes). ${ }^{16}$

In the time of Theodor von Leber (and also in the study of dr A.H.C. van Senus) ${ }^{17}$ it was recognized that $\mathrm{LHON}$ is inherited exclusively through the maternal line, but with the scientific knowledge available at that time, no explanation for this pattern of inheritance could be given.

\subsection{Clinical aspects}

The presentation of LHON is typically a (sub) acute, painless, visual impairment in previously healthy individuals. The symptoms develop predominantly between ages $18-24$ years (range $6-62$ years) ${ }^{18}$ (Figure 2); more than $95 \%$ of all patients develop symptoms before the age of 50, but an onset above this age is still possible. The visual impairment is nearly always bilateral and after the symptoms have started in one eye, the second eye will be involved after 6-12 weeks. The initial symptoms are blurring or clouding of vision caused by an enlargement of a blind spot (scotoma). A specific form of colour blindness (dyschromatopsia) is invariably present, often with blue as the colour that remains best seen. Patients with severe loss of vision only appreciate grey shades. 
Figure 2

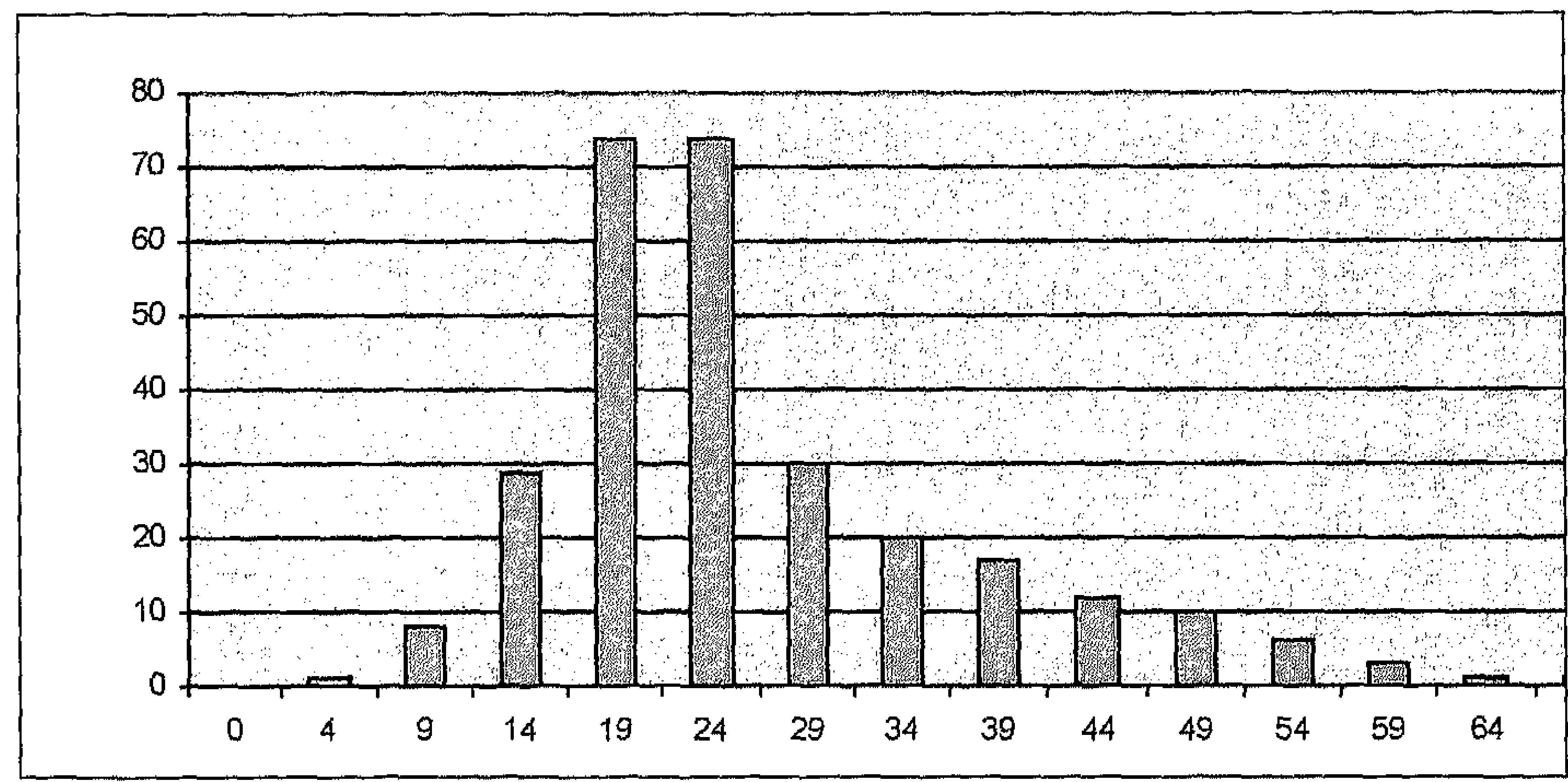

Mean age of onset in the Dutch LHON population. Peak incidence is in early adulthood. More than $95 \%$ of the patients develop symptoms before the age of 50 and very few before the age of 9.18

The symptoms start relatively acute, but this does vary among patients, usually progressing over a time period of 4-6 weeks. ${ }^{19}$ The visual impairment is typically severe and although not common, complete blindness can occur. More than half of the patients $(64 \%)$ with the m.14484T>C mutation exhibit a partial recovery of vision, regardless of the acuteness of disease onset, whereas the $\mathrm{m} .11778 \mathrm{G}>\mathrm{A}$ and $\mathrm{m} .3460 \mathrm{G}>\mathrm{A}$ mutation have a worse prognosis (4-20\% recovery). Recovery appears usually not within a year after disease onset and mostly not later than after four years. ${ }^{20}$ The penetrance of the disease is not complete, indicating that not all mutation carriers will develop disease symptoms (Figure 3). Approximately $50 \%$ of male and $10 \%$ of female LHON mutation carriers will eventually become visually impaired. Details on factors influencing expression are discussed below.

Nearly all $(-100 \%)$ patients with a m.14484T $>$ C mutation and the majority $(-80 \%)$ of the $\mathrm{m} .3460 \mathrm{G}>\mathrm{A}$ mutation carriers have a history of similarly affected relatives while this is seen only in half of patients with the $\mathrm{m} .11778 \mathrm{G}>\mathrm{A}$ mutation. The affected male to female ratio is as well dependent on the mutation: 2.5:1 for the m.11778G >A mutation, 2:1 in case of a m.3460G $>$ A mutation and $5.7: 1$ in the m.14488T>C mutation.

\section{Examination}

In the presymptomatic and acute phase some, but not all, patients may show abnormalities of the retinal blood vessels (micro-angiopathy) on ophthaimological examination. The- 
re is an absent staining on fluoresceine angiography. The micro-angiopathy might also be seen in unaffected family members and is not a prognostic finding. The micro-angiopathy disappears as the disease progresses towards the chronic phase and is followed by a pale optic nerve (optic disc) earliest at 1 month after disease onset and is virtually universal at 6 months. ${ }^{21}$ These changes may be absent or minimal in some cases. ${ }^{22}$ The differential diagnosis from other causes of optic atrophy may be difficult in this phase in the absence of typical signs or a positive family history.

Figure 3

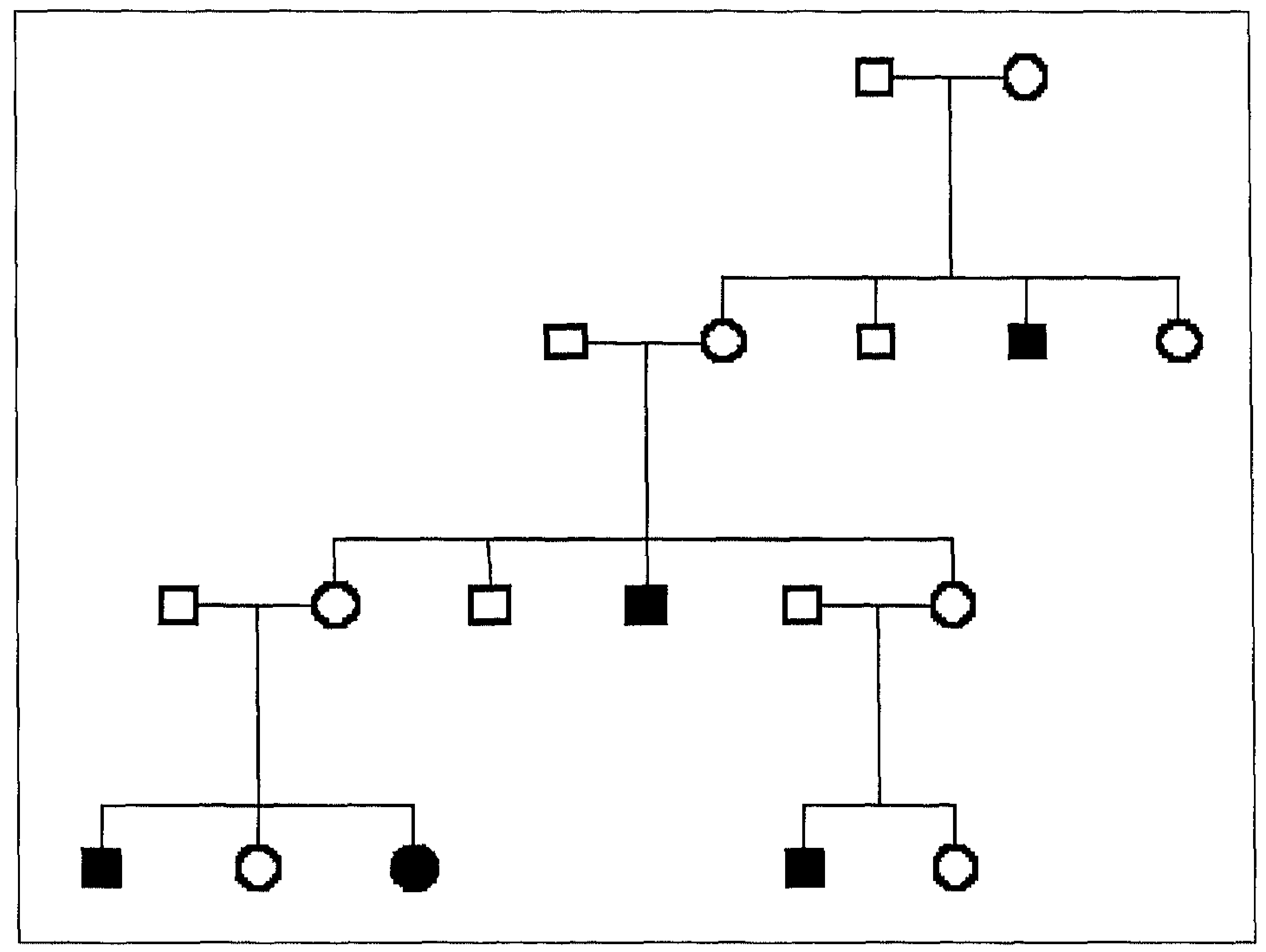

Example of mitochondrial transmission in a pedigree of a LHON family. A square represents a male and a circle a female. Affected patients are indicated in black. All maternal related relatives are LHON mIDNA mutation carriers. Note the incomplete penetrance (not all family members will become affected).

The electroretinography examination (ERG) is usually normal. But damage to ganglion cells and nerve fibres caused by LHON can be detected in multifocal ERG ( $m$ fERG) recordings and indicate that activity from the inner retina can contribute significantly to first and second 
order waveforms. The flash and pattern visual evoked potentials (VEP) show either a decreased amplitude and/or increased latency or are absent. Cerebral MRI is in general normal but multiple sclerosis-like white matter lesions have been reported. ${ }^{23}$

\section{Extra-ocular symptoms}

Optic atrophy is in general the main and only symptom in LHON. But multisystemic involvement of the central nervous system and the heart was identified in families with a LHON mutation. The neurological problems are movement disorders, tremor, tics, parkinsonism, migraine, peripheral neuropathy and a multiple sclerosis-like illness. The combination of spastic dystonia and Leber hereditary optic neuropathy (LHON) (OMIM 500001) has been reported in a few unconnected families in association with the non-primary mtDNA mutations m.14459G>A/ND6, m.14596T>A/ND6 or without a mtDNA mutation.

The reported cardiac abnormalities are pre-excitation syndromes, like Wolff-ParkinsonWhite (WPW) and Lown-Ganong-Levine (LGL) syndrome, hypertrophic cardiomyopathy and left ventricular hypertrabeculation (Lone compaction). ${ }^{24-26}$ These are however only present in occasional reports of isolated families.

\section{Differential diagnosis}

LHON shows some clinical overlap with autosomal dominant optic atrophy (ADOA) caused by a mutation in the OPA1 gene (3q28-ter), which is characterized by an insidious onset of visual impairment in early childhood with moderate to severe loss of visual acuity, temporal optic disc pallor, colour vision deficits, and centrocecal scotoma. The OPA1 gene (3q28ter) has a possible function in the biogenesis of mitochondria and stabilisation of the integrity of the mitochondrial membrane.

Tobacco-alcohol amblyopia is a disease characterized by subacute loss of visual acuity and centrocecal scotomas occurring in patients with a history of heavy tobacco-use, alcohol use, or both. The fundus characteristics are very similar to those described in LHON patients. ${ }^{27}$

\subsection{Epidemiology}

The incidence of LHON in Western Europe is $1 / 30,000-1 / 50,000$; at least 1 in 14,000 males is affected and that makes $L H O N$ the most frequent occurring mitochondrial disorder. ${ }^{18,25,26}$ In the Australian population 28 in the premolecular era the prevalence was estimated slightly lower. Little is known about the LHON prevalence in other parts of the world. 


\subsection{Genetics}

The mitochondrial DNA is a multicopy genome. While present in human cells in between 500-10,000 copies, the mature oocyte contains 100,000 to 600,000 copies. ${ }^{29}$ In contrast, sperm cells contain only very few copies of mtDNA. In the fertilisation process, the few mtDNAs derived from sperm cells are destroyed. The paternal mitochondria enter the oocyte at fertilization and are specifically targeted for degradation..$^{\circ}$ Occasional occurrence of paternal inheritance of mtDNA has been suggested ${ }^{31}$ and may occur but is extremely rare. ${ }^{32}$ In the time of Theodor von Leber, the second half of the $19^{\text {th }}$ century, and also in the time of van Senus in the early sixties of the past century, ${ }^{17}$ it was recognized that LHON is inherited exclusively through the maternal line (figure 3). Since the first report in 1988 of the m.11778G >A point mutation, ${ }^{33}$ it is now known that this maternal inheritance is caused by a mutation in the mitochondrial genome. The m.11778G >A mutation results in an arginineto-histidine substitution at amino acid position 340 of the ND4 subunit. ${ }^{33}$ Shortly after that two other important mutations were found, the m.3460G>A that causes a substitution in the ND1 subunit ${ }^{34,35}$ and the m.14484T $>C$ mutation causing an amino acid substitution in the ND6 subunit ${ }^{36}$. These three mutations now have been designated as primary LHON mutations and they are present in more than $95 \%$ of individuals with LHON worldwide. De novo mutations in these genes have been reported but are assumed to be rare. ${ }^{18,37}$ Besides the three primary mutations, more than 30 other rare occurring mitochondrial mutations

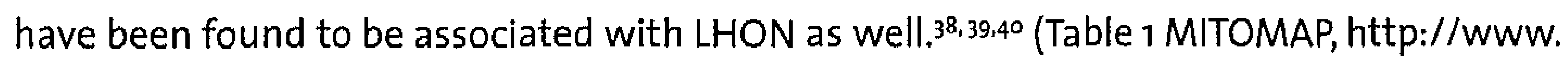
mitomap.org). All mutations are encoding a subunit of complex I of the ETC. Secondary mutations are more frequent among LHON patients than among non-LHON individuals. These secondary mutations, relative to the primary LHON mutations, tend to produce more conservative amino acid substitutions and/ or to affect less stringently conserved residues. The distinction between primary and secondary LHON mutations is not always sharp, and there are some mutations that have a more intermediate character. 
Table 7

"Top 10" Primary LHON mutations, the first 3 mutations listed (in boldface) represent approximately $95 \%$ of all cases. The remaining "Top 10" primary mutations are listed in nucleotide order (wWw.mitomap.org)

\begin{tabular}{|c|c|c|c|c|c|}
\hline Mutation & Gene & Patients \% & $\begin{array}{l}\text { Penetrance } \\
\text { Overall }\end{array}$ & $\begin{array}{l}\text { Penetrance } \\
\text { Males }\end{array}$ & Recovery \% \\
\hline $1177^{8 G}>A$ & $\mathrm{ND}_{4}$ & 69 & $33-60$ & 82 & 4 \\
\hline $3460 G>A$ & ND1 & 13 & $14-75$ & $40-80$ & 22 \\
\hline $14484 T>C$ & ND6 & 14 & $27-80$ & 68 & $37-65$ \\
\hline $3733 G>A$ & ND1 & $<1$ & 58 & 66 & $?$ \\
\hline $4171 C>A$ & ND1 & $<1$ & 29 & 43 & Yes \\
\hline $10663 T>C$ & $N_{4}$ & $<1$ & 56 & 60 & $?$ \\
\hline $14459 G>A$ & ND6 & $<1$ & $?$ & $?$ & Low \\
\hline $14482 C>G$ & ND6 & $<1$ & $?$ & 89 & Yes \\
\hline $14482 C>A$ & ND6 & $<1$ & $?$ & $?$ & $?$ \\
\hline $14495 A>G$ & ND6 & $<1$ & $?$ & $?$ & Low \\
\hline $14568 C>T$ & ND6 & $<1$ & $?$ & $?$ & $?$ \\
\hline
\end{tabular}

Normal individuals are homoplasmic for wild-type mtDNA signifying that all the mitochondria in each cell contain the same mEDNA. But in most mitochondrial disorders with a mtDNA mutation, the mutation is heteroplasmic indicating that these individuals harbour a mixture of mutated and wild-type mtDNA. LHON is one of the exceptions. LHON mutations are usual homoplasmic and only in $\sim 15 \%$ of LHON pedigrees are heteroplasmic. ${ }^{8.41}$ Overall, $\sim 30 \%$ of the LHON families have at least one heteroplasmic individual. For the three primary mutations $\sim 10 \%$ with a m.3460G>A mutation, $\sim 15 \%$ with the $\mathrm{m} .11778 \mathrm{G}>\mathrm{A}$ mutation and rarely individuals were the m.14484T $>C$ mutation are heteroplasmic. ${ }^{42}$ The risk of developing symptoms is different for homoplasmic and heteroplasmic mutation carriers (see genetic counselling).

The distribution of the primary mutation in the LHON population is reported in literature as $75-60 \%$ (m.11778G $>A), 15 \%$ (m.14484T>A) and $10-15 \%$ (m.3460G>A). ${ }^{19}$ This distribution is different between populations. The m.14484T>A mutation for example is highly represented in the Dutch population and in the French-Canadian LHON population ${ }^{43}$ but is rare $(<15 \%)$ in Finland, in other Caucasian populations and in Asia. ${ }^{44.45}$ The m.11778G $>$ A mutation, on the other hand, has a very high incidence in Asian patients ( $90 \%$ ). ${ }^{46}$ 
There appears a small phenotype-genotype correlation between the different primary mutations. The $\mathrm{m} .11778 \mathrm{G}>\mathrm{A}$ and $\mathrm{m} .3460 \mathrm{G}>\mathrm{A}$ mutations are associated with a more severe clinical and biochemical phenotype than the m.14484T>C mutation. Patients with this last mutation have usually a better outcome with a chance of approximately $50 \%$ of (partial) recovery after several years. ${ }^{19}$

It is generally assumed that there is in mitochondria a genetic bottleneck whereby a single or small number of the many thousands of mtDNAs in every oocyte are selected and populate the organism..$^{47.48}$ The mitochondrial mutation load in offspring of a woman with a heteroplasmic mtDNA mutation can therefore vary extremely. It is not known at which stages the restriction/amplification of mtDNA subtype(s) occur. ${ }^{49}$ The bottleneck plays a role in the heteroplasmic situation and probably not in homoplasmy. The distribution of mtDNAs in homoplasmic LHON patients is virtually identical in the different tissues.

\subsection{Modifier genes}

Mitochondrial mutations are not the sole determinants of the LHON phenotype but rather give a hereditary predisposition for optic atrophy. As themselves they are not sufficient to cause visual impairment. Not all individuals with a mtDNA LHON mutation develop visual symptoms which indicates that there are additional, yet unknown, precipitating factors..$^{\circ}$ The penetrance of LHON is reportedly not equally distributed in the different branches of the LHON pedigrees. In some branches the penetrance seems to be decreasing close to zero while in the high-penetrance branches, the expression of LHON in males varies between $30-67 \% .^{51}$ Approximately $50 \%$ of male and $10 \%$ of female LHON mutation carriers will eventually be visually impaired. Because of the male preponderance, the X-chromosome was the first location that was screened for such a modifying gene. Segregation analyses confirmed evidence for this nuclear-encoded $X$-linked susceptibility. The first attempts to identify this additional genetic factor started with 15 widely spaced polymorphic markers in six families showing evidence of linkage to a region on the proximal Xp (DXS7) without evidence for heterogeneity. ${ }^{52}$ These studies were inconclusive due to too widely spaced, often non-informative markers and a reduced penetrance in patients with a lower than $80 \%$ heteroplasmy which was not accounted for. Later, linkage to this region was ruled out in British, Italian, Australian and German families.53,54 In some studies an X-linked recessive model was used but this cannot explain the segregation pattern in all pedigrees. ${ }^{55}$ Mackey concluded that both dominant and recessive transmission of an X-linked factor is unlikely in the expression of LHON; some other sex-variable factor must be involved.55X-inactivation can neither explain affected LHON females..$^{4,56}$ Statistical analysis based on segregation 
analysis in LHON families 57.58 however did support a two-locus model: one responsible gene being mitochondrial and the other nuclear and $X$ chromosome-linked.

The group that initially showed linkage after all reported that this conclusion was implausible after introducing new data. When the information on disease frequency, penetrance, expression in heterozygous women and liability classes were included in the calculations and the families were separated according to the LHON mutation, there were no indications for a linkage on the $X$ chromosome anymore. The pitfalls of linkage analysis are illustrated by this and the finding a modifier gene is much more complex than thought before. Recent data imply an interaction with a recessive X-chromosomal locus. ${ }^{59}$

LHON is known to affect individuals in large multigenerational pedigrees. If a nuclear modifier locus is supposed to contribute to the clinical expression it is more likely that it will be a common factor (frequent in the general population) that moves in and out of the maternal pedigree through random mating between mothers who transmit the LHON mtDNA mutation (who largely remain unaffected) and unrelated male partners not harbouring the LHON mtDNA mutation. Co-inheritance of a rare factor and the primary mtDNA mutation (already rare by itself, throughout the whole pedigree is an unlikely explanation. Nonparametric linkage (NPL) analysis resulted in the defining of an X-chromosomal haplotype bounded by markers located in Xp11.59

In summary, there are indications that there is a modifier gene on the X-chromosome in some LHON families, but that in others an autosomal location is more probable. The fact that this gene is difficult to find implies that there exists a more complex inheritance in LHON than suspected initially.

\subsection{Pathogenesis}

The exact pathogenesis of LHON is not established despite extensive research. The general concept is that there is an interaction of several factors with the primary mutation, like the aforementioned genetic background and environmental factors.

When the mitochondrial respiration is failing, mitochondrial dysfunction can cause an increase in free radical production. This all contributes to an increased oxidative stress and a reduced cellular respiration and finally produces apoptosis in vulnerable neurons. Such a defect will specifically damage the retina and optic nerve because of their extremely high energy demands and might explain why usually there are no other physical complaints besides the visual symptoms.

The 1.2 million fibres of the optic nerve all derive from the retinal ganglion cells (RGC) of the inner retina. The degeneration of the optic nerve in LHON is due to a massive loss $195 \%$ to 
$99 \%)$ and diffuse demyelinisation of retinal and optic nerve axons, which are responsible for central vision. Histopathologic investigations demonstrated a relative sparing of the most peripherally placed fibres in the optic nerves and a normal retina. In comparison to normal controls, there is a preferential loss of the smallest axons corresponding to the $\mathrm{P}$ cell population and relative preservation of the M-cells in the optic nerve. ${ }^{60}$ Loss of P-cells may explain the clinical features of dyschromatopsia, central scotoma, and preservation of pupillary light response in $\mathrm{LHON}$ patients. ${ }^{60}$ The only two LHON patients that were studied post-mortem had already symptoms for years. ${ }^{61}$ The mutation rate was $\sim 100 \%$ in the optic nerve, retina and muscle tissues but only $33 \%$ in blood leucocytes.

There appears to be an inversed relationship between the mitochondrial activity and myelinisation. The axons are unmyelinated and extremely rich in mitochondria in their tract before entering the lamina cribrosa. Behind the lamina cribrosa the axons connect with oligodendroglia cells and become myelinated and contain far less mitochondria in this part, because less energy is required there..$^{22}$

\section{Environmental factors}

Heavy smoking and high alcohol consumption are the main environmental factors mentioned to act as triggering factors for LHON expression. ${ }^{62,63}$ However this was not found in a large epidemiological study. ${ }^{64}$ The role of these substances has yet to be further established. Other "life style factors" like head trauma, infections and vitamin deficiencies cannot be excluded. ${ }^{28}$ Lastly, even the aging process itself might be one of the contributing determinants of the phenotype.

\subsection{Biochemistry}

Complex I (nicotinamide adenine dinucleotide (NADH) ubiquinone reductase) is the largest of the proteins of the electron transport chain. Complex I has many roles, and many are still unidentified. Since all three primary LHON mutations occur in genes that encode one of the subunits of complex I (NADH dehydrogenase) this raises the suggestion that this complex plays a key role in the pathogenesis of LHON. It might therefore be helpful to examine several aspects of the biochemical function on cultured models to understand the underlying pathophysiology.

Biochemical defects in complex I were first demonstrated in platelet mitochondria carrying the LHON m.3460G>A mutation. The citrate synthese (CS) activities were higher in LHON patients than in controls. Rotenone sensitive complex I activity was reduced about $80 \%$ in both lymphoblast mitochondria ${ }^{65,66}$, fibroblasts and platelet mitochondria. ${ }^{34,66}$ The other 
LHON mutations induce only subtle or no changes in complex I function. ${ }^{39,67,68}$ Complex I shows also a decreased sensitivity to its inhibitor rotenone in all three LHON mutations. ${ }^{22,67,69}$ The last is suggesting that the mutation is interfering with the interaction between complex I and co-enzyme Q (COQ), the electron acceptor of complex I and/or that the CoO intermediates have a reduced stability. ${ }^{69,70}$ The sensitivity to other complex I inhibitors (rolliniastatin-2, amytal) that are not interfering with the $C O Q$ binding site are not changed.71 However, when the inhibitory effect of rotenone on complex I as the result of the whole respiratory chain (ATP synthesis) was measured, no defect was found. 72 Further, cybrid cells have been applied to study the biochemical dysfunction of complex I as well. Cybrids are fused cell lines between cells depleted of the original mtDNA (po cells) and exogenous mtDNA from for example LHON patients. ${ }^{73}$ They are used in order to exam the effect of the mitochondrial mutation without the influence of the nuclear background. Since both the genotypes of mtDNA and nuclear DNA, play a role in the respiratory competence of a cell, it is useful to examine the effect of the mtDNA mutation separately in vitro. Cybrids containing the LHON mutations showed in some studies a severe reduction in the rate of complex I-dependent ATP synthesis..$^{74}$ This is suggesting a common biochemical path. Cybrids have been used also to study cell death induced by complex I dysfunction in LHON, by growing these cells in glucose free medium. LHON cybrids grown in these circumstances exhibit massive apoptotic cell death in contrast to control cells. In galactose medium (glucose free) cells are forced to rely only on the mitochondrial ETC to synthesize ATP.75

Most of the biochemical studies were usually performed in small groups of patients or cells. The affection status of the patients in the study was only evaluated in the minority of cases. In thoses studies it was found not to be of influence on the biochemical parameters. ${ }^{76,68} \mathrm{~A}$ disadvantage of cybrid cell examination is that it represents in vitro studies. Other limitations are the tissue specific affection of the retinal ganglion cells in LHON patients, which might not be reflected in bloodcells. Although the distribution of mutated mtDNA is relatively homogeneous in all tissues, post mortem studies in LHON patients showed a lower mutation rate $(\sim 33 \%)$ in leucocytes than in the affected tissues. ${ }^{61}$

\subsection{Treatment options}

At the present time there is no effective treatment nor are there any precautions known to prevent the symptoms of LHON to develop. Patients with LHON and their relatives at risk often receive general dietary advice such as a balanced diet rich in antioxidants (Vitamins $A, C$ and $E$, selenium and zinc) and avoidance of smoking and drinking alcohol. Injections of vitamin $\mathrm{B} 12$ during the first few months after disease onset might help some patients but 
there are no indications that it might be useful for all patients. Drugs that are possibly interfering with the mitochondrial metabolism like valproic acid (Depakine $\circledast$ ), vancomycine, fenobarbital, or corticosteroids in high doses are better avoided. Idebenone (a quinine/ CoO analogue) has been studied as a therapy in LHON patients. One study suggested that idebenone, vitamin B2, and vitamin C improved the recovery of vision in patients with LHON. 7 This remains however an incidental report. Topical brimonidine purite as a prophylactic treatment after first eye involvement appears to be ineffective in preventing second eye involvement. ${ }^{78}$

The initial steps in using gene therapy in LHON have been made by studies on cellular level. It was found that cybrid cells with the m.11778G>A/ND4 gene mutation showed a 3 -fold improvement in complex I-dependent ATP synthesis and a 3 -fold greater cell survival when the gene product of a normal functioning ND4 gene was imported in the cell. This improvement in the function of these so called allotopically transfected cells suggests a rescue of the oxidative phosphorylation defect. ${ }^{29}$ Cells with the m.11778G $>$ A mutation that were infected with the human mitochondrial superoxide dismutase (SODz) gene showed an increased survival in galactose medium (glucose free). This might suggest that therapy with antioxidant genes may protect patients with LHON against visual impairment, at least in vitro ${ }^{80}$ Antioxidants and agents that interfere with the critical steps of mitochondrial-dependant, oxidative stress-induced apoptosis are also candidates for a future LHON therapy.

Altogether this means that there are no proven options in treating LHON patients and there is no method available yet to prevent the clinical expression in mutation carriers. The decision whether to use valproic acid (Depakine ${ }^{\circledR}$ ), vancomycine, fenobarbital and high doses of corticosteroids should be taken carefully and alternatives are recommended, even if there is no strong evidence that they trigger the expression of LHON.

\subsection{Genetic counselling}

Genetic counselling is a fundamental part in the management of patients and families with a genetic disorder. Once the diagnosis is established by mutation detection in the proband, other at risk family members can be tested. But the genetic counselling of LHON patients and their relatives is complicated by the gender- and age-dependent expression. This makes it impossible to predict who in a LHON mutation family will become symptomatic. Male LHON patients or healthy male mutation carriers cannot transmit the mutation to their offspring while female mutation carriers (either affected or unaffected) will transmit the mutation to all their offspring. In case of a homoplasmic mutation, all relatives through 
the maternal line are at risk for the development of LHON. The risk for other family members depends upon the genetic status of their mother. If she has a mitochondrial DNA mutation, her siblings and mother are at risk as well. The risk of developing clinical symptoms in a heteroplasmic male with a mutation load of $>80 \%$ is comparable with the homoplasmic situation; between $60-80 \%$ the risk is slightly reduced; the risk is not increased in cases with $<60 \%$ heteroplasmia. ${ }^{42}$ The risk for females with a heteroplasmic mutation is lower than for males with the same mutation percentage. In offspring of LHON mothers with $>80 \%$ mutated mtDNA the probability to develop symptoms are similar as for offspring of homoplasmic mothers, but is reduced when the heteroplasmia of the mother falls below $80 \%{ }^{42}$ But since transmission of the heteroplasmic LHON mutation is under selective pressure in favour of the mutated allele (the genetic bottleneck) this explains why there still is a considerable amount of male offspring $(-30 \%)$ affected that have mothers with a mutation load of $\langle 60 \% .42,81$ More than two third of the patients with a heteroplasmic mutation harbour a greater mutation load than their mother. In heteroplasmic LHON families there is often a segregation to a homoplasmic situation within a few generations. Since heteroplasmy occurs in a considerable amount of LHON pedigrees it might be possible that a maternal relative of an index case is no mutation carrier. In these cases in particular, genetic testing for each maternal family member is warranted.

There is only a small genotype-phenotype correlation predicting a better visual outcome for m.14484 T $>$ C mutation carriers and better chances for recovery. ${ }^{20},{ }^{82} \mathrm{The}$ m.11778G $>\mathrm{A}$ mutation has the worst prognosis with the most severe visual failure and slim chance of recovery and the $\mathrm{m} .3460 \mathrm{C}>\mathrm{A}$ presents an intermediate phenotype.

The options to reduce transmission of LHON are limited. Some women with visual impairment themselves will decide that their handicap as such is not a restraint in their decision in having children, while others experience it as an important burden in their daily life and therefore refrain from having children or consider adoption. Affected males make similar choices, except that they cannot transmit the disorder to their children. Prenatal diagnosis for mitochondrial mutations in general is available, but appears of no use in LHON. Although DNA analysis in a homoplasmic mtDNA disorder does not encounter the problems that exist in heteroplasmic mutations it remains impossible to predict if someone with a homoplasmic LHON mutation will become affected. All mothers that are carrier of a homoplasmic LHON mutation will obligatory have offspring with the same LHON mutation. An alternative possibility in reproductive decisions is gender determination, and consequently, selection of female embryos because of their lower risk in developing visual impairment in life. However, the risk for females is still increased to a lifetime risk of at least $10 \%$. There never will be an age that one can be sure not to develop symptoms anymore and there are no ways in preventing the symptoms yet. Preimplantation genetic diagnosis (PGD), although 
this method is avoiding the dilemmatic choice of termination of an affected pregnancy, has the same dilemmas as prenatal diagnosis. PGD with gender determination and selective transfer of female embryos is an option and has been applied as such. ${ }^{83}$ However, in comparison with a spontaneous conception PGD lowers the risk of visual impaired offspring in fact from $30 \%(=1 / 2$ (foetus is a boy) $\times 1 / 2$ (boy is affected) $+1 / 2$ (foetus is a girl) $\times 1 / 10$ (girl is affected) to $10 \%$ ( 1 (foetus is a girl) $\times 1 / 10$ (girl is affected). In PGD it is still debatable if such a risk reduction is ethically and morally acceptable. In most situations PGD is meant to get healthy offspring.

The use of donor oocytes is another option to prevent transmission of LHON. Potential donors are evidently never maternal relatives, because they often carry the same mutation..$^{{ }_{4}}$ The reproductive options in LHON will improve the additional risk factors are known and if a definitive estimation of the disease expression can be made. This is yet another reason why the identification of a modifier gene will be an immense improvement in direct clinical patient care. 


\section{References}

7. Oostra RJ, Bolhuis PA, Wijburg FA, Bleeker-Wagemakers EM. [Leber's optic nerve atrophy; a mitochondrial hereditary disease]. Ned Tijdschr Geneeskd. 1995;139:1327-1331.

2. Oostra RJ, Bolhuis PA, Wijburg FA, Zorn-Ende G, Bleeker-Wagemakers EM. Leber's hereditary optic neuropathy: correlations between mitochondrial genotype and visual outcome. J Med Genet. 1994;31:280-286.

3. Oostra RJ, Bolhuis PA, Zorn-Ende I, de Kok-Nazaruk MM, Bleeker-Wagemakers EM. Leber's hereditary optic neuropathy: no significant evidence for primary or secondary pathogenicity of the 15257 mutation. Hum Genet. 1994;94:265-270.

4. Oostra RJ, Kemp S, Bolhuis PA, Bleeker-Wagemakers EM. No evidence for 'skewed' inactivation of the $X$-chromosome as cause of Leber's hereditary optic neuropathy in female carriers. Hum Genet. 1996;97:500-505.

5. Oostra RJ, Van den Bogert C, Nijtmans LG, et al. Simultaneous occurrence of the 11778 (ND4) and the 9438 (COX III) mtDNA mutations in Leber hereditary optic neuropathy: molecular, biochemical, and clinical findings. Am J Hum Genet. 1995;57:954-957.

6. Oostra RJ, Van Galen MJ, Bolhuis PA, Bleeker-Wagemakers EM, Van den Bogert C. The mitochondrial DNA mutation ND6* $14,484 C$ associated with leber hereditary optic neuropathy, leads to deficiency of complex I of the respiratory chain. Biochem Biophys Res Commun. 1995;215:1001-1005.

7. Clayton DA. Transcription and replication of mitochondrial DNA. Hum Reprod. 2000;15 Suppl 2:11-17.

8. Chinnery PF, Johnson MA, Wardell TM, et al. The epidemiology of pathogenic mitochondrial DNA mutations. Ann Neurol. 2000;48:188-193.

9. Walker JE. The NADH:ubiquinone oxidoreductase (complex I) of respiratory chains. $Q$ Rev Biophys. 1992;25:253-324.

10. Saraste M. Oxidative phosphorylation at the fin de siecle. Science. 1999;283: $1488-1493$.

11. Smeitink J, van den Heuvel L, DiMauro S. The genetics and pathology of oxidative phosphorylation. Nat Rev Genet. 2001;2:342-352.

12. Sengers RC, Stadhouders AM, Trijbels JM. Mitochondrial myopathies. Clinical, morphological and biochemical aspects. Eur J Pediatr. 1984;141:192-207.

13. Leber T. Ueber hereditare und congenitalangelegte Sehnervenleiden. Graefes Arch Clin Exp Ophthalmol. 1871;2:249-291.

14. Leber T. Ueber Retinitis pigmentosa und angeborene Amaurose. ALbreacht von Graefe Arch Ophthal. 1869;15:1-25.

15. Leber T. Die Krankheiten der Netzhaut. 7 vol. Leipzig: Engelmann, 1916 
16. Leber T. Ueber eine durch Vorkommen multipler Miliaraneurysmen charakterisiere Form von Retinaldegeneration. Graefes Arch Clin Exp Ophthalmol. 1912;81:1-14.

17. van Senus A. Leber's disease in the Netherlands. Doc Ophthalmol. 1963;17:1-163.

18. Man PY, Griffiths PG, Brown DT, et al. The epidemiology of Leber hereditary optic neuropathy in the North East of England. Am J Hum Genet. 2003;72:333-339.

19. Riordan-Eva P, Sanders MD, Govan GG, et al. The clinical features of Leber's hereditary optic neuropathy defined by the presence of a pathogenic mitochondrial DNA mutation. Brain. 1995;118 (Pt 2):319-337.

20. Spruijt L, Kolbach DN, de Coo RF, et al. Influence of mutation type on clinical expression of Leber hereditary optic neuropathy. Am J Ophthalmol. 2006;141:676-682.

21. Nikoskelainen EK, Savontaus ML, Huoponen K, Antila K, Hartiala J. Pre-excitation syndrome in Leber's hereditary optic neuropathy. Lancet. 1994;344:857-858.

22. Carelli V, Ross-Cisneros FN, Sadun AA. Mitochondrial dysfunction as a cause of optic neuropathies. Prog Retin Eye Res. 2004;23:53-89.

23. Vanopdenbosch L, Dubois B, D'Hooghe MB, Meire F, Carton H. Mitochondrial mutations of Leber's hereditary optic neuropathy: a risk factor for multiple sclerosis. $J$ Neurol. 2000;247:535-543.

24. Finsterer J, Stollberger C, Kopsa W, Jaksch M. Wolff-Parkinson-White syndrome and isolated left ventricular abnormal trabeculation as a manifestation of Leber's hereditary optic neuropathy. Can J Cardiol. 2001;17:464-466.

25. Finsterer J, Stollberger $C$, Michaela J. Familial left ventricular hypertrabeculation in two blind brothers. Cardiovasc Pathol. 2002;11:146-148.

26. Finsterer J, Stollberger C, Prainer C, Hochwarter A. Lone noncompaction in Leber's hereditary optic neuropathy. Acta Cardiol. 2004;59:187-190.

27. Cullom ME, Heher KL, Miller NR, Savino PJ, Johns DR. Leber's hereditary optic neuropathy masquerading as tobacco-alcohol amblyopia. Arch Ophthalmol. 1993;111:1482-1485.

28. Mackey DA, Oostra RJ, Rosenberg T, et al. Primary pathogenic mtDNA mutations in multigeneration pedigrees with Leber hereditary optic neuropathy. Am J Hum Genet. 1996;59:481-485.

29. Reynier P, May-Panloup P, Chretien MF, et al. Mitochondrial DNA content affects the fertilizability of human oocytes. Mol Hum Reprod. 2001;7:425-429.

30. Sutovsky P. Ubiquitin-dependent proteolysis in mammalian spermatogenesis, fertilization, and sperm quality control: killing three birds with one stone. Microsc Res Tech. 2003;61:88-102.

31. Schwartz $M$, Vissing J. Paternal inheritance of mitochondrial DNA. N Engl J Med. 2002;347:576-580. 
32. Schwartz $M$, Vissing J. No evidence for paternal inheritance of mtDNA in patients with sporadic mtDNA mutations. J Neurol Sci. 2004;218:99-101.

33. Wallace DC, Singh G, Lott MT, et al. Mitochondrial DNA mutation associated with Leber's hereditary optic neuropathy. Science. 1988;242:1427-1430.

34. Howell N, Bindoff LA, McCullough DA, et al. Leber hereditary optic neuropathy: identification of the same mitochondrial ND1 mutation in six pedigrees. Am J Hum Genet. 1991;49:939-950.

35. Huoponen K, Vilkki J, Aula P, Nikoskelainen EK, Savontaus ML. A new mtDNA mutation associated with Leber hereditary optic neuroretinopathy. Am J Hum Genet. 1991;48:1147-1153.

36. Mackey D, Howell N. A variant of Leber hereditary optic neuropathy characterized by recovery of vision and by an unusual mitochondrial genetic etiology. Am J Hum Genet. 1992;51:1218-1228.

37. Biousse V, Brown MD, Newman NJ, et al. De novo 14484 mitochondrial DNA mutation in monozygotic twins discordant for Leber's hereditary optic neuropathy. Neurology. 1997;49:1136-1138.

38. Chinnery PF, Taylor GA, Howell N, et al. Point mutations of the mtDNA control region in normal and neurodegenerative human brains. Am J Hum Genet. 2001;68:529-532.

39. Brown MD, Allen JC, Van Stavern GP, Newman NJ, Wallace DC.Clinical, genetic, and biochemical characterization of a Leber hereditary optic neuropathy family containing both the 11778 and 14484 primary mutations. Am J Med Genet. 2001;104:331-338.

40. Man PY, Turnbull DM, Chinnery PF. Leber hereditary optic neuropathy. J Med Genet. 2002;39:162-169.

41. Torroni A, Petrozzi M, D'Urbano L, et al. Haplotype and phylogenetic analyses suggest that one European-specific mtDNA background plays a role in the expression of Leber hereditary optic neuropathy by increasing the penetrance of the primary mutations 11778 and 14484. Am J Hum Genet. 1997;60:1107-1121.

42. Chinnery PF, Andrews RM, Turnbull DM, Howell NN. Leber hereditary optic neuropathy: Does heteroplasmy influence the inheritance and expression of the $G 11778 \mathrm{~A}$ mitochondrial DNA mutation? Am J Med Genet. 2001;98:235-243.

43. Howell N, Oostra RJ, Bolhuis PA, et al. Sequence analysis of the mitochondrial genomes from Dutch pedigrees with Leber hereditary optic neuropathy. Am J Hum Genet. 2003;72:1460-1469.

44. Mashima $Y$, Yamada K, Wakakura $M$, et al. Spectrum of pathogenic mitochondrial DNA mutations and clinical features in Japanese families with Leber's hereditary optic neuropathy. Curr Eye Res. 1998;17:403-408. 
45. Taylor RW, Jobling MS, Turnbull DM, Chinnery PF. Frequency of rare mitochondrial DNA mutations in patients with suspected Leber's hereditary optic neuropathy. J Med Genet. 2003;40:e85.

46. Mashima $Y$, Hiida $Y$, Oguchi $Y$, Kudoh J, Shimizu N. High frequency of mutations at position 11778 in mitochondrial ND4 gene in Japanese families with Leber's hereditary optic neuropathy. Hum Genet. 1993;92:101-102.

47. Hauswirth WW, Van de Walle MJ, Laipis PJ, Olivo PD. Heterogeneous mitochondrial DNA D-loop sequences in bovine tissue. Cell. 1984;37:1001-1007.

48. Laipis PJ, Van de Walle MJ, Hauswirth WW. Unequal partitioning of bovine mitochondrial genotypes among siblings. Proc Nat/ Acad Sci U S A. 1988;85:8107-8110.

49. Poulton J, Marchington DR. Prospects for DNA-based prenatal diagnosis of mitochondrial disorders. Prenat Diagn. 1996;16:1247-1256.

50. Huoponen K. Leber hereditary optic neuropathy: clinical and molecular genetic findings. Neurogenetics. 2001;3:119-125.

51. Howell N, Mackey DA. Low-penetrance branches in matrilineal pedigrees with leber hereditary optic neuropathy. Am J Hum Genet. 1998;63:1214-1218.

52. Vilkki J, Ott J, Savontaus ML, Aula P, Nikoskelainen EK. Optic atrophy in Leber hereditary optic neuroretinopathy is probably determined by an X-chromosomal gene closely linked to DXS7. Am J Hum Genet. 1991;48:486-491.

53. Carvalho MR, Muller B, Rotzer $E$, et al. Leber's hereditary optic neuroretinopathy and the X-chromosomal susceptibility factor: no linkage to DXs7. Hum Hered. 1992;42:316-320.

54. Sweeney MG, Davis MB, Lashwood A, et al. Evidence against an X-linked locus close to DXS7 determining visual loss susceptibility in British and Italian families with Leber hereditary optic neuropathy. Am J Hum Genet. 1992;51:741-748.

55. Mackey D. Blindness in offspring of women blinded by Leber's hereditary optic neuropathy. Lancet. 1993;341:1020-1021.

56. Pegoraro $E$, Carelli V, Zeviani M, et al.X-inactivation patterns in female Leber's hereditary optic neuropathy patients do not support a strong X-linked determinant. Am J Med Genet. 1996;61:356-362.

57. Bu X, Yang HY, Shohat M, Rotter JI. Two-locus mitochondrial and nuclear gene models for mitochondrial disorders. Genet Epidemiol. 1992;9:27-44.

58. Bu XD, Rotter Jl. X chromosome-linked and mitochondrial gene control of Leber hereditary optic neuropathy: evidence from segregation analysis for dependence on $X$ chromosome inactivation. Proc Natl Acad Sci U S A. 1991;88:8198-8202.

59. Hudson $G$, Keers $S$, Yu Wai Man P, et al. Identification of an X-chromosomal locus and haplotype modulating the phenotype of a mitochondrial DNA disorder. Am J Hum Genet. 2005;77:1086-1091. 
60. Sadun AA, Win PH, Ross-Cisneros FN, Walker SO, Carelli V. Leber's hereditary optic neuropathy differentially affects smaller axons in the optic nerve. Trans Am Ophthalmol Soc. 2000;98:223-232; discussion 232-225.

61. Howell N, XU M, Halvorson S, Bodis-Wollner I, Sherman J. A heteroplasmic LHON family: tissue distribution and transmission of the 11778 mutation. Am J Hum Genet. 1994;55:203-206.

62. Tsao K, Aitken PA, Johns DR. Smoking as an aetiological factor in a pedigree with Leber's hereditary optic neuropathy. Br J Ophthalmol. 1999;83:577-581.

63. Sadun AA, Carelli V, Salomao SR, et al. Extensive investigation of a large Brazilian pedigree of 11778 /haplogroup J Leber hereditary optic neuropathy. Am J Ophthalmol. 2003;136:231-238.

64. Kerrison JB, Miller NR, Hsu F, et al. A case-control study of tobacco and alcohol consumption in Leber hereditary optic neuropathy. Am J Ophthalmol. 2000;130:803-812.

65. Majander A, Huoponen K, Savontaus ML, Nikoskelainen E, Wikstrom M. Electron transfer properties of NADH:ubiquinone reductase in the ND1/3460 and the ND4/11778 mutations of the Leber hereditary optic neuroretinopathy (LHON). FEBS Lett. 1991;292:289-292.

66. Smith PR, Cooper JM, Govan GG, Harding AE, Schapira AH. Platelet mitochondrial function in Leber's hereditary optic neuropathy. J Neuro/ Sci. 1994;122:80-83.

67. Carelli V, Ghelli A, Ratta M, et al. Leber's hereditary optic neuropathy: biochemical effect of $11778 / N_{4}$ and $3460 / N_{1}$ mutations and correlation with the mitochondrial genotype. Neurology. 1997;48:1623-1632.

68. Carelli V, Ghelli A, Bucchi L, et al. Biochemical features of mtDNA 14484 (ND6/M64V) point mutation associated with Leber's hereditary optic neuropathy. Ann Neurol. 1999;45:320-328

69. Degli Esposti M, Carelli V, Ghelli A, et al. Functional alterations of the mitochondrially encoded ND4 subunit associated with Leber's hereditary optic neuropathy. FEBS Lett. 1994;352:375-379.

70. Ghelli A, Degli Esposti M, Carelli V, Lenaz G. Changes in mitochondrial complex I activity and coenzyme $\mathrm{Q}$ binding site in Leber's hereditary optic neuropathy (LHON). Mol Aspects Med. 1997;18 Suppl:S263-267.

71. Lenaz G, Baracca A, Carelli V, et al. Bioenergetics of mitochondrial diseases associated with mtDNA mutations. Biochim Biophys Acta. 2004;1658:89-94

72. Cock HR, Cooper JM, Schapira AH. Functional consequences of the 3460-bp mitochondrial DNA mutation associated with Leber's hereditary optic neuropathy. I Neurol Sci. 1999;165:10-17.

73. King MP, Attardi G. Human cells lacking mtDNA: repopulation with exogenous mitochondria by complementation. Science. 1989;246:500-503. 
74. Baracca A, Solaini G, Sgarbi G, et al. Severe impairment of complex 1-driven adenosine triphosphate synthesis in leber hereditary optic neuropathy cybrids. Arch Neurol. 2005;62:730-736.

75. Robinson $B H$, Petrova-Benedict $R$, Buncic $J R$, Wallace DC. Nonviability of cells with oxidative defects in galactose medium: a screening test for affected patient fibroblasts. Biochem Med Metab Biol. 1992;48:122-126.

76. Trounce IA, Kim YL, Jun AS, Wallace DC. Assessment of mitochondrial oxidative phosphorylation in patient muscle biopsies, lymphoblasts, and transmitochondrial cell lines. Methods Enzymol. 1996;264:484-509.

77. Mashima Y, Kigasawa K, Wakakura M, Oguchi Y. Do idebenone and vitamin therapy shorten the time to achieve visual recovery in Leber hereditary optic neuropathy? J Neuroophthalmol. 2000;20:166-170.

78. Newman NJ, Biousse V, David R, et al. Prophylaxis for second eye involvement in leber hereditary optic neuropathy: an open-labeled, nonrandomized multicenter trial of topical brimonidine purite. Am J Ophthalmol. 2005;140:407-415.

79. Guy J, Oi X, Wang $H$, Hauswirth WW. Adenoviral gene therapy with catalase suppresses experimental optic neuritis. Arch Ophthalmol. 1999;117:1533-1539.

8o. Qi X, Sun L, Hauswirth WW, Lewin AS, Guy J. Use of mitochondrial antioxidant defenses for rescue of cells with a Leber hereditary optic neuropathy-causing mutation. Arch Ophthalmol. 2007;125:268-272.

81. Poulton J, Macaulay V, Marchington DR. Mitochondrial genetics ' 98 is the bottleneck cracked? Am J Hum Genet. 1998;62:752-757.

82. Yamada K, Mashima Y, Kigasawa K, et al. High incidence of visual recovery among four Japanese patients with Leber's hereditary optic neuropathy with the 14484 mutation. J Neuroophthalmol. 1997;17:103-107.

83. Thornhill AR, deDie-Smulders CE, Geraedts JP, et al. ESHRE PGD Consortium 'Best praCtice guidelines for clinical preimplantation genetic diagnosis (PGD) and preimplantation genetic screening (PG5)'. Hum Reprod. 2005;20:35-48.

84. Jacobs LJ, de Wert G, Geraedts JP, de Coo IF, Smeets HJ. The transmission of OXPHOS disease and methods to prevent this. Hum Reprod Update. 2006;12:119-136. 


\section{Clinical Studies chapter 3}

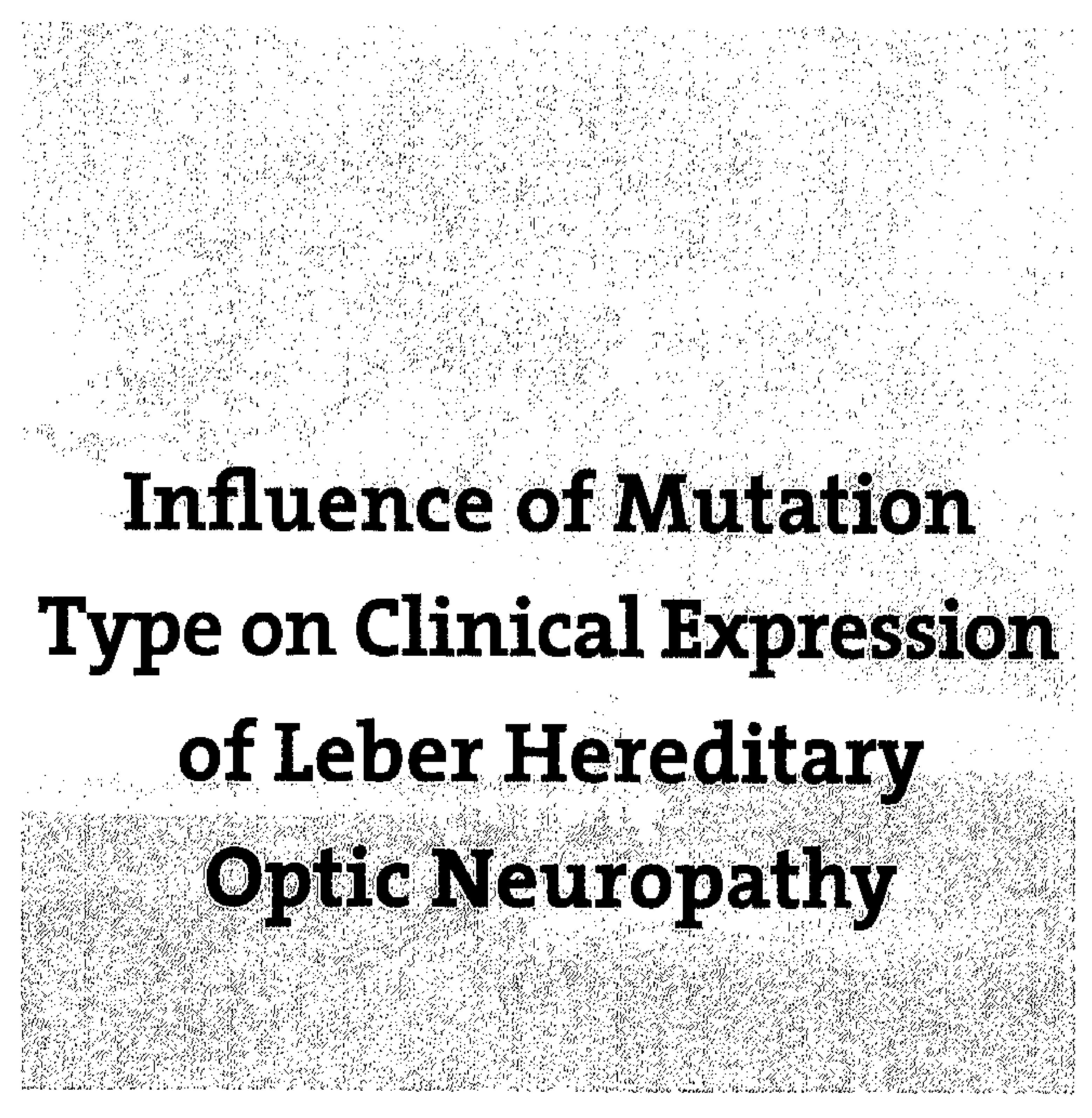

Liesbeth Spruijt, Dinanda Kolbach, Rene de Coo, Astrid Plomp, Noël Bauer, Bert Smeets, Christine de Die-Smulders.

American Journal of Ophthalmology 2006; 141(4):676-682 


\section{Abstract}

Purpose: The aim of this research was to determine the molecular factors of influence on the clinical expression of Leber's hereditary optic neuropathy (LHON), which might aid in counselling LHON patients and families. The prevalence of LHON in the Dutch population was determined.

Design: Observational, retrospective population cohort study.

Methods: The clinical characteristics of LHON patients of 25 families, previously described in 1963 , were re-evaluated. The mutation and haplotype were determined in the DNA of one affected LHON patient per family. The genotype of their relatives could be deducted enabling us to evaluate retrospectively the genotype-phenotype correlation. The prevalence of LHON was determined based on anamnestic evaluation of patients in 1963 and by using population registers of that period.

Results: The LHON mutation is not of influence on the disease penetrance $150 \%$ in males; $10-20 \%$ in females). More than half of the patients with the m.14484T>C mutation exhibit a partial recovery of vision, indifferent of the acuteness of disease onset $(p=0.001)$, whereas only $22 \%$ of the m.11778G>A carriers and $15.4 \%$ of the 3460 carriers experienced recovery. The recovery did not take place within the first year after onset and was uncommon after 4 years. The onset of LHON is in general very acute but might be more gradual in m.11778G>A carriers and in children. The calculated prevalence of LHON in the Dutch population $(1 / 39,000)$ is very likely an underestimation caused by a selection bias of familial cases in the original study.

Conclusions: The LHON genotype is of influence on the recovery of vision and disease onset but unrelated with age and acuteness of onset or sex. The genotype does not influence disease penetrance. Children might show a slower disease onset. 


\section{Introduction}

Leber's hereditary optic neuropathy (LHON) is a mitochondrial genetic disease characterized by a bilateral (sub) acute and painless loss of vision. Most patients ( $>98 \%)$ have a severe decrease in visual acuity of less than $2 / 20$, caused by a large central or cecocentral scotoma. LHON usually affects previously healthy young male adults with a mean age of onset at 22 years (range $5-65$ years). ${ }^{1}$ In more than $95 \%$ of the LHON patients the onset of the disease is before the age of $50 .{ }^{2}$ Some patients have a (partial) recovery of vision after the acute phase. The degeneration of the optic nerve is due to a loss of retinal ganglion cells and optic nerve axons, with a preferential loss of the P-ganglion cells, which are responsible for central vision. The exact pathogenesis of LHON has not been resolved yet and consequently, the therapeutic possibilities are still very limited. A small amount of the LHON mutation carriers have additional neurological defects $3-5$ or cardiac arrhythmia such as Wolff-Parkinson-White syndrome. ${ }^{6,7}$

One of the three primary mitochondrial DNA (mtDNA) mutations m.11778G>A, m.14484T>C or $m .3460 \mathrm{G}>\mathrm{A}$ are found in more than $95 \%$ of the patients with LHON. ${ }^{8}$ More than 30 other rare mitochondrial mutations have been associated with LHON 9,10 (MITOMAP, http://www. mitomap.org). LHON mutations are usually homoplasmic, meaning that all the mitochondria in each cell of mutation carriers contain only mutated mtDNA. Mutations in other mitochondrial diseases are usually heteroplasmic signifying that only a certain percentage of the mtDNA in each cell is mutated. LHON has an incomplete penetrance that has been recognized since the earliest studies. The chances for carriers of a LHON mutation to become affected are $-30-50 \%$ for males and $\sim 10-15 \%$ for females." The mutation in the mtDNA is clearly necessary but not enough to initiate the disease. Secondary genetic and/or epigenetic or environmental risk factors might play a role in the pathogenesis. Non-hereditary causes such as intoxications, (smoking, alcohol, drugs) trauma or vascular causes have been postulated as risk factors for the expression of LHON. ${ }^{12}$ These claims have however not been substantiated by others. ${ }^{13}$ Another possible risk factor is the genetic background. The mtDNA has a high mutation rate which has resulted in accumulation of a wide range of single mtDNA nucleotide polymorphisms dividing the population in different haplotypes. ${ }^{14}$ These haplotypes in themselves are neutral polymorphisms, but some have shown to increase the penetrance of LHON, in particular the J haplotype that has been associated with the $\mathrm{m} .14484 \mathrm{~T}>\mathrm{C}$ and $\mathrm{m} .11778 \mathrm{G}>\mathrm{A}$ mutations. ${ }^{15}$

There are only few prevalence figures for genetically confirmed cases of LHON. The prevalence of LHON in North East England and Finland is 1/30,000-1/50,000,1, which was somewhat higher than the prevalence reported in the Australian population in the premolecular era. ${ }^{8}$ This present study provide on of the most complete studies in a population since Mackey presented his study on the Australian population in $1992 .{ }^{7}$ 
The genetic counselling of LHON patients is challenging. One of the major issues is the impossibility to predict who in a LHON mutation family is at risk for developing visual loss and how the clinical course of each individual will be eventually. The main aim of this study was to find molecular characteristics related with an increased risk of visual loss or specific clinical course of LHON. This might aid in the genetic counselling of LHON patients and their families.

\section{Patients and methods}

\section{Patients}

The clinical information of 351 LHON patients from 27 families used in this study was collected in 1963 by van Senus. ${ }^{18}$ His aim was to give a complete overview of the disease in the Netherlands in order to establish an archive for future investigators. He traced the families in various ways, mainly from previous investigations and publications on causes of blindness. The pedigree information was verified with the help of birth and death registers. All patients had visual loss typical of LHON, a positive family history with other affected relatives and a strict maternal inheritance. The van Senus pedigrees were numbered So01-027. Sporadic patients were not included in his study, since at the time of van Senus it was nearly impossible to make the correct diagnosis in these cases due to the lack of molecular studies. Van Senus and his co-workers clinically examined 202 of the patients personally. The standard examination included a detailed case and family history and when possible the ophthalmological and other medical reports were collected. The clinical data of 150 deceased patients were mainly based on anamnestic information. The number of patients per pedigree ranged from 2 to 66 , with an average of 10.7 patients per family. Most families spanned more than 8 generations, traced back to an ancestor living in the $17^{\text {th }}$ or $18^{\text {th }}$ century. These pedigrees compromise more than $\sim 3000$ maternally related individuals. We could trace and collect the blood of one or more living family members of 25 of the 27 van Senus families. The protocols were approved by the University Hospital Maastricht Medical Ethics Committee and we obtained informed consent of the patients.

\section{Methods}

The presence of one of the three primary LHON mutations and the haplotype in peripheral blood leucocytes was determined with Restriction Fragment Length Polymorphism Analysis (RFLP). Total genomic DNA was extracted from peripheral EDTA blood with the Wizard DNA clean up system (Promega) and the m.11778G>A, m.3460G $>A$ and m.14484T>C mutations were detected by RFLP analysis of PCR fragments. ${ }^{119}$ The five major European mtDNA 
haplotypes, $\mathrm{U}, \mathrm{K}, \mathrm{J}, \mathrm{T}$ and $\mathrm{H}$ were determined as described previously. ${ }^{14}$ We determined the mutations and haplotypes in one patient per pedigree, knowing that all patients and relatives through the maternal line will carry the same mtDNA mutation. We determined the penetrance of each of the primary LHON mutations by counting the total number of affected and unaffected brothers and sisters of each index patient in each generation. Figure I gives an example of this method in a simplified branch of the van Senus pedigree S005A. The proband has one affected brother, one unaffected brother and two unaffected sisters. In the same way this information was collected from all index patients. We also gathered information on the disease onset, in particular the rapidity with which symptoms developed. If applicable, we included the time interval of visual improvement.

In order to establish the prevalence of LHON in the Dutch population of 1963 we assumed that van Senus covered the entire LHON population at that time. The number of inhabitants in 1963 was obtained from the historical data available from the Central Office for Statistics (CBS) at http://statline.cbs.nl. We are aware that, because LHON was less widely known in 1963 and sporadic LHON cases were excluded in the original study of van Senus, the calculated prevalence is possibly a significant underestimation of the actual prevalence.

Statistical analyses were performed with the software package SPSS version 11.01. The m.3460G>A mutation was not included in all the statistical analyses because of the small number of patients. A student T-test was used to examine if the age of onset is of influence on recovery of vision. We used a chi square test for trend to compare the acuteness of disease onset of the m.11778G $>A$ and $m .14484 T>C$ mutations and to compare differences in recovery between males and females. Logistic regression was done to show a possible relationship for the difference in acuteness of disease onset and the improvement of the symptoms between both mutations. Statistical significance was reached when $p<0.05$.

\section{Results}

Table I shows the primary mutation and haplotypes in the different van Senus pedigrees. We could deduce the mutation and haplotype in a total of 325 symptomatic patients, 274 males and 51 females. Three families were excluded from further analysis; in one of the families, none of the primary LHON mutations could be found (12 patients), and in two other families there were no living patients (total 14 patients). The m.11778G>A mutation was presumed to be present in 145 patients of 14 families ( $41 \%$ ), the $\mathrm{m} .14484 \mathrm{~T}>\mathrm{C}$ mutation in 155 patients of 7 families ( $44 \%$ ) and the $m .3460 G>A$ mutation in 25 patients of 3 families (7\%). These index patients had 264 unaffected male siblings and 403 unaffected female siblings, who were all obligate carriers. The overall penetrance of LHON, in patients with a 
known mtDNA mutation, was $50.9 \%(274 / 538)$ for males and $11.2 \%(51 / 454)$ for females. The penetrance is not significantly different (chi square test $p>0.05$ ) between the m.11778G $>A$ and $m .14484 T>C$ mutation, neither for males nor for females. The affected male to female ratio is 1: 5.9 for the $m .11778 \mathrm{G}>\mathrm{A}$ mutation, $1: 5.5$ for the m.14484T $>C$ mutation and $1: 3.2$ for the $m .346 \circ G>A$ mutation. All m.14484T $>C$ carriers had a I haplotype while this was only present in 1 of the 13 families with the $\mathrm{m} .11778 \mathrm{G}>\mathrm{A}$ mutation. There were two m.3460G $>\mathrm{A}$ families with a $J$ haplotype and 1 with an $\mathrm{H}$ haplotype. None of the 29 female siblings in families with a $T$ and $U$ background were affected. On the contrary, 23 of the 39 males in these families were symptomatic. The differences in penetrance of the different haplogroups could not be analyzed because of the small size of the groups.

The acuteness of disease onset is shown in Table 2. This information was available for 205 of the total of 351 cases. Patients with the m.14484T>C and m.3460G>A mutation developed visual impairment of the first eye within 21 days in respectively $95.9 \%(94 / 98)$ and $93.8 \%(15 / 16)$ of cases whereas $79.1 \%(72 / 91)$ of the m.11778G>A patients had this acute disease onset. The symptoms of LHON developed significantly slower, meaning an interval of longer than 21 days, in patients with the $m .11778 \mathrm{G}>\mathrm{A}$ mutation than in patients with the m.14484T $>C$ mutation (chi square test $p<0.001$ ).

The influence of the age at onset on the time interval of symptom development was studied (not in table). In 288 of the 351 patients information about the age at onset was known (mean 24.2; median 22.0 years). There were 50 patients in the study with a disease onset at age 15 or younger and the data on the acuteness were available of 36 of them. There were 169 patients older than 15 years with available data on disease onset. The majority $(92.9 \%)$ of them reported a vision loss within 21 days. On the contrary, patients younger than 15 years, reported in two third of all cases (67.7\%) an acute onset. Patients younger than 15 had a significantly (chi square test $p<0.001$ ) slower onset of symptoms than patients older than 15 .

Table 3 shows the time until eventual recovery of vision, after the initial onset of LHON symptoms of 199 patients. Almost half of the LHON patients $(43.7 \% ; 87 / 199)$ report an eventual improvement in visual acuity. Patients with the $m .14484 \mathrm{~T}>\mathrm{C}$ mutations reported significantly more often improvement of visual acuity $(64 \%)$ than $m .11778 \mathrm{G}>\mathrm{A}$ carriers $(22 \%)$ and $m .3460 G>A$ carriers $(15 \%)$ (chi square test for trend $p=0.001$ ). The improvement of vision usually does not occur in the first months after disease onset. In more than $81 \%$ of the patients improvement in sight occurred after more than one year of the initial visual loss. A small number of patients $(n=26)$ reported improvement even four years after the disease started. There was no significant difference in age of onset (T-test $p=0.095$ ) or gender (chi square test $p=0.366$ ) between the group with and without recovery. We are not aware of any relapses in patients after they showed recovery. 
We studied the correlation between acuteness of symptoms and the chances for recovery. Analyses depending on the mutation with logistic regression showed no influence of the acuteness of disease onset on chances for recovery.

According to historical data, the Netherlands had 11.89 million inhabitants in 1963 . At that time van Senus identified 222 symptomatic, living LHON patients. Assuming that he included in his study the complete LHON population we can infer a prevalence of at least $\sim 1 / 53.000$.

\section{Discussion}

In this study we re-examined the clinical data of the 1963 van Senus pedigrees, completed with the recent determined mutation and haplotype, in order to study the influence of the genotype on various clinical characteristics of LHON. The penetrance and sex ratio in our population is comparable with those in literature. ${ }^{1,2,20-22}$

Mitochondrial haplotypes, in particular the $\mathrm{J}$ haplotype, have an influence on the expression and penetrance of the LHON mutations. ${ }^{23,15}$ The m.14484T $>C$ and $\mathrm{m} .11778 \mathrm{G}>\mathrm{A}$ mutations have frequently a $\mathrm{J}$ haplotype, but this association does not exist for the m.3460G $>A$ mutation, and in our study, the $\mathrm{J}$ haplotype is present in all $\mathrm{m} .14484 \mathrm{~T}>\mathrm{C}$ carriers but in only 1 of the 13 families with the $\mathrm{m} .11778 \mathrm{G}>\mathrm{A}$ mutation. We found a possible favourable prognosis for female mutation carriers with a $T$ or $U$ haplotype although we could not determine if this is significant due to the small sample size. The relation between a non-J haplotype and a low penetrance of LHON has been described in literature for both sexes. ${ }^{15}$

There are relative more patients with a $\mathrm{m} .14484 \mathrm{~T}>\mathrm{C}$ mutation than there are with the other two primary mutations in the Dutch population due to a strong founder effect similar to the one reported for the French-Canadian LHON population. ${ }^{24}$ The m.14484T $>C$ mutation is not common ( $<15 \%)$ in Finland, other Caucasian populations, and Asia. ${ }^{25.26}$ The m.11778G $>\mathrm{A}$ mutation is the most frequent one reported in Asian LHON patients (90\%) and in the general Caucasian population $(50-75 \%) .{ }^{27}$

The onset of LHON is generally known to be very acute. We found a significant more gradual onset in patients with the $\mathrm{m} .11778 \mathrm{G}>\mathrm{A}$ mutation. There are, as far as we know, no other studies reporting this difference in disease onset between the different mutations. Because of the less acute onset and a negative family history of at least $50 \%$ for the m.11778G $>\mathrm{A}$ mutation ${ }^{2}$ there is a possibility that the diagnosis will be missed. Patients younger than 15 years old have a more gradual vision loss than adults. Whether the disease onset is in reality more gradual in children or that it is related to differences in communicating the symptoms or flexible adaptation we do not know and further studies are necessary. The 
more subclinical onset of LHON in young children and m.11778G $>\mathrm{A}$ carriers is an important finding since the standard teaching is that LHON is a more acute process. Especially in children it is difficult to differentiate LHON clinically from autosomal dominant optic atrophy (ADOA; OMIM 165500), an optic atrophy with insidious onset in early childhood. Further pedigree and molecular analysis is indicated to search for either LHON mutations of for mutations in the ADOA gene (OPA1).

The chances for recovery are said to be highest $(37-65 \%)^{28-31}$ in patients with a m.14484T $\mathrm{C}$ mutation, lower in the m.3460G>A mutation (-20-40\%) and rare in the $\mathrm{m} .11778 \mathrm{G}>\mathrm{A} \mathrm{mu}$ tation $(4 \%))^{6,22,32}$ The majority of the patients with the m.14484T>C mutation in our study $(64 \%)$ have a partial recovery of vision unrelated to the acuteness of onset. In contrast with the low recovery rate of $4 \%$ reported in patients with the $m .11778 \mathrm{G}>\mathrm{A}$ mutation ${ }^{33}$ we found a substantial recovery rate of $22 \%$ in patients with the same mutation. This recovery rate is more consistent with the recovery rate reported by Mashima et al. ${ }^{34}$ We think that the prognosis in patients with the $\mathrm{m} .11778 \mathrm{G}>\mathrm{A}$ might be better than is usually believed. We observed that the improvement in all cases did usually not occur in the first months after disease onset but rather after more than one year or longer. Improvement in our group has even been reported 4 years after the initial symptoms. Van Senus suggested that the prognosis is possibly more favorable in patients which develop the disease at a younger age. In a more recent report 29 it was shown that patients with the m.14484T $>C$ mutation are more likely to show improvement if visual loss occurs before the age of 20. Nevertheless we did not find in our study a significant lower age in the group of patients with recovery compared to patients without recovery. The prognosis for females is not different than those for males. Important is that relapses after an improvement are fortunately very exceptional..$^{18}$ The partial visual recovery is unexplained but is possibly an important feature in the pathophysiology of LHON. In LHON there is a marked cell body and axonal degeneration, with associated demyelination and atrophy. ${ }^{35} \mathrm{~A}$ proposed explanation for the visual recovery is remyelination of optic nerve axons. A number of LHON patients report (partial) recovery of vision after the initial acute onset. The recovery is usually not complete but some patients are able to read without special tools and sometimes even drive a car again.

The prevalence of LHON has been determined only in two other Northern-European populations. LHON appeared to be one of the most common mitochondrial disorders (3.22 per 100,000). ${ }^{36}$ The prevalence of at least $1 / 53,000$ in the Dutch population is very likely an underestimation caused by a selection bias in favor of LHON patients with a positive family history. $U p$ to $\sim 50 \%$ of the $\mathrm{m} .11778 \mathrm{G}>\mathrm{A}$ patients and $-30 \%$ of the $\mathrm{m} .3460 \mathrm{G}>\mathrm{A}$ individuals with $\mathrm{LHON}^{2,29}$ have no history of similar affected relatives, isolated patients with the disease are missing in this study with a selection bias in favor of patients with a positive 
family history. On the contrary, carriers of the m.14484T>C mutation have in virtually all cases a positive history of affected relatives explaining the high prevalence of this mutation in the van Senus population. ${ }^{2}$ Adjusting for this bias we found a maximum prevalence of symptomatic LHON patients of $-1 / 39,000$. This number resembles the ones reported in two other Northern-European countries. ${ }^{1,16}$

The cause of LHON is clearly complex and an mIDNA LHON mutation is necessary, but not sufficient for the expression of this disorder. The reason for the predominance of male patients is still unknown but a role for an $X$-linked modifier gene has been proposed. $37,3^{8}$ Despite more than a decade of linkage studies by several different groups, such a modifier has not been identified. ${ }^{39-41}$ Genetic heterogeneity and/or interaction with different environmental factors might play a role in this complex disease.

The genetic counseling of patients and relatives with LHON pedigrees is difficult, as well for the patients involved as the physician dealing with it. One important issue is the inability to predict if and when a LHON mutation carrier will become symptomatic in the future. In addition, there is no adequate therapy available or precautions known to be effective. The characteristic fundus findings, such as peripapillary microangiopathy, have no prognostic value because it can be present in relatives of LHON patients who remain aymptomatic throughout life. When a LHON mutation has been identified in a patient, unaffected family members might request genetic testing. If offered, they should be cautioned that finding the mutation in relatives in maternal line is very likely, since de novo mutations are rare. Moreover the results will not help to give a prognosis. Male LHON patients can be reassured that transmission to their children is not possible. On the other hand their mothers and siblings are at risk. Although the peak incidence of this disease is in adulthood, one can never be certain that a family member will not become affected later in life. ${ }^{22}$ Nevertheless, the chance of become symptomatic is less than $5 \%$ in persons older than 50 years of age. ${ }^{2}$ Females, either symptomatic or asymptomatic, will transmit the pathogenic mutation to all their children. Children of symptomatic females do not have a higher chance than asymptomatic carriers to get LHON. Since there are indication that external factors, in particular smoking have an influence on the development of LHON the use of this substance should be discouraged in mutation carriers.

In conclusion, LHON has in general a very acute onset but is significantly more gradual in patients with the $\mathrm{m} .11778 \mathrm{G}>\mathrm{A}$ mutation and in children. The genotype is of influence on the recovery of vision but there is no relation with age at onset, acuteness of onset and sex. The best prospects are in $\mathrm{m} .14484 \mathrm{~T}>C$ patients, but recovery does not often occur within a year after disease onset. The $T$ or $U$ haplotype might indicate a favorable prognosis in females but further studies are required. In the Dutch population the m.14484T>C mutation occurs more in Dutch LHON patients than has been reported in other populations. The genetic 
counselling for LHON remains challenging and the information that can be provided to families limited. Further studies for other genetic or biochemical markers that will help predicting the clinical course are required to solve this problem

\section{Acknowledgments}

This work was supported by "The Netherlands Society for Ophthalmological Research" (SOON)", the "The Netherlands Society for Prevention of Blindness" (ANVVB), and the EUFP6 STREP MITOCIRCLE.

Figure 1

Example of a Leber's hereditary optic atrophy family (Van Senus pedigree S005A).

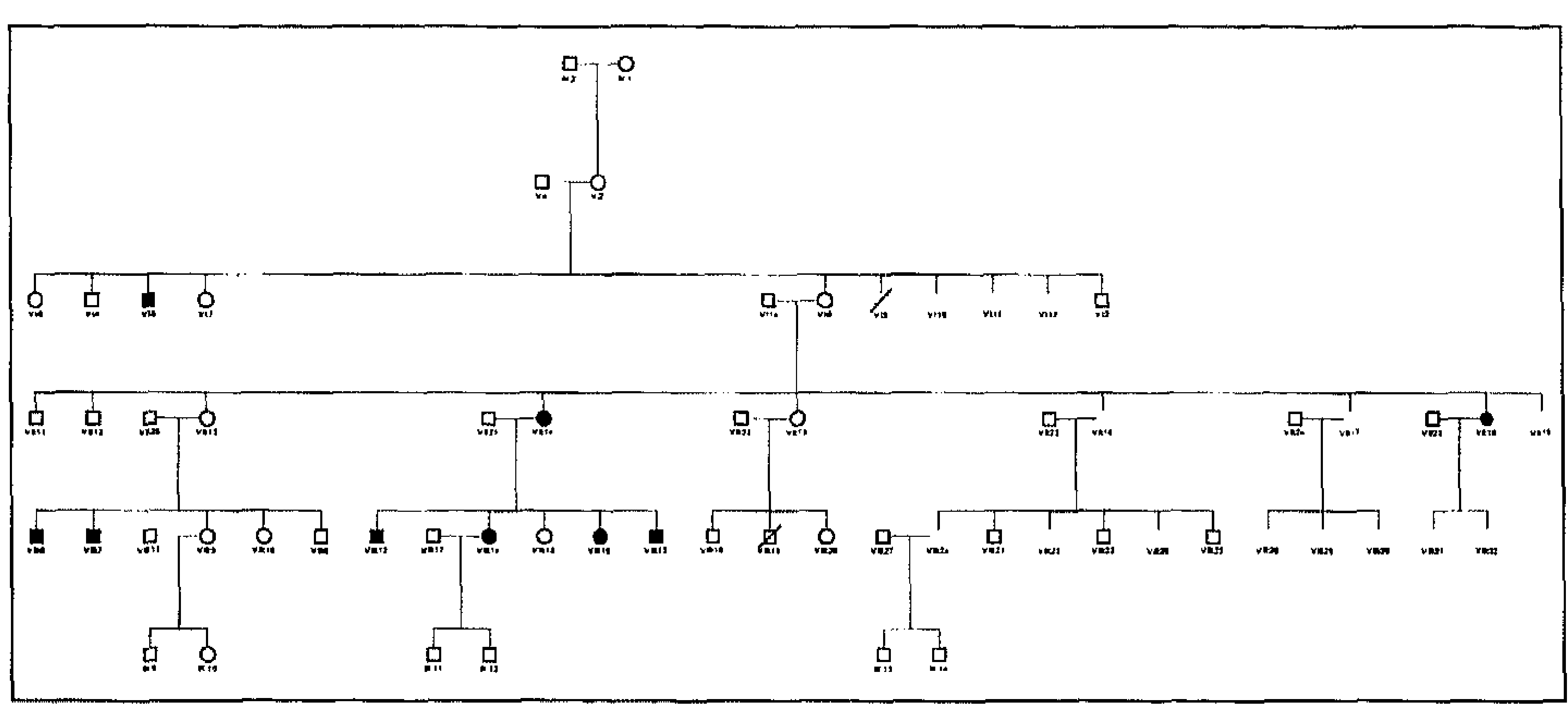

The arrow indicates the index patient. 
Table 7

Leber's hereditary optic neuropathy (LHON) patients described by van Senus in database of 1963. Distribution of mutation, haplotypes and disease penetrance in index patients and their relatives. ND= Not determined "This family was not included in the calculation of disease penetrance

\begin{tabular}{|c|c|c|c|c|c|c|}
\hline \multirow{2}{*}{$\begin{array}{l}\text { “Van Senus” } \\
\text { affected patients } \\
\text { (351) }\end{array}$} & \multirow{2}{*}{$\begin{array}{l}\text { Haplo- } \\
\text { type }\end{array}$} & \multirow[t]{2}{*}{ Families } & \multicolumn{4}{|l|}{ Penetrance } \\
\hline & & & Males & & Female & \\
\hline \multirow{6}{*}{$\begin{array}{l}11778 \\
(145 / 351)\end{array}$} & & & Affected (\%) & Normal & Affected (\%) & Normal \\
\hline & $\mathrm{H}$ & 10 & $95(51.6 \%)$ & 89 & $17(9.8 \%)$ & 156 \\
\hline & J & 1 & $6(40.0 \%)$ & 9 & $4(22.2 \%)$ & 14 \\
\hline & $T$ & 2 & $18(56.0 \%)$ & 14 & - & 24 \\
\hline & $U$ & 1 & $5(71.4 \%)$ & 2 & - & 5 \\
\hline & & Subtotal & $124(52.1 \%)$ & 114 & $21(9.5 \%)$ & 199 \\
\hline \multirow{5}{*}{$\begin{array}{l}14484 \\
(155 / 351)\end{array}$} & $H$ & - & - & - & - & - \\
\hline & J & 7 & $131(50.5 \%)$ & 128 & $24(11.8 \%)$ & 179 \\
\hline & $T$ & - & - & - & - & - \\
\hline & $U$ & - & - & - & $\sim$ & - \\
\hline & & Subtotal & $131(50.5 \%)$ & 128 & $24(11.8 \%)$ & 179 \\
\hline \multirow{5}{*}{$\begin{array}{l}3460 \\
(25 / 351)\end{array}$} & $H$ & 1 & $3(42.9 \%)$ & 4 & $2(40.0 \%)$ & 3 \\
\hline & J & 2 & $16(47.1 \%)$ & 18 & $4(15.4 \%)$ & 22 \\
\hline & $T$ & - & - & - & - & - \\
\hline & $U$ & - & - & - & - & - \\
\hline & & Subtotal & $19(46.3 \%)$ & 22 & $6(19.4 \%)$ & 25 \\
\hline \multirow{2}{*}{$\begin{array}{l}\text { Excluded } \\
(26 / 351)\end{array}$} & & & & & & \\
\hline & & 24 & $274(50.9 \%)$ & 264 & $57(17.2 \%)$ & 403 \\
\hline
\end{tabular}


Table 2 Onset symptoms (time) according to LHON mutation and age $(n=205)$

\begin{tabular}{|l|c|c|}
\hline & \multicolumn{2}{|c|}{ Onset symptoms } \\
\hline $\begin{array}{l}\text { Mutation } \\
\text { (number of } \\
\text { patients) }\end{array}$ & $<21$ days & $>21$ days \\
\hline 1178 & & \\
$n=91$ & 72 & 19 \\
14484 & 94 & 4 \\
$n=98$ & 15 & 1 \\
3460 & & \\
$n=16$ & & \\
\hline
\end{tabular}

Table 3 Improvement of vision (time interval) after initial onset of LHON symptoms.

\begin{tabular}{|l|c|c|c|c|}
\hline Time (years) & $<1$ & $1-4$ & $>4$ & Total improvement \\
\hline $\begin{array}{l}\text { Mutation } \\
11778 \\
n=82\end{array}$ & $7(9 \%)$ & $4(5 \%)$ & $7(9 \%)$ & $22 \%$ \\
$\begin{array}{l}14484 \\
n=104\end{array}$ & $17(16 \%)$ & $31(30 \%)$ & $19(19 \%)$ & $64 \%$ \\
3460 & $1(8 \%)$ & $1(8 \%)$ & & $15 \%$ \\
$n=13$ & $25(13 \%)$ & $36(18 \%)$ & $26(13 \%)$ & $87 / 199$ \\
\hline $\begin{array}{l}\text { Total } \\
199\end{array}$ & & & & \\
\hline
\end{tabular}




\section{References}

1. Man PY, Griffiths PG, Brown DT, Howell N, Turnbull DM, Chinnery PF. The epidemiology of Leber hereditary optic neuropathy in the North East of England. Am J Hum Genet 2003;72:333-9.

2. Harding AE, Sweeney MG, Govan GG, Riordan-Eva P. Pedigree analysis in Leber hereditary optic neuropathy families with a pathogenic mtDNA mutation. Am J Hum Genet 1995:57:77-86.

3. Meire FM, Van Coster R, Cochaux P, Obermaier-Kusser B, Candaele C, Martin JJ. Neurological disorders in members of families with Leber's hereditary optic neuropathy (LHON) caused by different mitochondrial mutations. Ophthalmic Genet 1995;16:119-26.

4. Chalmers RM, Schapira AH. Clinical, biochemical and molecular genetic features of Leber's hereditary optic neuropathy. Biochim Biophys Acta 1999;1410:147-58.

5. Nikoskelainen EK, Marttila RJ, Huoponen K, et al. Leber's "plus": neurological abnormalities in patients with Leber's hereditary optic neuropathy. $J$ Neurol Neurosurg Psychiatry 1995;59:160-4.

6. Nikoskelainen EK, Savontaus ML, Huoponen K, Antila K, Hartiala J. Pre-excitation syndrome in Leber's hereditary optic neuropathy. Lancet 1994;344:857-8.

7. Bower SP, Hawley I, Mackey DA. Cardiac arrhythmia and Leber's hereditary optic neuropathy. Lancet 1992;339;1427-8.

8. Mackey DA, Oostra RJ, Rosenberg T, et al. Primary pathogenic mtDNA mutations in multigeneration pedigrees with Leber hereditary optic neuropathy. Am J Hum Genet 1996;59:481-5.

9. Chinnery PF, Taylor GA, Howell N, Brown DT, Parson TJ, Turnbull DM. Point mutations of the mtDNA control region in normal and neurodegenerative human brains. Am J Hum Genet 2001:68:529-32.

10. Brown MD, Allen JC, Van Stavern GP, Newman NJ, Wallace DC. Clinical, genetic, and biochemical characterization of a Leber's hereditary optic neuropathy family containing both the 11778 and 14484 primary mutations. Am J Med Genet 2001;104:331-8.

11. Riordan-Eva P, Harding AE. Leber's hereditary optic neuropathy: the clinical relevance of different mitochondrial DNA mutations.J Med Genet 1995;32:81-7.

12. Sadun AA, Carelli V, Salomao SR, et al. Extensive investigation of a large Brazilian pedigree of $11778 /$ haplogroup J Leber hereditary optic neuropathy. Am J Ophthalmol 2003;136:231-8.

13. Kerrison JB, Howell N, Miller NR, Hirst L, Green WR. Leber hereditary optic neuropathy. Electron microscopy and molecular genetic analysis of a case. Ophthalmology 1995;102:1509-16. 
14. Torroni A, Huoponen K, Francalacci $P$, et al. Classification of European mtDNAs from an analysis of three European populations. Genetics 1996;144:1835-50.

15. Howell N, Herrnstadt C, Shults C, Mackey DA. Low penetrance of the 14484 LHON mutation when it arises in a non-haplogroup J mtDNA background. Am J Med Genet 2003:119A:147-51.

16. Huoponen K. Leber hereditary optic neuropathy: clinical and molecular genetic findings. Neurogenetics 2001;3:119-25.

17. Mackey DA, Buttery RG. Leber hereditary optic neuropathy in Australia. Aust N ZJ Ophtalmol 1992;20:177-84.

18. van Senus A. Leber's disease in the Netherlands. Doc Ophthalmol 1963; 7:1-163.

19. Black GC, Morten K, Laborde A, Poulton J. Leber's hereditary optic neuropathy: heteroplasmy is likely to be significant in the expression of LHON in families with the $3460 \mathrm{ND} 1$ mutation. BrJ Ophthalmol 1996;80:915-7.

20. Macmillan C, Kirkham T, Fu K, et al. Pedigree analysis of French Canadian families with the Tr4484C Leber's hereditary optic neuropathy. Neurology 1998;50:417-22.

21. Newman NJ. Leber"s hereditary optic neuropathy. New genetic considerations. Arch Neurol 1993;50:540-8.

22. Johns DR, Smith KH, Miller NR. Leber's hereditary optic neuropathy. Clinical manifestations of the 3460 mutation. Arch Ophthalmol 1992;110:1577-81.

23. Torroni A, Petrozzi M, D'Urbano L, et al. Haplotype and phylogenetic analyses suggest that one European-specific mtDNA background plays a role in the expression of Leber hereditary optic neuropathy by increasing the penetrance of the primary mutations 11778 and 14484 . Am J Hum Genet 1997;60:1107-21.

24. Howell N, Oostra RJ, Bolhuis PA et al. Sequence analysis in the mitochondrial genomes from Dutch pedigrees with Leber hereditary optic neuropathy. Am J Hum Genet 2003;72:1460/9.

25. Mashima $Y$, Yamada $K$, Wakakura $M$, et al. Spectrum of pathogenic mitochondrial DNA mutations and clinical features in Japanese families with Leber's hereditary optic neuropathy. Curr Eye Res 1998;17:403-8.

26. Taylor RW, Joblings MS, Turnbull DM, Chinnery PF. Frequency of rare mitochondrial DNA mutations in patients with suspected Leber's hereditary optic neuropathy J Med Genet 2003;40:e85.

27. Mashima Y, Hiida Y, Oguchi Y, Kudoh J, Shimizu N. High frequency of mutations at position 11778 in mitochondrial ND4 gene in Japanese families with Leber's hereditary optic neuropathy. Hum Genet 1993;92:101-2.

28. Oostra RJ, Bolhuis PA, Wijburg FA, Zorn-Ende G, Bleeker-Wagemans EM. Leber's hereditary optic neuropathy: correlation between mitochondrial genotype and visual outcome. I Med Genet 1994;31:280-6. 
29. Riordan-Eva P, Sanders MD, Govan GG, Sweeney MG, Da Costa J, Harding AE. The clinical features of Leber's Hereditary Optic Neuropathy defined by the presence of a pathogenic mitochondrial mutation. Brain 1995;118 (Pt2):319-37.

30. Mackay D, Howell N. A variant of Leber hereditary optic neuropathy characterized by recovery of vision and by an unusual mitochondrial genetic etiology. Am J Hum Genet 1992;51:1218-28.

31. Johns DR, Heher KL, Miller NR, Smith KH. Leber's hereditary optic neuropathy. Clinical manifestations of the 14484 mutation. Arch Ophthalmol 1993;111:495-8.

32. Wallace DC, Brown MD, Lott MT. Mitochondrial DNA variation in human evolution and disease. Gene 1999;238:211-30.

33. Stone AM, Newman NJ, Miller NR, Johns DR, Lott MT, Wallace DC. Visual recovery in patients with Leber's hereditary optic neuropathy and the 11778 mutation. J Clin Neuroophthalmol 1992;12:10-4.

34. Mashima Y, Kigasawa K, Wakakura M, Oguchi Y. Do idebenone and vitamin therapy shorten the time to achieve visual recovery in Leber hereditary optic neuropathy? J Neuroophthalmol 2000;20:166-70.

35. CarelliV, Ross-Cisneros FN, Sadun AA. Optic nerve degeneration and mitochondrial dysfunction: genetic and acquired optic neuropathies. Neurochem Int 2002;40:573-84.

36. Chinnery PF, Johnson MA, Wardell TM, et al. The epidemiology of pathogenic mitochondrial DNA mutations. Ann Neurol 2000; 48:188-91.

37. Vilkii J, Ott J, Savontaus ML, Aula P, Nikoskelainen EK. Optic atrophy in Leber hereditary optic neuroretinopathy is probably determined by a X-chromosomal gene closely linked to DXS7. Am J Hum Genet 1991;48:486-91.

38. Bu X, Yang HY, Shohat M, Rotter Jl. Two-locus mitochondrial and nuclear gene models for mitochondrial disorders. Genet Epidemiol 1992;9:27-44.

39. Chalmers RM, Davis MB, Sweeney MG, Wood NW, Harding AE. Evidence against an Xlinked visual loss susceptibility locus in Leber hereditary optic neuropathy. Am J Hum Genet 1996;59:103-8.

40. Sweeney MG, Davis MB, Lashwood A, Brockington M, Toscano A, Harding AE. Evidence against an X-linked locus close to DXS7 determining visual loss susceptibility in British and Italian families with Leber hereditary optic neuropathy. Am I Hum Genet 1992;51:741-8.

41. Carvalho MR, Muller B, Rotzer E, et al. Leber's hereditary optic neuroretinopathy and the $X$-chromosomal susceptibility factor: no linkage to DXS7. Hum Hered 1992;42:316-20.

42. Man PY, Turnbull DM, Chinnery PF. Leber hereditary optic neuropathy. J Med

Genet 2002;39:162-9. 


\section{Chapter 4}

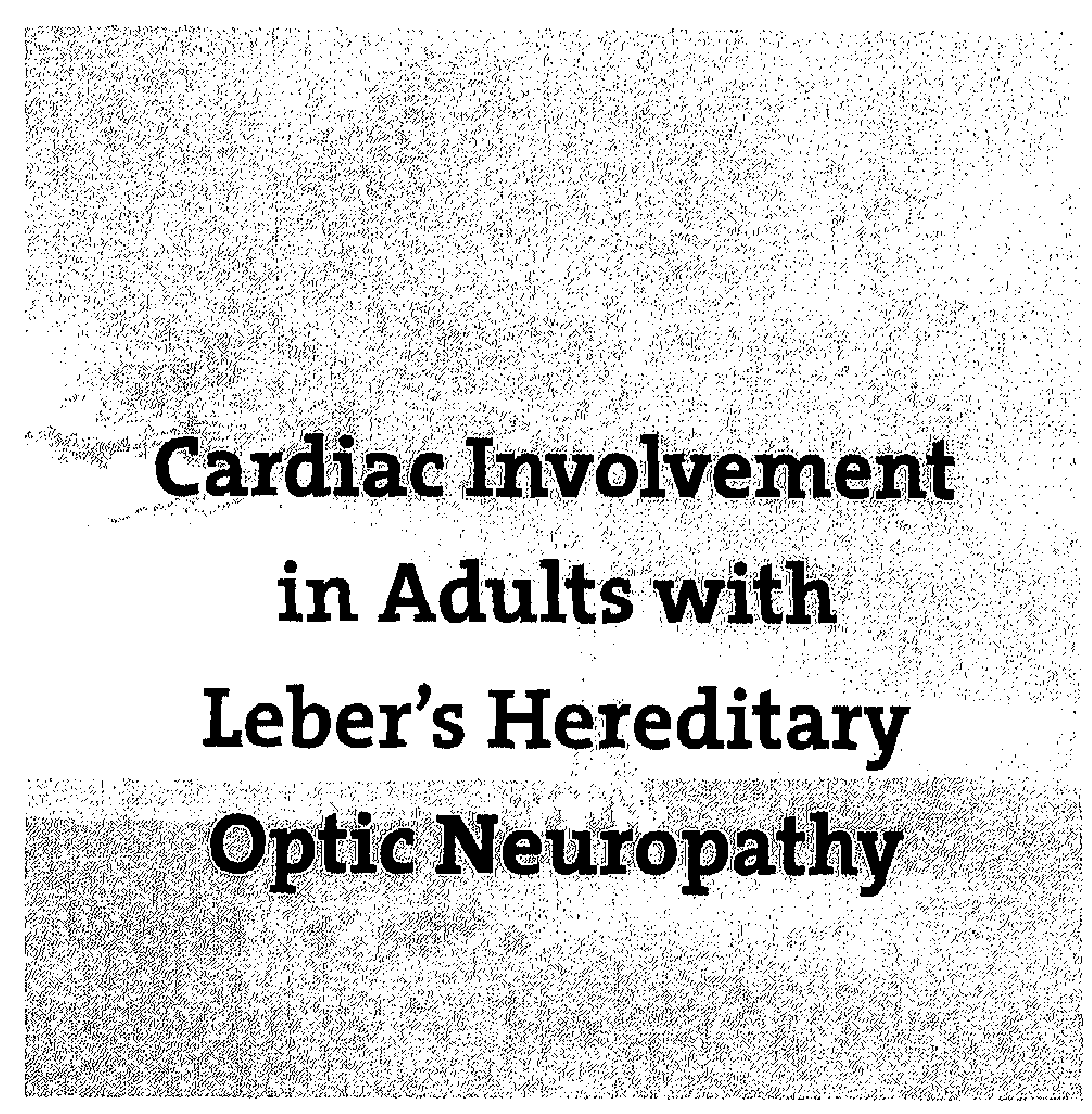

Liesbeth Spruijt, Osama I. Soliman, Marcel L. Geleijnse, Wim B. Vletter, Atilla Nemes, Folkert J. ten Cate, Wim Sluiter, Hubert J. Smeets, René F. de Coo. Submitted 


\section{Abstract}

Left ventricular (LV) pre-excitation and hyperthrophic cardiomyopathy have been reported in Leber's hereditary optic neuropathy (LHON) patients. In the present study cardiac involvement in Dutch subjects with LHON harboring one of the mitochondrial DNA (mtDNA) point mutations $\mathrm{m} .3460 \mathrm{G}>\mathrm{A}, \mathrm{m} .11778 \mathrm{G}>\mathrm{A}$, or $\mathrm{m} .14484 \mathrm{~T}>\mathrm{C}$ was studied.

A clinical and genetic evaluation was performed in 28 LHON mutation carriers. Subsequently, each subject underwent electrocardiography and two-dimensional echocardiography, including tissue myocardial Doppler imaging. One patient showed LV pre-excitation characterized by a short PR interval ( $112 \mathrm{~ms}$ ) without a wave. Three patients had right bundle branch block. None of the patients had increased LV end-diastolic dimensions or overt LV systolic (ejection fraction) abnormalities. One patient known with poorly controlled hypertension had increased left atrial dimension, increased LV mass and low mitral annular systolic velocity. Three other patients had despite normal LV ejection fraction low mitral annular systolic velocities and/or diastolic dysfunction grade I. All these latter three patients had a history of hypertension or an advanced age. The prevalence of cardiac involvement in Dutch LHON patients was found to be comparable to the normal population. Cardiac abnormalities previously reported in LHON patients might be co-incidental, linked to other genetic abnormalities or related to epigenetic factors. 


\section{Introduction}

Leber's Hereditary Optic Neuropathy (LHON) is a mitochondrial inherited optic atrophy that characteristically presents with (sub) acute, bilateral vision loss in previously healthy young adults. 'More than $95 \%$ of cases have one of the primary mitochondrial point mutations $\mathrm{m} .3460 \mathrm{G}>\mathrm{A}, \mathrm{m} .11778 \mathrm{G}>\mathrm{A}$ or m.14484 $>\mathrm{C}$. Secondary genetic and/or epigenetic factors, that still remain to be elucidated, are possibly an explanation for the variable expression of this disorder. In contrast to the nuclear DNA, mtDNA is exclusively maternally inherited because the zygote only contains mitochondria derived from the oocyte.

Although optic neuropathy is the main and usually sole symptom of LHON, multisystemic involvement including neurological and cardiac abnormalities have been described. Neurological problems include movement disorders, tremor, tics, parkinsonism, dystonia, migraine, peripheral neuropathy. ${ }^{2-4}$ Cardiac abnormalities include left ventricular (LV) preexcitation, ${ }^{5,6}$ hypertrophic cardiomyopathy ${ }^{7}$ and LV hypertrabeculation. ${ }^{8}$ Most reports of cardiac involvement in LHON are, however, in isolated cases ${ }^{8}$ or small studies that are influenced by the selection of patients with cardiac complaints in a single family. ${ }^{7}$ To evaluate if cardiac abnormalities are indeed frequently present in LHON patients we performed a prospective study in non-selected LHON patients and mutation carriers from different families.

\section{Methods}

\section{Patients}

Patients and their relatives were approached and recruited through the patient support group on a voluntary base. Each person that participated was selected only by mutation, but not for age, sex, visual or cardiac complaints or other medical history. All participants gave informed consent before entering the study. The institutional review board approved the study.

In 28 adults with a LHON-associated mitochondrial DNA (mtDNA) point mutation from 16 families, cardiac function was prospectively investigated by 12 -lead electrocardiography and echocardiography. Mean age of the patients was $42 \pm 15$ years (range 20 to 67 years) and $16(57 \%)$ were male. Sixteen of the 28 patients $(57 \%)$ had visual impairment. Eight patients had the m.3460G>A mutation, 10 patients the m.11778G $>\mathrm{A}$ mutation, and 10 the m.14484T>C mutation. One symptomatic LHON patient with the $11778 \mathrm{G}>\mathrm{A}$ mutation, inherited from his father M. Steinert ( $n r$ 19). A 51-year-old woman ( $n r$ 1), a 14484T>C mutation carrier without visual disturbances, recently developed exercise intolerance and an ocular 
strabismus. Patient $\mathrm{nr} 17$, a symptomatic $11778 \mathrm{G}>\mathrm{A}$ mutation carrier had a mother and brother with multiple sclerosis-like symptoms.

\section{DNA studies}

LHON mutation. Total genomic DNA and mtDNA was extracted from peripheral EDTA blood with the Wizard DNA clean up system (Promega) according to the instructions of the ma* nufacturer. The m.3460G >A/ND1 (BsaHI), m.11778G >A/ND4 (Maelli, SfaNI) and m.14484T>CI ND6 (Dpnil) mutations were tested by digesting the respective polymerase chain reaction (PCR) products with mutation specific restriction enzymes. ${ }^{9}$ Digestion products were resolved by agarose gel electrophoresis. Mutation m.11778G $>$ A was digested with two enzymes (MaellI, SfaNI) in order to prevent false positive results caused by the $m .11779 \mathrm{C}>T$ polymorphism. The percentage heteroplasmy was determined by fluorescent labelling of the $P C R$ fragment, followed by digestion of the fragment with a mutation specific restriction enzyme and analysis on an ABI Prism 3100 with Genescan analysis software 3.7 (Applied Biosystems) as described before. ${ }^{10}$

RYR2 mutation. In patient $\mathrm{nr} z$ the RYR2 gene associated with catecholaminergic polymorphic ventricular tachycardia was analyzed by dHPLC and sequence analysis. With this method $>98 \%$ of all point mutations, 5 mall deletions and insertions can be detected, but large rearrangements or copy number changes cannot be identified.

\section{Two-dimensional echocardiography}

Echocardiographic studies were performed with a Sonos 7500 ultrasound system (Philips, Best, The Netherlands) by a single, experienced sonographer (WV). The acquired data were digitally stored and subsequently analyzed by two observers (MLG, OllS) who were blinded for the clinical data. All echocardiographic measurements were averaged from three beats.

From the second harmonic $M$-mode recordings the following data were acquired: left atrial dimension (normal value ffi $40 \mathrm{~mm}$ ), LV septal and posterior wall thickness (normal value $<12 \mathrm{~mm}$ ), LV end-diastolic dimension (normal value ffi6o $\mathrm{mm}$ ), and the tricuspid annular plane systolic excursion (normal value ffl2o $\mathrm{mm}$ ). LV ejection fraction was calculated by biplane Simpson rule in accordance with guidelines (normal value ffl5o\%)."

LV mass was calculated using the Devereux formula and indexed by body surface area (normal values in men: ffi150 $\mathrm{g} / \mathrm{m2}$, in women ffi120 $\mathrm{g} / \mathrm{m2}$ ). ${ }^{12}$ From the mitral-inflow pattern peak early $(E)$ and late $(A)$ filling velocities, E/A ratio, E-velocity deceleration time and duration of the A-velocity were measured. Pulmonary vein systolic and diastolic flow and atrial reversal (velocity and duration) were also measured. Diastolic function was graded I to IV according to standard guidelines. ${ }^{13}$ 


\section{Tissue Doppler imaging}

Tissue Doppler was applied in the pulsed-wave Doppler mode at the level of the mitral annulus and the basal right ventricular free wall from the apical 4-chamber view. To acquire the highest wall tissue velocities, the angle between the Doppler beam and the longitudinal motion of the investigated structure was adjusted to a minimal level. The spectral pulsed Doppler velocity range was adjusted to obtain an appropriate scale of $10-20 \mathrm{~cm} / \mathrm{s}$. LV systolic (LV-Sm) and early diastolic (EM) peak velocities were averaged from three samples. Subsequently, mean (calculated from the inferoseptal and lateral wall) $\mathrm{Sm}$, mean Em and the dimensionless parameter $\mathrm{E} /$ mean $\mathrm{Em}$ were calculated from the mitral annulus measurements.

Normal values for mean LV-Sm and mean Em were calculated from 28 for age and gender matched volunteers with normal left atrial and LV dimensions, and LV function as described before. ${ }^{4}$ Normal lower cut-off values for mean LV-Sm and mean Em were, respectively, $7.4 \mathrm{~cm} / \mathrm{sec}$ and $9.9 \mathrm{~cm} / \mathrm{sec}$. The (literature derived) normal higher cut-off value for $\mathrm{E} / \mathrm{Em}$, indicating a most likely low end-diastolic LV pressure, was set to ${ }^{9.15,16}$

\section{Results}

\section{DNA analysis}

Most LHON mutations were homoplasmic ( $100 \%$ mtDNA mutation), except in patients numbered 12-16, who were carriers of a $11778 \mathrm{G}>\mathrm{A}$ mutation. (Table 1) Since their mutation load was above $>80 \%$ they are clinically comparable to the homoplasmic patients. ${ }^{17} \mathrm{Be}$ cause of the history of a catecholamine-induced supraventricular tachycardia a RYR2 gene mutation was excluded in patient 2 .

\section{Rhythm and conduction abnormalities}

Arrhythmia and conduction abnormalities were present in 6 patients (20\%) (Table 1). Prior to this study, one patient ( $\mathrm{nr} 5$ ) was known with atrial tachycardias, one patient ( $\mathrm{nr}$ 2) was known with catecholamine-induced polymorphic ventricular tachycardias, and one patient (nr 1) was known with pre-excitation characterized by a short PR interval (112 ms) without a $\delta$-wave. Another three patients ( $\mathrm{nr} 15,18,24)$ had right bundle branch block, in one ( $\mathrm{nr} 15)$ in combination with left anterior hemi-block.

\section{Echocardiographic abnormalities}

As shown in Table 1, none of the patients had increased LV end-diastolic dimensions or overt LV systolic (ejection fraction) abnormalities. One 59-year-old male ( $\mathrm{nr} 24$ ) known with 
poorly controlled hypertension had increased LA dimension, increased LV mass and low LV-Sm. Two other patients (nrs. 13 and 14) had despite normal LV ejection fraction low LV$\mathrm{Sm}$ values and two of these patients had diastolic dysfunction grade l. Patient $\mathrm{nr} 13$ was a 67-year-old female who was diagnosed as being hypertensive on two separate occasions (blood pressure $170 / 105 \mathrm{mmHg}$ ) during this study. Patient number 14 was a 61-year-old male known with a history of inferior myocardial infarction and hypertension.

\section{Discussion}

In this study we reported cardiac findings in a group of adult patients with LHON, a maternally inherited optic atrophy characterized by (sub) acute, symmetrical vision loss in previous healthy young adults. The main findings of our study are that in unselected LHON patients LV pre-excitation and hypertrophic cardiomyopathy are not frequently present.

\section{Rhythm and conduction abnormalities in LHON patients}

The occurrence of LV pre-excitation in one and a catecholamine-induced polymorphic tachycardia in a sibling is remarkable since both are not very common, not known to be related, and LHON has only a prevalence of 1 in 30.000. However, we do not have any arguments for a second co-inherited disorder and excluded this by not finding a RYR2 gene mutation. The relation between LV pre-excitation and catecholamine-induced polymorphic tachycardia is not known either and there were no other relatives with these disorders. Right bundle branch block and left anterior fascicular hemi-block was found in 3 relatively old LHON mutation carriers, all without visual symptoms. It should be noticed that the prevalence of right bundle branch block in healthy subjects increases with age to up to $10 \%$ in the elderly. ${ }^{18}$ Although the incidence of pre-excitation syndromes in the general population is approximately $0.1-3 / 1000^{19}$ there have been several reports of supraventricular tachycardia, prolonged QT-interval, and pre-excitation syndromes 5,20-22 in LHON patients. Nikoskelainen ${ }^{21}$ reported in Finnish families WPW syndrome in 5 out of 30 symptomatic m.11778G >A patients, none of the $10 \mathrm{~m} .3460 \mathrm{G}>\mathrm{A}$ mutation patients and none of the $11 \mathrm{pa}$ tients without a LHON mutation. Altogether, 5 of 51 LHON patients and 9 of 112 symptomfree maternal relatives had WPW syndrome ( $9 \%$ ), making the overall incidence in LHON mutation carriers therefore $9 \%$. This percentage is significantly higher than is found in the paternal relatives (1.6\%). ${ }^{21}$

In a study in 63 Japanese m.11778G>A LHON mutation carriers, $5(8 \%)$ were found to have LV pre-excitation. In both the Finnish and the Japanese study the conduction anomalies have been found in the affected as well as the symptom-free maternal relatives of patients 
with LHON. There are no other reports with pre-excitation in LHON mutation carriers from other ethnic groups. ${ }^{22-24}$ This raises an important issue about the incidence in Finnish and Japanese families. This difference is either linked to the mitochondrial DNA mutation and LHON or it is just co-incidence due to other genetic factors in these ethnic group. Neither of two possibilities has been proven in their results.

LV cardiomyopathy in LHON patients.

Cardiomyopathy is a frequent presentation in many patients with mtDNA point mutation, either alone or as part of a multisystemic disorder. ${ }^{25}$ In a recent study a $36 \%$ incidence in increased LV mass in LHON patients with the mLDNA m.3460G>A mutation was reported. ${ }^{7}$ It should be noted, however, that all patients included in this study were from one single family. Therefore, it cannot be excluded that a co-inheritance of familial cardiomyopathy with LHON was present rather than that a relation between the mtDNA mutation and cardiomyopathy exists. Unfortunately, genetic screening for inherited hypertrophic cardiomyopathy genes had not been performed. The occurrence of two genetic disorders in patients with a mitochondrial disease or the presence of more than 1 pathogenic mutation in the mtDNA has been reported before. ${ }^{26}$ In our study one of the LHON patients inherited a paternal increased CTG repeat in the DM1 gene causing an adult-onset of myotonic dystrophy.

In this present study, we detected in one out of 8 patients (patient nr. 24) with the m.3460G>A mutation (and in none of the patients with other point mutations) an increase in LV mass. The history of poorly controlled hypertension in this patient could well explain this moderate increase in LV mass. Minor cardiac abnormalities (low LV-Sm values, LV diastolic dysfunction grade I) were present in a few other patients (patients nrs. 13, 14, and 25). Apart from a history of myocardial infarction in one patient, all these patients had a history of hypertension or had advanced age. These conditions are known to be related to lower LV-Sm values. ${ }^{27,28}$

Myocardial thickening and isolated LV abnormal trabeculation has been described in two brothers and in an isolated patient with a m.3460G>A LHON mutation and appears to be a rare manifestation of LHON. ${ }^{8,29}$ None of our patients had evidence for abnormal LV trabeculation.

\section{Conclusion}

We report here on a large series of unselected LHON mutation carriers from several centres throughout the Netherlands. In contrast to previous reports, the incidence of LV pre-excitation or hypertrophy in the Dutch LHON population is low. 
Cardiac Involvement in Adults with Leber's Hereditary Optic Neuropathy

Acknowledgement

We are grateful to the patients who participated in this study and the LHON patient support group that helped us in contacting the patients. This work was supported in part by The Netherlands Society for Ophthalmologic Research (SOON), The Netherlands Society for Prevention of Blindness (ANVVB), and the EU-FP6 STREP MITOCIRCLE. 


\begin{tabular}{|c|c|c|}
\hline \multirow{3}{*}{ 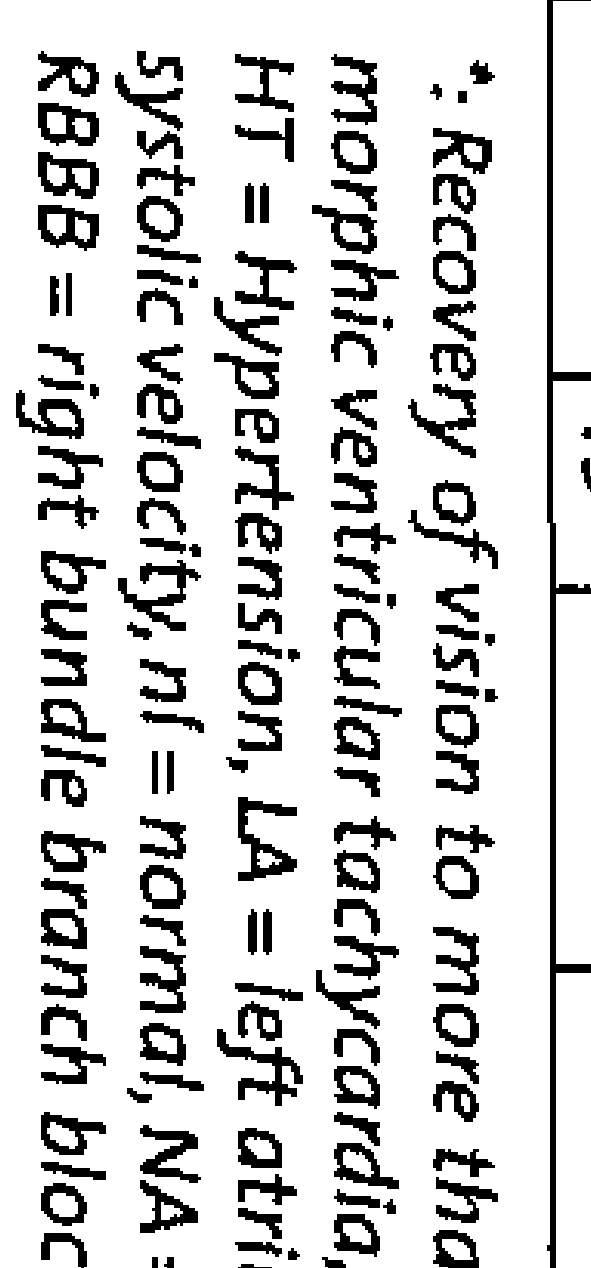 } & 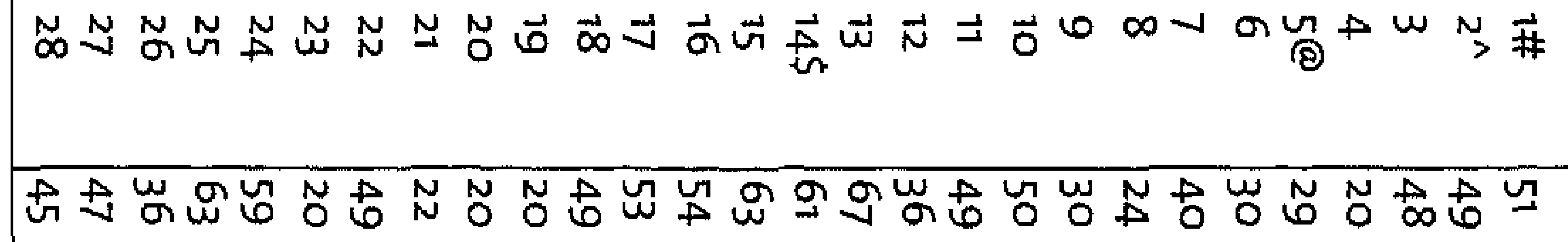 & 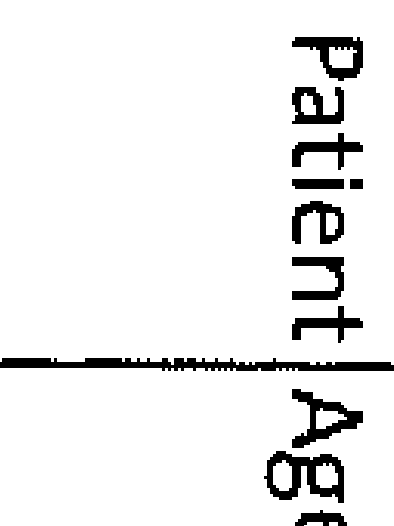 \\
\hline & $3 \pi \pi 333 \pi 333 \pi 3 \pi 33 \pi \pi 3 \pi 333 \pi \pi 3 \pi 3 \pi$ & 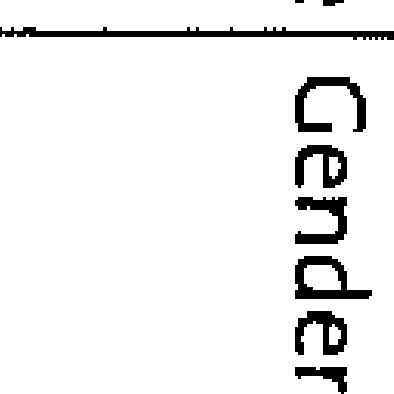 \\
\hline & 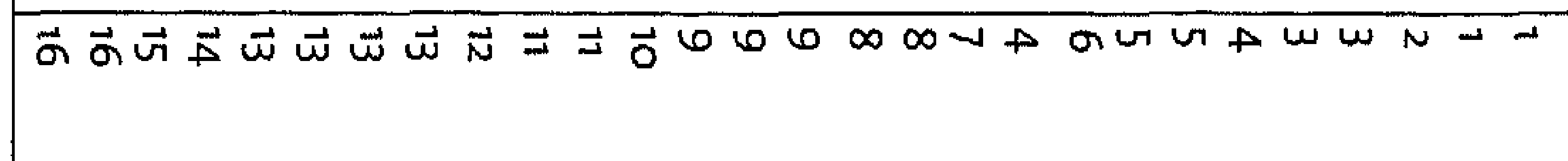 & 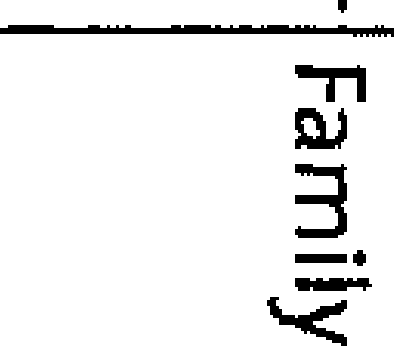 \\
\hline \multirow{3}{*}{ 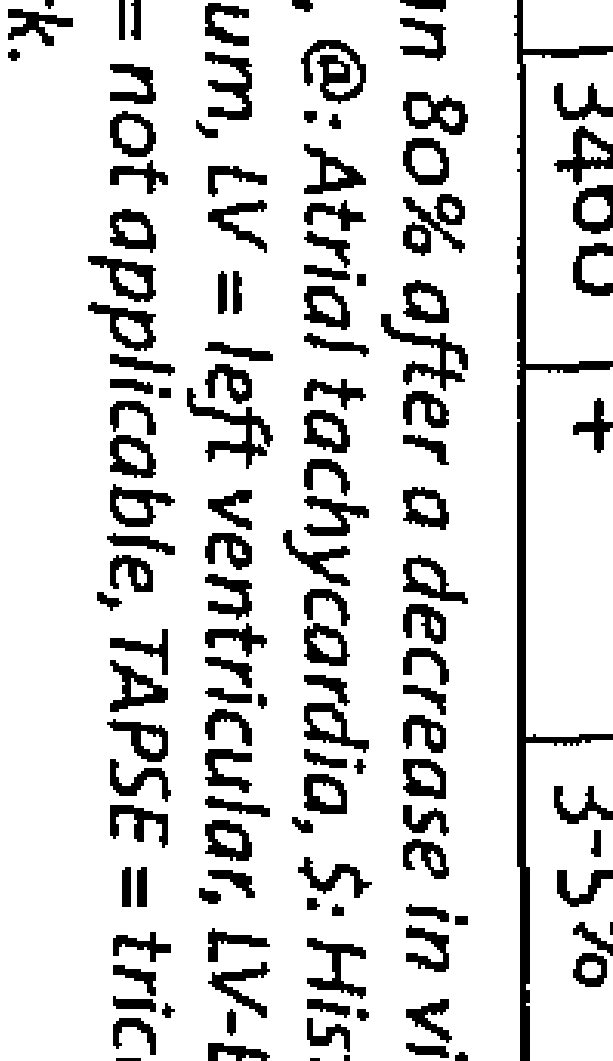 } & 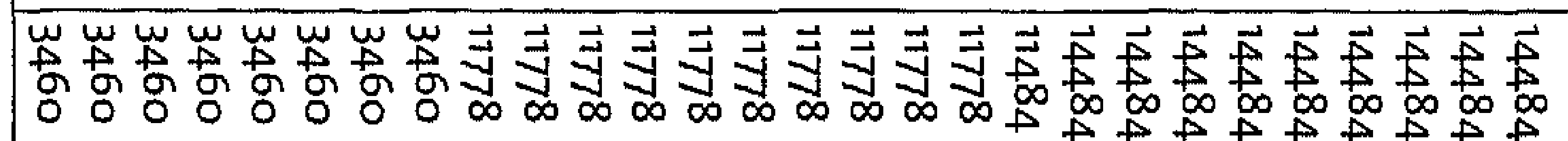 & 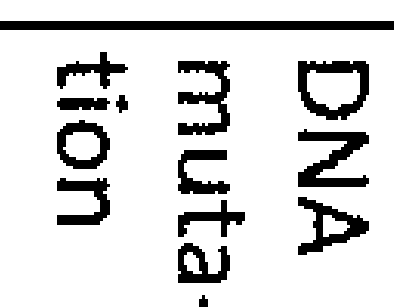 \\
\hline & +1 $1+1,++++1+1+11++1++++1+1+1$ & 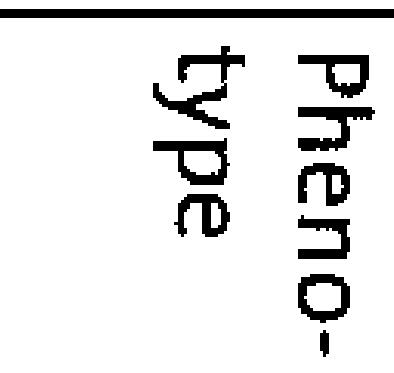 \\
\hline & 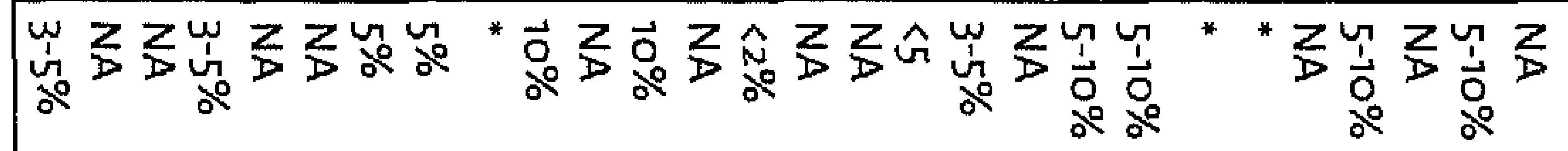 & $\frac{5}{\mathrm{~s}}$ \\
\hline \multirow{4}{*}{ 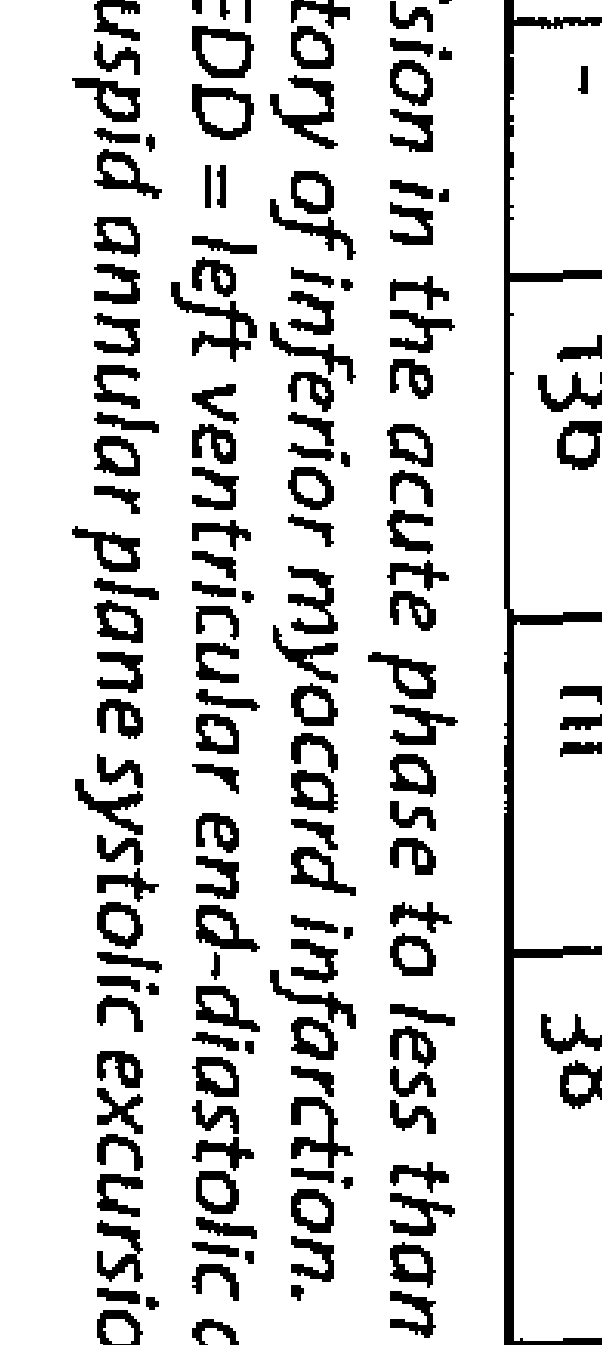 } & 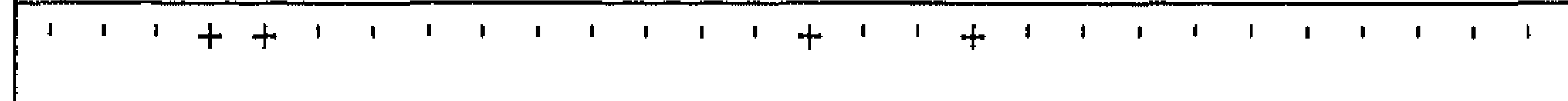 & I \\
\hline & 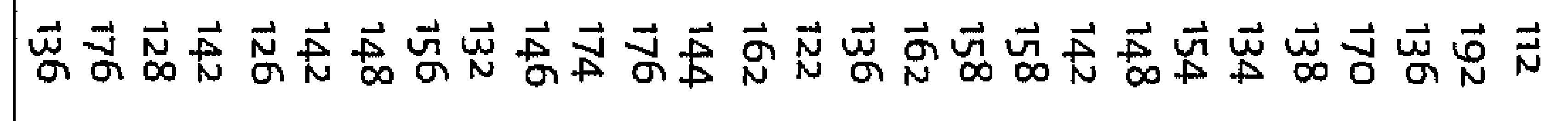 & 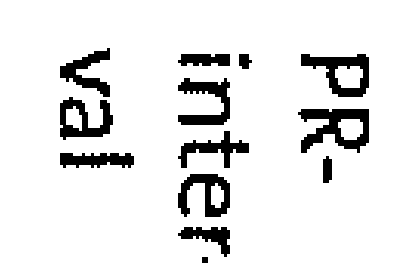 \\
\hline & 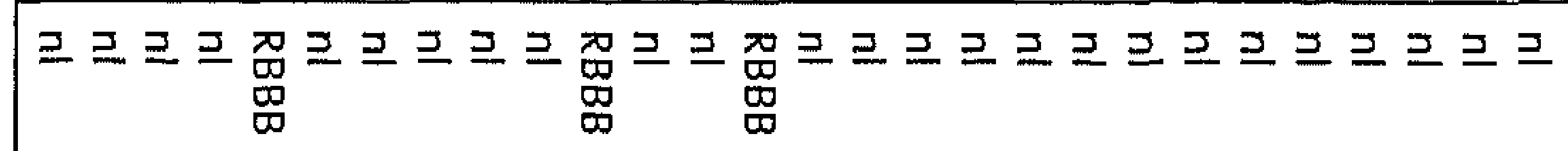 & 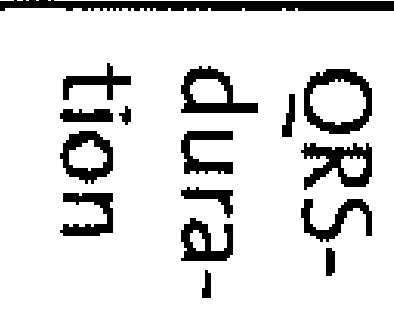 \\
\hline & 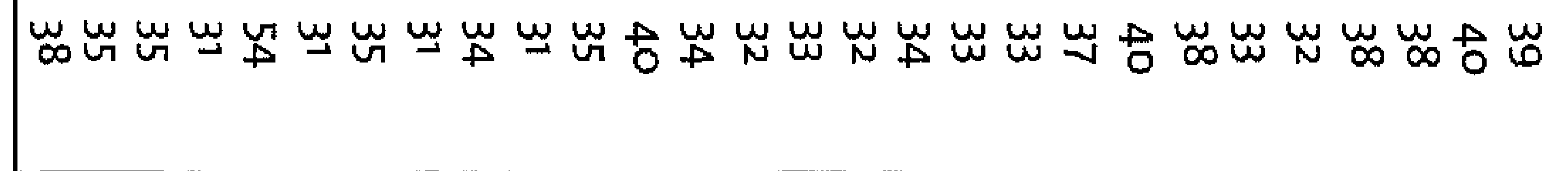 & 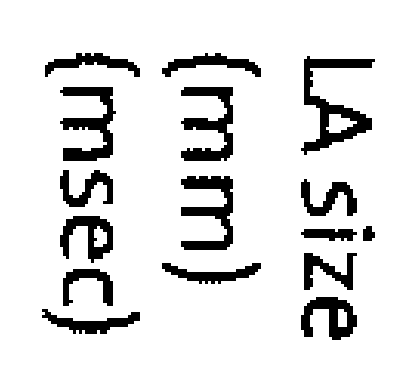 \\
\hline 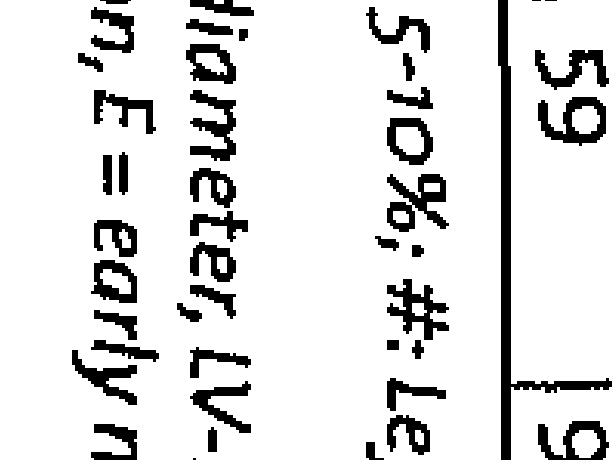 & 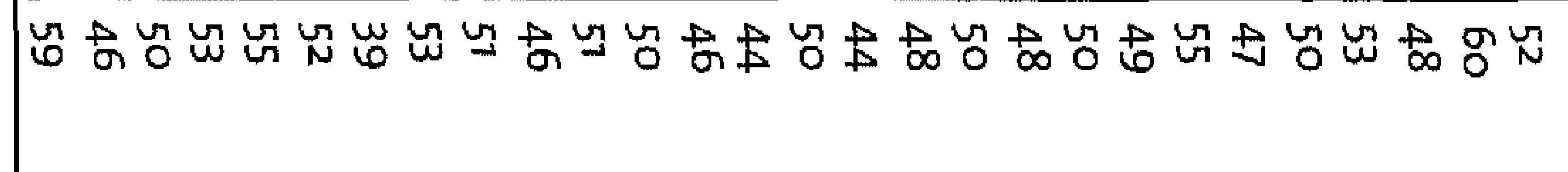 & 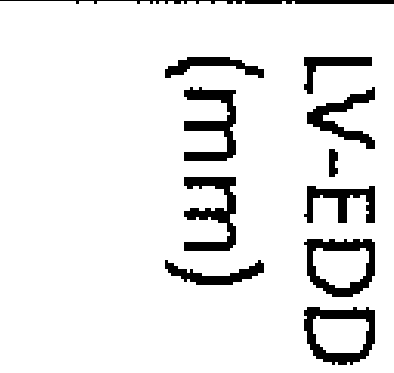 \\
\hline 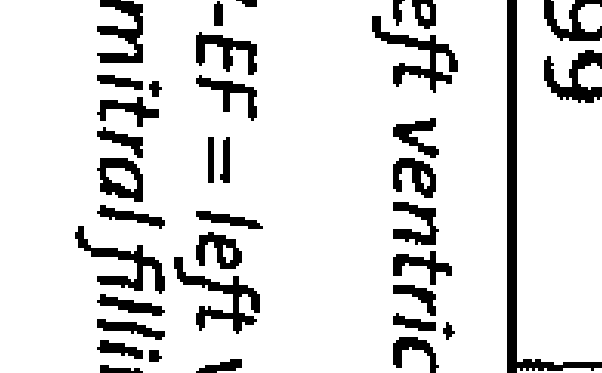 & 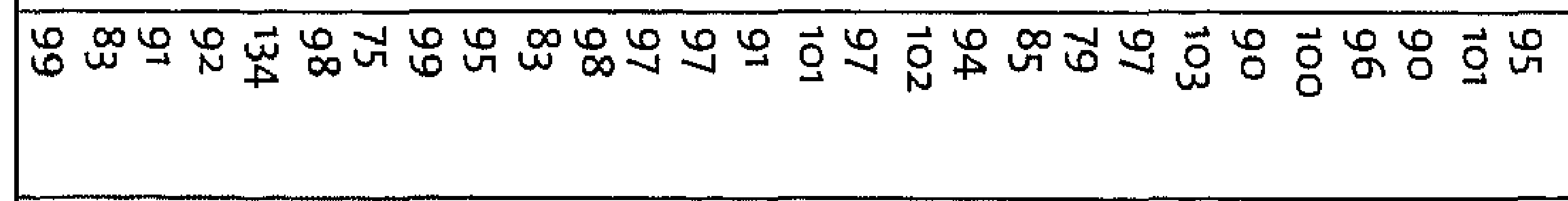 & 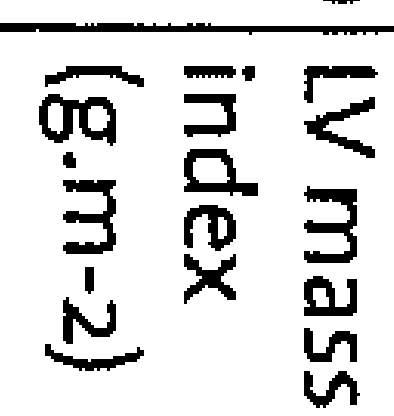 \\
\hline \multirow{5}{*}{ 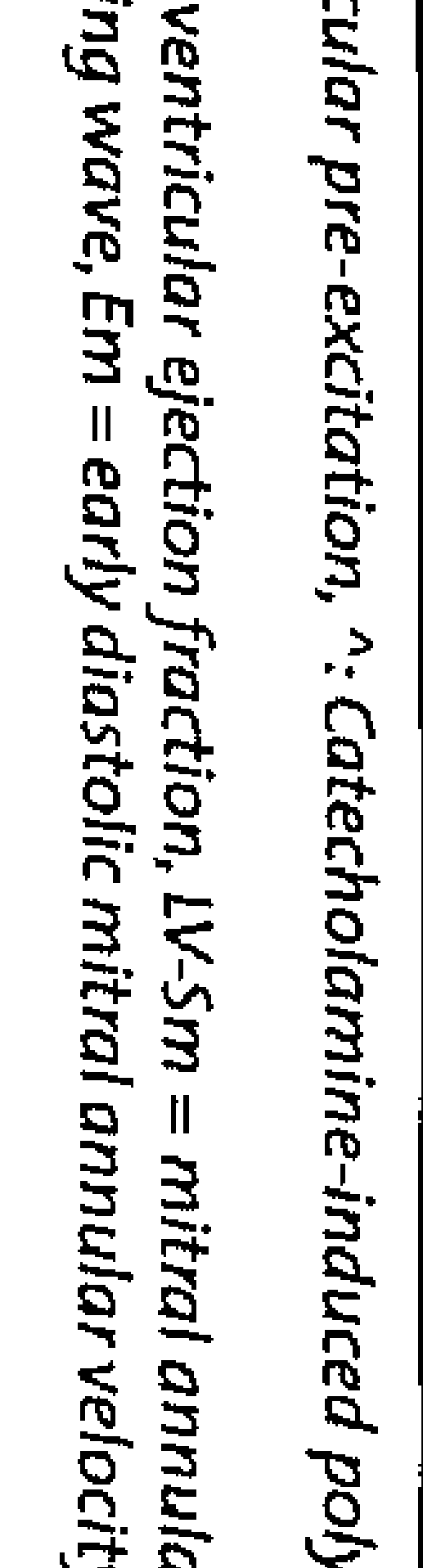 } & 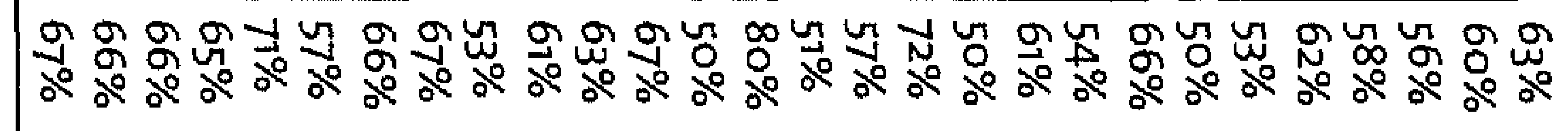 & ङ 产 \\
\hline & 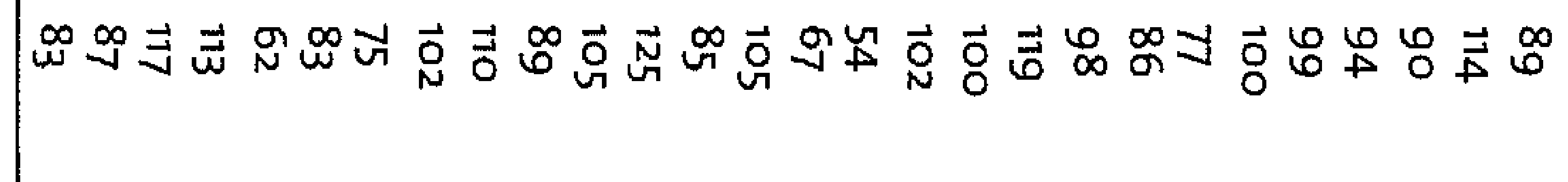 & 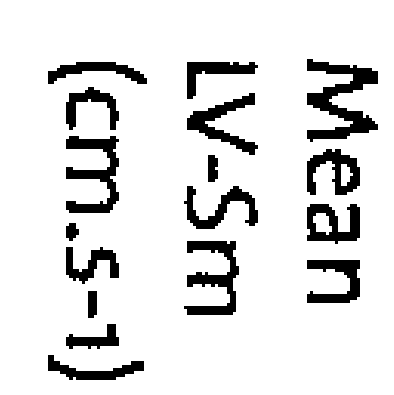 \\
\hline & 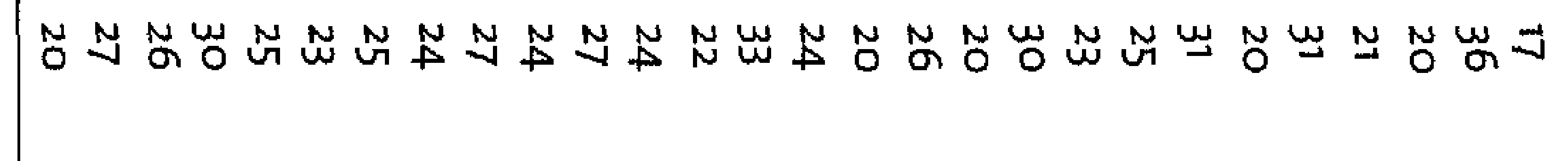 & 胥点 \\
\hline & 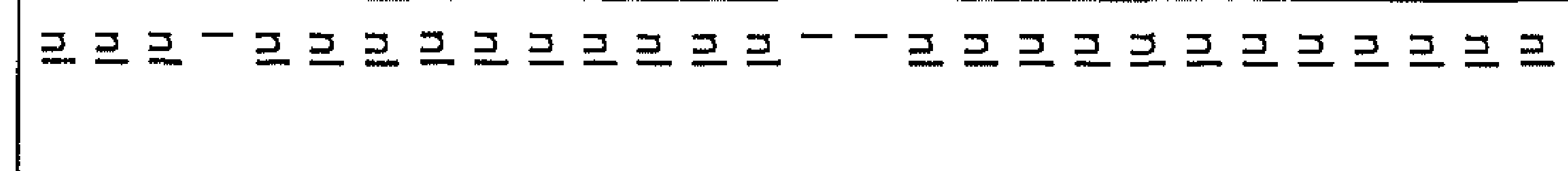 & 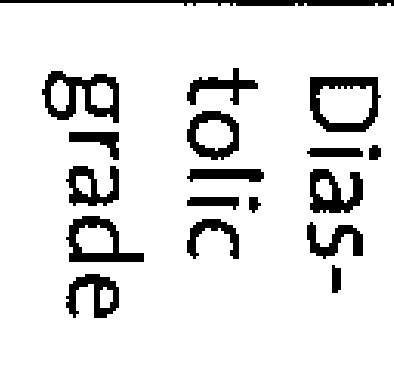 \\
\hline & 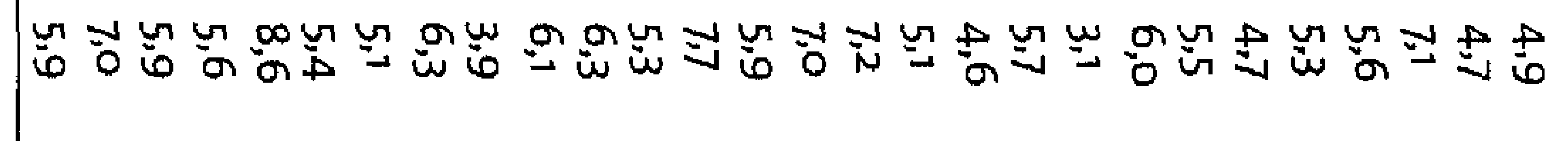 & $\stackrel{\Xi}{3}$ \\
\hline
\end{tabular}




\section{References}

1. Nikoskelainen EK, Savontaus ML, Wanne OP, Katila MJ, Nummelin KU. Leber's hereditary optic neuroretinopathy, a maternally inherited disease. A genealogic study in four pedigrees. Arch Ophthalmol.1987;105:665-671.

2. Harding AE, Sweeney MG, Miller DH, et al. Occurrence of a multiple sclerosis-like illness in women who have a Leber's hereditary optic neuropathy mitochondrial DNA mutation. Brain. 1992;115 (Pt 4):979-989.

3. Meire FM, Van Coster $R$, Cochaux $P$, et al. Neurological disorders in members of families with Leber's hereditary optic neuropathy (LHON) caused by different mitochondrial mutations. Ophthalmic Genet. 1995;16:119-126.

4. Vanopdenbosch L, Dubois B, D'Hooghe MB, Meire F, Carton H. Mitochondrial mutations of Leber's hereditary optic neuropathy: a risk factor for multiple sclerosis.J Neurol. 2000;247:535-543.

5. Mashima $Y$, Kigasawa $K$, Hasegawa $H$, Tani $M$, Oguchi $Y$. High incidence of pre-excitation syndrome in Japanese families with Leber's hereditary optic neuropathy. Clin Genet. 1996;50:535-537.

6. Huoponen K, Juvonen V, litia A, et al. Time-resolved fluorometry in the diagnosis of Leber hereditary optic neuroretinopathy. Hum Mutat. 1994;3:29-36.

7. Sorajja P, Sweeney MG, Chalmers R, et al. Cardiac abnormalities in patients with Leber's hereditary optic neuropathy. Heart. 2003;89:791-792.

8. Finsterer J, Stollberger C, Prainer C, Hochwarter A. Lone noncompaction in Leber's hereditary optic neuropathy. Acta Cardiol. 2004;59:187-190.

9. Brown DT, Samuels DC, Michael EM, Turnbull DM, Chinnery PF. Random genetic drift determines the level of mutant mtDNA in human primary oocytes. Am J Hum Genet. 2001;68:533-536.

10. van Den Bosch BJ, de Coo RF, Scholte HR, et al. Mutation analysis of the entire mitochondrial genome using denaturing high performance liquid chromatography. $\mathrm{Nu}$ cleic Acids Res. 2000;28:E89.

11. Schiller NB, Shah PM, Crawford M, et al. Recommendations for quantitation of the left ventricle by two-dimensional echocardiography. American Society of Echocardiography Committee on Standards, Subcommittee on Quantitation of Two-Dimensional Echocardiograms. J Am Soc Echocardiogr. 1989;2:358-367.

12. Devereux RB, Alonso DR, Lutas EM, et al. Echocardiographic assessment of left ventricular hypertrophy: comparison to necropsy findings. Am J Cardiol. 1986;57:450-458.

13. Khouri SJ, Maly GT, Suh DD, Walsh TE. A practical approach to the echocardiographic evaluation of diastolic function. J Am Soc Echocardiogr. 2004;17:290-297. 
14. Nikitin NP, Witte KK, Thackray SD, et al. Longitudinal ventricular function: normal values of atrioventricular annular and myocardial velocities measured with quantitative twodimensional color Doppler tissue imaging. J Am Soc Echocardiogr. 2003;16:906-921.

15. Nagueh SF, Middleton KJ, Kopelen HA, Zoghbi WA, Quinones MA. Doppler tissue imaging: a noninvasive technique for evaluation of left ventricular relaxation and estimation of filling pressures. J Am Coll Cardiol. 1997;30:1527-1533.

16. Ommen SR, Nishimura RA, Appleton CP, et al. Clinical utility of Doppler echocardiography and tissue Doppler imaging in the estimation of left ventricular filling pressures: A comparative simultaneous Doppler-catheterization study. Circulation. 2000;102:1788-1794.

17. Chinnery PF, Andrews RM, Turnbull DM, Howell NN. Leber hereditary optic neuropathy: Does heteroplasmy influence the inheritance and expression of the $611778 \mathrm{~A}$ mitochondrial DNA mutation? Am J Med Genet. 2001;98:235-243.

18. Eriksson P, Hansson PO, Eriksson H, Dellborg M. Bundle-branch block in a general male population: the study of men born 1913. Circulation. 1998;98:2494-2500.

19. Vidaillet HJ,Jr., Pressley JC, Henke E, Harrell FE, Jr., German LD. Familial occurrence of accessory atrioventricular pathways (preexcitation syndrome). N Engl J Med. 1987;317:65-69.

20. Nikoskelainen E, Wanne O, Dahl M. Pre-excitation syndrome and Leber's hereditary optic neuroretinopathy. Lancet. 1985;1:696.

21. Nikoskelainen EK, Savontaus ML, Huoponen K, Antila K, Hartiala J. Pre-excitation syndrome in Leber's hereditary optic neuropathy. Lancet. 1994;344:857-858.

22. Bower SP, Hawley I, Mackey DA. Cardiac arrhythmia and Leber's hereditary optic neuropathy. Lancet. 1992;339:1427-1428.

23. Riordan-Eva P, Sanders MD, Govan GG, et al. The clinical features of Leber's hereditary optic neuropathy defined by the presence of a pathogenic mitochondrial DNA mutation. Brain. 1995;118 (Pt 2):319-337.

24. Newman NJ, LottMT, Wallace DC.The clinical characteristics of pedigrees of Leber's hereditary optic neuropathy with the 11778 mutation. Am J Ophthalmol. 1991;111:750-762.

25. Lev $D$, Nissenkorn A, Leshinsky-Silver $E$, et al. Clinical presentations of mitochondrial cardiomyopathies. Pediatr Cardiol. 2004;25:443-450.

26. Spruijt $L$, Hoogendijk JE, Hendrickx AT, et al. Additional mitochondrial DNA mutations may explain extra-ocular involvement in LHON. Am J Med Genet A. 2006;140:1478-1481.

27. Vydt TC, de Coo RF, Soliman Ol, et al. Cardiac involvement in adults with m.3243A>G MELAS gene mutation. Am J Cardiol. 2007;99:264-269.

28. Munagala VK, Jacobsen SJ, Mahoney DW, et al. Association of newer diastolic function parameters with age in healthy subjects: a population-based study. $J$ Am Soc Echocardiogr. 2003;16:1049-1056. 
29. Finsterer J, Stollberger C, Kopsa W, Jaksch M. Wolff-Parkinson-White syndrome and isolated left ventricular abnormal trabeculation as a manifestation of Leber's hereditary optic neuropathy. Can J Cardiol. 2001;17:464-466. 


\section{Biochemical Studies Chapter 5}

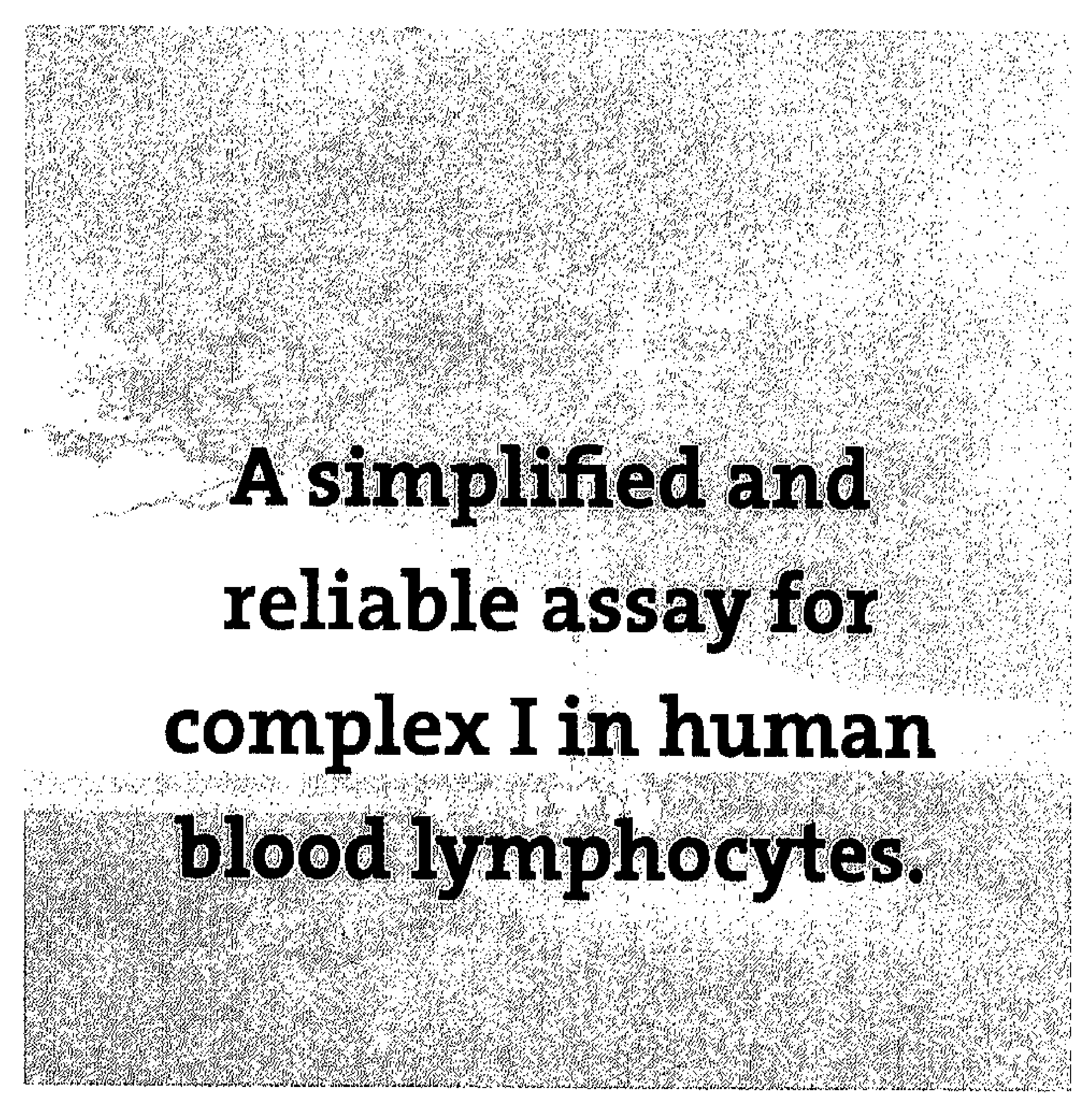

Elly de Wit, Liesbeth Spruijt, Kees Schoonderwoerd, René F. de Coo, Hubert J. Smeets, Hans Scholte, Wim. Sluiter

J Immunol Methods, 2007, 326(1-2):76-82. 


\section{Abstract}

Complex I activity of the mitochondrial respiratory chain is difficult to measure in blood lymphocytes because of the limited access of substrates to the enzyme complex in these cells.

The results of the present study show that permeabilization of human blood lymphocytes in the presence of protease inhibitors by three cycles of freeze thawing enables reproducible detection of the rotenone-sensitive complex l activity. To that end, the water-soluble coenzyme $\mathrm{O}_{10}$ analogue $\mathrm{COO}_{1}$ and a relatively high concentration of blood lymphocytes were combined in small quartz cuvettes so that the amount of blood needed for this assay remained low. The relationship between the initial rate of NADH oxidation by complex 1 and the protein concentration was quasi-linear.

The fractional inhibition of the total NADH:COQ1 oxidoreductase by a saturating concentration of rotenone decreased sharply at higher $\mathrm{COQ}_{1}$ concentrations than $20 \mu \mathrm{M}$, which is indicative, but does not proof the involvement of a second $\mathrm{CO}_{1}$ binding site at complex $\mathrm{I}$. Since the present complex I assay requires only a small amount of blood, the functionality of this important respiratory chain complex can be assessed in an easy and reliable manner not only in adult patients but also in children suspected to suffer from a mitochondrial disease. 


\section{Introduction}

Abnormalities in the common final pathway of mitochondrial energy metabolism, i.e., oxidative phosphorylation (OXPHOS) are recognized in an increasing number of neuromuscular syndromes as the underlying cause of the disease.' At least 1000 genes are involved in a proper functioning of the mitochondrion ${ }^{2}$, making a genetic diagnosis often difficult to achieve. The identification of an enzymatic defect in OXPHOS in a muscle biopsy is an important measure for the diagnosis of mitochondrial encephalomyopathy. All respiratory chain complexes can be reliably measured in muscle homogenates, but obtaining a muscle biopsy is invasive and puts a heavy burden on a patient. A skin biopsy is a less demanding alternative and is often used additionally for the diagnosis of mitochondrial encephalomyopathy. One of the drawbacks of this method is that a genetic defect in the mitochondrial DNA may disappear during culture of the fibroblasts leading to false-negative enzymatic results 3 making a reliable measurement of complex I difficult in these cells.

${ }^{4-6}$ The obvious alternative is the use of blood lymphocytes. These cells are not often used to measure complex I activity spectrophotometrically due to a limited access of substrates to the respiratory chain complex. ${ }^{7}$ Chretien et al. ${ }^{4}$ developed a method to overcome this problem by treating blood lymphocytes by hypotonic shock in the presence of digitonin and Percoll prior to collecting the permeabilized cells by two rounds of centrifugation.

Here we present a simpler approach implying the use of sub microcell cuvettes (volume 80 $\mu l)$ and the short-chain ubiquinone homologue coenzyme $Q_{1}$ as a water-soluble substrate to measure complex I enzyme activity in blood lymphocytes.

\section{Materials and methods}

\subsection{Isolation of blood lymphocytes}

Blood from healthy donors was obtained by venepuncture and anti-coagulation with EDTA. The lymphocytes were isolated as previously described by density centrifugation using Lymphoprep ${ }^{8}$ and resuspended in an ice-cold buffer (SHE-PIM) consisting of $250 \mathrm{mM}$ sucrose, $10 \mathrm{mM}$ HEPES PH 7.4, and $1 \mathrm{mM}$ EDTA (SHE) supplemented with a protease inhibitor mixture (PIM) of two Complete tablets per $50 \mathrm{~mL}$ (Roche Diagnostics, Almere, The Netherlands), 1 mM 4-(2-aminoethyl)-benzenesulfonyl-fluoride hydrochloride (Pefabloc SC, Roche) and $2 \mathrm{mM}$ diisopropyl fluorophosphate (DFP) (Fluka Chemica, Steinheim, Switzerland). The addition of DFP is important to effectively inhibit the active serine proteases from blood neutrophils. ${ }^{9}$ Small 50- $\mu \mathrm{L}$ aliquots of lymphocytes at a concentration of $100 \times 10^{6}$ cells per $\mathrm{mLSHE}-\mathrm{PIM}$ were rapidly frozen in liquid nitrogen, and stored at $80^{\circ} \mathrm{C}$ in brown Eppendorf vials to protect the mitochondria from light. ${ }^{\circ}$ 
were obtained, individual groups means were tested for differences according to Bonferroni's correction for multiple comparisons. The criterion for significance was $P<0.05$ for all comparisons.

\section{Results}

3.1 Kinetic characteristics of complex I from blood lymphocytes

\subsubsection{NADH oxidation rate}

The oxidation of NADH by the NADH:CoQ reductases of blood lymphocytes is quasi-linear for up to 1-2 min (mean: $125 \mathrm{sec}$, SD: $8 \mathrm{sec}, \mathrm{n}=4$; Fig. 1). Rotenone, the inhibitor of complex $\mathrm{I}$, is used to enable the discrimination between complex I activity and other NADH:COO reductases ${ }^{14}$. As a consequence of the short duration of first order kinetics of complex I and the fact that the binding of rotenone to the enzyme complex is not instantaneous ", it is mandatory to add the inhibitor in a separate cuvette, and to measure the residual activity simultaneously with the total activity in the absence of rotenone.

\subsubsection{Coenzyme $Q$ dependency}

To study the dependency of the rate of $\mathrm{NADH}$ oxidation by complex I on CoQ, various concentrations of CoO1 up to $1.8 \mathrm{mM}$ were added to $3.5 \times 10^{6}$ permeabilized blood lymphocytes per $\mathrm{mL}$ in the presence and absence of a fully saturating concentration of $5 \mu \mathrm{M}$ rotenone. The results showed that at that cell concentration, which is equivalent to $145 \mu \mathrm{g}$ protein per $\mathrm{mL}$, the Vmax of $1.7 \mathrm{nmol} \mathrm{NADH} . \mathrm{min}^{-1} . \mathrm{mL}^{1}$ is reached at a CoO1 concentration of approximately $50 \mu \mathrm{M}$ (Fig. 2). The apparent $\mathrm{Km}$ amounted to $6.6 \mu \mathrm{M}$ CoQ 1 . 


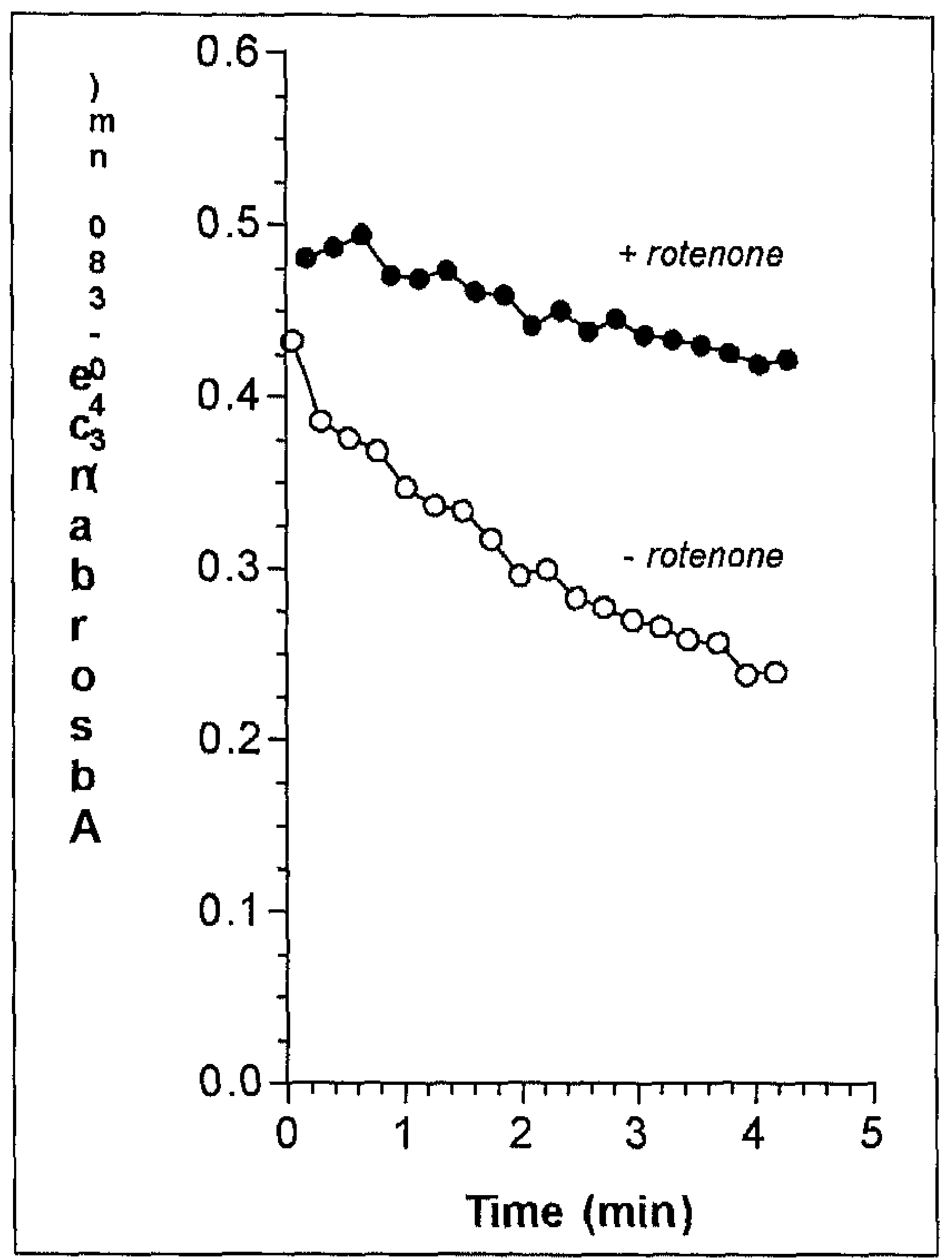

Figure 1. Course of the decrease in absorbance at $340 \mathrm{~nm}$ with $380 \mathrm{~nm}$ as the reference wavelength in the presence (-0-) and absence (-0) of $5 \mu \mathrm{M}$ rotenone due to the oxidation of $\mathrm{NADH}$ by $3.5 \times 10^{6}$ permeabilized blood lymphocytes per $\mathrm{mL}$ reaction mixture. The reaction mixture consisted of $20 \mathrm{mM} \mathrm{K2} \mathrm{HPO}_{4}$, $\mathrm{pH} 7.4,4 \mathrm{mM} \mathrm{MgCl} 2,0.2 \%$ fatty acid free BSA, $1.7 \mathrm{mM} \mathrm{KCN}, 3 \mu \mathrm{M}$ antimycin $\mathrm{A}, 90 \mu \mathrm{M} \mathrm{NADH}$ and $65 \mu \mathrm{M}$ CoQ1. The decrease in absorbance in the absence of rotenone reflects the total NADH:COQ oxidoreductase activity of which the velocity is slowing down after 1-2 $\mathrm{min}$. In the presence of rotenone the decrease in absorbance is less than in its absence reflecting the rotenone-insensitive NADH:COQ oxidoreductase activity (RINQ). Subtraction of this latter rate from the total rate of CoQ-dependent NADH oxidation gives the complex lactivity.

\subsubsection{Protein dependency}

Using an excess of $\mathrm{COQ}_{1}$ of almost ten-fold compared to the apparent $\mathrm{Km}$ of complex I, the protein dependency of the reaction was investigated. A linear relationship in the enzyme activity was found from 1.75 up to $7.0 \times 106$ lymphocytes $/ \mathrm{mL}\left(R_{2}=0.963 ; P=0.019\right.$ ) (Fig. 3) which is equivalent with 70 up to $290 \mu \mathrm{g}$ protein. $\mathrm{mL}-1$. The intra-assay variation amounted to $12.0 \%(n=10)$ on protein basis. 
The duration of the (quasi-)linearity of the reaction rate did not increase by decreasing the concentration of blood lymphocytes, but was hardly measurable after lowering the cell concentration below $1.75 \times 10^{6} / \mathrm{mL}$. However, by doubling the concentration of NADH to 180 $\mu M$ the time span of the (quasi-)linear reaction rate increased by $21 \sec (16.8 \% ; P=0.02, n$ $=4)$ to $146($ SD: 13$) \mathrm{sec}$.

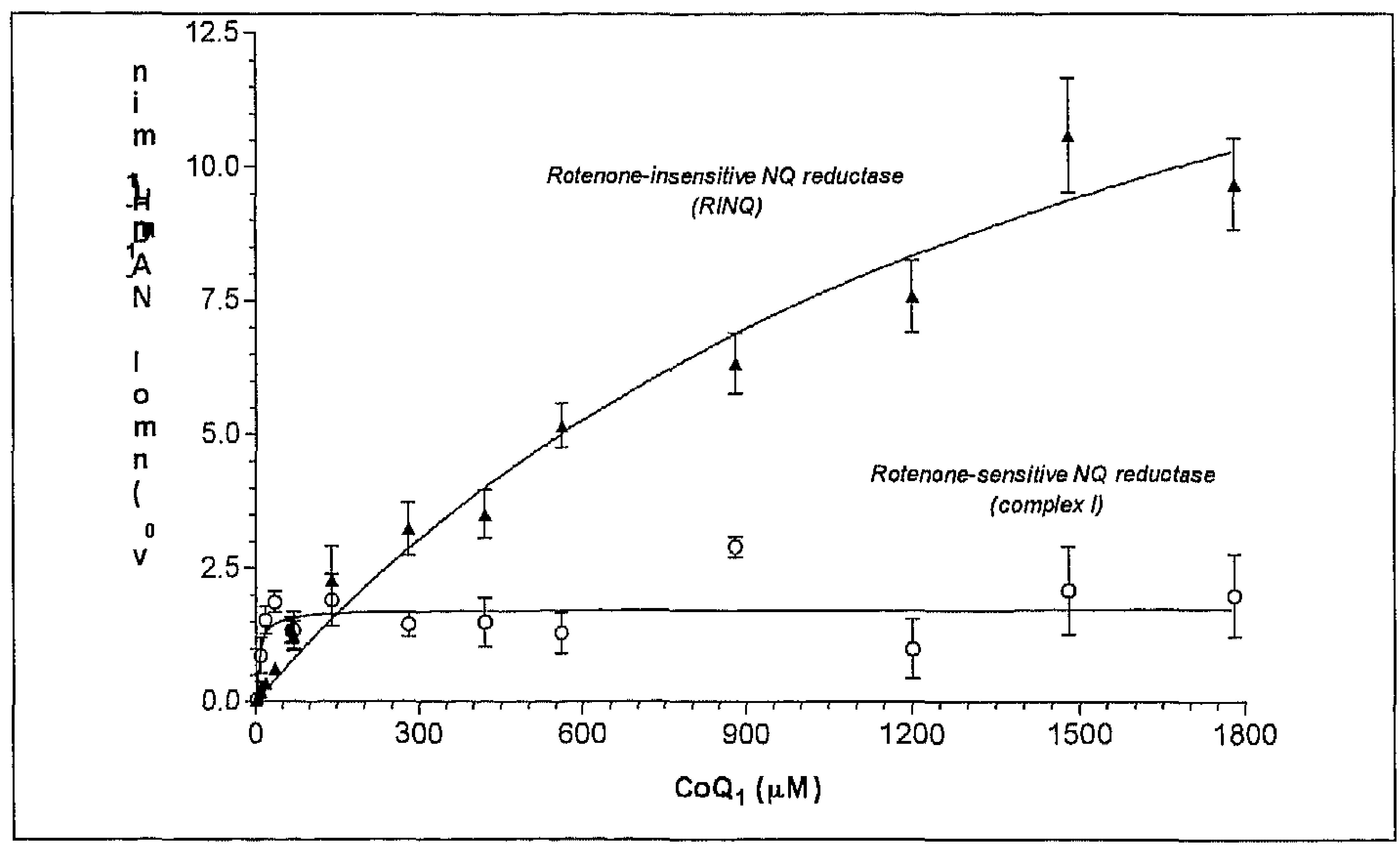

Complex I kinetic characteristics:

\begin{tabular}{|l|l|l|}
\hline $\begin{array}{l}\text { Vmax } \\
\text { (nmol NADH. } \\
\text { min-1.mL-1) }\end{array}$ & $\begin{array}{l}\mathrm{Km} \\
(\mu \mathrm{M})\end{array}$ & $\mathrm{R} 2$ \\
\hline 1.72 & 6.6 & 0.887 \\
\hline
\end{tabular}

Figure 2. CoQ1-dependent NADH oxidation rates at a fixed concentration of $90 \mu \mathrm{MNADH}$ by the rotenone-sensitive complex I (-O-) and rotenone-insensitive NADH:COQ oxidoreductase (RINQ) (- $\triangle$-) of permeabilized blood lymphocytes. The reaction mixture and cell concentration are as described under the legend to Fig. 1. Each symbol represents the mean ( \pm SEM) of 3-10 determinations. Solid lines were obtained by fitting the data to the Michaelis-Menten equation. While the initial reaction velocity (vo) of RINQ (which, together with the complex l activity, makes up the total CoQ-dependent NADH oxidase activity) still increases with increasing concentrations of $C_{0} Q 1$, the complex I activity has reached its $V$ max already at about $50 \mu M \mathrm{COQ}_{1}$ indicating that the RINQ and complex l activity are two independent entities of the same enzyme and that RINQ activity has not been measured under optimal (saturating substrate) conditions. 


\subsubsection{CoQ1-dependent rotenone sensitivity}

We found that with increasing concentrations of $\mathrm{COO}_{1}$, the rotenone-sensitive complex 1 activity became maximal at about $50 \mu \mathrm{M}$ of $\mathrm{CoQ}_{1}$ (Fig. 2), while the rotenone-insensitive $\mathrm{NADH}: \mathrm{COQ}$ oxidase (RINO) did not reach a maximum. As depicted in Fig. 4 , the fractional

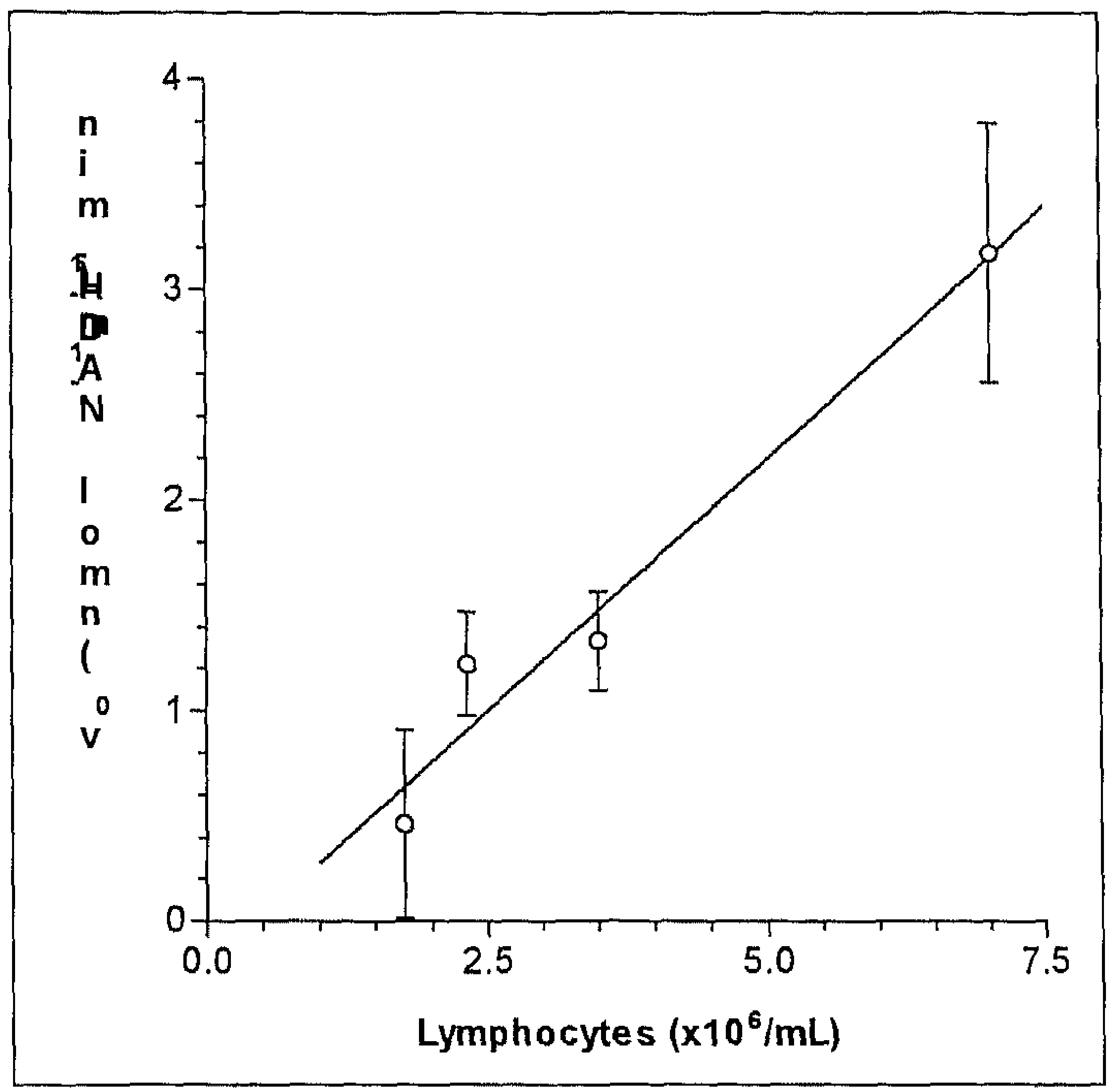

Figure 3. Relationship between the initial rate of NADH oxidation by the rotenone-sensitive complex 1 and the blood lymphocyte concentration at substrate concentrations of $90 \mu \mathrm{M} \mathrm{NADH}$ and $65 \mu \mathrm{M}$ CoQ1 that can be described by the equation: $y=-0.20+0.48 \times, R 2=0.963$, in which y represents the initial rate expressed as $n$ mol NADH. min-1.mL 1 , and $x$, the number of lymphocytes times 106 per $m L$. The mean $( \pm$ SEM) of 3-5 determinations per cell concentration is presented.

inhibition by rotenone of the total $\mathrm{NADH}: \mathrm{COO}_{1}$ oxidoreductase activity sharply decreased with increasing concentrations of $\mathrm{COO}_{1}$ from $20 \mu \mathrm{M}$ onward. At above $1.0 \mathrm{mM}$ CoO1, rotenone inhibited only $15 \%$ of the total activity.

protein bound to the endoplasmic reticulum membrane. However, proof that RINQ represents a second binding site of COQ1 on complex I of blood lymphocytes can only be obtained by extensively studying the purified complex $I$. 
3.2 Kinetic characteristics of the rotenone-insensitive NADH:Coenzyme O reductase of blood lymphocytes

3.2.2. Coenzyme $Q$ dependency. To study the kinetic characteristics of the RINQ activity in more detail, its $\mathrm{COO}_{1}$ dependency was determined using three different concentrations of blood lymphocytes. The results showed that RINO activities fitted to the Michaelis-Menten equation well, having a mean apparent $\mathrm{Km}$ for $\mathrm{COO}_{1}$ of slightly more than $1.0 \mathrm{mM}$ and a cell protein dependent Vmax (Fig. 5).

This finding reminisces to the reported second $\mathrm{COQ}_{1}$ binding site of bovine heart $\mathrm{NADH}$ :Coenzyme Q reductase 15 , that has a $\mathrm{Km}$ for $\mathrm{CoQ} 1$ of $0.5 \mathrm{mM}$ and becomes insensitive to rotenone at $\mathrm{COQ}_{1}$ concentrations above $50 \mu \mathrm{M}$. However, RINQ and complex I activity of blood lymphocytes were measured on crude homogenates and instead of being two entities of the same enzyme complex these activities might well be two different enzymes. By isolating and studying the mitochondria from the lymphocytes we found indications that RINO is not likely a non-mitochondrial enzyme. In fact, in this fraction the activities of RINQ, complex I and citrate synthase per mg protein increased by a factor of $3.7,3.0$ and 2.0 , respectively. Furthermore, volume densitometry of the Western blots of the lymphocyte homogenate and their mitochondria showed that the mitochondrial membrane protein prohibitin increased by $70 \%$ in the mitochondrial fraction as compared to calnexin.

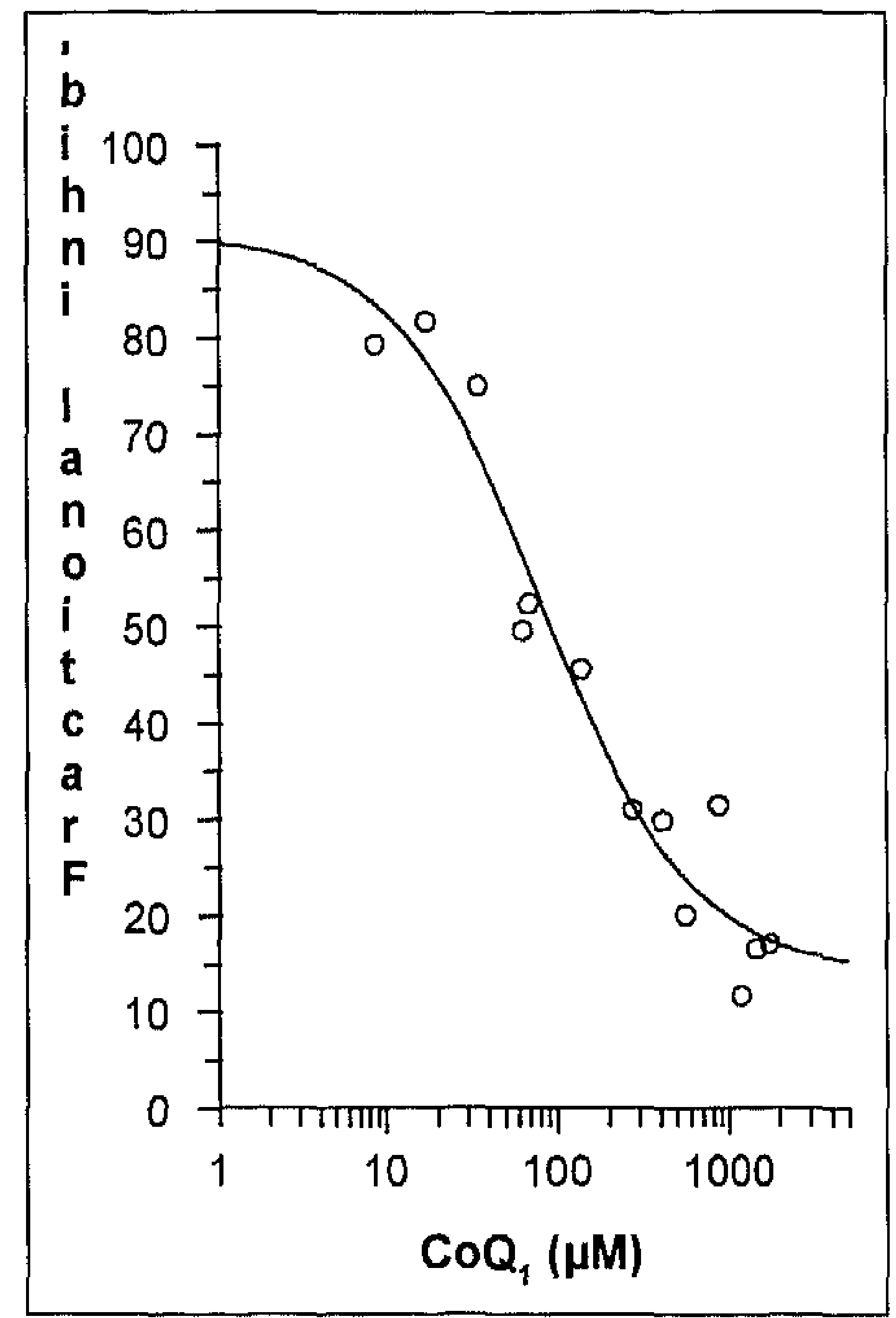

Figure 4. Effect of the $\mathrm{COO}_{1}$ concentration on the rotenone sensitivity of complex I of blood lymphocytes. Fractional rotenone-inhibition values (percent decrease in the total enzyme activity in the presence of rotenone) are plotted against the $\mathrm{COQ}_{1}$ concentration in the reaction mixture as described under the legend to Fig. 7. The relationship between the fractional inhibition and the COQ1 concentration can be described by the logistic dose-response equation: $y=\left(76.6 /\left(1+(x / 83.1)^{1.007}\right)+14.0\right.$, $R_{2}=0.951$ Apparently, the rotenone-sensitivity of the NADH:COQ oxidoreductase decreases with increasing CoQ1 concentrations. Although at $\mathrm{COQ}_{1}$ concentrations below $20 \mu \mathrm{M}$ rotenone inhibition appears not to exceed $90 \%$, at above $1 \mathrm{mM}$ the rotenone-sensitive activity was much lower than the total activity (about $15 \%$ ) allowing the study of the kinetic characteristics of the RINO entity of the enzyme. 
3.3 Enzymatic activities of complex I in blood lymphocytes from healthy donors Using the above described method we determined the amount of complex I in blood lymphocytes from a number of healthy donors (Table I). From these results we could calculate the inter-assay variation of complex I of $41.1 \%(n=15)$, which is considerably higher than the calculated intra-assay variation of $12.0 \%$ but not different from values reported earlier in muscle and liver. ${ }^{16,17}$

In order to use this method for diagnostic purposes in patients suspected to suffer from a mitochondrial disorder, the complex I activity should be expressed per mitochondrial unity to correct for any compensation of a complex I defect by increasing mitochondrial mass. The mitochondrial matrix enzyme citrate synthase can serve as such a marker.13.17

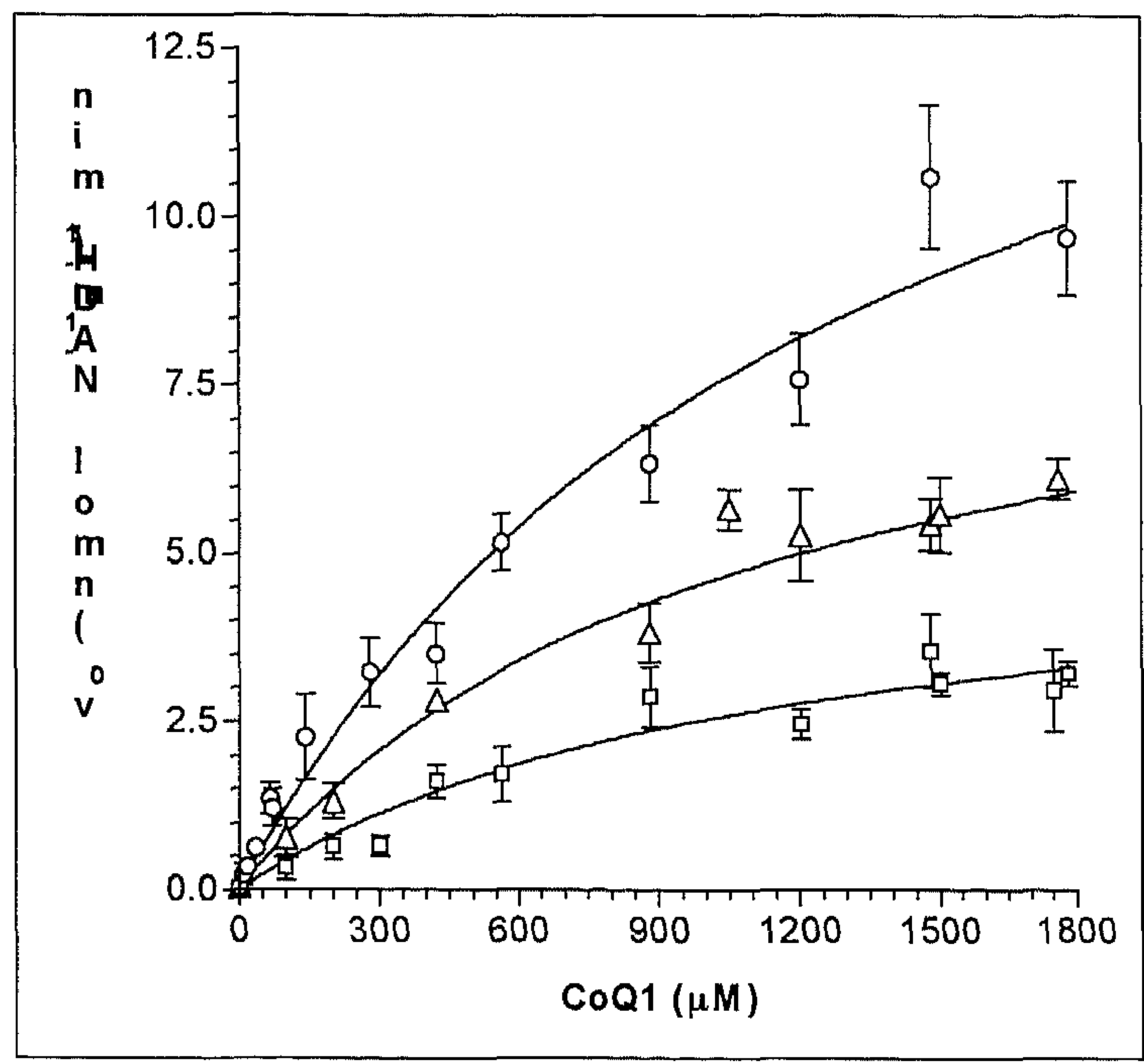

Hyperbola: 1 site binding:

\begin{tabular}{|l|l|l|l|l|l|}
\hline Lymphocytes/mL & factor: & $\begin{array}{l}\mathrm{Vmax} \\
(\mathrm{nmol} \mathrm{NADH} . \\
\left.\mathrm{min}^{-1} \cdot \mathrm{mL}^{-1}\right)\end{array}$ & factor: & $\mathrm{Km}(\mu \mathrm{M})$ & $\mathrm{R2}$ \\
\hline$(-O-) 3.5 \times 10^{6}$ & $2.5 \times$ & 17.16 & $1.8 \times$ & 1309 & 0.918 \\
\hline$(-\triangle-) 1.4 \times 10^{6}$ & $2.0 \times$ & 9.38 & $1.8 \times$ & 1050 & 0.824 \\
\hline$(-\square-) 0.7 \times 10^{6}$ & & 5.31 & & 1093 & 0.664 \\
\hline
\end{tabular}


Figure 5. CoQ1-dependent NADH oxidation rates at three fixed concentrations of blood lymphocytes and a saturating rotenone concentration of $5 \mu \mathrm{M}$ in the reaction mixture as described under the legend to Fig. 1. Each symbol represents the mean ( \pm SEM) of 3-10 determinations, respectively of $0.7(-\square-), 1.4(-\triangle-)$, and $3.5(-0-) \times 10^{6} \mathrm{cells}$ per $\mathrm{mL}$. Solid lines were obtained by fitting the data to the Michaelis-Menten equation. Obviously, the RINQ activity of blood lymphocytes is cell number (and thus protein) dependent and has an estimated apparent $\mathrm{Km}$ of about $1.0 \mathrm{mM} \mathrm{CoQ}$. Since CoQ 1 will precipitate at concentrations of more than $1.9 \mathrm{mM}, \mathrm{RINQ}$ activity cannot be measured under optimal (saturating substrate) conditions and should be studied therefore at its apparent $\mathrm{Km}$.

\section{Discussion}

The present study shows that the OXPHOS enzyme complex I can be measured reliably in a small amount of blood lymphocytes. For an assay in duplo only $3 \times 10^{6}$ lymphocytes are needed.

A decade ago, Chretien et al. summarized the well-accepted methods for determination of the OXPHOS complexes to provide reference charts for each of the respiratory chain enzyme activities in various human tissues including blood lymphocytes. ${ }^{17}$

\begin{tabular}{|l|l|l|l|l|}
\hline & Protein & Citrate synthase & \multicolumn{2}{l|}{ Complex I } \\
& $\mathrm{mg} / 108$ cells & $\mathrm{mU} / \mathrm{mg}$ prot & $\mathrm{mU} / \mathrm{mg}$ prot & $\mathrm{mU} / \mathrm{U}$ CS \\
\hline & & & & \\
mean & 4.1 & 148.6 & 7.4 & 48.4 \\
$\mathrm{SD}$ & 1.5 & 35.2 & 3.6 & 19.4 \\
$95 \% \mathrm{CL}$ & 0.7 & 17.8 & 1.8 & 9.8 \\
range & $2.3-8.0$ & $99.9-208.9$ & $1.7-13.0$ & $16.8-76.3$ \\
\hline $\mathrm{n}$ & 15 & 15 & 15 & 15 \\
\hline
\end{tabular}

Table I: Enzymatic activities of Complex / and citrate synthase in healthy donors prot $=$ protein $\mathrm{CS}=$ citrate synthase

Besides the fact that the absolute enzyme activities expressed per mg protein scattered on one to three orders of magnitude in all tissues, it was not possible to determine complex I activity in lymphocytes. Therefore this important enzyme could not be included as reference value. In a future reference, these authors claimed that complex l of lymphocytes is measurable if the access of substrates to the mitochondria of these blood cells was im- 
proved by hypotonic shock in the presence of digitonin. 4 Unfortunately, we were not able to repeat their results and our scepticism became substantiated by the publication of a modification of their method in a recent paper without any further notification. ${ }^{18}$

The success of our present method depends on 1), a sufficiently high concentration of lymphocytes that is only feasible without the necessity to obtain large amounts of blood by using very small quartz cuvettes, 2), the availability of a stable, sensitive spectrophotometer, and 3 ), the addition of rotenone to the preincubation mixture in separate cuvettes. Furthermore, 4), using the water-soluble coenzyme Q10 analogue CoO1 and permeabilization of the lymphocytes in the presence of protease inhibitors through three cycles of freeze thawing we ensure the access of substrates to the mitochondria.

It is important to add rotenone immediately to a separate cuvette, and not after assessing the initial rate of $\mathrm{NADH}$ oxidation, because the velocity of the reaction decreases after only 1-2 min independent of the presence or absence of rotenone. In all other cases, it is impossible to correctly discriminate between the rotenone-sensitive complex I activity and other rotenone-insensitive $\mathrm{NADH}$-quinone oxidoreductases.

As can be seen from Table I there is a large range in complex I activities from the lymphocytes of 15 healthy donors which varied from 1.7 to $13.0 \mathrm{mU} / \mathrm{mg}$ protein. Although these values did not differ much from the well-established range in human skeletal muscle ${ }^{17}$, such a large range makes it difficult to determine a cut-off value in lymphocytes for the detection of complex I deficient patients. Rustin et al. ${ }^{19}$ provided a solution to this problem by their finding that the ratio between the four respiratory enzyme complexes in various tissues of healthy controls is constant. Since the activities of the three other respiratory enzyme complexes of blood lymphocytes can be determined easily by well-accepted methods 7,20 , by expressing complex I as ratios of the three other respiratory enzyme activities the range of values will be reduced considerably enabling the unambiguous diagnosis of complex I deficient patients.

Here, we characterized a second type of NADH oxidase in blood lymphocytes and found indications that this rotenone-insensitive NADH:Coenzyme Q reductase (RINO) is not likely a nonmitochondrial enzyme. If RINQ is a different enzyme or just another entity of complexI, this can only be established after rigorous purification of complex I from blood lymphocytes. A second binding site of coenzyme $Q$ could be physiologically functional as shown previously for bovine heart mitochondria 15 and might become relevant if the normal electron transport route in complex I is interrupted, for example, as can be seen in Leber's Hereditary Optic Neuropathy patients with a mutation in the mitochondrial encoded subunit ND1 that normally interacts with $\mathrm{CoO}{ }^{21,22}$. Although its high apparent $\mathrm{Km}$ for $\mathrm{COQ} 1$, as we found here, indicates that such a site may not function very efficiently, of relevance to this is that the coenzyme $\mathbf{Q}_{10}$ concentration in bovine mitochondrial membranes is estimated to be higher than $10 \mathrm{mM} .{ }^{23}$ 
In conclusion, using the present miniaturized assay of complex $1,5 \mathrm{~mL}$ of blood contain sufficient lymphocytes to determine the four respiratory chain complexes in duplicate. This makes it possible to characterize complex I of blood lymphocytes enzymatically and to express its activity as ratios for diagnostic purposes, not only in adult patients but in children as well.

\section{Acknowledgements}

This work was subsidized in part by the FP6 Concerted Action MITOCIRCLE (contract $5260)$.

We thank Nathalie Biesheuvel and Alia el Addouti-el Belhajji for collecting all blood samples, and Kim Wever for correcting the English manuscript. 
References

1. Zeviani M, Di Donato S. Mitochondrial disorders. Brain. 2004;127:2153-2172.

2. Wallace DC, Lott MT. Mitochondrial genes in degenerative diseases, cancer and aging. In: Rimoin DL, Connor JM, Pyeritz RE, Korf BR, eds. Principles and practice of medical genetics. London: Churchill Livingstone, 2002:299-409

3. van den Ouweland JM, de Klerk JB, van de Corput MP, et al. Characterization of a novel mitochondrial DNA deletion in a patient with a variant of the Pearson marrow-pancreas syndrome. Eur J Hum Genet. 2000;8:195-203.

4. Chretien D, Benit $P, C$ hol $M$, et al. Assay of mitochondrial respiratory chain complex I in human lymphocytes and cultured skin fibroblasts. Biochem Biophys Res Commun. 2003;301:222-224.

5. Saada A, Bar-Meir M, Belaiche C, Miller $C$, Elpeleg O. Evaluation of enzymatic assays and compounds affecting ATP production in mitochondrial respiratory chain complex I deficiency. Anal Biochem. 2004;335:66-72.

6. Cameron JM, Levandovskiy V, Mackay N, Robinson BH. Respiratory chain analysis of skin fibroblasts in mitochondrial disease. Mitochondrion. 2004;4:387-394.

7. Rustin P, Chretien D, Bourgeron T, et al. Biochemical and molecular investigations in respiratory chain deficiencies. Clin Chim Acta. 1994;228:35-51.

8. Pietersma $A$, Kofflard $M$, de Wit LE, et al. Late lumen loss after coronary angioplasty is associated with the activation status of circulating phagocytes before treatment. Circulation. 1995;91:1320-1325.

9. Maianski NA, Geissler J, Srinivasula SM, et al. Functional characterization of mitochondria in neutrophils: a role restricted to apoptosis. Cell Death Differ. 2004;11:143-153.

10. Scholte HR, Yu Y, Ross JD, et al. Rapid isolation of muscle and heart mitochondria, the lability of oxidative phosphorylation and attempts to stabilize the process in vitro by taurine, carnitine and other compounds. Mol Cell Biochem. 1997;174:61-66.

11. Nakashima $Y$, Shinzawa-Itoh K, Watanabe K, et al. Steady-state kinetics of $\mathrm{NADH}$ :coenzyme $\mathrm{Q}$ oxidoreductase isolated from bovine heart mitochondria. I Bioenerg Biomembr. 2002;34:11-19.

12. Majander A, Finel M, Savontaus ML, Nikoskelainen E, Wikstrom M. Catalytic activity of complex I in cell lines that possess replacement mutations in the ND genes in Leber's hereditary optic neuropathy. Eur J Biochem. 1996;239:201-207.

13. Srere P. Citrate synthase. Methods Enzymol. 1969;13:3-11.

14. De Vries DD, Went LN, Bruyn GW, et al. Genetic and biochemical impairment of mitochondrial complex I activity in a family with Leber hereditary optic neuropathy and hereditary spastic dystonia. Am J Hum Genet. 1996;58:703-711. 
15. Nakashima $Y$, Shinzawa-Itoh $K$, Watanabe $K$, et al. The second coenzyme $Q_{1}$ binding site of bovine heart NADH: coenzyme $\mathrm{Q}$ oxidoreductase. J Bioenerg Biomembr. 2002;34:89-94.

16. Thorburn DR, Chow CW, Kirby DM. Respiratory chain enzyme analysis in muscle and liver. Mitochondrion. 2004;4:363-375.

17. Chretien $D$, Rustin $P$, Bourgeron $T$, et al. Reference charts for respiratory chain activities in human tissues. Clin Chim Acta. 1994;228:53-70.

18. Vahsen N, Cande C, Briere JJ, et al. AIF deficiency compromises oxidative phosphorylation. Embo J. 2004;23:4679-4689.

19. Rustin $P$, Chretien D, Bourgeron T, et al. Assessment of the mitochondrial respiratory chain. Lancet. 1991;338:60.

20. Birch-Machin MA, Turnbull DM. Assaying mitochondrial respiratory complex activity in mitochondria isolated from human cells and tissues. Methods Cell Biol. 2001;65:97-117.

21. Majander A, Huoponen K, Savontaus ML, Nikoskelainen E, Wikstrom M. Electron transfer properties of $N A D H:$ ubiquinone reductase in the ND1/3460 and the ND4/11778 mutations of the Leber hereditary optic neuroretinopathy (LHON). FEBS Lett. 1991;292:289-292.

22. Cock HR, Cooper JM, Schapira AH. Functional consequences of the 3460-bp mitochondrial DNA mutation associated with Leber's hereditary optic neuropathy. J Neurol Sci. 1999;165:10-17.

23. Fleischer S, Rouser G, Fleischer B, Casu A, Kritchevsky G. Lipid composition of mitochondria from bovine heart, liver, and kidney. J Lipid Res. 1967;8:170-180. 


\section{Chapter 6}

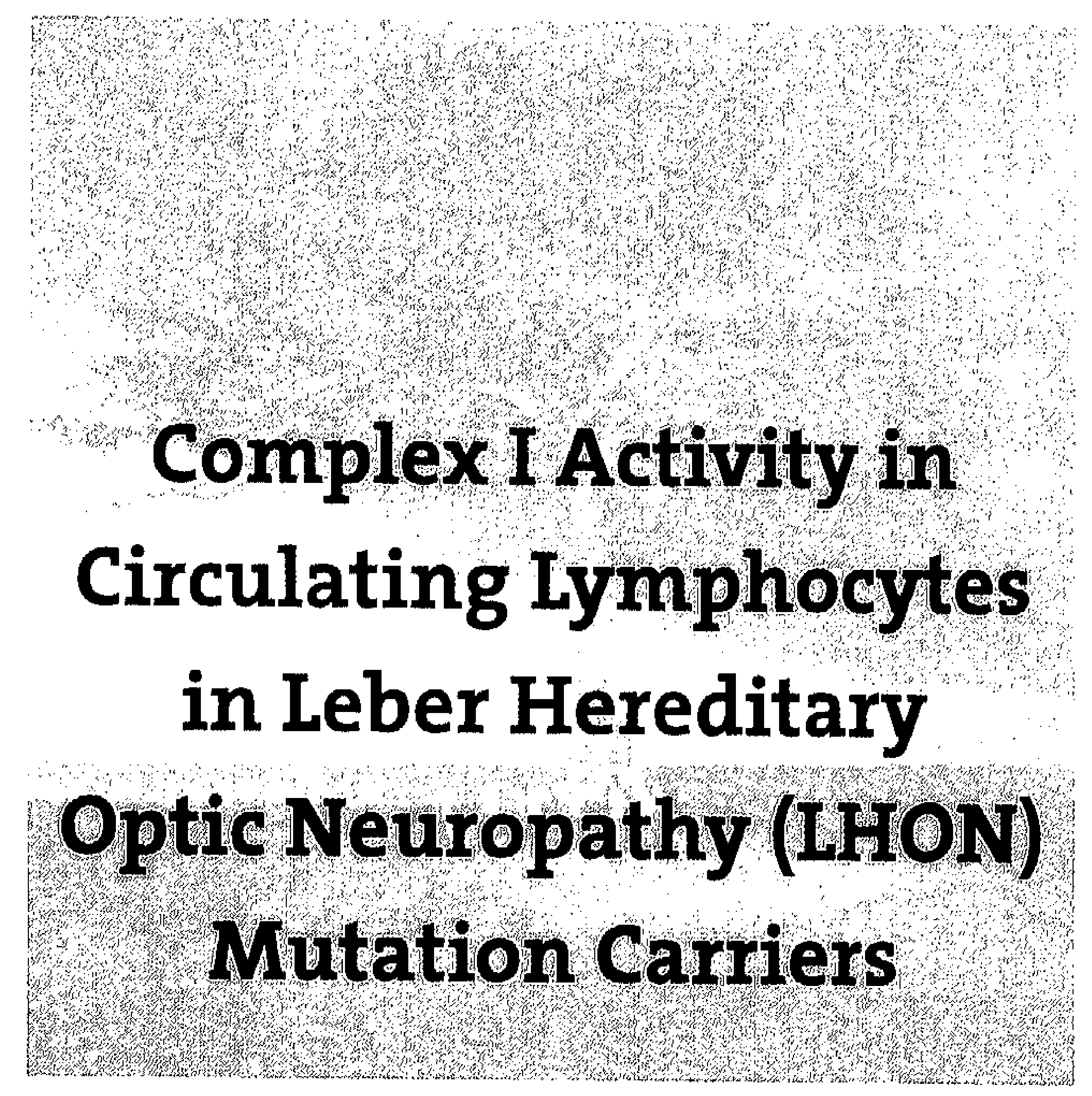

L. Spruijt, I.F. de Coo, E. de Wit, H.J. Smeets, W. Sluiter

Submitted 


\section{Abstract}

Patients with Leber hereditary optic neuropathy (LHON) carry mutations in one of the mtDNA encoded complex I genes. We describe here the implementation of a new biochemical assay in measuring complex I activity in 49 patients with the $m .346 \circ \mathrm{G}>\mathrm{A}(\mathrm{n}=12), \mathrm{m} .11778 \mathrm{G}>\mathrm{A}$ $(n=21)$ or $m .14484 T>C(n=16)$ mutation. Furthermore we evaluated the possibility to discriminate a biochemical phenotype that would allow alternative approaches in the identification of a modifier gene involved in the incomplete penetrance of this disorder.

Defects in the respiratory chain complexes can lead to reactive oxygen species (ROS) overproduction and consequently to cell damage. The slightly higher complex I activity in the affected m.11778G $>A$ and m.14484T $>C$ mutation carriers as found could indeed point into that direction. An increased citrate synthase (CS) activity, indicating an increase in the number of mitochondria that compensate for a defect in complex I, detected in all unaffected LHON mutation groups. The m.3460G $>$ A mutation is in our study an exception with a reduced $\mathrm{Cl}$ activity in all mutation carriers but only elevated $\mathrm{CS}$ in the unaffected. In m.11778G >A and m.14484T>C mutation carriers it could be possible to find a modifier gene that determines the defect in complex I on the basis of this present biochemical assay, because in these two groups, unexpectedly, the mutation appears to lead to an increased activity of the first respiratory chain enzyme complex. 


\section{Introduction}

Leber Hereditary Optic Neuropathy (LHON) is a mitochondrial genetic disorder characterized by a bilateral (sub) acute, painless, optical atrophy occurring in previous healthy patients. LHON is characterized by reduced penetrance. Approximately $30-50 \%$ of males and $10-20 \%$ of female LHON mutation carriers become symptomatic at an average age of 22 years (range 5-65 years). 1 Secondary genetic and/or epigenetic factors are possibly an explanation for the variable expression of this disorder. More than $95 \%$ of the patients with LHON carry one of the three "primary" mtDNA mutations at position 11778 G $>A / N D 4$, 14484 T>C/ND6 and 3460G>A/ND1.2 All three mutations occur in genes that encode one of the subunits of complex I (NADH dehydrogenase).

Previous studies showed consistently a reduction of $\mathrm{NADH}$ :ubiquinone reductase activity to $60-80 \%$ in $\mathrm{m} .3460 \mathrm{G}>\mathrm{A}$ carriers 3.4 The $\mathrm{m.11778 \textrm {G }}>\mathrm{A}$ and $\mathrm{m} .14484 \mathrm{~T}>\mathrm{C}$ mutations induce only subtle or no changes in complex 1 activity. ${ }^{5,6}$ Most of these studies are performed in small groups of patients and evaluated often only one of the LHON mutations. The few studies that discriminated between affected and unaffected mutation carriers showed no influence of the affection status upon the biochemical parameters. ${ }^{6}$

The activity of complex $I$ is traditionally measured as the rotenone sensitive activity of NADH dehydrogenase. To assess a biochemical functional defect in complex I for obvious reasons mitochondria of the optic nerve of LHON patients cannot be used. The alternative tissues, skeletal muscle, skin fibroblasts or blood lymphocytes, all have their particular disadvantages. In skeletal muscle biopsies, the determination of respiratory chain complexes is reliable but this method requires an invasive procedure. In fibroblasts the measurement of complex I is complicated because of their high content of rotenone-insensitive NADH oxidase activity. Furthermore, cell culturing might influence the percentage of a heteroplasmic mtDNA mutation, causing false negative or positive results. In circulating lymphocytes the limited access of substrates to the enzyme complex hampers the reliable measurement of complex I activity.

Recently, we were able to ensure the access of substrates to the mitochondria by using the water-soluble coenzyme Q10 analogue CoQ1 and permeabilization of the lymphocytes in the presence of protease inhibitors through three cycles of freeze thawing. In addition, the success of this method depends on 1), a sufficiently high concentration of lymphocytes that is only feasible, without the necessity to obtain large amounts of blood, by using very small quartz cuvettes, 2 ), the availability of a stable, sensitive spectrophotometer, and 3 ), the addition of rotenone to the preincubation mixture in separate cuvettes. We therefore choose to determine the complex I activity with this new and easy assay in the three primary LHON mutations to evaluate if each mutation would lead to a biochemical phenotype in blood 
lymphocytes. Furthermore we studied if affected and unaffected mutation carriers could be discriminated on the basis of a biochemical different phenotype. In the latter case, the presence of a consistent biochemical phenotype in families could allow alternative approaches in the identification of the involved modifier genes in LHON by biochemical studies.

\section{Material and methods}

Ethics

This study was approved by the Medical Ethical Committee (University Hospital Maastricht). Blood samples were obtained with informed consent of the involved patients.

Patients

This study included 49 LHON mutation carriers with an average age of 47.3 ( \pm 15.2 SD) ranging from 20-79 years old. The patients came from 22 different families; the largest sampled family contained 5 persons. There were 29 symptomatic LHON patients; 8 females and 21 males, who exhibited typical clinical signs of LHON. The other 20 mutation carriers; 16 females and 4 males, have a normal vision. (Table 1) All, of the unaffected LHON mutation carriers except for one, are beyond the average age of onset of the disease (mean 51.9 years; median 50.5 years). In this way we reduced a sampling error by not including unaffected individuals who might still become affected later in life to less than $5 \%$. ' Five fathers of symptomatic LHON patients were evaluated too. Neither one of them carried an mtDNA LHON mutation. There were 17 unrelated healthy control subjects all without a history of visual impairment themselves or in their family (age range 29-67 years; mean 41.6 years, median 40.0). All subjects in this study were Caucasian.

Table 1. LHON mutation carriers according to mutation, affection status and sex.

\begin{tabular}{|l|c|l|l|l|l|}
\hline Mutation & \multicolumn{2}{|c|}{ Affected patients } & \multicolumn{2}{|c|}{ Healthy carriers } & Total \\
\hline & $\uparrow$ & $\bigcirc$ & $\uparrow$ & $\bigcirc$ & \\
$3460 /$ ND1 & 3 & 3 & 3 & 3 & 12 \\
$11778 /$ ND4 & 10 & 4 & 1 & 6 & 21 \\
$14484 /$ ND6 & 8 & 1 & - & 7 & 16 \\
\hline Total & 21 & 8 & 4 & 16 & 49 \\
\hline
\end{tabular}




\section{DNA isolation}

DNA mutation analysis was performed in DNA derived from $2 \mathrm{~mL}$ of EDTA blood. Molecular testing confirmed the presence of either an $\mathrm{m} .3460 \mathrm{G}>\mathrm{A}, \mathrm{m} .11778 \mathrm{G}>\mathrm{A}$, or $\mathrm{m} .14484 \mathrm{~T}>\mathrm{C} \mathrm{mu}$ tation in the patients and their relatives. The primary LHON mutations were studied with a PCR amplification followed by mutation specific restriction endonuclease digestion.?

Isolation of blood lymphocytes

Blood was withdrawn in glass EDTA tubes $(5 \mathrm{~mL})$. The lymphocytes were isolated as previously described ${ }^{8}$, and resuspended in a buffer consisting of $250 \mathrm{mM}$ sucrose, $10 \mathrm{mM}$ HEPES $\mathrm{pH} 7.4$, and $1 \mathrm{mM} \mathrm{EDTA}$ (SHE) at a concentration of $100 \times 10^{6}$ cells per mL. After adding protease inhibitors, the cells were divided in $50 \mu \mathrm{L}$ aliquots and stored at $-80^{\circ} \mathrm{C}$.

The complex I activities were normalized to the activity of citrate synthase determined according to Srere. ${ }^{9}$ Protein concentration in the mitochondrial suspension were determined by the Bio-Rad DC assay (Bio-Rad Laboratories Inc., Veenendaal, the Netherlands). All assays were performed at least in duplicate.

\section{Statistical analysis}

The data are presented as mean \pm SD. Differences between the means of two or more mutations groups were statistically evaluated for significance by Student's t-test or analysis of variances, respectively, performed with the software package SPSS version 11.01. When significant $F$ values were obtained, individual group means were tested for significance according to Bonferroni's correction for multiple comparisons. A value of $\mathrm{P}<0.05$ was considered statistically significant.

Figure 2.

Homoplasmic LHON 3460 mutation family and corresponding biochemical parameters. Square: male. Circle: female. Filled circle or square: affected male of female LHON patient.

Cl: complex lactivity in mU/U CS. CS: citrate synthase activity in mU/mg prot

\begin{tabular}{|c|c|c|c|c|c|c|}
\hline Normals & $\begin{array}{c}\mathrm{Cl} \\
48.4( \pm 19.4)\end{array}$ & $\begin{array}{c}C S \\
148.6( \pm 35.2)\end{array}$ & \multirow{4}{*}{$\square$} & $又_{1: 1}$ & \multicolumn{2}{|c|}{$\varnothing_{1: 2}$} \\
\hline II:3 & 38,3 & 149,5 & & & & $\square$ \\
\hline $11: 2$ & 8,8 & 175,3 & & $\begin{array}{c}11: 2 \\
47 \text { years }\end{array}$ & $\begin{array}{c}\text { 1li: } 3 \\
55 \text { years }\end{array}$ & $\begin{array}{c}\text { 111.4 } \\
60 \text { years }\end{array}$ \\
\hline $11: 3$ & 18,5 & 208,6 & & & & \\
\hline$\|: 4$ & 23,1 & 357,3 & & & & \\
\hline|| $\mid: 1$ & 16,6 & 124,3 & & 口 & & \\
\hline III:2 & 32,3 & 180,8 & 23 years & $\begin{array}{l}\text { 211:2 } \\
21 \text { years }\end{array}$ & & \\
\hline
\end{tabular}




\section{Results}

\section{Mutations}

There were 12 persons with the m.3460G>A mutation (of whom 6 affected and 6 asymptomatic), 21 persons with the m.11778G $>$ A mutation (of whom 14 affected and 7 asymptomatic) and 16 with the m.14484T $>C$ mutation (of whom 9 affected and 7 asymptomatic) (Table 1). The LHON mutation was homoplasmic in all but two families, both with the m.11778G>A mutation. Since their mutation load was above $>80 \%$ they are clinically comparable to the homoplasmic patients.

The complex 1 activity values were normalized to citrate synthase (CS), with the aim to account for increases in the number of mitochondria. The complex 1 activity in the affected m.3460G $>$ A mutation carriers $(29.1 \pm 20.7 \mathrm{mU} / U C 5 ; p=0.05)$ and in the unaffected $m .3460 G>A$ carriers ( $29.7 \pm 11.5 \mathrm{mU} / \mathrm{CS} ; \mathrm{p}=0.04$ ) is significantly lower than in the controls (Table 2; Fig. 1A). The two groups were not significantly different from each other. In Fig. 2 we show an example of one of the examined families. It shows a reduced level of $\mathrm{Cl}$ per unit $\mathrm{CS}$ activity in the two affected patients. It is noteworthy that this unaffected brother's age is far below the final age of expression of clinical symptoms, and that the mother (II:2) showed already the low $\mathrm{Cl}$ activity before the clinical symptoms became apparent recently.

\section{Figure 1 A.}

Complex I enzyme activities (X-axis), in normal and symptomatic LHON patients with a m.3460G>A, m.11778G $>A$ or m.14484T $>C$ mutation ( $Y$-axis). Solid lines are the mean values and dotted line reflects the $\pm 75 D$ of the controls.

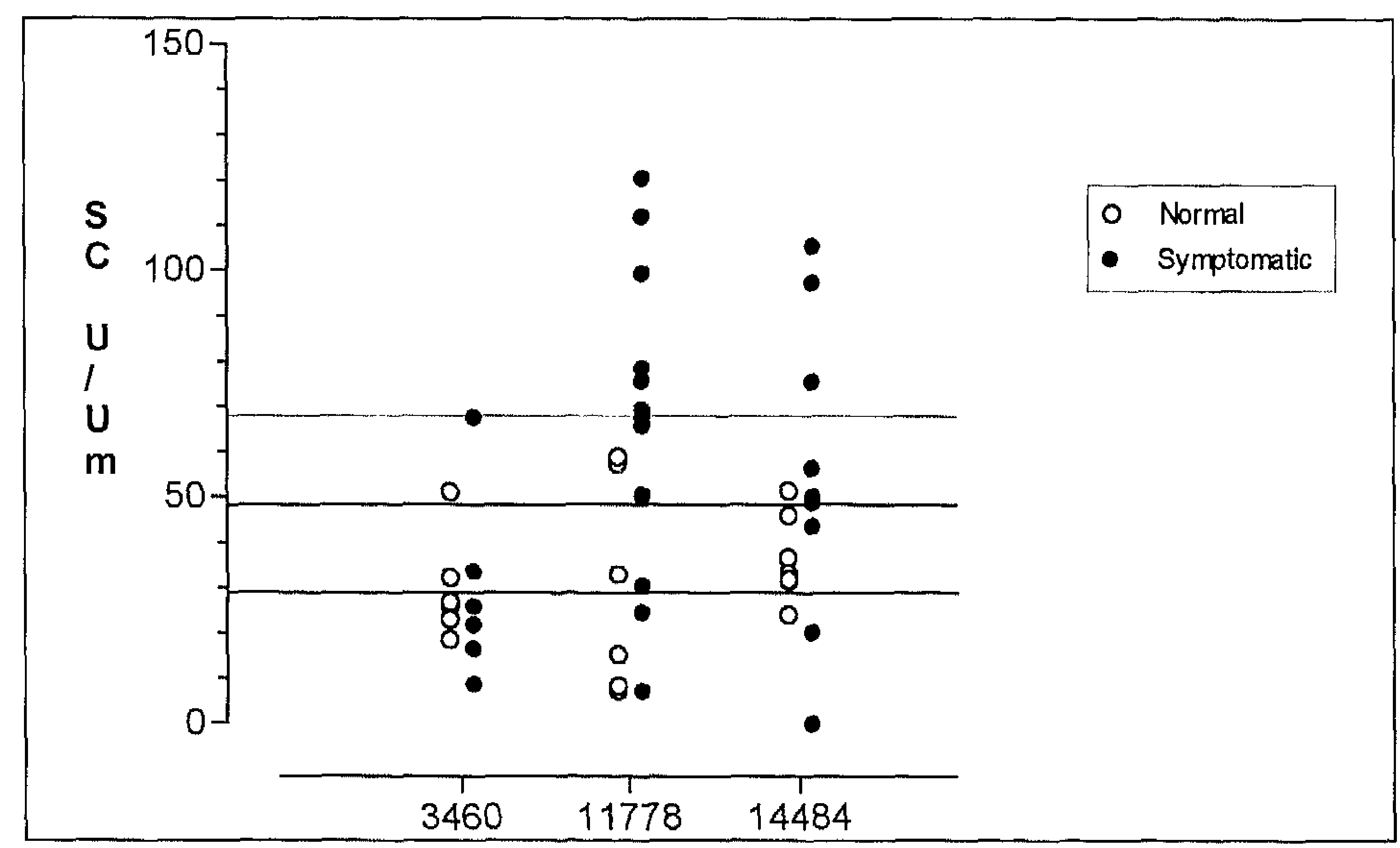


Table 2.

Mitochondrial respiratory function in controls and LHON patient's lymphocytes.

\begin{tabular}{|c|c|c|c|}
\hline & $\begin{array}{l}\mathrm{Cl} \\
\mathrm{mU} / \mathrm{mg} \text { prot } \\
\operatorname{mean}(\mathrm{SD})\end{array}$ & $\begin{array}{l}\mathrm{CS} \\
\mathrm{mU} / \mathrm{mg} \text { prot } \\
\text { mean }(\mathrm{SD})\end{array}$ & $\begin{array}{l}\mathrm{Cl} \\
\mathrm{mU} / \mathrm{UCS} \\
\operatorname{mean}(\mathrm{SD})\end{array}$ \\
\hline Affected & $\begin{array}{ll}6.5 & ( \pm 2.1) \\
& p=0.65\end{array}$ & $\begin{array}{cl}190.6 & ( \pm 42.0) \\
& p=0.02\end{array}$ & $\begin{aligned} 29.19 & ( \pm 20.7) \\
& p=0.05\end{aligned}$ \\
\hline Unaffected & $\begin{array}{ll}5.7 & ( \pm 4.8) \\
& p=0.45\end{array}$ & $\begin{aligned} 236.1 & ( \pm 98.1) \\
& p=0.003\end{aligned}$ & $\begin{array}{ll}29.7 & ( \pm 11.5) \\
& p=0.04\end{array}$ \\
\hline $\begin{array}{l}1177^{8} \\
\text { Affected } \\
\text { Unaffected }\end{array}$ & $\begin{array}{ll}9.9 & ( \pm 4.2) \\
& p=0.04 \\
5.2 & ( \pm 3.6) \\
& p=0.2\end{array}$ & $\begin{array}{ll}162.9 & ( \pm 51.8) \\
& p=0.25 \\
212.3 & ( \pm 76.2) \\
& p=0.007\end{array}$ & $\begin{array}{ll}65.1 & ( \pm 32.5) \\
& p=0.09 \\
30.0 & ( \pm 23.6) \\
& p=0.08\end{array}$ \\
\hline $\begin{array}{l}14484 \\
\text { Affected } \\
\text { Unaffected }\end{array}$ & $\begin{array}{ll}10.0 & ( \pm 6.9) \\
& p=0.18 \\
7.8 & ( \pm 2.5) \\
& p=0.67\end{array}$ & $\begin{array}{ll}180.9 & ( \pm 47.1) \\
& p=0.34 \\
234.5 & ( \pm 131.9) \\
& p=0.01\end{array}$ & $\begin{array}{ll}55.3 & ( \pm 33.9) \\
& p=0.18 \\
36.4 & ( \pm 9.3) \\
& p=0.06\end{array}$ \\
\hline $\begin{array}{l}\text { Fathers } \\
(n=5)\end{array}$ & $7.4 \quad( \pm 0.96)$ & $151.1 \quad( \pm 50.6)$ & $46.2 \quad( \pm 15.1)$ \\
\hline $\begin{array}{l}\text { Controls } \\
(n=17)\end{array}$ & $7.2 \quad( \pm 3.6)$ & $148.6 \quad( \pm 35.2)$ & $48.4 \quad( \pm 19.4)$ \\
\hline
\end{tabular}

If a range of one SD from the mean complex I activity of the control group is taken as the criterion for normal, i.e., $48.4 \pm 19.4 \mathrm{mU} / \mathrm{U} \mathrm{CS}$, then 8 out of the $12 \mathrm{~m} .3460 \mathrm{G}>\mathrm{A}$ mutation carriers can be classified as having a biochemical phenotype (66.7\%; Fig. 1A), while 6 out 12 have a clinical phenotype. There was no statistically significant association between the dichotomous biochemical- and clinical phenotypes. 


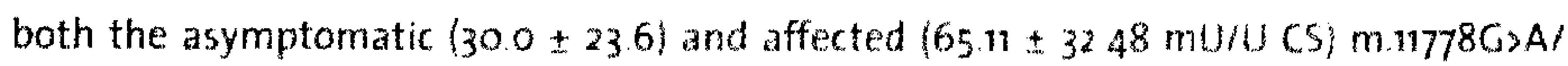
ND4 carriers had no significantly different complex 1 activity (per init $C S$ ) compared to the controls (48.4 \pm 19.4 mu/U CS) (Table 2; Fig. 1A). Between the affected and unaffected m.1778C >A groups there was a significant difference in the level of complex lactivity between the two $(p=0.03)$. Only 11 out of 20 of the m.11778G>A mutation carriers showed a biochemical phenotype (55.0\%; Fig. IA). To find out if the significant difference in the level of complex 1 activity between the affected and unaffected m.11778G>A carriers was associated with the clinical outcome, we calculated the receiver-operating characteristic (ROC) area of the dichotomous biochemical phenotype on the basis of the criterion described above of 20 out of the 21 patients of whom the CI/CS activity could be determined. The ROC area amounted to only 0.536 (SE: 0.144 ) that was not statistically significant (Pearson $x_{2}=0.066 ; p=0.783$ ).

Figure $1 B$.

Citrate synthase (CS) enzyme activities (X-axis), in normal and symptomatic LHON patients with a $m .3460 G>A, m .11778 G>A$ or m.14484 T>C mutation (Y-axis). Solid lines are the mean values and dotted line reflects the $\pm 15 D$ of the controls.

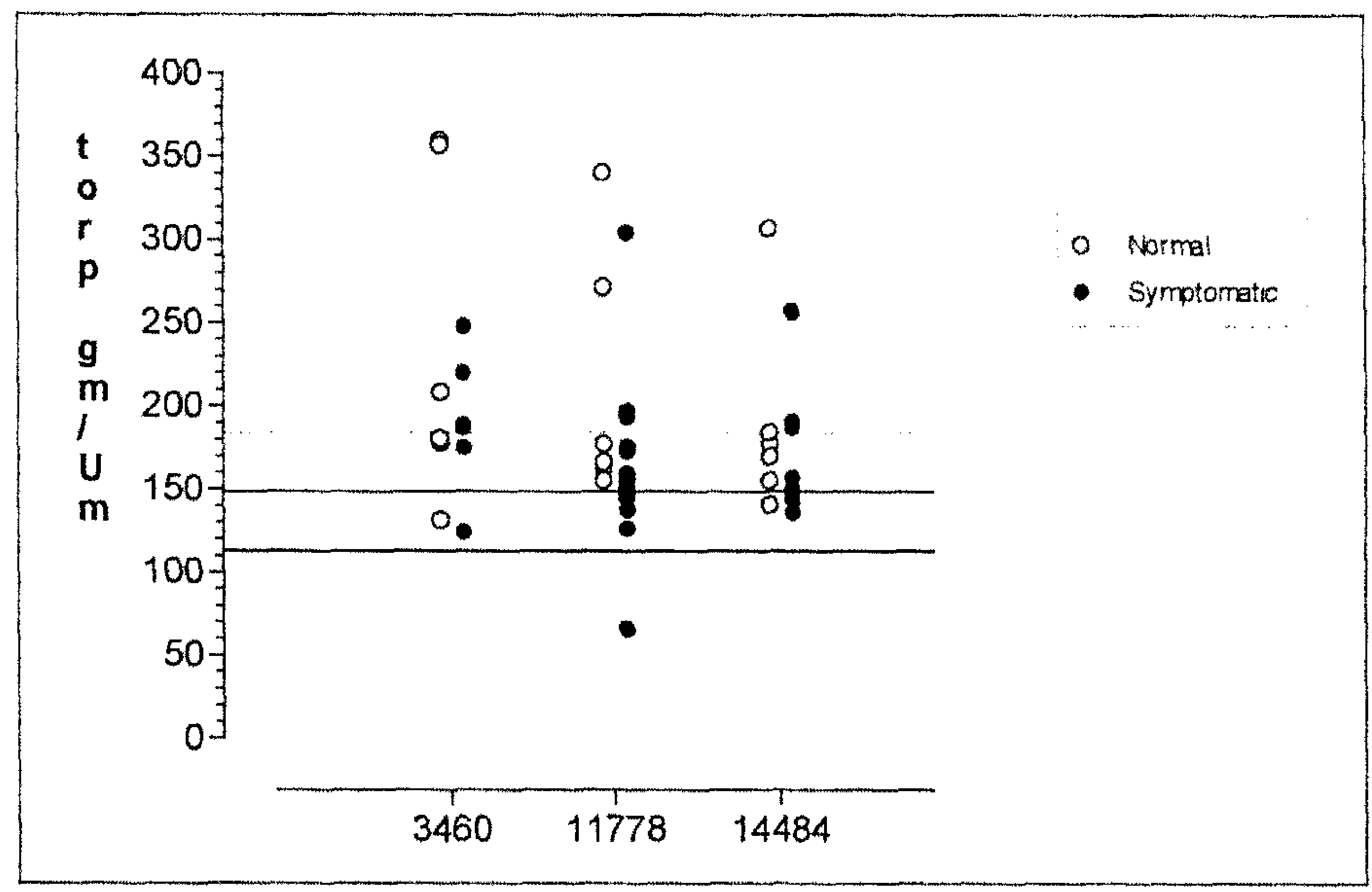


While the unaffected m.14484T $>C$ carriers $(36.4 \pm 9.34 \mathrm{mU} / \mathrm{U} C \mathrm{CS})$ were nearly significantly $(p=0.06)$ different from the control group, the affected m.14484T $>C$ carriers $(55.3 \pm 33.9$ $\mathrm{mU} / \mathrm{U} \mathrm{CS}$ ) were not $(\mathrm{p}=0.18)$, but the two groups were significantly different from each other $(p=0.04$ ) (Table 2; Fig. 1A). Only 6 out of 16 carriers showed a biochemical phenotype (37.5\%; Fig. 1A), but the ROC area amounted to 0.706 (SE: 0.113 ) and was almost statistically significant $\left(\mathrm{X}^{2}=2.861 ; \mathrm{P}=0.091\right)$. The percentage of correctly classified patients on the basis of the binary biochemical phenotype amounted to $68.8 \%$ with a sensitivity (true positive) of $55.6 \%$ and a specificity (true negative) of $85.7 \%$.

The level of CI/CS in blood lymphocytes of fathers of symptomatic LHON patient was not significantly different from the control group (46.2 $\pm 15.1 \mathrm{mU} / \mathrm{U}$ CS; Table 2 ).

\section{Citrate synthase}

The amount of citrate synthase activity per unit protein (CS) is an indication for the quantity of the mitochondria per cell. When the mitochondrial function is insufficient, to a certain degree, the number of mitochondria can increase in order to compensate for the functional defect. Vice versa such an increase in CS is therefore a sign for a defect in mitochondrial function. The CS in the control group was $148.6 \pm 35.2 \mathrm{mU} / \mathrm{mg}$ prot. In all unaffected LHON mutation groups there was a significantly elevated CS activity, respectively amounting in the unaffected $m .3460 G>A$ carriers to $236.1 \pm 98.1$ ( $p=0.003$ ), in the unaffected $m .11778 G>A$ carriers to $212.3 \pm 76.2(p=0.007)$, and in the unaffected $m .14484 T>C$ carriers to $234.5 \pm 131.9$ $\mathrm{mU} / \mathrm{mg}$ prot $(p=0.01$ ). In the affected patients, only patients carrying the $\mathrm{m} .3460 \mathrm{G}>\mathrm{A} \mathrm{mu}$ tation had significantly elevated CS values (190.6 $\pm 41,97 \mathrm{mU} / \mathrm{mg}$ prot; $p=0.02$ ) (Table 2; Fig. $1 B$ ). Therefore, if considering CS activities beyond one SD of the mean CS activity of the normal group as biochemically abnormal, the m.3460G $>$ A mutation group showed a relatively high biochemical phenotype ( $58.3 \%$ ), but this amounted for the $\mathrm{m} .11778 \mathrm{G}>\mathrm{A}$ and m.14484T $>C$ mutation to only $30.0 \%$ and $43.8 \%$, respectively (Fig. $1 B$ ).

On the other hand, within each mutation group, the association between the dichotomous biochemical- and clinical phenotype was not statistically significant (for the m.3460G>A mutation: $R O C$ area $=0.583, X^{2}=0.343, P=0.558$; for the m.11778G $>A$ mutation: $R O C$ area $=$ $0.476, X^{2}=0.048, P=0.842$ and for the m.14484 $>C$ mutation: $R O C$ area $=0.508, X^{2}=0.004$, $P=0.949)$.

The level of CS in blood lymphocytes of fathers of symptomatic LHON patient was not significantly different from the control group (151.1 $\pm 50.6 \mathrm{mU} / \mathrm{mg}$ prot; Table 2).

Illustrative in the example of the m.3460G>A family (Fig. 2) is the significantly elevated CS levels in the unaffected family members that were not seen in the affected patients. The father in this family is not a LHON mutation carrier and had comparable biochemical parameters with the control population. 


\section{Discussion}

In this study we evaluated the complex I activity in a large group of LHON mutation carriers using a relatively easy assay requiring circulating lymphocytes. The advantage of this present method is that it is hardly invasive, rapid and does not require cell culturing. The assays can be completed in a short time period ( 3 hours after blood sampling) and require a relatively small amount of blood $(<5 \mathrm{ml}) .^{10}$

We showed a reduction to $60 \%$ in the complex I activity normalized to CS (CI) in affected and unaffected $\mathrm{m} \cdot 3460 \mathrm{G}>\mathrm{A}$ mutation carriers. This result is consistent with previous studies $3.4,10$ where a reduction to $60-80 \%$ of complex I activity was found in platelets," lymphoblasts, 3.5 and fibroblasts ${ }^{12}$ of symptomatic and asymptomatic $m .3460 \mathrm{C}>\mathrm{A}$ carriers. This suggests first of all that the present, relatively new assay is reliable, not only in measuring complex I activity in controls but also in patients with a mitochondrial disorder like LHON. Furthermore, we found that about $70 \%$ of the mutation carriers showed a biochemical phenotype if a level of $\mathrm{Cl}$ over CS activity beyond one SD of the normal mean is considered abnormal. No significant association of the biochemical phenotype with the clinical phenotype could be assessed, but recent studies indicate that unaffected LHON carriers show often already manifestations of subclinical optic nerve impairment and abnormalities. ${ }^{13}$ In the $\mathrm{m} .11778 \mathrm{G}>\mathrm{A}$ and $\mathrm{m} .14484 \mathrm{~T}>\mathrm{C}$ mutation groups, the biochemical phenotype was less expressed than in the $\mathrm{m} .3460 \mathrm{G}>\mathrm{A}$ mutation group, respectively amounting to $55.0 \%$ and $37.5 \%$. Because the complex I defect in $\mathrm{m} .3460 \mathrm{G}>\mathrm{A}$ mutation carriers is consistently found, we expected the affected LHON patients with the other two primary mutations would have decreased $\mathrm{Cl} / \mathrm{CS}$ activities as well, but the opposite was true. Unaffected $\mathrm{m} .11778 \mathrm{G}>\mathrm{A}$ and $\mathrm{m} .14484 \mathrm{~T}>\mathrm{C}$ carriers showed with a reduction of the $\mathrm{Cl}$ activity per unit $\mathrm{CS}$ to $62 \%$ and $75 \%$ respectively of the control values, while the affected m.11778 $>>A$ and $m .14484 \mathrm{~T}>\mathrm{C}$ carriers had normal or even slightly elevated complex I activities. The picture that emerges is that the primary LHON mutations in the subunits ND4 and ND6 seem to improve the enzymatic activity of complex I. Of course, the enzyme activity was measured in vitro under optimal conditions. The question is if this condition reflects the situation in vivo in a realistic manner, but such an increase in complex I activity may bear the risk of an increase in the generation of superoxide anion radicals. It is well known that complex $I$ is the major site of superoxide production in the cell, ${ }^{14}$ and if not inactivated adequately may lead to increased oxidative stress. It is tempting to speculate in this respect about a role for a genetic modifier factor that prevents the ND4/6-mutation induced spinning of complex I.

The complex I activity was expressed here per mitochondrial unity. CS is encoded by nuclear DNA and is commonly used as a quantitative enzyme marker for the number of mitochondria in tissues and cells. When the respiratory function of cells decreases (decreased 
ATP, acetyl-COA and/or NADH) the mitochondrial number could be adjusted upward by proliferation as a compensatory mechanism. ${ }^{15}$ Such an increase in relative mtDNA content was reported in some LHON patients and unaffected carriers and also in other mitochondrial disorders before. ${ }^{16}$ In the present study, the CS levels were increased for all mutations but only significantly for the unaffected groups with either a m.3460G $>A, m .11778 \mathrm{G}>\mathrm{A}$ or m.14484T>C mutation. This is a remarkable and constant finding. While true for the mutation groups as a whole, this may suggest that individuals whose mtDNA content had increased and been maintained at certain levels were symptom free, whereas those whose CS levels had not increased, developed LHON. However, analysis of the receiver-operating characteristics showed that no statistically significant association with the clinical phenotype could be demonstrated in either mutation group.

The $\mathrm{m} .3460 \mathrm{G}>\mathrm{A}$ mutation is in our study an exception with a reduced $\mathrm{Cl}$ activity in all mutation carriers but only elevated CS in the unaffected. This all might be related with the position of the m.3460G $>$ A mutation in complex l, at the site of CoQ binding. It is the rotenone sensitive NADH oxidation that is used to measure complex I activity. The ND1 subunit is the only complex I subunit that directly is implicated in the rotenone binding site and transfers electrons to the substrate $\mathrm{COQ}$ that binds to the hydrophobic site of the pocket in the complex. The m.11778G>A/ND4 and m.14484T>C/ND6 mutations are not involved in the electron transfer in complex $\mathrm{I}$, which might explain why these mutations have less or even a stimulating effect on the activity of complex 1 as determined in vitro. Either mutation would not necessarily have a dramatic effect on the ATP production in the affected tissue because an energy production failure due to a complex I defect in principle can be bypassed sufficiently through complex II. Ubiquinol is also produced by complex II in a parallel path to that of complex I. Complex III receives thus electrons by both complex I and II in two independent paths. Previously it was shown that $\mathrm{m} .11778 \mathrm{G}>\mathrm{A}$ mutation carriers have a small reduction (less than $20 \%$ ) and the m.14484T $>C$ mutation only a minor decrease in complex I activity. ${ }^{7,18}$ We found here that the $\mathrm{m} .11778 \mathrm{G}>\mathrm{A}$ mutation group had about $10 \%$ more complex I activity than the controls, and the complex I activity of the m.14484T>C group was at the control level. The m.11778G>A/ND4 mutation affects the proton pumping function of complex I and the binding of $\mathrm{COO}$ intermediates (semiubiquinone) ${ }^{19,20}$ causing less stability of the intermediates, and as a consequence an increase in the generation of ROS. ${ }^{21}$ Complex 1 is, besides complex III, one of the major sites of respiratory oxygen species (ROS) production. Defects in these complexes lead to ROS overproduction and can in this way lead again to cell damage. The slightly higher complex I activity (per unit CS) in the affected m.11778G $>A$ and m.14484T>C mutation carriers as found in the present study indeed point into that direction.

Our work demonstrated that measuring complex I in circulating lymphocytes with our new assay is reliable and reproducible in patients with a mitochondrial DNA mutation, in par- 
ticular in patients with a LHON mutation. This enables the use of circulating blood cells in further study of the mechanism that is underlying the difference in activity of complex 1 in normal and symptomatic $\mathrm{m} .11778 \mathrm{G}>\mathrm{A}$ and $\mathrm{m} .14484 \mathrm{~T}>\mathrm{C}$ mutation carriers. It is unlikely that in $\mathrm{m} .3460 \mathrm{G}>\mathrm{A}$ mutation carriers a modifier gene that determines the defect in complex I

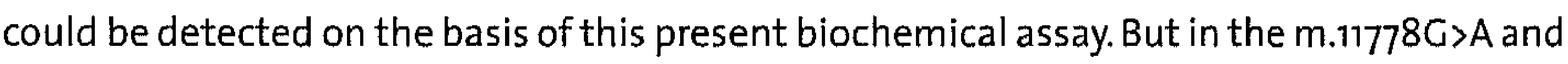
m.14484T >C mutation carriers it could be possible because in these two groups the present study indicates, unexpectedly, that the mutation appears to lead to an increased activity of the first respiratory chain enzyme complex.

\section{Acknowledgments}

This work was supported by "The Netherlands Society for Ophthalmological Research" (SOON)", the "The Netherlands Society for Prevention of Blindness" (ANVVB), and the EUFP6 STREP MITOCIRCLE 


\section{References}

1. Man PY, Griffiths PG, Brown DT, et al. The epidemiology of Leber hereditary optic neuropathy in the North East of England. Am J Hum Genet. 2003;72:333-339.

2. Mackey DA, Oostra RJ, Rosenberg T, et al. Primary pathogenic mtDNA mutations in multigeneration pedigrees with Leber hereditary optic neuropathy. Am J Hum Genet. 1996:59:481-485.

3. Majander A, Huoponen K, Savontaus ML, Nikoskelainen E, Wikstrom M. Electron transfer properties of NADH:ubiquinone reductase in the ND1/3460 and the ND4/11778 mutations of the Leber hereditary optic neuroretinopathy (LHON). FEBS Lett. 1991;292:289-292.

4. Smith PR, Cooper IM, Govan GG, Harding AE, Schapira AH. Platelet mitochondrial function in Leber's hereditary optic neuropathy.J Neurol Sci. 1994;122:80-83.

5. Brown MD, Trounce IA, Jun AS, Allen JC, Wallace DC. Functional analysis of lymphoblast and cybrid mitochondria containing the 3460,11778 , or 14484 Leber's hereditary optic neuropathy mitochondrial DNA mutation. J Biol Chem. 2000;275:39831-39836.

6. Carelli V, Ghelli A, Bucchi L, et al. Biochemical features of mtDNA 14484 (ND6/M64V) point mutation associated with Leber's hereditary optic neuropathy. Ann Neurol. 1999;45:320-328.

7. Brown MD, Torroni A, Reckord CL, Wallace DC. Phylogenetic analysis of Leber's hereditary optic neuropathy mitochondrial DNA's indicates multiple independent occurrences of the common mutations. Hum Mutat. 1995;6:311-325.

8. Pietersma A, Kofflard M, de Wit LE, et al. Late lumen loss after coronary angioplasty is associated with the activation status of circulating phagocytes before treatment. Circulation. 1995;91:1320-1325.

9. Srere PA. The molecular physiology of citrate. Curr Top Cell Regul. 1992;33:261-275.

10. Cock HR, Tabrizi SJ, Cooper JM, Schapira AH. The influence of nuclear background on the biochemical expression of 3460 Leber's hereditary optic neuropathy. Ann Neurol. 1998;44:187-193.

11. Parker WD, Jr., Oley CA, Parks JK. A defect in mitochondrial electron-transport activity (NADH-coenzyme O oxidoreductase) in Leber's hereditary optic neuropathy. $N$ Engl J Med. 1989;320:1331-1333.

12. Cock HR, Cooper JM, Schapira AH. Functional consequences of the 3460-bp mitochondrial DNA mutation associated with Leber's hereditary optic neuropathy. I Neurol Sci. 1999;165:10-17.

13. Sadun AA, Salomao SR, Berezovsky A, et al. Subclinical carriers and conversions in Leber hereditary optic neuropathy: a prospective psychophysical study. Trans Am Ophthalmol Soc. 2006;104:51-61. 
14. Abu-Amero KK, Bosley TM. Increased relative mitochondrial DNA content in leucocytes of patients with NAION. Br J Ophthalmol. 2006;90:823-825.

15. Wei $\mathrm{YH}$, Lee $\mathrm{HC}$. Oxidative stress, mitochondrial DNA mutation, and impairment of antioxidant enzymes in aging. Exp Biol Med (Maywood). 2002;227:671-682.

16. Yen MY, Chen CS, Wang AG, Wei YH. Increase of mitochondrial DNA in blood cells of patients with Leber's hereditary optic neuropathy with 11778 mutation. Br J Ophthalmol. 2002;86:1027-1030.

17. Oostra RJ, Van Galen MJ, Bolhuis PA, Bleeker-Wagemakers EM, Van den Bogert C. The mitochondrial DNA mutation ND6*14,484C associated with leber hereditary optic neuropathy, leads to deficiency of complex I of the respiratory chain. Biochem Biophys Res Commun. 1995;215:1001-1005.

18. Cock HR, Cooper JM, Schapira AH. The 14484 ND6 mtDNA mutation in Leber hereditary optic neuropathy does not affect fibroblast complex I activity. Am J Hum Genet. 1995;57:1501- 1502.

19. Baracca A, Solaini G, Sgarbi G, et al. Severe impairment of complex I-driven adenosine triphosphate synthesis in leber hereditary optic neuropathy cybrids. Arch Neurol. 2005;6z:730-736.

20. Yano T. The energy-transducing NADH: quinone oxidoreductase, complex I. Mol Aspects Med. 2002;23:345-368.

21. Degli Esposti $M$, Carelli V, Ghelli A, et al. Functional alterations of the mitochondrially encoded ND4 subunit associated with Leber's hereditary optic neuropathy. FEBS Lett. 1994;352:375-379. 


\title{
Mitochondrial DNA mutations and variants
}

\author{
Chapter 7
}

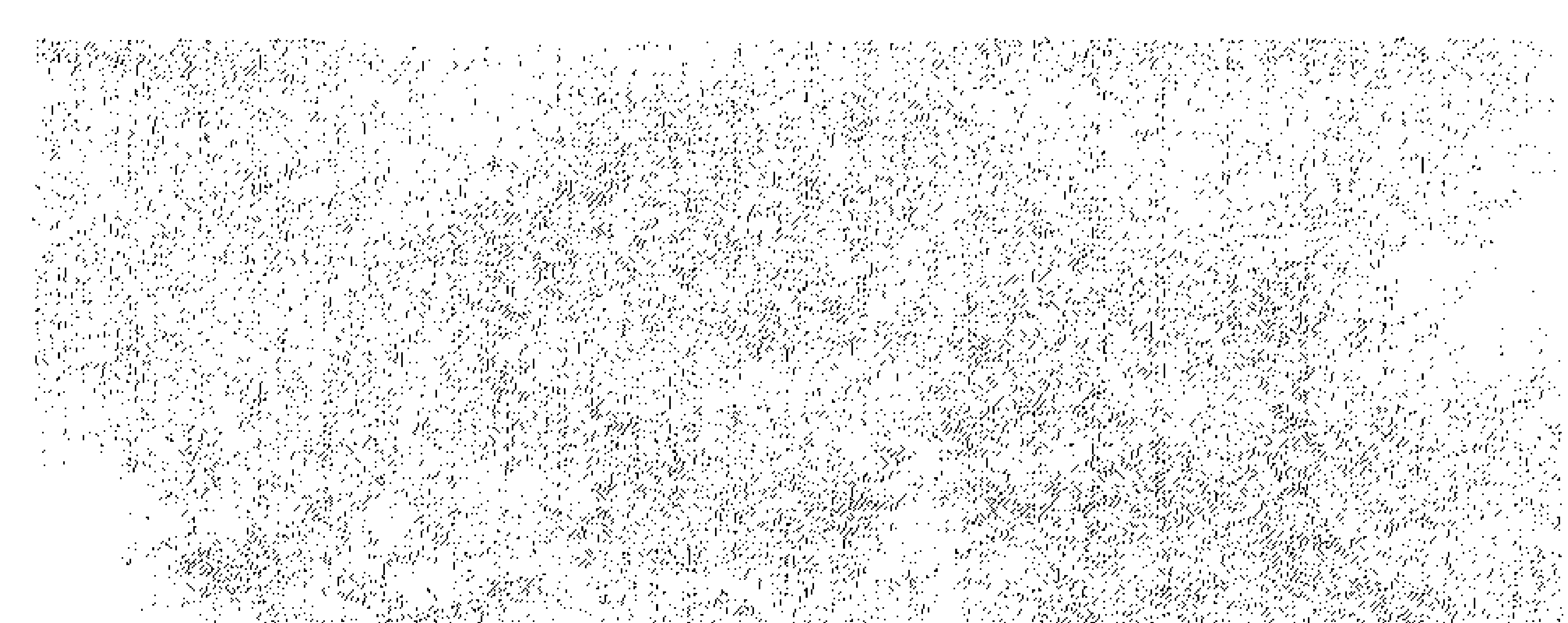

Additional mitochondrial DNA mutations may explain extra-ocular involvement in LHON.

Liesbeth Spruijt, Jessica Hoogendijk, Alexandra Hendrickx, René de Coo, Pieter Doevendans, Paulus de Jong, Wim Spliet, Hester Kroes, Bert Smeets.

Am J Med Genet 2006; 140(13):1478-1481 


\begin{abstract}
Leber's Hereditary Optic Neuropathy (LHON) is a mitochondrial inherited optic atrophy which characteristically presents with (sub) acute, bilateral vision loss occurring in early adulthood. Three primary mtDNA mutations (m.11778G $>A, m .3460 \mathrm{G}>\mathrm{A}$ and m.14484T>C) explain more than $95 \%$ of all LHON patients. The symptoms of LHON are in general limited to the optic system, but some patients have neurological symptoms. We report a 52-yearold man with Leber's Hereditary Optic Neuropathy ( $L H O N$ ), deafness and encephalomyopathy with both a homoplasmic m.14484T>C ND6 mutation and a heteroplasmic m.4269A>C tRNA (lle) mutation in the mtDNA. The first mutation explains the ocular symptoms and the second the neurological signs. Extra-ocular symptoms have been attributed to the primary LHON mutation only, but a complete analysis of the mEDNA is often not performed. We recommend therefore screening for additional mtDNA mutations in LHON patients who present extra-ocular symptoms.
\end{abstract}




\section{Introduction}

Leber's Hereditary Optic Neuropathy (LHON) is a mitochondrial inherited optic atrophy which characteristically presents with (sub) acute, bilateral vision loss at an average on. set age of 19-24 years.' Three primary mtDNA mutations (m.11778G $>A, m .3460 G>A$ and m.14484T $>C$ ) explain more than $95 \%$ of all LHON patients. Approximately $50 \%$ of the male and $10 \%$ of the female carriers of a primary mutation will eventually be visually impaired. The m.11778G>A and m.3460G>A mutations are associated with a more severe clinical and biochemical phenotype than the m.14484T>C mutation. Patients with this last mutation have usually a better visual outcome and have approximately $50 \%$ chance of (partial) recovery of their sight after several years. ${ }^{2}$ The symptoms of LHON are, in general, limited to the optic system, but in some patients a multiple sclerosis-like illness, movement disorders, chronic motor tics, parkinsonism and dystonia can occur, mainly reported in patients with the m.11778G $>$ A mutation. 3.4 We report two mutations in the mtDNA of an adult male patient with LHON and extensive extra-ocular symptoms and signs.

\section{Case report}

\section{Clinical history and presentation}

This patient, first child of healthy unrelated parents, had a normal early development. Since childhood his walking was noted to be "clumsy" and he never excelled in sport. This could have been related to a non-progressive left-sided weakness and facial paresis which was noted at some point in childhood and was attributed to head trauma. He followed normal education. He suffered from headache attacks with nausea and emesis. His mother also had complaints compatible with migraine that stopped after menopause. At age 18 he was tested and considered fit for military service. After that, he worked as a farmer. At age 45 visual acuity in both eyes acutely dropped to $1 / 60$ (finger counting). His pupil reactions were normal without a relative afferent defect. He had marked optic disc and peripapillary atrophy in both eyes. Visual field examination showed central scotomas within $10^{\circ}$ in both eyes extending to $20^{\circ}$ below the horizontal meridian, with intact periphery. The electroretinography displayed mildly lowered amplitudes. There was hardly any measurable response in the cortically evoked potentials. The following years, he noticed difficulties with concentration and memory. He now has to rely on others for his financial administration and several household tasks. From age 40 on he noticed hearing problems and recent examination (at age 51) showed a bilateral perceptive deafness of 70-100 dB. Presently, neurological examination at age 52 , showed a right-handed man of average stature $(1.86 \mathrm{~m})$ and below 
average weight $(63 \mathrm{~kg})$ carrying a hearing aid at both sides. Neuropsychological testing, impaired by the visual and hearing impairment, indicated intellectual decline (Wechsler intelligence test). Visual acuity was restricted to hand movements (right eye) and finger counting (left eye). Neurological examination showed a left-sided facial weakness, impaired sensation, hypertonia, clumsiness, hyperreflexia, Babinski sign, and pes cavus. There was no external ophthalmoplegia and no weakness in arms or legs, but there was some bilateral wasting of lower leg muscles. Resting blood lactate was $3.6 \mathrm{mM}$ (normal <1.8 mM) and creatinine kinase level was $274 \mathrm{U} / \mathrm{L}$ (normal $<180 \mathrm{U} / \mathrm{L}$ ). Neurophysiological examination showed too many polyphasic motor unit potentials. The sural nerve conduction velocity and amplitude were normal. A biopsy taken from the lateral vastus muscle (Figure 1) showed some atrophic fibres, degenerating and regenerating fibres, and abundant basophilic staining, ragged red fibres, and ragged blue and dark blue fibres in the $\mathrm{HE}, \mathrm{NADH}$, and SDH staining, and many COX-negative fibres.

Figure 1.

A: SDH (succinate dehydrogenase) enzyme histochemistry showing fibers with increased activity (ragged blue and dark blue fibers) indicating an increased number of (defective) mitochondria.

B:The cytochrome oxidase (COX) enzyme histochemistry shows the non-functional COX-negative fibers.

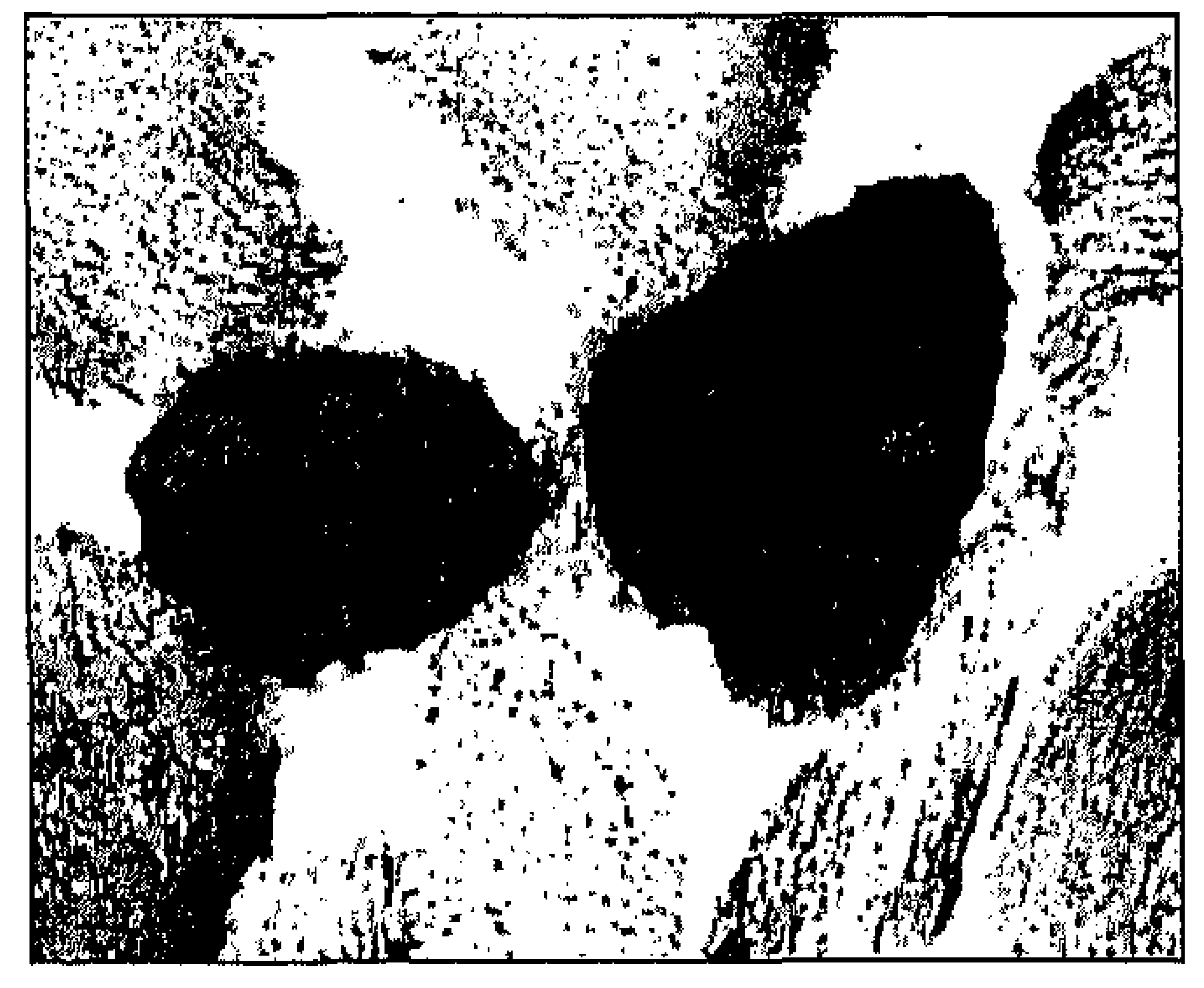

A

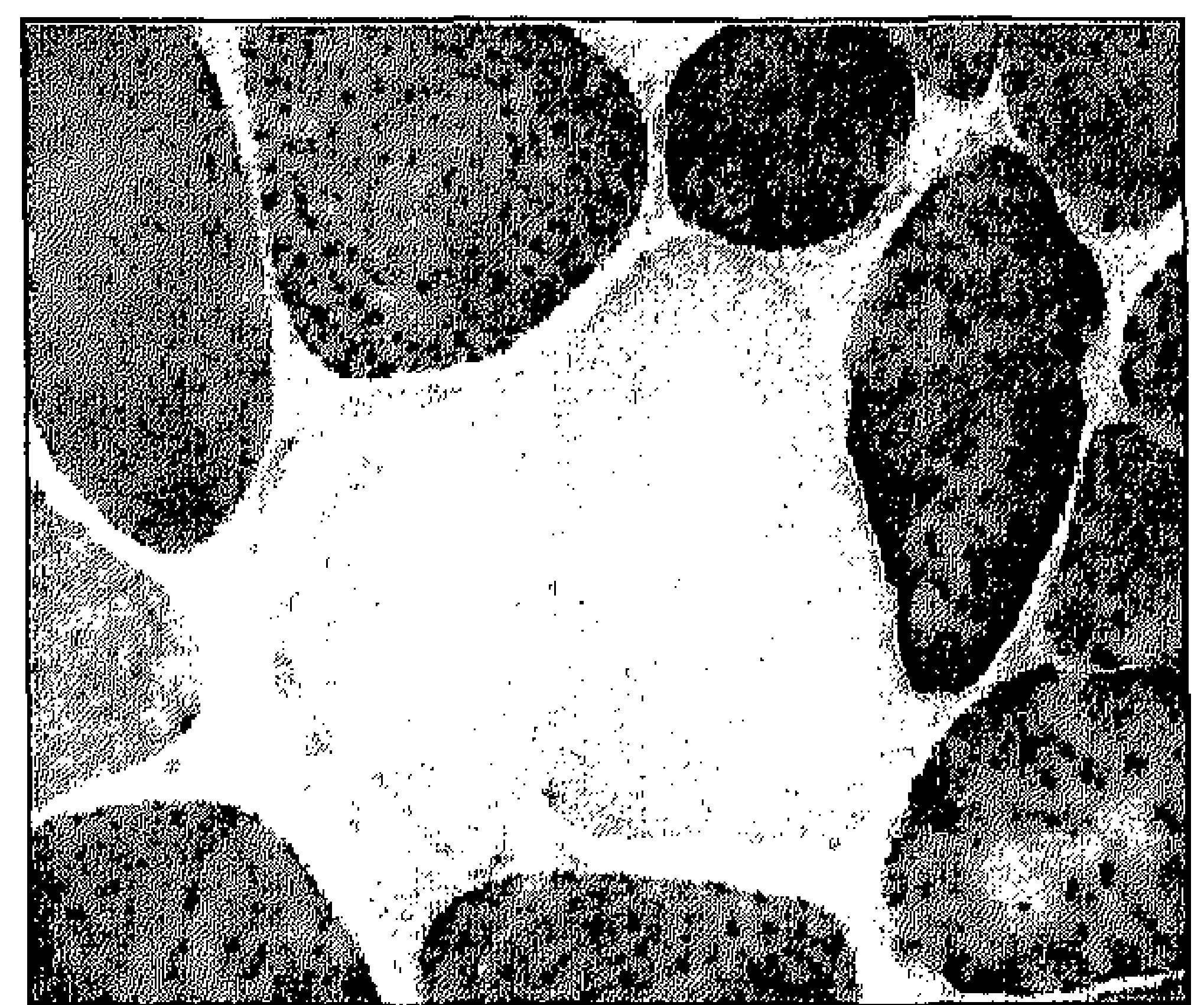

B

MRI imaging of the brain was normal. By echocardiography the left ventricular ejection fraction was estimated at $40 \%$ with a diffusely impaired contraction pattern and fractional shortening. Size and function of the right ventricle and both atria were normal, as were the electrocardiogram, the exercise test at 95 Watts, and Holter-examination. There were no affected relatives in the maternal line. 


\begin{abstract}
Molecular genetic analysis
Total genomic DNA was extracted from peripheral EDTA blood and muscle with the Wizard DNA clean up system (Promega). The m.11778G>A/ND4, m.3460G>A/ND1 and m.14484T>C/ ND6 mutations were tested by digesting the respective polymerase chain reaction (PCR) products with mutation specific restriction enzymes Mae III and SfaN I, BsaH l, and Dpn II. Digestion products were resolved by agarose gel electrophoresis. Mutation $\mathrm{m} .11778 \mathrm{G}>\mathrm{A}$ was digested with two enzymes in order to prevent false positive results caused by the $11779 C>T$ polymorphism. The mtDNA was further screened for additional mutations by $\mathrm{DH}-$ PLC analysis, as described before.5 Screening for the primary LHON mutations revealed a homoplasmic m.14484T>C mutation in the blood of the patient and his mother. In addition, we identified a second pathogenic mutation at position mtDNA m.4269A>G in the tRNA (IIe) gene at a level of $81 \%$ in blood, and $95 \%$ in muscle tissue. His mother had a mutation load of the m.426gA>G mutation of $9 \%$ in blood. The mtDNA background of the patient was an $H$ haplotype.
\end{abstract}

\title{
Discussion
}

In this paper we describe a patient with optic atrophy and, in addition, perceptive hearing loss, myopathy, cognitive decline, and cardiac involvement. The unilateral pyramidal tract syndrome remained ill understood, as there were no white matter lesions or any abnormalities on brain imaging. The disease course and involvement of multiple organ systems made a mitochondrial disease as the underlying cause for these features very likely. The patient carries two mutations in the mLDNA, a homoplasmic primary LHON mutation m.14484T $>$ C) and a heteroplasmic tRNA (lle) m.4269A>G mutation in a high percentage in blood ( $81 \%)$ and muscle tissue (95\%). The asymptomatic mother was homoplasmic for the m.14484T>C mutation and was heteroplasmic for the $m .4269 \mathrm{~A}>\mathrm{G}$ mutation ( $9 \%$ in blood). The low mutation load of the latter mutation can explain the absence of symptoms. None of the relatives in maternal line $(n=14)$ had visual problems, which is remarkable since virtually all carriers of the m.14484T $>C$ mutation have a history of visual loss in affected relatives. ${ }^{6}$ The penetrance of the $m .14484>C$ mutation can vary considerably between LHON families, ranging from close to zero to about 30-67\%. The genetic background, the haplotype, is of influence on LHON disease penetrance. A J haplotype is considered to increase the disease penetrance and a non-J haplotype, like in this family the $\mathrm{H}$ haplotype, explains the low penetrance. ${ }^{8}$ 
FIG. 2.

A: Sequencing electropherogram showing the $4269 A>G$ mutation compared with the wild-type mtDNA sequence $(B)$. [Color figure can be viewed in the online issue, which is available at www.interscience.wiley. com.]

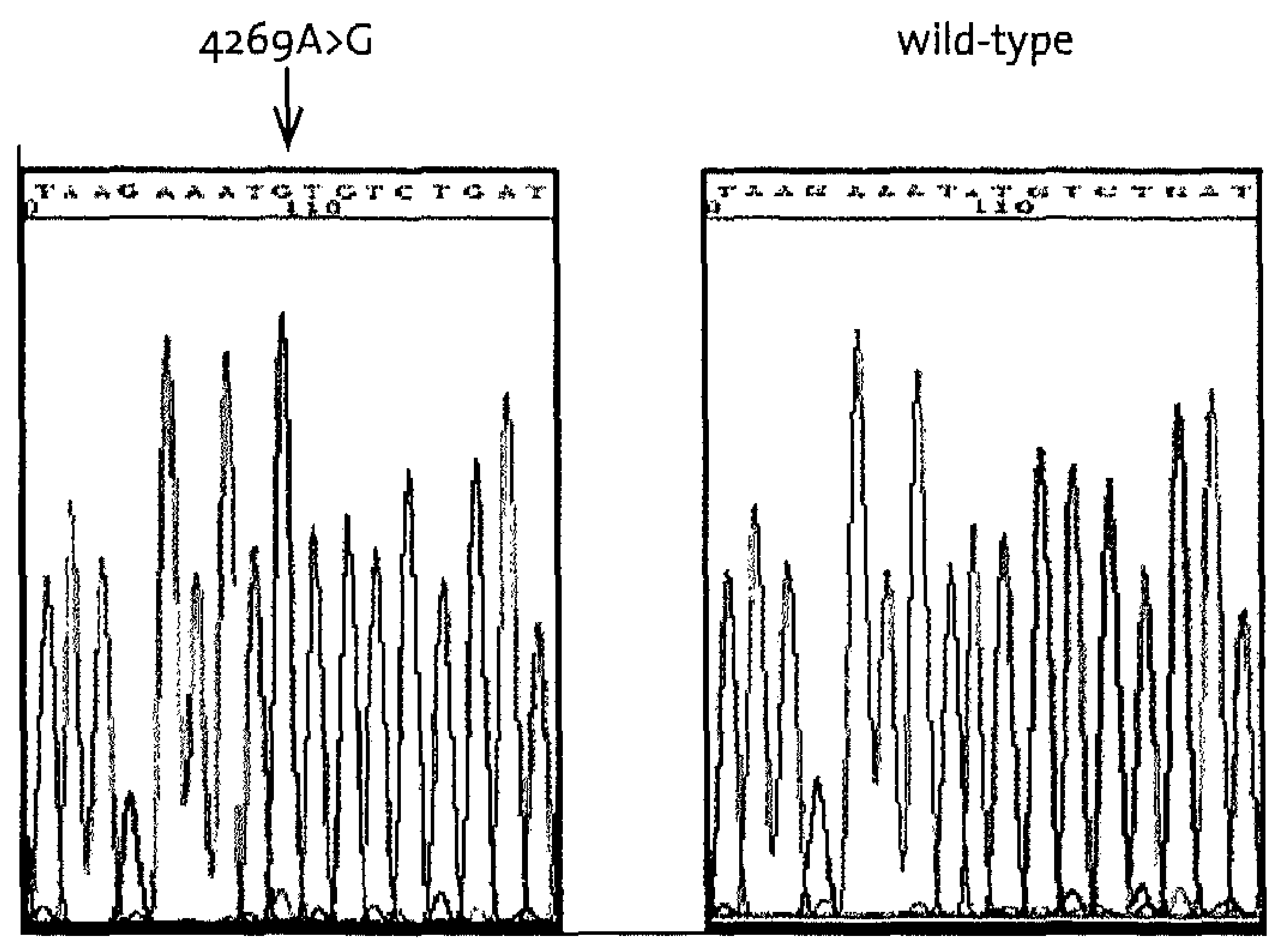

A

B

The m.4269A $>G$ mutation has been reported once in a patient with a mitochondrial encephalomyopathy presenting at age 4 years with short stature, progressive neurogenic hearing loss, focal glomerulosclerosis, epilepsy and progressive dilating cardiomyopathy resulting in fatal cardiac failure at age $18 .{ }^{9}$ The $\mathrm{m} .4269 \mathrm{~A}>\mathrm{G}$ mutation was heteroplasmic in this patient with a high amount of mutated mtDNA in blood, skeletal and cardiac muscle. His healthy mother had only a low amount of the mutation in her blood, but exact percentages were not provided. The mutation fulfils accepted criteria for pathogenicity (heteroplasmic, conserved, absent in controls), ${ }^{9}$ which was further confirmed by mtDNA transfer experiments in cybrid cells showing a complete inhibition of protein synthesis in mitochondria, thereby significantly reducing their respiratory activity..$^{10}$ The substitution from $A$ to $G$ at position $m .4269$ results in an aberrant tertiary structure of tRNA(Ile) which destabilizes the T-stem of the mutant tRNA(Ile) gene." As a consequence the mutant tRNA(lle) is degraded more rapidly than wild-type tRNA (lle), resulting in inhibition of the protein synthesis in mitochondria and reduced respiratory activity. ${ }^{12}$ The $m .4269 A>G$ mutation is also located close to the tRNA (lle)/NDi junction, and might therefore also interfere with RNA processing and ND1 production. 
The symptoms in LHON are in general restricted to the visual system but neurological problems like movement disorders, tremor, tics, parkinsonism, dystonia, peripheral neuropathy and pre-excitation syndromes have also been described. ${ }^{3.13}$ Most of these symptoms have been reported in patients with the m.11778G $>\mathrm{A}$ mutation. On the other hand the m.14484T $>C$ LHON mutation is only rarely associated with neurological and cardiac symptoms. ${ }^{14.15}$ A woman with a m.14484T $>C$ mutation and extra-ocular symptoms was reported to suffer from relapsing episodes of visual loss of both eyes and consecutively developed Hashimoto thyroiditis and widespread demyelization CNS lesions outside the visual pathways. She was not tested for additional mtDNA mutations. ${ }^{14}$ Simultaneous occurrence of a LHON mutation with a second mutation in the mTDNA has been reported once. A symptomatic LHON patient with cardiomyopathy and the m.11778G $>$ A mutation turned out to have a second homoplasmic m.12192G>A transition in the tRNA (His) gene related with the cardiac symptoms. ${ }^{16}$ Even the simultaneous occurrence of two different HON mutations, the m.11778G $>A$ and $m .14484$ T $>C$ mutation, has been reported 2,17 In these patients only ocular symptoms comparable with patients with a single LHON mutation were present.

In conclusion, the m.14484T $>C$ mutation is responsible for the typical visual impairment in our patient, whereas the other neurological symptoms are likely to be attributable to the $4269 A>G$ mtDNA mutation. Our observation implies that when LHON is associated with ancillary extra-ocular symptoms further search for mitochondrial mutations is mandatory.

\section{Acknowledgements}

This work was supported by the "The Netherlands Society for Ophthalmological Research", (SOON)", the "The Netherlands Society for Prevention of Blindness", (ANVVB), and the EUFP6 STREP MITOCIRCLE. 


\section{References}

1. Man PY, Griffiths PG, Brown DT, et al. The epidemiology of Leber hereditary optic neuropathy in the North East of England. Am J Hum Genet. 2003;72:333-339.

2. Riordan-Eva P, Sanders MD, Govan GG, et al. The clinical features of Leber's hereditary optic neuropathy defined by the presence of a pathogenic mitochondrial DNA mutation. Brain. 1995;118 ( Pt 2):319-337.

3. Nikoskelainen EK, Marttila RJ, Huoponen K, et al. Leber's "plus": neurological abnormalities in patients with Leber's hereditary optic neuropathy. J Neurol Neurosurg Psychiatry. 1995;59:160-164.

4. Kovacs GG, Hoftberger R, Majtenyi K, et al. Neuropathology of white matter disease in Leber's hereditary optic neuropathy. Brain. 2005;128:35-41.

5. van Den Bosch BJ, de Coo RF, Scholte HR, et al. Mutation analysis of the entire mitochondrial genome using denaturing high performance liquid chromatography. $\mathrm{Nu}$ cleic Acids Res. 2000;28:E89.

6. Harding AE, Sweeney MG, Govan GG, Riordan-Eva P. Pedigree analysis in Leber heredjtary optic neuropathy families with a pathogenic mtDNA mutation. Am J Hum Genet. 1995;57:77-86.

7. Howell N, Mackey DA. Low-penetrance branches in matrilineal pedigrees with leber hereditary optic neuropathy. Am J Hum Genet. 1998;63:1214-1218.

8. Howell N, Herrnstadt C, Shults C, Mackey DA. Low penetrance of the 14484 LHON mutation when it arises in a non-haplogroup J mtDNA background. Am J Med Genet. 2003;119A:147-151.

9. Taniike $M$, Fukushima H, Yanagihara I, et al. Mitochondrial tRNA(lle) mutation in fatal cardiomyopathy. Biochem Biophys Res Commun. 1992;186:47-53.

10. Hayashi J, Ohta S, Kagawa Y, et al. Functional and morphological abnormalities of mitochondria in human cells containing mitochondrial DNA with pathogenic point mutations in tRNA genes. J Biol Chem.1994;269:19060-19066.

11. Hino N, Suzuki T, Yasukawa T, et al. The pathogenic A4269G mutation in human mitochondrial tRNA(Ile) alters the T-stem structure and decreases the binding affinity for elongation factor Tu. Genes Cells. 2004;9:243-252.

12. Yasukawa $T$, Hino N, Suzuki T, et al. A pathogenic point mutation reduces stability of mitochondrial mutant tRNA(lle). Nucleic Acids Res. 2000;28:3779-3784.

13. Nikoskelainen EK, Savontaus ML, Huoponen K, Antila K, Hartiala J. Pre-excitation syndrome in Leber's hereditary optic neuropathy. Lancet. 1994;344:857-858.

14. Horvath $R$, Abicht $A$, Shoubridge EA, et al. Leber's hereditary optic neuropathy presenting as multiple sclerosis-like disease of the CNS. J Neurol. 2000;247:65-67. 
15. Vanopdenbosch L, Dubois B, D'Hooghe MB, Meire F, Carton H. Mitochondrial mutations of Leber's hereditary optic neuropathy: a risk factor for multiple sclerosis. $J$ Neurol. 2000;247:535-543.

16. Mimaki $M$, lkota $A$, Sato $A$, et al. A double mutation ( $G_{11778 A}$ and $G 12192 A$ ) in mitochondrial DNA associated with Leber's hereditary optic neuropathy and cardiomyopathy. J Hum Genet. 2003;48:47-50.

17. Brown MD, Allen JC, Van Stavern GP, Newman NJ, Wallace DC. Clinical, genetic, and biochemical characterization of a Leber hereditary optic neuropathy family containing both the 11778 and 14484 primary mutations. Am J Med Genet. 2001;104:331-338. 


\section{Chapter 8}

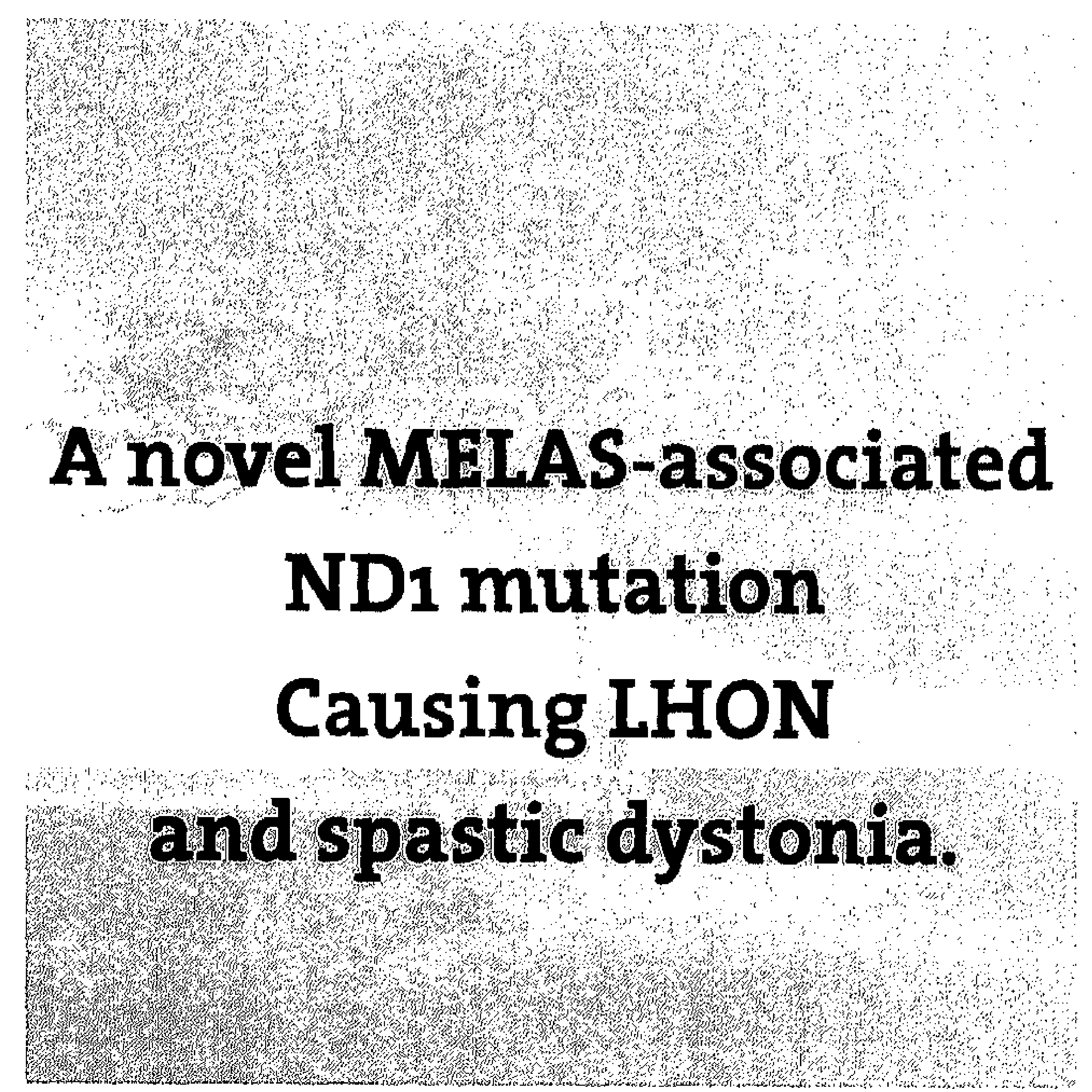

Liesbeth Spruijt, Hubert, J. Smeets, Alexandra Hendrickx, Marijke Wefers Bettink-Remeijer, Anneke Maat-Kievit, Kees C. Schoonderwoerd, Wim Sluiter, René F. de Coo, Rogier O. Hintzen.

Archives of Neurology, 2007, 64(6):890-3. 


\section{Abstract}

LHON is a mitochondrial disorder characterized by an isolated central visual loss. We here report a novel m.3697G>A/ND1 mitochondrial DNA mutation and isolated complex I deficiency that is associated with LHON and within the same family with spastic dystonia.

This family has similar clinical characteristic as the previous reported LHON and dystonia families with an ND6 mutation. This mutation can also cause MELAS syndrome and apparently other genetic factors may contribute to the clinical expression. 


\section{Introduction}

Leber Hereditary Optic Neuropathy (LHON) is a mitochondrial inherited optic atrophy, characteristically presenting with (sub) acute, bilateral visual loss.' More than $95 \%$ of all cases are caused by one of three primary mitochondrial DNA mutations $\mathrm{m} .11778 \mathrm{G}>\mathrm{A}, \mathrm{m} .3460 \mathrm{G}>\mathrm{A}$ or m.14484T $>\mathrm{C}$ that are all encoding a subunit of complex I. The other $5 \%$ is either linked with other mutations, also involving complex I genes ${ }^{2}$ or can not be linked with a known mutation.

Association of LHON with spastic dystonia is rare (OMIM 500001) and all mutations thus far occurred in the ND6 subunit of complex I. The common characteristics are optic atrophy and spastic dystonia, (asymptomatic) basal ganglia lesions and a nearly absent complex I activity. In this study we sequenced the complete mIDNA of a female patient with LHON in whom the primary mutations were absent. This search for a novel mtDNA mutation was also motivated by the fact that the brother of the proband suffered from childhood onset spastic dystonia with unknown cause.

We found a rare pathogenic m.3697G $>A / N D 1$ mutation in both patients, which has only once been reported in association with MELAS. ${ }^{3}$ This present report is the first of a ND1 mutation causing LHON and spastic dystonia. The family had a presentation very similar to the previously reported LHON and spastic dystonia families with ND6 mutations.

\section{Methods}

\section{Case report}

The proband is a 35-year-old Caucasian female (Figure 1) with sequential left and right visual loss, reaching a level of bilateral count vision in 14 months. Funduscopy revealed no abnormalities at the start of the symptoms, after 6 months optic nerve atrophy became apparent. Colour vision was disturbed and visual fields showed a bilateral central scotoma. Visual evoked potentials and contrast vision were disturbed in both eyes. Neurological examination was normal. MRI of the brain showed only a few aspecific punctuated white matter abnormalities in both hemispheres. Serum and CSF lactate was increased to $2.2 \mathrm{mM}$ (normal $<1.8 \mathrm{mM}$ ) and $3.7 \mathrm{mM}$ (normal <2.0mM). Muscle biopsy showed discrete increase of fibre type diameter variation, without ragged red fibres or other signs of mitochondrial myopathy. She smoked 10 cigarettes per day and did not abuse alcohol. She has two healthy children of 2 and 4 years old. Three years after the initial onset of symptoms the visual acuity of the left eye improved to 0.05 and the scotoma in the left visual field has become smaller.

Her one year younger brother had developed a slowly progressive (later stationary) generalized spastic dystonia that had appeared since age 3 years. He is wheelchair bound since 
age 27 and has mental retardation, scoliosis, dysarthria and bilateral divergent strabismus without ophthalmoplegia. Lactate in serum was increased $(3.0 \mathrm{mmol} / \mathrm{l})$ and accumulated, swollen mitochondria were observed after electronmicroscopy analysis of a sural nerve biopsy. Magnetic resonance imaging of the brain showed bilateral hyperintensities in the putamen.

The family history was unremarkable, except for frequent occurrence of migraine. The mother of both siblings is healthy.

\section{MtDNA analysis}

The entire mtDNA coding region was amplified with two $25 \mu l$ PCR reactions ${ }^{4}$, using the Expand Long Template PCR System (Roche). After purification, fragmentation and labelling, the products were hybridised on a prehybridised MitoChip as described in the Affymetrix customSeqTM resequencing protocol. The chips were washed and stained on the GeneChip fluidics station 400 (Affymetrix) using the preprogrammed CustumSeq Resequencing wash and stain protocol (DNA ARRAY-WS2). Mitochips were scanned using the Affymetrix GeneChip scanner 3000 creating. CEL files for subsequent batch analysis. The Affymetrix GeneChip DNA Analysis Software (GDAS) version 3.0.1.3 beta was used for the analysis. The presence and percentage of a mutation was determined by mutation specific restriction digestion of a fluorescently labelled PCR product and Gene scan analysis on an AB/3100 Genetic Analyser ${ }^{4}$

Figure 1

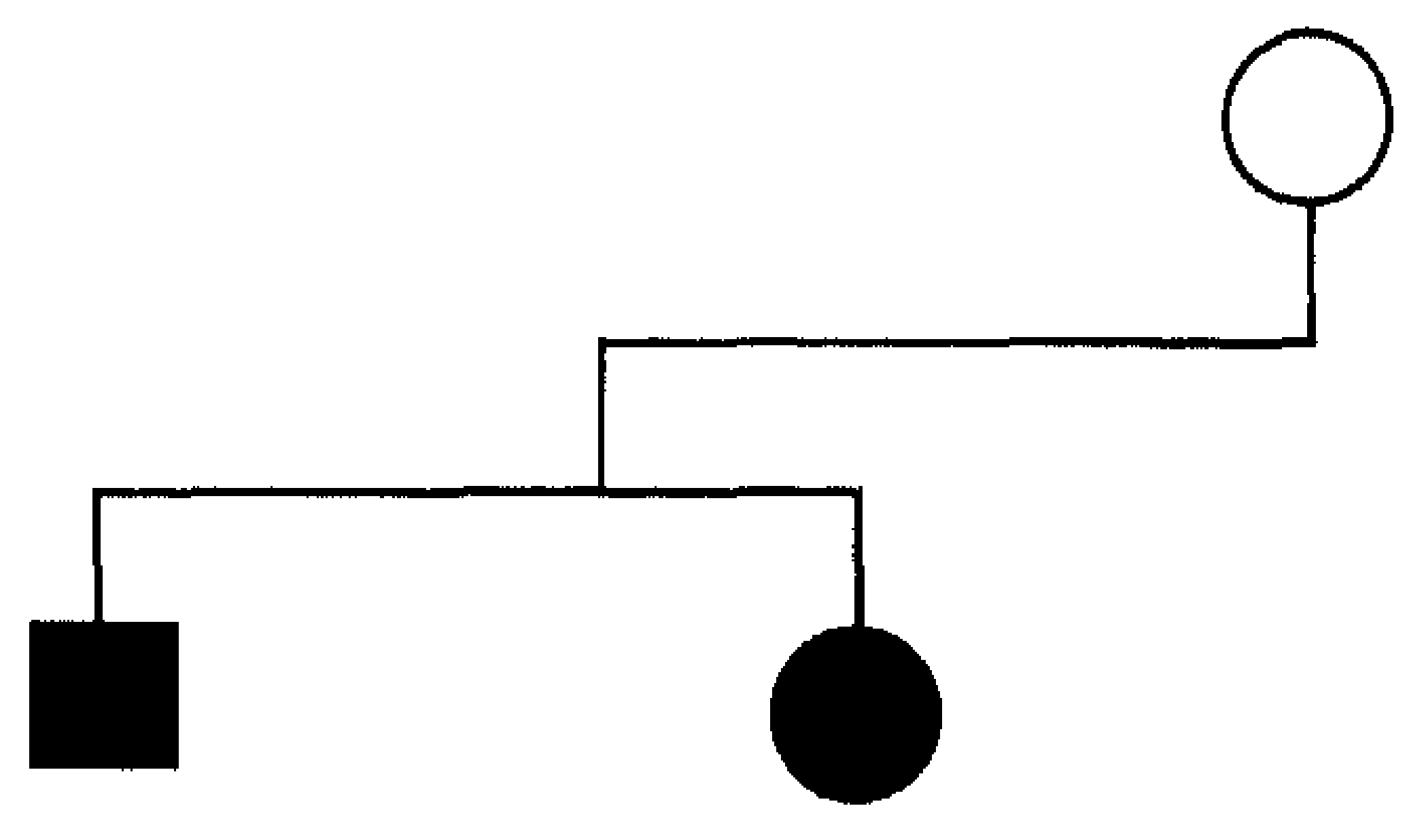

\begin{tabular}{|l|c|c|c|}
\hline Mutation load blood & $88 \%$ & $56 \%$ & $19 \%$ \\
\hline Mutation load muscle & - & $97 \%$ & - \\
\hline Complex l activity (muscle) & $16 \%$ & $8 \%$ & - \\
\hline Clinical phenotype & $\begin{array}{c}\text { Spastic dystonia, } \\
\text { mental retardation, } \\
\text { hyperintensities putamen }\end{array}$ & LHON & Healthy \\
\hline
\end{tabular}


Biochemistry

Tissue homogenates were prepared from frozen muscle in $0.25 \mathrm{M}$ sucrose, $10 \mathrm{mM} \mathrm{N}$ (2-hydroxyethyl) piperazine- $N^{\prime}$-(2 ethylsulfonic acid)(HEPES) and $1 \mathrm{mM}$ Ethylene diamine tetraacetic acid(EDTA), pH 7.4. Citrate synthetase (CS) was measured according to Srere (1969). ${ }^{5}$ Activities of the complexes of the mitochondrial respiratory chain were measured in muscle homogenates as described before. ${ }^{6 \cdot 8}$

\section{Results}

The $m .3697 \mathrm{G}>\mathrm{A} / \mathrm{ND}_{1}\left(\mathrm{G}_{1315}\right)$ mutation was detected with a mutation load was of $>97 \%$ in muscle of the LHON patient. (Figure 2) Mutation load was $56 \%$ in her blood and, respectively, $88 \%$ and $19 \%$ in blood of her severely affected brother and e healthy mother in $19 \%$ (blood). Apart from the pathogenic mutation we identified 21 indicating that this family belongs to the European haplogroup T.9

Respiration and enzyme studies in muscle tissue of the LHON patient and her brother revealed an isolated complex I residual activity to respectively $8 \%$ and $16 \%$ compared to controls. The other complexes were normal. CS was significantly increased in both sister (168\%) and brother $(216 \%)$.

Figure 2

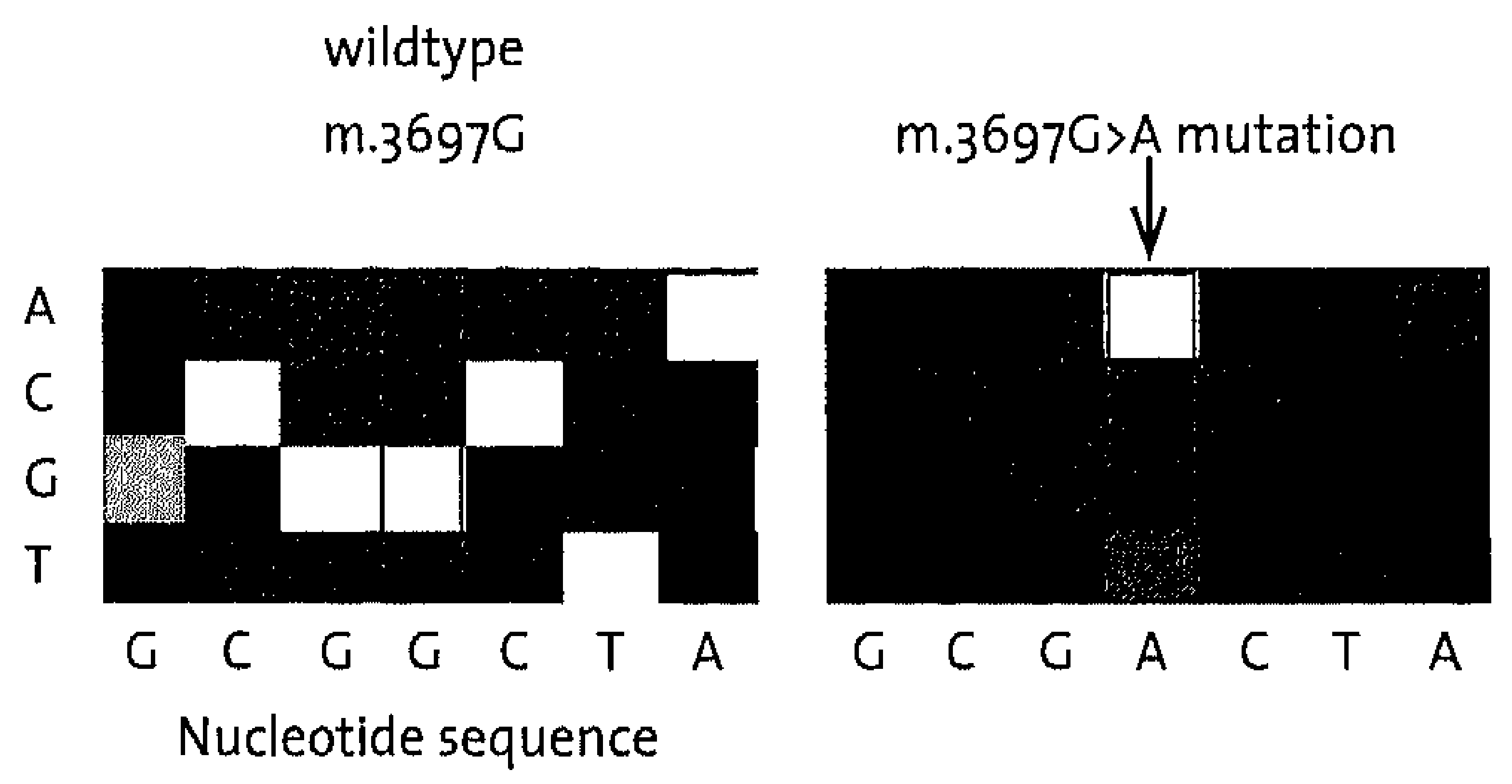

\section{Discussion}

The m.3697G>A/ND1 mutation had been reported once before in a young boy with a typical MELAS phenotype. ${ }^{3}$ The mutation changes an evolutionary highly conserved amino acid 
(G131S) within the hydrophilic extra-membrane loop of the MTND1 protein. Pathogenicity was confirmed by cybrid studies. ${ }^{3}$ The mutation causes an isolated complex I defect, as well in our patients as in the MELAS patient. Haplotypes differed between the MELAS and LHON and spastic dystonia patients, respectively $\mathrm{H} 1$ and $\mathrm{T}$, but although specific mtDNA haplotypes may confer a higher risk for the expression of certain complex diseases ${ }^{\circ}$, it is unlikely that this is the case and the difference merely indicated that the m.3697G>A mutation occurred independently and are not caused by a common founder. The mutation load (in blood, muscle, fibroblasts) was comparable in the present reported patients and the previous reported MELAS case and can therefore unlikely explain the clinically distinct presentations.

In this report we show that the m.3697G $>A$ mutation can cause LHON or infantile spastic dystonia in sibs, which is different from the previous reported MELAS phenotype. ${ }^{3}$ Both optic atrophy and spastic dystonia are uncommon features for MELAS and in the current cases there were no indications of stroke-like events or mitochondrial accumulation in muscle tissue. Ragged red fibres, which are associated with MELAS, were absent here. Moreover, brain MRI of the MELAS case ${ }^{3}$ showed several lesions of the right thalamus, basal ganglia and bifrontal cortical region while in our patients there were a few punctuate hyperintensities in one case and specific lesions in the putamen in the other. Lactic acidosis, in particular in the CSF, and isolated complex I deficiency, however, are features that are shared among the two families. We conclude that the $\mathrm{m} .3697 \mathrm{C}>\mathrm{A}$ mutation causes an isolated severe complex I defect, leading to lactic acidosis and functional defects in the central nervous system and variable clinical phenotypes.

The combination of spastic dystonia and Leber hereditary optic neuropathy (LHON) (OMIM 500001) is extremely rare and has been reported in only a few unconnected families with a m.14459G>A/ND6 mutation 11-15, 14596T>A/ND6 ${ }^{16}$ mutation or without a mtDNA mutation. 17 It is remarkable that the present LHON and spastic dystonia family shares a very similar clinical presentation with those families. The reported clinical presentation was LHON only, spastic dystonia only or LHON and spastic dystonia ${ }^{12-15,18-19}$. When comparing this present case to the other nine reported LHON and dystonia families ${ }^{12-15}$ the first striking similarities are the bilateral lesions in de basal ganglia, in particular in the putamen, the isolated and severe complex I defect and the extreme clinical variable phenotype within a family. Spastic dystonia has consistently been observed associated with basal ganglia lesions, mainly in the nucleus lentiformis (putamen and globus pallidus). Spastic dystonia develops universally before the age of 5 , and causes a moderate to severe generalized movement disorder sometimes associated with mental retardation. The mutation load might correlate with the phenotype (Figure 2), which has also been reported for most m.14459 families ${ }^{12,14}$ but not in all.13,15 The m.14459G $>$ A mutation occurs in the hydrophilic 
extra-membrane loop of the ND6 protein between the transmembrane helices C and D facing the intermembrane space and the present m.3697G $>\mathrm{A}$ is as well situated in the extramembrane loop between the same transmembrane helices $C$ and $D$ in the ND1 protein, but on the contrary is facing the mitochondrial matrix.

The intrafamilial variation in clinical expression indicates that very likely modifying nuclear factors are involved, playing a role in the clinical expression of mitochondrial disease. A recent report of LHON and dystonia family without a mLDNA mutation but with a severe isolated complex 1 defect 17 is another indication for this. Patients with sporadic focal dystonia have been identified with an isolated complex I defect. Cybrid studies in these families showed that in these cases the complex I defect was not caused by a mtDNA mutation. ${ }^{20}$ These data indicate that prognosis or counseling based on the mtDNA mutation and percentage only is troublesome and should be done with great care. It also means that female carriers have no reliable reproductive option to prevent the birth of a severely affected child. Despite this, we advise that patient with LHON or with LHON without the common LHON mutations, but with complex I deficiency will be screened for additional mutations in the mtDNA, preferably the ND-genes. 


\section{References}

1. Man PY, Griffiths PG, Brown DT, et al. The epidemiology of Leber hereditary optic neuropathy in the North East of England. Am J Hum Genet. 2003;72:333-339.

2. Carelli V, Ross-Cisneros FN, Sadun AA. Mitochondrial dysfunction as a cause of optic neuropathies. Prog Retin Eye Res. 2004;23:53-89.

3. Kirby DM, MCFarland R, Ohtake A, et al. Mutations of the mitochondrial ND1 gene as a cause of MELAS. J Med Genet. 2004;41:784-789.

4. van Eijsden RGE, Gerards $M$, Eijssen $L M$, et al. Chip-based mtDNA mutation screening enables fast and reliable genetic diagnosis of OXPHOS patients. Genetics in Medicine. accepted for publication

5. Srere PA. Citrate synthase. Methods Enzymol. 1969;13:3-11.

6. Scholte HR, Busch HF, Bakker HD, et al. Riboflavin-responsive complex I deficiency. Biochim Biophys Acta. 1995;1271:75-83.

7. Scholte HR, Busch HF, Luyt-Houwen IE, et al. Defects in oxidative phosphorylation. Biochemical investigations in skeletal muscle and expression of the lesion in other cells. J Inherit Metab Dis. 1987;10 Suppl 1:81-97.

8. Trounce IA, Kim YL, Jun AS, Wallace DC. Assessment of mitochondrial oxidative phosphorylation in patient muscle biopsies, lymphoblasts, and transmitochondrial cell lines. Methods Enzymol. 1996;264:484-509.

9. Finnila S, Lehtonen MS, Majamaa K. Phylogenetic network for European mtDNA. Am J Hum Genet. 2001;68:1475-1484.

10. Forster $\mathrm{P}$, Harding R, Torroni A, Bandelt HJ. Origin and evolution of Native American mtDNA variation: a reappraisal. Am J Hum Genet. 1996;59:935-945.

11. Watanabe M, Mita S, Takita T, et al. Leber's hereditary optic neuropathy with dystonia in a Japanese family. J Neurol Sci. 2006;243:31-34.

12. Jun AS, Brown MD, Wallace DC. A mitochondrial DNA mutation at nucleotide pair 14459 of the NADH dehydrogenase subunit 6 gene associated with maternally inherited Leber hereditary optic neuropathy and dystonia. Proc Natl Acad Sci U S A. 1994;91:6206-6210.

13. Gropman A, Chen TJ, Perng CL, et al. Variable clinical manifestation of homoplasmic G14459A mitochondrial DNA mutation. Am J Med Genet A. 2004;124:377-382.

14. Tarnopolsky MA, Baker SK, Myint $T$, et al. Clinical variability in maternally inherited leber hereditary optic neuropathy with the G14459A mutation. Am J Med Genet A. 2004;124:372-376.

15. Shoffner JM, Brown MD, Stugard C, et al. Leber's hereditary optic neuropathy plus dystonia is caused by a mitochondrial DNA point mutation. Ann Neurol. 1995;38:163-169. 
16. De Vries DD, Went $L N$, Bruyn GW, et al. Genetic and biochemical impairment of mitochondrial complex I activity in a family with Leber hereditary optic neuropathy and hereditary spastic dystonia. Am J Hum Genet. 1996;58:703-711.

17. Abu-Amero KK, Bosley TM, Bohlega S, McLean D. Complex I respiratory defect in LHON plus dystonia with no mitochondrial DNA mutation. $\mathrm{Br} J$ Ophthalmol. 2005;89:1380-1381.

18. Novotny EJ, Jr., Singh G, Wallace DC, et al. Leber's disease and dystonia: a mitochondrial disease. Neurology. 1986;36:1053-1060.

19. Watanabe M, Mita S, Takita T, et al. Leber's hereditary optic neuropathy with dystonia in a Japanese family. J Neurol Sci. 2005

20. Schapira AH. Human complex I defects in neurodegenerative diseases. Biochim Biophys Acta. 1998;1364:261-270. 


\title{
Nuclear genetic factors chapter 9
}

\author{
Clinical expression of \\ Leber hereditary optic \\ neuropathy is affected \\ by the mitochondrial DNA \\ haplogroup background
}

G. Hudson, V.Carelli, L. Spruijt, M. Gerards, C. Mowbray, A. Achilli, A. Pyle, J. Elson, N. Howell, C. La Morgia, M. Valentino, K. Huoponen, M. Savontaus, E. Nikoskelainen, A. Sadun, S.Salomao, R. Belfort Jr, P. Griffiths, P. Man, I.F de Coo, R. Horvath, M. Zeviani, H. Smeets, A. Torroni, P. Chinnery.

Am J Hum Genet, 2007, 81(2): 228-33. 


\section{Summary}

Leber hereditary optic neuropathy (LHON) is primarily due to point mutations of mitochondrial DNA (mtDNA), but the incomplete penetrance implicates additional genetic and/or environmental factors in the pathophysiology of the disorder. Both the m.11778G $>\mathrm{A}$ and m.14484T >C LHON mutations are preferentially found on a specific mtDNA genetic background, but not $\mathrm{m} .3460 \mathrm{G}>\mathrm{A}$. However, there is no clear evidence that any background influences clinical penetrance of either mutation. By studying 3613 subjects from 159 LHON pedigrees we show that the risk of visual failure is greater when the m.11778G $>A$ or m.14484T $C$ mutations are present on specific subgroups of haplogroup $J\left(J_{2}\right.$ for $m .11778 \mathrm{G}>\mathrm{A}$ and $\mathrm{J} 1$ for m.14484T $>C$ ), and also when the $m .3460 G>A$ is present on a haplogroup $K$. By contrast, the risk of visual failure is significantly less when the $\mathrm{m} .11778 \mathrm{G}>\mathrm{A}$ occurs on haplogroup $H$. Substitutions on MTCYB provide an explanation for these findings, which demonstrate that common genetic variants have a marked effect on the expression of an ostensibly monogenic mtDNA disorder. 


\section{Introduction}

Leber hereditary optic neuropathy (LHON, MIM 535000) is a common cause of maternally inherited visual failure affecting at least ' in 14,000 males. LHON typically presents in young adult life with dyschromatopsia followed by a subacute painless loss of vision in one eye, with symptoms developing in the other eye 6-12. weeks after the initial onset. In over $95 \%$ of cases LHON is primarily due to one of three point mutations of mitochondrial DNA (mtDNA) which affect genes coding for different subunits of complex I of the mitochondrial respiratory chain: $m .3460 G>A$ in MTND1, m.11778G $>A$ in MTND4 and m.14484T $>C$ in MTND64. However, not all individuals who inherit a "primary" LHON mtDNA mutation will develop the optic neuropathy, indicating that additional environmental or genetic factors are important in the etiology of the disorder. $3,5,6$

Numerous anecdotal reports have linked the onset of blindness with various environmental insults, including excess alcohol and smoking. ${ }^{78}$ In addition, the analysis of large pedigrees followed over decades suggests that the penetrance of the primary LHON mutations may be decreasing in some families, possibly through an improved diet and reduced tobacco and alcohol consumption. However, rigorous cross-sectional epidemiological studies reached different conclusions, and the role of environmental agents has yet to be established.

By contrast, evidence supporting an additional genetic influence is more compelling. Although the majority of individuals with LHON only inherit mutated mtDNA from their mother, and thus are homoplasmic for the primary mtDNA LHON mutation, some subjects harbor a mixture of mutated and wild-type mtDNA (heteroplasmy). 1,4 Retrospective studies suggest that the risk of visual failure is reduced in family members with $<60 \%$ mutated mtDNA in blood. "12 Heteroplasmy cannot, however, explain the marked gender bias in LHON, with a predominance of affected males. Segregation analysis is consistent with an interacting recessive $X$-chromosomal locus in some families, which is supported by the results of genetic linkage analysis implicating a $-6 \mathrm{cM}$ region of the $\mathrm{X}$-chromosome which is likely to contain an interacting nuclear modifier. Finally, there is a well established strong association between the mtDNA genetic background and both the m.11778G $>\mathrm{A}$ and m.14484T $>$ C mutations, but not m.3460G $>$ A. ${ }^{15,16}$

MtDNA is inherited down the maternal line, is highly polymorphic, and can be divided into haplogroups based upon the presence of specific combinations of distinguishing mutations scattered throughout its entire sequence. MtDNAs belonging to the same haplogroup derive by descent from the same ancestral female ancestor as revealed by the sharing of the distinguishing mutational motif. ${ }^{17,18}$

Meta-analysis of the available data has shown that individuals with m.14484T $>C$ are $>27$ fold more likely to belong to Western Eurasian haplogroup $J$ than control subjects, ${ }^{19}$ and 
that individuals with $\mathrm{m} .11778 \mathrm{G}>\mathrm{A}$ are $>3$ fold more likely to belong to haplogroup $\mathrm{J}$ than controls. This has been observed in different Western Eurasian populations, in genetically distinct pedigrees, indicating that this is not a founder effect. ${ }^{15,20}$ The reasons for the association are not clear, but it may relate to functional variants in the MTCYB gene interacting synergistically with the primary LHON mutation leading to further compromise of complex I activity. ${ }^{21}$ If this is the case, then the clinical penetrance of both the m.11778G $>\mathrm{A}$ and $\mathrm{m} .14484 \mathrm{~T}>\mathrm{C}$ mutations should be increased on a haplogroup J background - but this hypothesis has not been formally tested. Intriguingly, in one pedigree $\mathrm{m} .14484 \mathrm{~T}>\mathrm{C}$ had a low penetrance on a haplogroup $H$ background, ${ }^{9}$ raising the possibility that other mtDNA haplogroups might alter penetrance of the primary LHON mutations in a mutation-specific manner.

The three primary LHON mutations were identified almost two decades ago, but despite major advances in our understanding of the molecular pathophysiology of LHON, clinical management has largely remained the same. Molecular genetic testing and genetic counseling based upon empirical recurrence risks has changed little in the last decade. Given the potential role of mtDNA haplotypes in the penetrance of LHON we carried out a multi-center study of 3613 subjects from 159 different families transmitting m.3460G $>A, m .11778 \mathrm{G}>\mathrm{A}$ and m.14484T>C. By defining the role of each haplogroup in LHON, we would hopefully improve the accuracy of genetic counseling in LHON, and also advance our understanding of mtDNA genetic variation and its role in complex disease. Using this approach we also formally explored the possibility that the penetrance of LHON is changing over time.

\section{Methods}

Pedigrees were identified through a pan-European collaboration and anonymously entered onto a central database. To minimize ascertainment bias we did not analyze singleton cases (i.e. pedigrees with one affected individual). Extensive pedigree analysis was carried out in each center. Sibships were only included if there was one affected individual and/or the mother harbored a primary LHON mtDNA mutation. The clinical phenotype was determined by a local ophthalmologist. Unaffected individuals had no visual symptoms. Previous studies have only included unaffected subjects if they had no symptoms over a specific age (typically 30 years, given the median age of visual failure in LHON is $\sim 24$ years). This would, however, introduce an ascertainment bias into a study of this type, as only affected individuals <30 years old would be included, elevating the penetrance value. We therefore included all subjects, irrespective of age, in order to assess the life-time penetrance of the disorder. The primary aim of this study was to determine the effect of mtDNA haplogroups on clinical penetrance, and 
we had no a priori reason to think that this would be influenced by the age of subjects.

The diagnosis was confirmed in affected individuals by direct sequencing of the MTND genes or PCR-RFLP analysis. For the purposes of this study we did not accurately quantify heteroplasmy, and only classified sib-ships as either homoplasmic if the mother was shown to be homoplasmic by an established technique, or heteroplasmic if one member of the nuclear family had been shown to be heteroplasmic. Retrospective analysis omitting the heteroplasmic sibships did not influence the overall conclusions. MtDNA haplogroup analysis was performed either by PCR-RFLP analysis or by direct sequencing of the mIDNA coding or control regions. ${ }^{16}$ Haplogroup I sub-analysis was performed by direct sequencing across nucleotide positions (nps) 3010 (3010A in J1) and $15257\left(15257 \mathrm{~A}\right.$ in J2) as described. ${ }^{21}$ We identified 3613 individuals harboring a primary LHON mutation ( $m .11778 \mathrm{G}$ ) A, $n=2104$, $58.2 \% ; m .14484 T>C, n=851,23.6 \% ; m .3460 G>A, n=658,18.2 \%)$, from 159 genealogically independent pedigrees ( $m .11778 \mathrm{G}>\mathrm{A}, \mathrm{n}=90,56.6 \% ; \mathrm{m} .14484 \mathrm{~T}>\mathrm{C}, \mathrm{n}=33,20.8 \% ; \mathrm{m} .3460 \mathrm{G}>\mathrm{A}$, $n=36,22.6 \%) .48 .9 \%$ of the subjects were male $(95 \% \mathrm{Cl}=47.3-50.6)$. These proportions are in concordance with other published smaller series. ${ }^{4}$ The mtDNA haplogroup distribution for each mtDNA LHON mutation is shown in table 1 , and reflects the well-established over-representation of haplogroup $J$ in European LHON pedigrees. The complete data set is shown in supplementary table 1 on-line. The gender was not known for four subjects who all belonged to the same m.11778G $\mathrm{A}$ haplogroup $\mathrm{H}$ family. $4.6 \%$ of sib-ships harbored at least one heteroplasmic individual.

Binary logistic regression was used to determine simultaneously which variables influence the risk of developing visual failure across the whole cohort. This approach reduces the chance of type I error (false positive) and controls for differences in the frequency of key variables between the different groups. Visual failure was the dependent variable in the model, with the following independent categorical variables: gender, primary LHON mtDNA mutation (modeled as a single categorical variable), presence of heteroplasmy, and mtDNA haplogroup. Since each haplogroup is an independent categorical variable associated with a different cluster of haplotype-specific polymorphisms, we introduced each haplogroup separately into the regression equation whilst including all of the other potential confounding variables. We only studied haplogroups present at $>1 \%$ frequency across the whole study group in keeping with the "rule of thumb" whereby logistic regression should only be carried out when the number of study subjects is one order of magnitude greater than the number of parameters under study. To test the hypothesis that the penetrance of primary LHON mutations has decreased over the generations, we coded the present generation 1 , and previous generations $2,3,4 . . . n$ thus allowing us to include sib-ship generation as a continuous variable in the logistic regression model. If the penetrance of LHON were changing with subsequent generations, the model would identify a significant direct correlation between penetrance and generation number.

116 


\section{Results}

Before studying the mtDNA haplogroups, we initially investigated the effects of the other variables on the risk of visual failure (Table 2). As expected, the strongest predictor of visual failure was male gender, which was associated with a 5.41 fold increased risk of blindness when compared to females. In addition, mtDNA heteroplasmy was associated with a 0.37 fold reduced risk of visual failure when compared to homoplasmic pedigrees. By contrast, there was no difference in the risk of visual failure for the different LHON mtDNA mutations $(P=0.70)$, nor any evidence to support a change in penetrance in different generations $(P=0.26)$.

Given the well established mutation-specific association with mtDNA haplogroup J, ${ }^{19}$ we studied the effect of common mtDNA haplogroups on the risk of visual failure for each LHON mtDNA mutation separately (Table 3 for the results of the logistic regression, supplementary table 1 for the complete data set). For $m .11778 \mathrm{G}>\mathrm{A}$, the risk of visual failure was increased on pedigrees with a haplogroup J background $(P=0.02$, odds ratio, $O R=1.31,95 \%$ confidence interval, $\mathrm{Cl}=1.03-1.65)$, but reduced in pedigrees with a haplogroup $\mathrm{H}(\mathrm{P}=0.04$, $O R=0.79,95 \% \mathrm{Cl}=0.63-0.98)$ background. For $\mathrm{m} .3460 \mathrm{G}>\mathrm{A}$, the risk of visual failure was increased in pedigrees with a haplogroup $K$ background $(P=2.35 \times 10-3)$.

We were initially surprised that the analysis did not identify an association between m.14484T $>C$ and haplogroup J (Table 3). However, the lack of increased risk of visual failure among the 840 subjects with $\mathrm{m} .14484 \mathrm{~T}>\mathrm{C}$ on haplogroup $\mathrm{J}$ is most likely to be a consequence of the virtual absence of non-J pedigrees (only 11 subjects, $\sim 1 \%$, Table 1). Taking into account that haplogroup $J$ frequencies range between $3 \%$ and $15 \%$ in European populations, ${ }^{22}$ the $99 \%$ frequency of m.14484T>C on J mtDNAs observed in this study (Table 1) strongly suggests that the clinical penetrance of the $\mathrm{m} .14484 \mathrm{~T}>\mathrm{C}$ mutation is close to zero when occurring on European mtDNA backgrounds other than J. The m.14484T $>C$ mutation and the pedigrees in which it occurs remain undetected simply because LHON do not show up in the family when the mtDNA belong to a non-J haplogroup. This scenario is for supported by the finding of an U8b mtDNA harboring the m.14484T $>C$ mutation in the course of a random survey of $U$ mtDNAs from healthy subjects. ${ }^{23}$ Moreover, recent work has also shown that the preferential association between m.14484T $>$ C LHON pedigrees and $J$ is largely attributable to $J_{7}$ - a specific subgroup of haplogroup $J$. We therefore compared the clinical penetrance of the m.14484T $>C$ mutation on the $\mathrm{J}^{21}$ background $v$ s that on the $\mathrm{J} 2$ background. We observed a 1.85 fold increased risk of visual failure for $\mathrm{J} 1$ relative to $J_{2}(P=2.3 \times 10-2,95 \% \mathrm{Cl}$ for $\mathrm{OR}=1.09-3.15)$ in agreement with the observation that $28.3 \%$ of the $J_{1}$ subjects vs only $14.5 \%$ of the $J_{2}$ subjects are clinically affected (Table 1 ). The same kind of comparison ( $J_{2}$ vs $J_{1}$ ) was performed for the $m .11778 \mathrm{G}>\mathrm{A}$ mutation. In this case, the 
situation was just opposite, with $\mathrm{J} 2$ harboring a 1.73 fold increased risk of visual failure $(P=$ $1.7 \times 10-2,95 \% \mathrm{Cl}=1.10-2.72$ ) relative to $\mathrm{J}_{1}$.

\section{Discussion}

By studying 3613 individuals from 159 pedigrees we provide the first clear evidence that different mtDNA haplogroups influence the clinical penetrance of the three primary LHON mtDNA mutations. We made four principal observations: (1) the penetrance of m.14484T>C is increased on a haplogroup $\mathrm{J}$ background, most prominently on the $\mathrm{J} 1$ sub-haplogroup; (2) the penetrance of $\mathrm{m} .11778 \mathrm{G}>\mathrm{A}$ is also increased on a haplogroup J background, but for this mutation, the effect is most prominent on the 12 sub-haplogroup; (3) The penetrance of $\mathrm{m} .11778 \mathrm{G}>\mathrm{A}$ is reduced on a haplogroup $\mathrm{H}$ background; and (4) the penetrance of $\mathrm{m} .3460 \mathrm{G}>\mathrm{A}$ in increased on a haplogroup $\mathrm{K}$ background.

The increased penetrance of $m .14484 T>C$ and $m .11778 \mathrm{G}>A$ on different sub-J haplogroups is in keeping with previous haplogroup association studies reporting an increased frequency of haplogroup $\mathrm{J}_{1}$ in $\mathrm{m} .14484 \mathrm{~T}>\mathrm{C}$ pedigrees and an increased frequency of $\mathrm{J}_{2}$ in $\mathrm{m} .11778 \mathrm{G}>\mathrm{A}$ pedigrees. ${ }^{21}$ It is, however, most intriguing that closely related sub-haplotypes appear have different effects on the two most common LHON mtDNA mutations. For m.3460G>A, the most striking novel finding was the marked increased risk of visual failure on the haplogroup $\mathrm{K}$ background. This was not apparent in m.11778G $>$ A pedigrees, despite there being a greater number of subjects (Table 1). In keeping with this, haplogroup $K$ subjects were over-represented in the $\mathrm{m} .3460 \mathrm{G}>\mathrm{A}$ group $(11 \%$, which is greater than the frequency in most published European datasets). The m.3460G>A mutation was the least common in our sample ( $18 \%$ of subjects), and some haplogroups were not represented (Table 1 ), limiting statistical power and our ability to confidently interpret a slightly tendency towards increased penetrance of $\mathrm{m} .3460 \mathrm{G}>\mathrm{A}$ on haplogroup $\mathrm{J} 2$ and a reduced penetrance on haplogroup $\mathrm{H}$. Finally, although the reduced penetrance on a haplogroup $\mathrm{H}$ background has been described in a single m.14484T $>C$ family, this has not been previously described for m.11778G >A. Together, these findings demonstrate that the clinical penetrance of LHON mtDNA mutations depends upon the background mtDNA haplotype, implicating epistatic genetic mechanisms that modulate the biochemical defect of complex 1 that underpins the pathophysiology. How can we explain these observations?

Relative to the root of the superhaplogroup $\mathrm{R}$, haplogroup $\mathrm{H}$ is defined by the synonymous $T 7208 \mathrm{C}$ and $\mathrm{A} 11719 \mathrm{G}$, the non-synonymous $\mathrm{T}_{14766} \mathrm{C}$ in the cytochrome $\mathrm{b}$ gene (cyt $\mathrm{b} / 7 \mathrm{~T}$ ), and the 125 rRNA gene substitution 62706A. ${ }^{24}$ Polymorphic variation in the mtDNA rRNA genes can alter susceptibility to the organ-specific non-syndromic deafness through a 
gene-environment interaction, and it is conceivable that different polymorphisms in the same gene might reduce susceptibility to environmental precipitants of the acute visual failure in LHON. Alternatively, genetic variation in the MTCYB gene might be responsible. Recent phylogenetic analysis has shown that MTCYB mutations are over-represented on both $J_{1}$ and $J_{2}$ sub-haplogroups, and that $J_{1} \mathrm{c}$ and $J_{2}$ b are the principal clades responsible for the association with $\mathrm{m} .11778 \mathrm{G}>\mathrm{A}$, while $\mathrm{J} 1$ is associated with $\mathrm{m} .14484 \mathrm{~T}>\mathrm{C}$. In addition to the 15452 C $>$ A substitution (MTCYB L2361) common to all haplogroup J mtDNAs, Jic harbors an additional MTCYB substitution (14798T >C / $\mathrm{F}_{18 \mathrm{~L}}$ ), and $\mathrm{J}_{2} \mathrm{~b}$ also carries two additional MTCYB substitutions (15257G>A/D171N and 15812A>G / $356 \mathrm{M}$ ). ${ }^{21}$

Is this explanation consistent with the increased risk of visual failure in m.3460G>A families on a haplogroup $K$ background? The MTND3 10398 reversion is shared by both haplogroups $J$ and $K$ (and $I$ ), and has been proposed as the functional variant responsible for the decreased risk of Parkinson's disease associated with these two haplogroups. ${ }^{26,27}$ However, like J1C, haplogroup $\mathrm{K}$ is defined by MTCYB 14798T>C / F18L, in keeping with the MTCYB hypothesis explaining the haplogroup associations in LHON. ${ }^{21}$ Although the association with MTCYB substitutions could be a chance finding, ${ }^{21}$ recent evidence supporting the existence of super complexes, consisting of complex I and dimeric complex $111,{ }^{28}$ raises the possibility that genetic variation in MTCYB might alter complex I function, possibly by destabilizing the assembled super-complex. ${ }^{29}$ Differences in the amino acid sequence of both cyt $b$ (through sub-haplogroup specific polymorphisms), ND1, ND4 and ND6 (through primary LHON mutations) could alter the known physical interaction between complex I and III, ${ }^{30}$ leading to the loss of complex I activity, as has been observed in a patient with a MTCYB mutation. ${ }^{31-34}$ Likewise, it is also conceivable that the I-III super-complex could be relatively stabilized by specific cyt $b$ substitutions (in haplogroup $H$ ), although there is no experimental data to support this possibility at present.

Differences in the size of individual pedigrees is one possible confounding factor in a study of this kind. To minimize ascertainment bias, we excluded singleton cases from this study. In addition, for the major haplogroup-effects we obtained the same result when the study population was subdivided into small pedigrees (2-5 generations) or large pedigrees (>5 generations). The lack of a clear relationship between penetrance and the pedigree generation is surprising, especially given the size of this study and the extensive clinical data from a large number of generations. Given the major improvement in the socio-economic scene in Europe and a corresponding improvement in nutritional status, this implies that a simple improvement in these variables is unlikely to reduce the penetrance of LHON. This, and other studies, 10 highlight the difficulty in establishing a link with major environmental precipitants.

Given the marked geographic variation in specific mtDNA sub-haplogroups, it is conceivable that an association may be important in one country but not another. For example, the 
absence of $\mathrm{J}_{1 \mathrm{C}}$ from the Iranian population probably explains why the association between LHON and haplogroup $J$ is not seen in Iran. ${ }^{21}$ This poses a challenge when it comes to genetic counseling, and highlights the importance of carrying out further studies to determine the basis of the varied penetrance. We have shown a number of variables modulate the clinical expression of LHON, and smaller studies should be interpreted with great caution because of the possibility of confounding factors. Defining these factors will, however, have a major impact in the clinical management of families transmitting this disorder.

\section{Acknowledgements}

PFC is a Wellcome Trust Senior Fellow in Clinical Science who also receives funding from the United Mitochondrial Diseases Foundation, and the EU FP program EUmitocombat and MITOCIRCLE. This research received support also from the Italian Ministry of the University (Progetti Ricerca Interesse Nazionale 2005) (to A.T.), Fondazione Cariplo (to A.T.).

\section{Web Resources}

URLS for data presented herein are as follows:

Online Mendelian Inheritance in Man (OMIM), http://www.ncbi.nlm.nih.gov/Omim/

Table 1. Haplogroup Frequencies for the 3613 Subjects with the $11778 G>A, 14484 T>C$, m.3460G $>A$ Mutations. w/o = without

\begin{tabular}{|c|c|c|c|c|}
\hline MtDNA haplogroup & $\begin{array}{l}11778 G>A \\
\text { No. }(\%)\end{array}$ & $\begin{array}{l}14484 T>C \\
\text { No. (\%) }\end{array}$ & $\begin{array}{l}3460 G>A \\
\text { No. }(\%)\end{array}$ & $\begin{array}{l}\text { Total } \\
\text { No. (\%) }\end{array}$ \\
\hline$H$ & $927(44)$ & $2(<1)$ & $307(47)$ & $1236(34)$ \\
\hline J & $593(28)$ & $840(99)$ & $169(26)$ & $1602(44)$ \\
\hline K & $101(5)$ & - & $75(11)$ & $176(5)$ \\
\hline$M$ & $3(<1)$ & - & - & $3(<1)$ \\
\hline $\mathrm{T}$ & $87(4)$ & - & - & $87(2)$ \\
\hline$U(W / O K)$ & $184(9)$ & - & $27(4)$ & $211(6)$ \\
\hline V & - & - & $41(6)$ & $41(1)$ \\
\hline W & $11(<1)$ & - & - & $11(<1)$ \\
\hline$x$ & $135(6)$ & $9(1)$ & - & $144(4)$ \\
\hline Other & $63(3)$ & - & $39(6)$ & $102(3)$ \\
\hline Total & 2104 & 851 & 658 & 3613 \\
\hline
\end{tabular}

aThere were no haplogroup I families. 
Table 2. Major Factors Influencing the Clinical Penetrance of the $11778 G>A, 14484 T>C, 3460 G>A$ Mutations in 3613 Subjects

\begin{tabular}{|l|l|l|l|l|}
\hline Variable & Significance $(\mathrm{P})$ & Odds ratio & \multicolumn{2}{|l|}{$\begin{array}{l}95 \% \text { confidence } \\
\text { intervals for odds ratio }\end{array}$} \\
\cline { 3 - 5 } & & & Lower & Upper \\
\hline Gender & $9.27 \times 10-76$ & 5.41 & 4.52 & 6.48 \\
LHON mutation & 0.70 & & & \\
Heteroplasmy & $1.37 \times 10-4$ & 0.37 & 0.22 & 0.62 \\
Pedigree generation & 0.26 & 0.97 & 0.90 & 1.01 \\
Constant & $6.80 \times 10-24$ & 0.05 & & \\
\hline
\end{tabular}

Table 3. Effect of mtDNA Haplogroups on the Clinical Penetrance: (a) $11778 G>A$, (b) $14484 T>C$, (c) m.3460G>A. Binary logistic regression model with visual failure as the dependent variable. The following independent variables we included in each model: gender, presence of heteroplasmy, generation of the pedigree (see legend to Table 1). The effect of the major European mtDNA haplogroups was modeled in turn, adding each sequentially to the logistic regression equation. No $14484 T>C$ pedigrees belonged to haplogroups $K, T$ and $U$, and no $m .3460 G>A$ pedigrees belonged to haplogroup $T$ or $X . w / O=$ without

(a)

$11778 G>A$

\begin{tabular}{|c|c|c|c|c|}
\hline \multirow[t]{2}{*}{$\begin{array}{l}\text { MtDNA } \\
\text { Haplogroup }\end{array}$} & \multirow[t]{2}{*}{ Significance (P) } & \multirow[t]{2}{*}{ Odds ratio } & \multicolumn{2}{|c|}{$\begin{array}{l}95 \% \text { confidence } \\
\text { intervals for odds ratio }\end{array}$} \\
\hline & & & Lower & Upper \\
\hline $\mathrm{H}$ & 0.04 & 0.79 & 0.63 & 0.98 \\
\hline$」$ & 0.02 & 1.31 & 1.03 & 1.65 \\
\hline K & 0.97 & 0.99 & 0.60 & 1.63 \\
\hline $\mathrm{T}$ & 0.31 & 1.30 & 0.79 & 2.14 \\
\hline $\mathrm{U}(\mathrm{w} / \mathrm{o} \mathrm{K})$ & 0.59 & 1.11 & 0.76 & 1.60 \\
\hline $\mathrm{X}$ & 0.05 & 0.62 & 0.39 & 1.0 \\
\hline
\end{tabular}


(b) 14484T>C

\begin{tabular}{|c|c|c|c|c|}
\hline \multirow[t]{2}{*}{$\begin{array}{l}\text { MtDNA } \\
\text { Haplogroup }\end{array}$} & \multirow[t]{2}{*}{ Significance $(P)$} & \multirow[t]{2}{*}{ Odds ratio } & \multicolumn{2}{|c|}{$\begin{array}{l}95 \% \text { confidence } \\
\text { intervals for odds ratio }\end{array}$} \\
\hline & & & Lower & Upper \\
\hline$H$ & 1.0 & $1.49 \times 10-9$ & 0 & - \\
\hline J & 0.40 & 2.06 & 0.40 & 10.66 \\
\hline$x$ & 0.60 & 0.64 & 0.12 & 3.53 \\
\hline
\end{tabular}

(c) $3460 G>A$

\begin{tabular}{|l|l|l|l|l|}
\hline MtDNA & Significance $(P)$ & \multirow{2}{*}{ Odds ratio } & \multicolumn{2}{|l|}{$\begin{array}{l}95 \% \text { confidence } \\
\text { intervals for odds ratio }\end{array}$} \\
\cline { 4 - 5 } & & & Lower & Upper \\
\hline$H$ & 0.14 & 0.72 & 0.47 & 1.11 \\
$J$ & 0.34 & 1.24 & 0.80 & 1.90 \\
K & $2.35 \times 10-3$ & 2.37 & 1.36 & 4.13 \\
U (w/o K) & 0.60 & 0.76 & 0.27 & 2.10 \\
\hline
\end{tabular}

Table 4. Effect of Sub-Haplogroups $/ 1$ and $J_{2}$ on the Penetrance of the $11778 G>A, 14484 T>C, 3460 G>A$ Mutations

Binary logistic regression model with visual failure as the dependent variable. The following independent variables we included in each model: gender, presence of heteroplasmy, generation of the pedigree (see legend to Table 1). The effect of the sub-haplogroups $/ 1$ and $J_{2}$ were studied independently.

\begin{tabular}{|l|l|l|l|l|l|}
\hline LHON mutation & $\begin{array}{l}\text { MtDNA sub- } \\
\text { haplogroup }\end{array}$ & Significance (P) & Odds ratio & \multicolumn{2}{|l|}{$\begin{array}{l}95 \% \text { confidence } \\
\text { intervals for odds ratio }\end{array}$} \\
\cline { 3 - 6 } $11778 \mathrm{G}>\mathrm{A}$ & $\mathrm{J} 1$ & 0.72 & 1.05 & 0.80 & 1.37 \\
& $\mathrm{~J} 2$ & $1.0 \times 10-3$ & 1.89 & 1.29 & 2.75 \\
$14484 \mathrm{~T}>\mathrm{C}$ & $\mathrm{J} 1$ & $1.5 \times 10-2$ & 1.88 & 1.13 & 3.14 \\
& $\mathrm{~J} 2$ & $2.6 \times 10-2$ & 0.55 & 0.32 & 0.93 \\
$3460 \mathrm{G}>\mathrm{A}$ & $\mathrm{J} 1$ & 0.90 & 0.96 & 0.58 & 1.60 \\
& $\mathrm{~J} 2$ & 0.10 & 1.68 & 0.90 & 3.13 \\
\hline
\end{tabular}




\section{References}

1. Man, PY, Griffiths, PG, Brown, DT, Howell, N, Turnbull, DM, and Chinnery, PF (2003). The epidemiology of Leber hereditary optic neuropathy in the North East of England. Am J Hum Genet 72, 333-339.

2. Nikoskelainen, EK (1994). Clinical picture of LHON. Clin Neurosci 2, 115-120.

3. Newman, NJ (2002). From genotype to phenotype in Leber hereditary optic neuropathy: still more questions than answers. J Neuroophthalmol. 22, 257-261.

4. Harding, AE, Sweeney, MG, Govan, GG, and Riordan-Eva, P (1995). Pedigree analysis in Leber hereditary optic neuropathy families with a pathogenic mtDNA mutation. Am J Hum Genet $57,77^{-86}$.

5. Howell, $N$ (1999). Human mitochondrial diseases: answering questions and questioning answers. Int Rev Cytol 186, 49-116.

6. Carelli, V, Ross-Cisneros, FN, and Sadun, AA (2004). Mitochondrial dysfunction as a cause of optic neuropathies. Prog Retin Eye Res 23, 53-89.

7. Tsao, K, Aitken, PA, and Johns, DR (1999). Smoking as an aetiological factor in a pedigree with Leber's hereditary optic neuropathy. $\mathrm{Br} J$ Ophthalmol 83, 577-581.

8. Sadun, F, De Negri, AM, Carelli, V, Salomao, SR, Berezovsky, A, Andrade, R, Moraes, $M$, Passos, $A$, Belfort, $R$, and da Rosa, $A B$, et al. (2004). Ophthalmologic findings in a large pedigree of 11778/haplogroup J Leber hereditary optic neuropathy. Am J Ophthalmol 137, 271-277.

9. Howell, N, Herrnstadt, C, Shults, C, and Mackey, DA (2003). Low penetrance of the 14484 LHON mutation when it arises in a non-haplogroup J mtDNA background. Am J Med Genet A 119, 147-151.

10. Kerrison, JB, Miller, NR, Hsu, F, Beaty, TH, Maumenee, IH, Smith, KH, Savino, PJ, Stone, $E M$, and Newman, NJ (2000). A case-control study of tobacco and alcohol consumption in Leber hereditary optic neuropathy. Am J Ophthalmol 130, 803-812.

11. Smith, KH, Johns, DR, Heher, KL, and Miller, NR (1993). Heteroplasmy in Leber's hereditary optic neuropathy. Arch Ophthalmol 111, 1486-1490.

12. Chinnery, PF, Andrews, RM, Turnbull, DM, and Howell, N (2001). Leber's hereditary optic neuropathy: does heteroplasmy influence the inheritance and expression of the G11778A mitochondrial DNA mutation?. Am J Med Genet 98, 235-243.

13. Bu, X, and Rotter, Jl (1991). X chromosomal-linked and mitochondrial gene control of Leber hereditary optic neuropathy: evidence from segregation analysis for dependence on X-chromosome inactivation. Proc Natl Acad Sci USA 88, 8198-8202.

14. Hudson, G, Keers, S, Man, PY, Griffiths, P, Huoponen, K, Savontaus, M-L, Nikoskelainen, E, Zeviani, M, Carrara, F, and Horvath, R, et al. (2005). Identification of an X-chromosomal 
locus and haplotype modulating the phenotype of a mitochondrial DNA disorder. Am J Hum Genet 77, 1086-1091.

15. Brown, MD, Sun, F, and Wallace, DC (1997). Clustering of Caucasian Leber hereditary optic neuropathy patients containing the 11778 or 14484 mutations on an mtDNA lineage. Am J Hum Genet 60, 381-387.

16. Torroni, A, Petrozzi, M, D'Urbano, L, Sellitto, D, Zeviani, M, Carrara, F, Carducci, C, Leuzzi, V, Carelli, V, and Barboni, P, et al. (1997). Haplotype and phylogenetic analyses suggest that one European-specific mtDNA background plays a role in the expression of Leber hereditary optic neuropathy by increasing the penetrance of the primary mutations 11778 and 14484. Am J Hum Genet 60, 1107-1121.

17. Wallace, DC (1994). Mitochondrial DNA sequence variation in human evolution and disease. Proc Natl Acad Sci USA 91, 8739-8746.

18. Torroni, A, Achilli, A, Macaulay, V, Richards, M, and Bandelt, $\mathrm{HJ}$ (2006). Harvesting the fruit of the human mtDNA tree. Trends Genet 22, 339-345.

19. Man, PY, Howell, N, Mackey, DA, Norby, S, Rosenberg, T, Turnbull, DM, and Chinnery, PF (2004). Mitochondrial DNA haplogroup distribution within Leber hereditary optic neuropathy pedigrees. I Med Genet 41, e41.

20. Torroni, A, Carelli, V, Petrozzi, M, Terracina, M, Barboni, P, Malpassi, $P$, Wallace, DC, and Scozzari, $R$ (1996). Detection of the mtDNA 14484 mutation on an African-specific haplotype: implications about its role in causing Leber hereditary optic neuropathy. Am J Hum Genet 59, 248-252.

21. Carelli, V, Achilli, A, Valentino, ML, Rengo, C, Semino, O, Pala, M, Olivieri, A, Mattiazzi, $M$, Pallotti, F, and Carrara, F, et al. (2006). Haplogroup effects and recombination of mitochondrial DNA: novel clues from the analysis of Leber hereditary optic neuropathy pedigrees. Am J Hum Genet 78, 564-574.

22. Achilli, A, Olivieri, A, Pala, M, Metspalu, E, Fornarino, S, Battaglia, V, Accetturo, M, Kutuev, I, Khusnutdinova, E, and Pennarun, E, et al. (2007). Mitochondrial DNA variation of modern Tuscans supports the Near East origin of Etruscans. Am J Hum Genet 80, 759-768.

23. Achilli, A, Rengo, C, Battaglia, V, Pala, M, Olivieri, A, Fornarino, S, Magri, C, Scozzari, R, Babudri, N, and Santachiara-Benerecetti, AS, et al. (2005). Saami and Berbers-an unexpected mitochondrial DNA link.

24. Herrnstadt, C, Elson, JL, Fahy, E, Preston, G, Turnbull, DM, Anderson, S, Ghosh, 5S, Olefsky, J, Beal, MF, and Davis, RE, et al. (2002). Reduced-median-network analysis of complete mtDNA coding-region sequences for the major African, Asian, and European haplogroups. Am J Hum Genet 70, 1152-1171. 
25. Prezant, TR, Agapian, JV, Bohlman, MC, Bu, X, Oztas, S, Qui, W-Q, Arnos, KS, Cortopassi, GA, Jabier, L, and Rotter, Jl, et al. (1993). Mitochondrial ribosomal RNA mutations associated with both antibiotic-induced and non-syndromic deafness. Nat Genet 4 , 289-294.

26. van der Walt, JM, Nicodemus, KK, Martin, ER, Scott, WK, Nance, MA, Watts, RL, Hubble, JP, Haines, JL, Koller, WC, and Lyons, K, et al. (2003). Mitochondrial polymorphisms significantly reduce the risk of Parkinson disease. Am J Hum Genet 72, 804-811.

27. Ghezzi, D, Marelli, C, Achilli, A, Goldwurm, S, Pezzoli, G, Barone, P, Pellecchia, MT, Stanzione, $P, B r u s a, L$, and Bentivoglio, AR, et al. (2005). Mitochondrial DNA haplogroup $K$ is associated with a lower risk of Parkinson's disease in Italians. Eur J Hum Genet 13, 748-752.

28. Dudkina, NV, Eubel, H, Keegstra, W, Boekema, EJ, and Braun, HP (2005). Structure of a mitochondrial supercomplex formed by respiratory-chain complexes I and III. Proc Natl Acad Sci USA 102, 3225-3229.

29. Acin-Perez, R, Bayona-Bafaluy, MP, Fernandez-Silva, P, Moreno-Loshuertos, R, PerezMartos, A, Bruno, C, Moraes, CT, and Enriquez, JA (2004). Respiratory complex 111 is required to maintain complex I in mammalian mitochondria. Mol Cell $13,805-815$

30. Schagger, $\mathrm{H}$, and Pfeiffer, $\mathrm{K}$ (2000). Supercomplexes in the respiratory chains of yeast and mammalian mitochondria. EMBO J 19, 1777-1783.

31. De Coo, IF, Renier, WO, Ruitenbeek, W, Ter Laak, HJ, Bakker, M, Schagger, H, Van Oost, BA, and Smeets, $\mathrm{HJ}$ (1999). A 4-base pair deletion in the mitochondrial cytochrome b gene associated with parkinsonism/MELAS overlap syndrome. Ann Neurol 45, 130-133.

32. Rana, M, de Coo, I, Diaz, F, Smeets, H, and Moraes, CT (2000). An out-of-frame cytochrome $b$ gene deletion from a patient with parkinsonism is associated with impaired complex III assembly and an increase in free radical production. Ann Neurol 48, 774-781.

33. Schagger, $H$, de Coo, R, Bauer, MF, Hofmann, S, Godinot, C, and Brandt, U (2004). Significance of respirasomes for the assembly/stability of human respiratory chain complex I. J Biol Chem 279, 36349-36353.

34. Bruno, C, Santorelli, FM, Assereto, S, Tonoli, E, Tessa, A, Traverso, M, Scapolan, S, Bado, $M$, Tedeschi, S, and Minetti, C (2003). Progressive exercise intolerance associated with a new muscle-restricted nonsense mutation $\left(\mathrm{G}_{142} \mathrm{X}\right)$ in the mitochondrial cytochrome b gene. Muscle Nerve 28, 508-511. 


\section{Chapter 10}

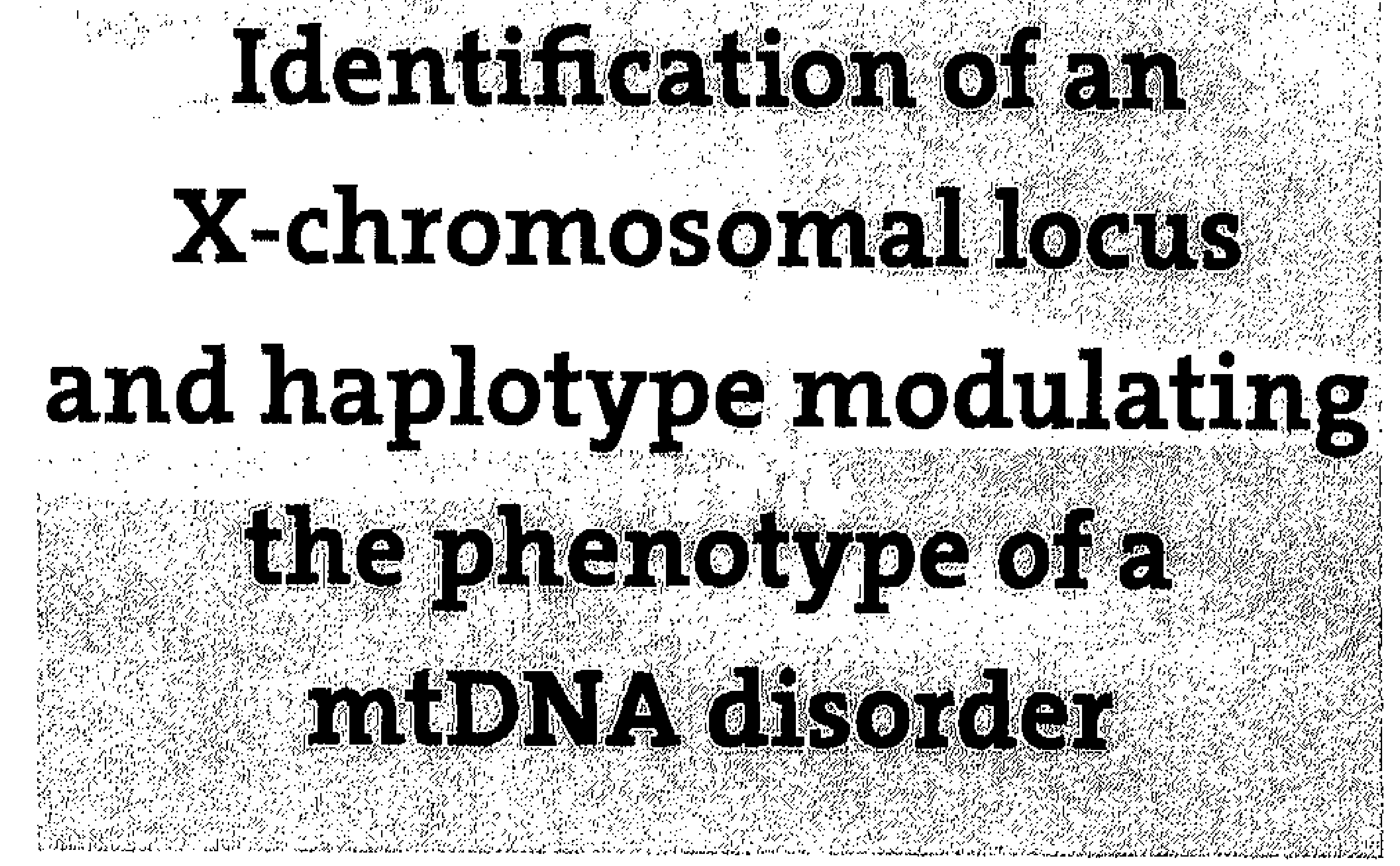

G. Hudson, S. Keers, P. Yu Wai Man, P. Griffiths, K. Huoponen, M.L. Savontaus, E. Nikoskelainen, M. Zeviani, F. Carrara, R. Hovath, V. Karcagi, L. Spruijt, I.F. de Coo, H.J. Smeets, P.F. Chinnery Am J Hum Genet, 2005, 17:1086-1091. 
Mitochondrial DNA (mtDNA) mutations are a major cause of human disease. A large number of different molecular defects ultimately compromise oxidative phosphorylation, but it is not clear why the same biochemical defect can cause diverse clinical phenotypes. There is emerging evidence that nuclear genes modulate the phenotype of primary mtDNA disorders. Here we define an X chromosomal haplotype that interacts with specific MTND mutations to cause visual failure in the most common mtDNA disease, Leber hereditary optic neuropathy. This effect is independent of the mtDNA genetic background, and explains the variable penetrance and gender bias that characterizes this disorder.

Leber hereditary optic neuropathy (LHON, MIM 535000) typically presents in young adult life with sequential bilateral visual failure due to focal degeneration of retinal ganglion cells within the optic nerve (Nikoskelainen et al. 1996; Howell 1997). In 95\% of cases worldwide LHON is due to one of three point mutations of mLDNA in genes that code for complex I of the respiratory chain: m.3460G $>A G>A$ in MTND1, 11778G $>A$ in MTND4 and $14484 T>C$ in MTND6 (Mackey et al. 1996). Only $\sim 50 \%$ of male and $\sim 10 \%$ of female mutation carriers develop symptoms, indicating that additional genetic or environmental factors are required for the phenotypic expression of LHON (Newman 2002). Epidemiological studies have failed to substantiate anecdotal reports of a link with excess alcohol and tobacco (Kerrison et al. 2000), but segregation analyses are consistent with a nuclear-encoded $X$-linked susceptibility allele in some pedigrees (Bu and Rotter 1991; Nakamura et al. 1993). Early attempts to map the locus were inconclusive (Chen et al. 1989; Vilkki et al. 1991; Carvalho et al. 1992), but these studies used widely spaced, often non-informative markers and failed to account for mtDNA heteroplasmy, which can influence the expression of LHON. Later studies were more comprehensive, but exclusion mapping was based upon an $X$-linked recessive model, which cannot explain the segregation pattern in all pedigrees (Mackey 1993), and study size limited the power to exclude a substantial portion of the X-chromosome (Juvonen et al. 1993; Chalmers et al. 1996).

LHON mutations are found in $\sim 1$ in 8,500 of the general population and are inherited down the maternal line (Man et al. 2003). Large multi-generational LHON pedigrees are well recognized, with affected individuals over ten or more generations. It is therefore unlikely that a nuclear modifier locus would be strictly co-inherited with the primary mtDNA mutation throughout the whole pedigree. Given the relative rarity of the primary mtDNA mutation, it is far more likely that the nuclear modifier is common in the general population and moves in and out of the maternal pedigree through random mating between mothers transmitting the LHON mtDNA mutation (who largely remain unaffected), and unrelated male partners not harboring the LHON mLDNA mutation. A nuclear modifier is therefore likely to be one or more ancient genetic variants which may be present at a high frequency 
in the population. We therefore used a non-parametric complex disease mapping strategy to identify the locus.

389 DNA samples were collected from affected and unaffected individuals from $100 \mathrm{LHON}$ families (Finland, $n=6$ families; United Kingdom, $n=23 ;$ italy, $n=54 ;$ Hungary, $n=15 ; 5$ pain, $n=1$; and Slovenia, $n=1$ ). The clinical phenotype was determined by local ophthalmologists. Affected individuals had the characteristic phenotype of LHON, presenting with acute or subacute painless sequential or bilateral visual failure in the presence of an established pathogenic mtDNA mutation, with no other inflammatory, metabolic or structural cause identified. Unaffected individuals had no visual symptoms and were older than the median age of onset for LHON (24 years). The diagnosis was confirmed in affected individuals by direct sequencing of the MTND genes or PCR-RFLP analysis. The percentage heteroplasmy was determined by fluorescent primer extension assay (Man et al. 2003). Only samples with $>70 \%$ mutated mtDNA were included in the linkage study, as this level of mutated mtDNA is associated with the same penetrance as homoplasmic mutated mtDNA (Chinnery et al, 2001a). Subjects were homoplasmic for the following primary LHON mtDNA mutations: $11778 G>A$ ( $n=290$ subjects, $51 \%$ male), $14484 T>C$ ( $n=18,61 \%$ male), m.3460G $>A$ ( $n=75$, $49 \%$ male), $14495 A>C$ ( $n=6,50 \%$ male).

Linkage disequilibrium (LD) blocks are generally larger in young, geographically isolated populations, facilitating low-density linkage mapping of complex traits (Wright et al. 1999). We therefore initially carried out non-parametric linkage (NPL) analysis in six Finnish families. X-chromosome microsatellite analysis was performed using part of the $9 \mathrm{cM} \mathrm{We-}$ ber human genome screening set (Invitrogen, version 10aRG) according to the manufacturer's conditions and sized using a Beckman Coulter CEQ 8000 fluorescent DNA analyzer. NPL was performed using Genehunter v1.3 Markers between DX59896 and DX57127 had multi-point NPL scores >2, identifying a region with a maximal-NPL score of 10.2 between DXS9896 and DXS1068 (Fig. 1a). The region was mapped further with 12 additional markers identified from the UniSTS database, synthesized with a forward fluorescent tag (Proligo) and sized using the same method. Fine mapping confirmed our findings, with a NPL score of $>45$ spanning $1 \mathrm{CM}$ for markers DXS8090, DXS8376, DX57487 (Fig. 1b).

$X$-linked reconstruction-combination transmission/disequilibrium tests (XRCTDT, Horvath et al. 2000) using informative markers confirmed that $2.4 \mathrm{Mb}$ of the Xchromosome flanked by DXS8090 and DXS8016 was being preferentially transmitted to affected male offspring in the Finnish families (Fig $\mathrm{TC}$ ). We then turned to two independent European LHON cohorts. In 30 trios from the European mainland, two markers (DXS1219 and DX58090) showed significant transition disequilibrium with the XRC-TDT, and in 30 British trios, DXS1069 showed significant transition disequilibrium with the XRC-TDT, confirming linkage and association with the same region of the $X$-chromosome (Fig $1 C$ ). Differences in the strength of 
the statistical association between adjacent markers in the different populations is likely to reflect different marker allele frequencies in the different sub-groups.

By comparing microsatellite allele frequencies in 150 European LHON males we identified the major high-risk haplotype defined by DX58090 and DX51068. Thirty seven of the 89 affected men (42\%) had the DXS8090(166)-DXS1068(258) haplotype, compared to only three of 57 unaffected men ( $5 \%$, Fisher's exact $P=0.0001$, odds ratio $12.81,95 \% \mathrm{Cl}=3.72-44.11$ ).

The m.3460G>AA>G is considered to be the most severe molecular defect, with a consistently reduced complex I activity (Howell et al. 1991), a less marked gender bias (Newman et al. 1991; Johns et al. 1993), and no association with the background mtDNA haplotype (Man et al. 2004). We therefore thought a nuclear-mitochondrial interaction would more prominent in non-3460A $>G$ pedigrees. In keeping with this, there was no significant increase in the risk of visual impairment in m.3460G $>A A>G$ males with the DXS8090(166)DXS1068(258) haplotype, but non-3460A>G males were over 35 fold more likely to develop visual failure with DXS809o(166)-DXS1068(258) (Table 1). In contrast to m.3460G>AA>G both $11778 \mathrm{G}>\mathrm{A}$ and $14484 \mathrm{~T}>\mathrm{C}$ are strongly association with mtDNA haplogroup J (Man et al. 2004). We therefore used logistic regression to determine whether the DXS8090(166) DXS1068(258) haplotype exerted its effect independently of haplogroup J status, modeling the effect of the nuclear or mtDNA haplotypes alone, through additive, synergistic or antagonistic interactions. An additive interaction between DX58090(166)-DXS1068(258) and mtDNA haplogroup was the most compelling model (Table 2, supplementary table 1). Non-m.3460G >AA>G males that did not harbor DXS8090(166)-DXS1068(258) and were mtDNA haplogroup J had a $35.1 \%$ risk of visual failure. The presence of either DXS8090(166)DXS1068(258) or not belonging to mtDNA haplogroup J was

associated with a $58.9 \%$ risk of visual failure, but $100 \%$ of individuals who were both $\mathrm{mtD}$ NA haplogroup J and had DXS8090(166)-DXS1068(258) were visually impaired ( $P<0.0001)$. The effect of the nuclear haplotype $(O R=33.84,95 \% \mathrm{Cl}=4.38-261.53)$ was over 10 fold greater than the mtDNA haplotype $(O R=2.45,95 \% \mathrm{Cl}=1.03-5.82)$.

To confirm our observations in males, we turned our attention to female non- 3460A>G subjects. $19.05 \%$ of 107 females were heterozygous for DX58090(166)-DXS1068(258). Given that LHON was $97 \%$ penetrant in non-3460A>G LHON males hemizygous for DXS8090(166)-DXS1068(258), we predicted that $\sim 4$ females would be homozygous for DX5809o(166)-DXS1068(258) and most would also be visually impaired. Five women were homozygous, with four being visually impaired, supporting a recessive haplo-insufficiency model. Molecular testing unaffected maternal relatives in known homoplasmic LHON pedigrees has been of limited clinical use to date, confirming the expected inheritance of the mutation, but not altering well-established recurrence risks. Here we show that identifying DX5809o(166)-DXS1068(258) in hemizygous males or homozygous females, greatly incre- 
ases the chance of visual failure during life. This may be of use in prenatal diagnosis and predictive testing. We also identified a second, less frequent predisposing haplotype in Europeans [DXS1068(258)-DXS8016(218)] present in $14.7 \%$ of males. All males harboring this haplotype were affected (Fisher's exact $P<0.0001$ ), and the majority of these individuals (74\%) also had DXS8090(166) indicating that this was a subgroup of the common disease haplotype. It is possible that diallelic mutation of microsatellites and recombination have generated other, less frequent high-risk marker haplotypes which remain undetected in this study, contributing to marker heterogeneity and confounding previous attempts to map the locus. We therefore performed homozygosity mapping using the 10K SNP microarray (Affymetrix) in four unrelated women with visual failure due to the $11778 \mathrm{~A}>\mathrm{G}$ mutation who had $>3$ male offspring, all of whom were clinically affected. All four individuals were homozygous for SNPs adjacent to the critical region, pointing towards a small common shared haplotype block (supplementary figure). On the other hand, the striking difference between the Finns and the other European subjects points towards allelic heterogeneity at the nuclear visual loss susceptibility locus, and not just the flanking markers. $63 \%$ of affected Finnish men had a high risk haplotype defined by DXS8090(168)-DX51069(262) (P= $0.0259, \mathrm{OR}=7.71,95 \% \mathrm{Cl}=1.28-46.37$ ), found in only $3.7 \%$ of mainland Europeans. Different nuclear alleles may behave in subtly different ways which are specific to particular LHON mtDNA mutation or geographic/ethnic regions.

Epigenetic mechanisms provide an alternative explanation for the reduced penetrance and gender bias in LHON. Although two studies failed to find skewed X-inactivation in the blood (Pegoraro et al. 1996) and ocular tissue (Pegoraro et al. 2003) from affected women with LHON, many imprinted disease genes do not showing X-skewing (Renieri et al. 2003). In families with no known disease, failure to fully correct a maternal imprint leads to the preferential transmission of grandpaternal Xchromosomes to male offspring (Naumova et al. 1998). The inheritance of a partially silenced grandpaternal gene could explain the characteristic penetrance of primary LHON mutations in males, and also explain the further reduced penetrance in women when superimposed on the normal female random inactivation pattern. $X$-chromosomal imprinting has been implicated in a number of common neurodevelopmental diseases (Falls et al. 1999), resulting in "parent of origin" effects. We therefore manually reconstructed the three generational X-chromosomal haplotypes 52 males with homoplasmic LHON mtDNA mutations. Overall we observed the same distortion of transmission of grandpaternal alleles that is well described in control populations (Proportion of grandpaternal alleles $=0.60,95 \% \mathrm{Cl}=0.45-0.73 . \mathrm{P}=0.87$ when compared to control data in Naumova et al. 1998). There was no difference in the frequency of grandpaternal alleles between affected and unaffected male offspring (supplementary table 2), nor affected and unaffected female offspring, suggesting that imprinting is not the principal 
mechanism underpinning the phenotypic variability seen in LHON.

In conclusion, we have identified a region of the X-chromosome containing a high-risk haplotype which explains the reduced penetrance and gender bias that characterizes LHON in the majority of pedigrees. Clarifying the underlying sequence variation is likely to have broader implications for our understanding of nuclearmitochondrial interactions in health and disease, opening new avenues for therapeutic intervention.

\section{Acknowledgements}

PFC is a Wellcome Trust Senior Fellow in Clinical Science. PFC also receives funding from Ataxia (UK), the Alzheimer's Research Trust, the Association Française contre les Myopathies, and the United Mitochondrial Diseases Foundation, and the EU FP program EUmitocombat. PFC, HIMS and IMFdeC are partners in the EU FP6 program MITOCIRCLE. RH and VK share a German-Hungarian Collaborative research grant DFG/436UNG113/153. We are grateful to Mike Gerards, Michael Knapp, Robert Vlietink, Andrew Carothers, and Alan Wright for their advice, and to the clinicians who sent DNA samples and clinical data, particularly Karin Writzl and John Tolmie.

Electronic-Database Information

Accession numbers and URLs for data presented herein are as follows: Online Mendelian Inheritance in Man (OMIM), http://www.ncbi.nIm.nih.gov/Omim (for LHON) UniSTS. http:// www.ncbi.nlm.nih.gov 


\section{References}

1. Bu X, Rotter JI (1991) X chromosomal-linked and mitochondrial gene control of Leber hereditary optic neuropathy: Evidence from segregation analysis for dependence on X-chromosome inactivation. Proc Natl Acad Sci USA 88:8198-8202

2. Carvalho MR, Muller B, Rotzer E, Berninger T, Kommerell G, Blankenagel A, Savontaus ML, Meitinger T, Lorenz B (1992) Leber's hereditary optic neuroretinopathy and the Xchromosomal susceptibility factor: no linkage to DXS7. Hum Hered 42:316-320

3. Chalmers RM, Davis MB, Sweeney MG, Wood NW, Harding AE (1996) Evidence against an X-linked visual loss susceptibility locus in Leber hereditary optic neuropathy. Am J Hum Genet 59:103-108

4. Chen JD, Cox I, Denton MJ (1989) Preliminary exclusion of an X-linked gene in Leber optic atrophy by linkage analysis. Hum Genet 82:203-207

5. Chinnery PF, Andrews RM, Turnbull DM, Howell N (2001a) Leber's hereditary optic neuropathy: does heteroplasmy influence the inheritance and expression of the $G 11778 \mathrm{~A}$ mitochondrial DNA mutation? Am J Med Genet 98:235-243

6. Chinnery PF, Brown DT, Andrews RM, Singh-Kler R, Riordan-Eva P, Lindley J, Applegarth D, Turnbull DM, Howell N (2001b) The Mitochondrial ND6 Gene is a Hotspot for Mutations that Cause Leber's Hereditary Optic Neuropathy. Brain 124:209-218

7. Falls JG, Pulford DJ, Wylie AA, Jirtle RL (1999) Genomic imprinting: implications for human disease. Am J Pathol 154:635-647

8. Horvath S, Laird NM, KnappM (2000) The transmission/disequilibrium test and parentalgenotype reconstruction for X-chromosomal markers. Am J Hum Genet 66:1161-1167

9. Howell N (1997) Leber hereditary optic neuropathy: how do mitochondrial DNA mutations cause degeneration of the optic nerve? J Bioenerget Biomemb 29:165-173

10. Howell N, Bindoff LA, McCullough DA, Kubacka I, Poulton J, Mackey D, Taylor L, Turnbull DM (1991) Leber hereditary optic neuropathy: identification of the same mitochondrial ND1 mutation in six pedigrees. Am J Hum Genet 49:939- 950

11. Johns DR, Heher KL, Miller NR, Smith KH (1993) Leber's hereditary optic neuropathy. Clinical manifestations of the 14484 mutation. Arch Ophthalmol 111:495-498

12. Juvonen V, Vilkki J, Aula P, Nikoskelainen E, Savontaus ML (1993) Reevaluation of the linkage of an optic atrophy susceptibility gene to X-chromosomal markers in Finnish families with Leber hereditary optic neuroretinopathy (LHON) [letter]. Am J Hum Genet 53:289-292

13. Kerrison JB, Miller NR, Hsu F, Beaty TH, Maumenee IH, Smith KH, Savino PJ, Stone EM, Newman NJ (2000) A case-control study of tobacco and alcohol consumption in Leber hereditary optic neuropathy. Am J Ophthalmol 130:803- 812 
14. Mackey D (1993) Blindness in offspring of women blinded by Leber's hereditary optic neuropathy [letter]. Lancet 341:1020-1021 Mackey DA, Oostra RJ, Rosenberg T, Nikoskelainen E, Bronte-Stewart J, Poulton J, Harding AE, Govan G, Bolhuis PA, Norby S (1996) Primary pathogenic mtDNA mutations in multigeneration pedigrees with Leber hereditary optic neuropathy. Am J Hum Genet 59:481-485

15. Man PY, Griffiths PG, Brown DT, Howell N, Turnbull DM, Chinnery PF (2003) The epidemiology of leber hereditary optic neuropathy in the north East of England. Am J Hum Genet 72:333-339

16. Man PY, Howell N, Mackey DA, Norby S, Rosenberg T, Turnbull DM, Chinnery PF (2004) Mitochondrial DNA haplogroup distribution within Leber hereditary optic neuropathy pedigrees. J Med Genet 41:e41

17. Nakamura M, Fujiwara Y, Yamamoto M (1993) The two locus control of Leber hereditary optic neuropathy and a high penetrance in Japanese pedigrees. Hum Genet 91:339-341

18. Naumova AK, Leppert M, Barker DF, Morgan K, Sapienza C (1998) Parental origin dependent, male offspring-specific transmission-ratio distortion at loci on the human $X$ chromosome. Am J Hum Genet 62:1493-1499

19. Newman NJ (2002) From genotype to phenotype in Leber hereditary optic neuropathy: still more questions than answers. J Neuroopthalmol 22:257-261 Newman NJ, Lott MT, Wallace DC (1991) The clinical characteristics of pedigrees of Leber's hereditary optic neuropathy with the 11778 mutation. Am J Ophthalmol 111:750-762

20. Nikoskelainen EK, Huoponen K, Juvonen V, Lamminen T, Nummelin K, Savontaus ML (1996) Ophthalmologic findings in Leber hereditary optic neuropathy, with special reference to mtDNA mutations. Ophthalmology 103:504-514

21. Pegoraro E, Carelli V, Zevianni M, Cortelli P, Montagna P, Barboni P, Angelini C, Hoffman EP (1996) X-inactivation patterns in female Leber's hereditary optic neuropathy patients do not support a strong X-linked determinant. Am J Med Genet 61:356-362

22. Pegoraro E, Vettori A, Valentino ML, Molon A, Mostacciuolo ML, Howell N, Carelli V (2003) X-inactivation pattern in multiple tissues from two Leber's hereditary optic neuropathy (LHON) patients. Am J Med Genet 119:37-40

23. Renieri A, Meloni I, Longo I, Ariani F, Mari F, Pescucci C, Cambi F (2003) Rett syndrome: the complex nature of a monogenic disease. J Mol Med 81:346-354

24. Vilkki J, Ott J, Savontaus ML, Aula P, Nikoskelainen EK (1991) Optic atrophy in Leber hereditary optic neuroretinopathy is probably determined by an Xchromosomal gene closely linked to DXS7 [see comments]. Am J Hum Genet 48:486-491

25. Wright AF, Carothers AD, Pirastu M (1999) Population choice in mapping genes for complex diseases. Nat Genet 23:397-404 
Identification of an X-chromosomal locus and haplotype modulating the phenotype of a mtDNA disorder

Table 1. Frequency of the DXS8090(766)-DXS1068(258) haplotype in European males with different primary LHON mIDNA mutations (British and mainland European data combined). $14495 A>G$ has been described in two LHON families and, like 14484T>C it affects the MTND6 gene and is associated with a good prognosis (Chinnery et al. 2001b). The single 14495A>G family was pooled with the other non-3460A>G LHON pedigrees because to the limited number of $14484 T>C$ and $14495 A>G$ pedigrees. $P=$ Fisher's exact $P . O R=$ odds ratio (corresponding to the risk of visual failure). Although it is possible that limited power explains the lack of an association between DXS8090(166)-DXS1068(258) and visual failure in 3460A>G males, the increased penetrance of LHON in $3460 A>G$ families (62\% of males affected and $29 \%$ of females in this study) suggests that a nuclear modifier locus is less influential in this subgroup.

\begin{tabular}{|c|c|c|c|c|c|}
\hline \multirow[t]{2}{*}{ LHON mIDNA mLtation } & \multirow[t]{2}{*}{ X-chromosomal haplatype } & \multicolumn{2}{|c|}{ Number of malos } & \multirow[t]{2}{*}{$P$} & \multirow{2}{*}{$\begin{array}{l}\text { Oddta ratio } \\
\text { (g5\% Cl) }\end{array}$} \\
\hline & & unafiected & afioclad & & \\
\hline \multirow[t]{2}{*}{$3400 A \times 0$} & Non-QX88080(166)-DX31068(268) & 7 & 8 & 0.86 & 1.75 \\
\hline & DXSS00A(165)-DX81068(258) & 2 & 4 & & $(0.24-12.84$ \\
\hline \multirow[t]{2}{*}{$\operatorname{Nan} 3480 A 20$} & 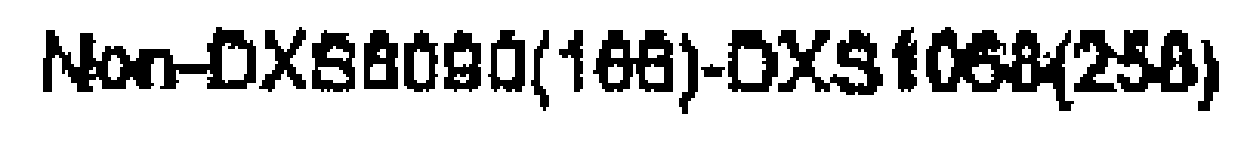 & 47 & 44 & $<0.0001$ & 35.25 \\
\hline & DXSB000(165)-0X81068(256) & 1 & 33 & & $4.82 .268 .00)$ \\
\hline
\end{tabular}

Table 2. Logistic regression model of the effects of mIDNA background haplotype and the DXS8090(766)$D X 51068(258)$ haplotype in males homoplasmic for $11778 A>G, 14484 T>C$ and $14495 A>G$. As expected, the frequency of non-3460A>C haplogroup I pedigrees (23\%) was greater than the European average (found in between 9-14\% of the European populations studied here). The effect of each genetic variable was approximately the same when modeled independently as when both were included in the same regression model. Modeling did not identify a significant direct interaction between mtDNA haplotype and the DXS8090(166)-DXS1068(258). X2 was greatest for the additive model shown below $\left(X_{2}=35.68, P<0.0001\right)$. When taken together, this indicates that each genetic factor exerts its effect is independent and additive. Logistic regression showed an increased risk of visual failure in non-J pedigrees in this cohort. A formal study of the penetrance of LHON in haplogroup J vs non-s pedigrees has not been carried out previously.

\begin{tabular}{|c|c|c|}
\hline Varlables in the equation & $\bar{P}$ & $\begin{array}{l}\text { Odds rato } \\
(95 \% \mathrm{Cl})\end{array}$ \\
\hline Non-miteNA haplotypB J & 0.043 & $\begin{array}{c}2.45 \\
(1.03 .5 .82)\end{array}$ \\
\hline DXS8080\{166)-DXS1008(25B) & 0.001 & $\begin{array}{c}33.84 \\
(4.36-361.59)\end{array}$ \\
\hline Constent & $\leqslant 0.01$ & 0.02 \\
\hline
\end{tabular}


Identification of an X-chromosomal locus and haplotype modulating the phenotype of a mIDNA disorder

\section{Figure legend}

Figure 1. Mapping the nuclear modifier locus in Finnish pedigrees transmitting homoplasmic LHON mtDNA mutations: (a) Human X-chromosome with the corresponding non-parametric linkage (NPL) score for the initial linkage screen (maximum NPL score $=10.2$ ). (b) Fine mapping of the linked locus confirming earlier findings and revealing a maximum non-parametric (NPL) score of 47.5. (c) Xlinked reconstructioncombination transmission/disequilibrium test (XRC-TDT) for informative markers in the Finnish, mainland European and British cohorts. As expected, the Finnish families show a large block of linkage and association corresponding to the linked region. There is significant transmission distortion for specific markers at the same locus for the British and mainland European cohorts, confirming our initial findings and demonstrating the smaller block of $L D$ present outside Finland. Black background = non-significant. Yellow background = significant at the 0.05 level. Straw colored = uninformative marker when the number of alleles $<$

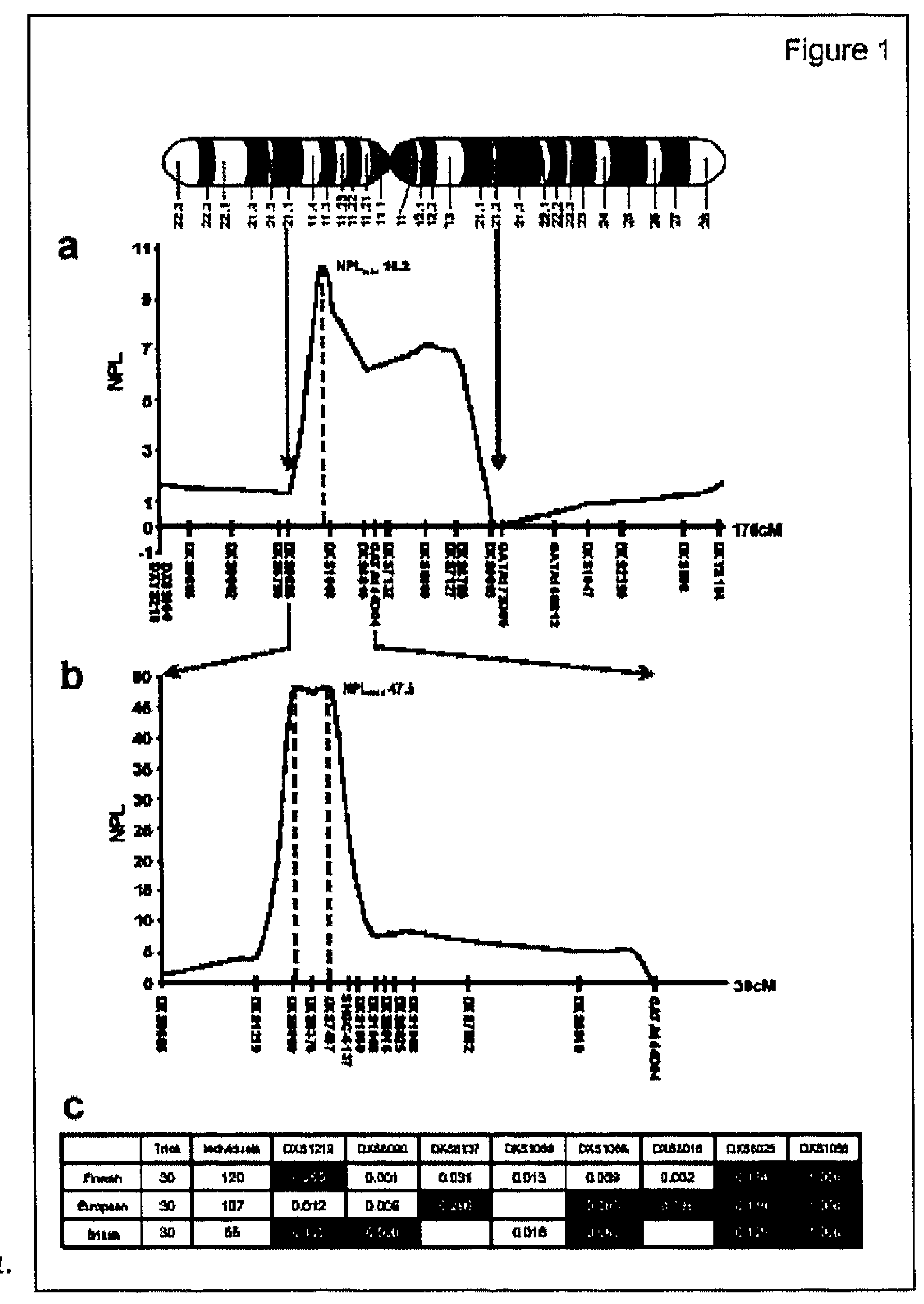


Supplementary table ?.

Logistic regression model of the effects of mtDNA background haplotype and the DXS809o(166)-DXS1068(258) nuclear haplotype in males homoplasmic for $71778 A>G, 14484 T>C$ and $14495 A>G$. The additive model is shown in the text and has the greatest $X_{2}$ of $35.68(P<0.0001)$.

(a) Independent effect of the nuclear haplotype DXS8090(166)-DXS1068(258) $X^{2}$ for this model $31.42, P<0.001$.

\begin{tabular}{|c|c|c|}
\hline Varlables in the equation & 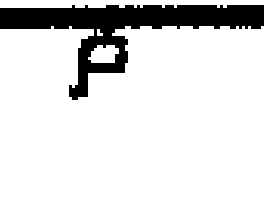 & $\begin{array}{l}\text { Odds ratio } \\
(95 \% \mathrm{Cl})\end{array}$ \\
\hline DXS8090\{166)-DXB1068(25B\} & 0.001 & $\frac{35.25}{44.62 .268 .73)}$ \\
\hline Constent & 0.001 & \\
\hline
\end{tabular}

(b) Independent effect of the mtDNA haplotype. $X^{2}$ for this model an $7.53, \mathrm{P}=$ 0.006 .

\begin{tabular}{|c|c|c|}
\hline Verlables in the equation & $P$ & $\begin{array}{l}\text { Odde ratio } \\
\text { (95\% cl) }\end{array}$ \\
\hline Non-mitoNA. hapdotype J & 0.007 & $\frac{289}{(1.346 .197)}$ \\
\hline
\end{tabular}

(c) Synergistic interaction between DX\$8090(166)-DXS1068(258) and non-J mtDNA background, $X^{2}$ for this model an $27.38, \mathrm{p}<0.001$.

\begin{tabular}{|c|c|c|}
\hline Variatles in the equatlon & $\boldsymbol{P}$ & $\begin{array}{l}\text { Odde rallo } \\
\text { (95\% Cl) }\end{array}$ \\
\hline 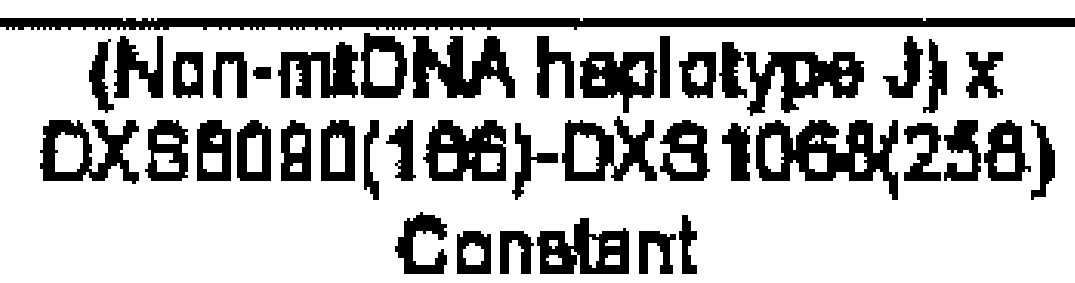 & $\begin{array}{l}0.65 \\
0.65\end{array}$ & $\begin{array}{c}8340.48 \\
\left(0-1.91 \times 10^{24}\right) \\
0\end{array}$ \\
\hline
\end{tabular}

(d) Antagonistic interaction between DX\$8090(166)-DXS1068(258) and non-J tmiDNA background. $X^{2}$ for this model $m 2,86, p=0,09$.

\begin{tabular}{|c|c|c|}
\hline Vorlables in the equation & $P$ & $\begin{array}{l}\text { Odda rallo } \\
(95 \% \text { cl) }\end{array}$ \\
\hline 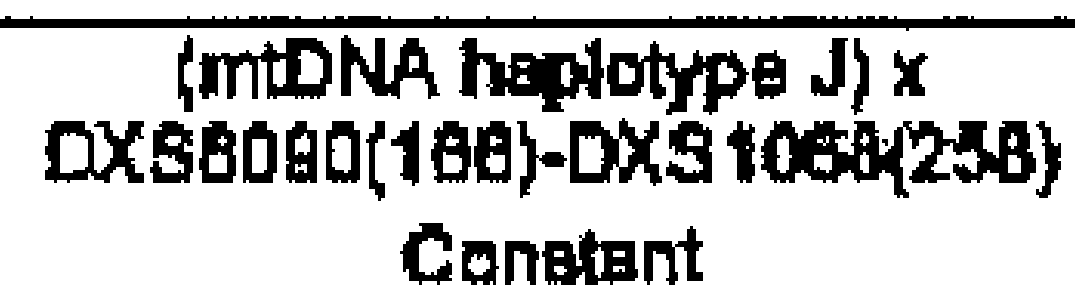 & $\begin{array}{l}0.152 \\
0.031\end{array}$ & $\begin{array}{c}4.73 \\
(0.58 .39 .61) \\
0.487\end{array}$ \\
\hline
\end{tabular}


Supplementary table 2.

Grandparental origin of $X$-chromosomal markers in males from three generation homoplasmic LHON mEDNA mutation pedigrees. Unaffected males, $n=24$. Affected males, $n=28 . P=$ Fisher's exact $P$ comparing the frequency of origin of grandpaternal (GP) and grandmaternal (GM) alleles in affected and unaffected individuals.

Supplementary figure legend

Heterozygosity mapping using the 1OK SNP Affymetrix microarray for four unrelated women with visual failure due to a homoplasmic LHON mutation. Subjects 1,2 and 3 are European. Subject 4 is Finnish. All four individuals had $>3$ affected sons and no unaffected sons. All four show homozygosity for the z SNPs adjacent to the principal linked markers which define the high risk disease haplotype.

\begin{tabular}{|c|c|c|c|c|c|}
\hline \multirow[t]{2}{*}{ Marker } & \multicolumn{2}{|c|}{$\begin{array}{c}\text { Una flected } \\
\text { males }\end{array}$} & \multicolumn{2}{|c|}{$\begin{array}{l}\text { Affected } \\
\text { malos }\end{array}$} & \multirow[t]{2}{*}{$P$} \\
\hline & GP & $G M$ & GP & $\mathrm{GM}$ & \\
\hline $\begin{array}{l}\text { DXS1219 } \\
\text { DXs8090 }\end{array}$ & $\begin{array}{l}14 \\
14\end{array}$ & $\begin{array}{l}10 \\
10\end{array}$ & $\begin{array}{l}15 \\
17\end{array}$ & $\begin{array}{l}13 \\
11\end{array}$ & $\begin{array}{c}0.7848 \\
1\end{array}$ \\
\hline $0 \times 58376$ & 14 & 10 & 17 & 11 & 1 \\
\hline DXs74a7 & 14 & 10 & 17 & 11 & 1 \\
\hline sHGC-8137 & 14 & 10 & 17 & 11 & 1 \\
\hline DXs1069 & 14 & 10 & 17 & 11 & 1 \\
\hline $0 \times 51066$ & 14 & 10 & 17 & 11 & 1 \\
\hline Dxsa016 & 14 & 10 & 17 & 11 & 1 \\
\hline DXs8025 & 14 & 10 & 17 & 11 & 1 \\
\hline DXs1056 & 18 & 10 & 15 & 13 & 0.5928 \\
\hline $0 \times 57582$ & 16 & 10 & 15 & 13 & 0.5828 \\
\hline DXseg10 & 14 & 10 & 15 & 13 & $0.7 \mathrm{e} 4 \mathrm{E}$ \\
\hline
\end{tabular}


Supplementary figure

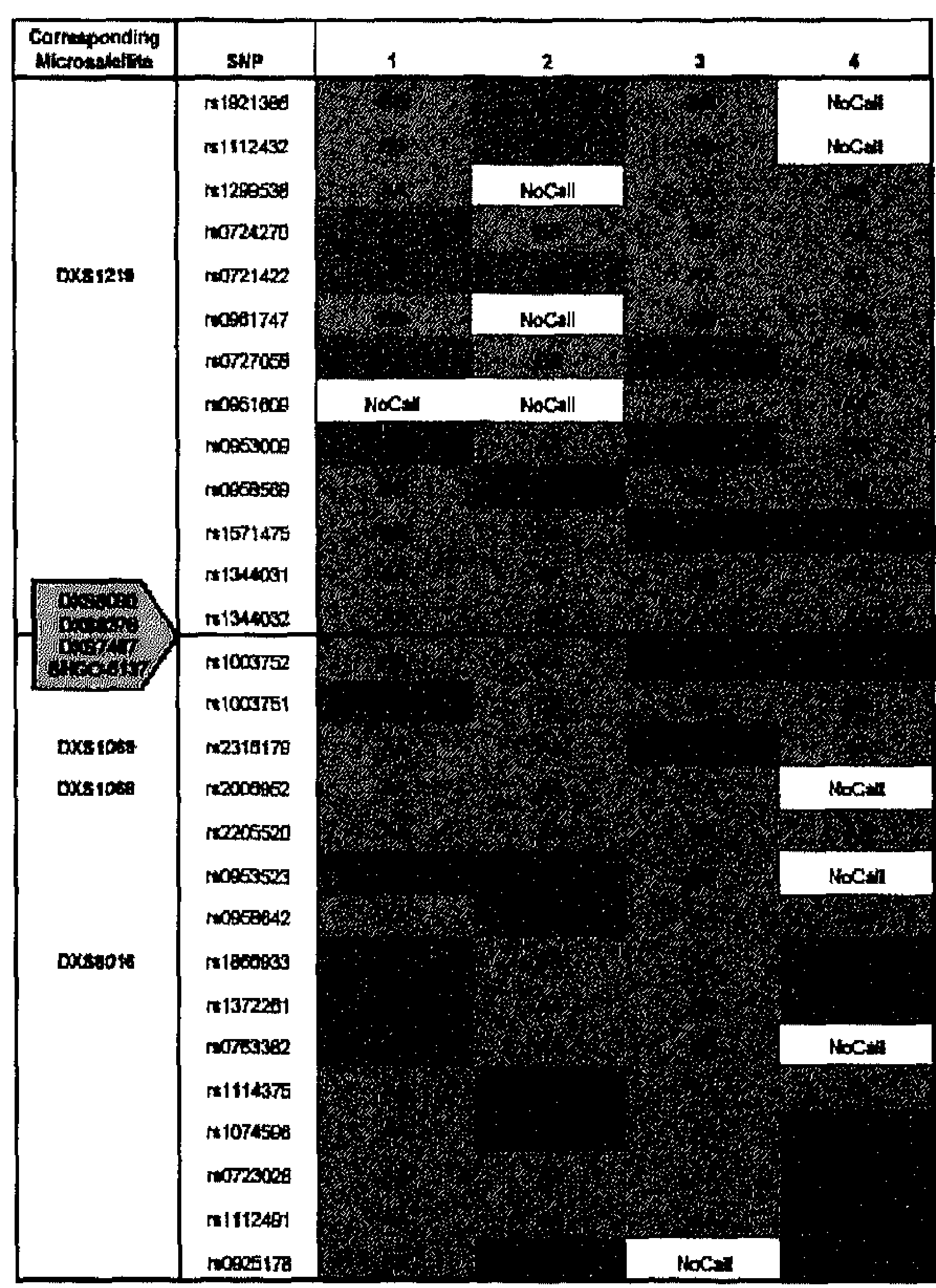



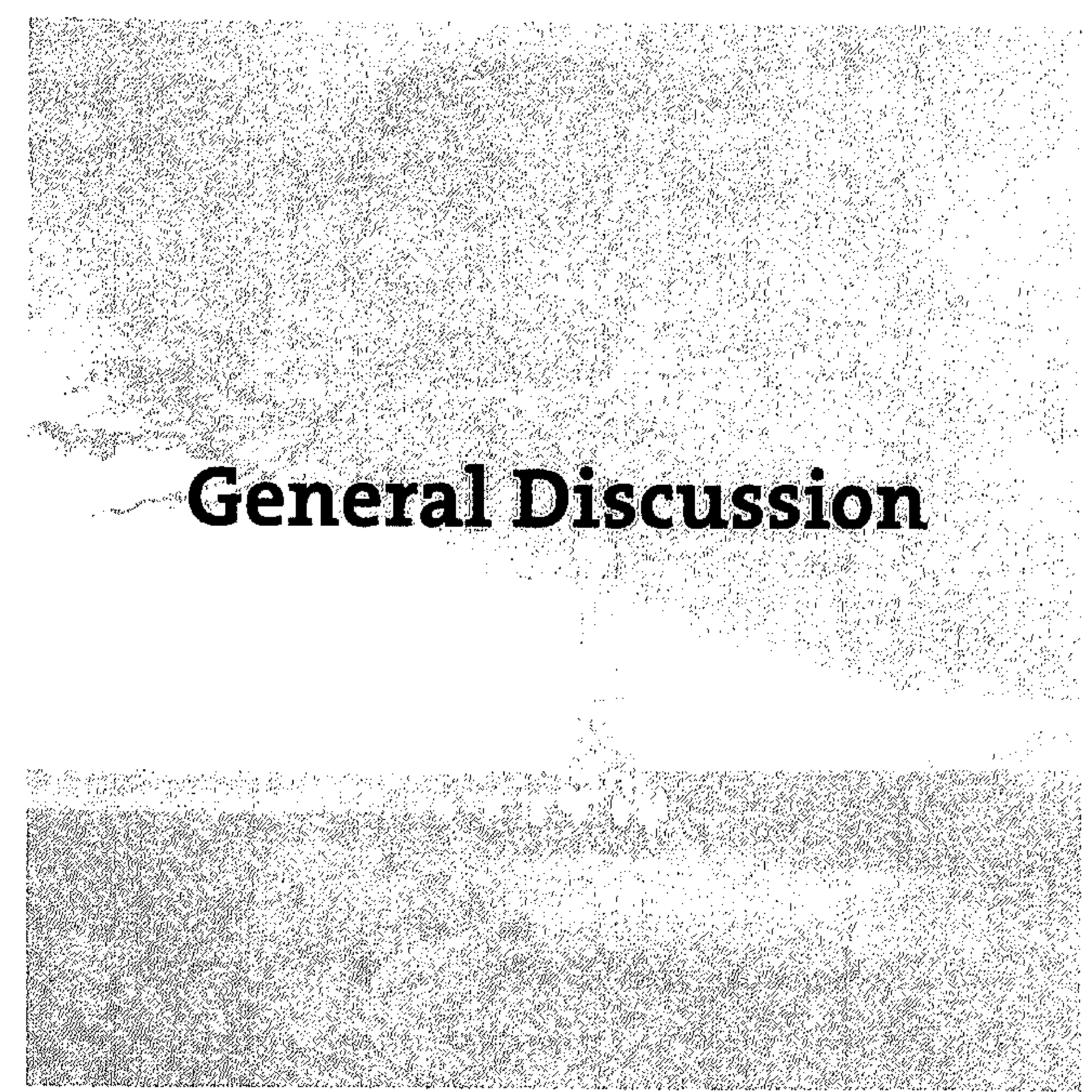


\section{General Discussion}

LHON is a rare genetic disorder and in spite of many years of intense scientific research worldwide still little is known about its pathogenesis. In particular the incomplete penetrance, the different expression in men and women and the variability in age at onset and pathogenesis cannot be explained yet. The study of LHON is complicated by several factors like the absence of a good animal model, the limited number of patients available and the fact that the cells involved (retinal ganglion cells) are practically impossible to examine directly in living patients. The main goal of this thesis is to determine if the interaction between the mitochondrial and the nuclear genome could be responsible for the variable presentation of LHON and might explain the incomplete penetrance. We studied the phenotypic expression (clinical and biochemical) and explored several genetic (mtDNA and nuclear) mechanisms. Insight in the disease mechanisms and identifying the pathogenesis is a crucial step before prevention and future treatment becomes a realistic option. In this discussion we will further elaborate on the key issues and main conclusions of the present study.

\section{Variable expression and phenotypic subtypes of LHON}

Since the early nineties of the previous century it is known that specific mtDNA mutations are responsible for the development of LHON, but that such a mutation on its own cannot explain the variability in disease penetrance and expression. To determine the phenotypic differences between the three primary LHON mutations we evaluated the genotype-phenotype correlation retrospectively in a large cohort of Dutch LHON patients. (Chapter 3 ) The penetrance was $\sim 50 \%$ males and $\sim 10-20 \%$ females similar to what was reported before. This was found to be the same in all three primary mutations. Others reported small difference in penetration between the three mutations (www.genetest.org LHON. PF Chinnery). Almost half of the patients carrying the m.14484T $>C$ mutation and some with the m.11778G $>A$ and $m .3460 G>A$ mutation experienced some recovery of vision. Recovery cannot be predicted by the clinical findings and it occurred between 1-4 years after the initial disease onset. Although the onset in LHON is usually acute, we found a more gradual onset in m.11778G >A carriers.'

The cardiac system has been involved in LHON patients as well and cardiomyopathy and pre-excitation disorders have been reported..$^{2-6}$ Most of these reports describe isolated patient cases or families with an apparent independent segregation of a cardiac disorder.7 To find out if cardiac defects are more frequently present in LHON patients we studied prospectively a group of 28 LHON patients and we found no indication of increased risk in 
the LHON population compared with the normal population. (Chapter 4) We postulate that earlier reports could be biased and it is not determined yet if screening and follow-up for cardiac defects is indeed required for LHON patients as was suggested previously.

A variety of neutral mtDNA polymorphisms represent different haplotypes, which modify the expression of LHON. The J haplotype has been more frequent than expected associated with the $\mathrm{m} .11778 \mathrm{G}>\mathrm{A}$ and $\mathrm{m} .14484 \mathrm{~T}>\mathrm{C}$ mutation. We tested the hypothesis whether the clinical penetrance of the m.11778G $>A$ and the m.14484T $>C$ mutation is increased on a I haplotype background (Chapter 9 ). The risk of visual failure is higher when a specific subgroup of haplogroup $\mathrm{J}\left(\mathrm{I}_{2}\right.$ for $\mathrm{m} .11778 \mathrm{G}>\mathrm{A}$ and $\mathrm{J}_{1}$ for $\mathrm{m} .14484 \mathrm{~T}>\mathrm{C}$ ) is present, but significantly less with a haplogroup $H(m .11778 G>A){ }^{8}$ The MTCYB gene, the only mitochondrial gene that encodes a complex III subunit, contains the $5452 \mathrm{C}>\mathrm{A}$ substitution which is one of the determinants of the haplogroup J. Jic harbors an additional MTCYB substitution and $J_{2} b$ carries even two additional MTCYB substitutions. ${ }^{9}$ This could be a chance finding, but recent evidence supported the existence of supercomplexes, consisting of complex dimeric complex III and I. ${ }^{10}$ The genetic variation in MTCYB might alter complex I function, possibly by destabilizing the assembled super-complex. Differences in the amino acid sequence of both cyt $b$ (haplotype) and the ND genes (primary LHON mutations) could alter the interaction between complex I and III. Opposite, the I-III super-complex could be relatively stabilized by specific cyt b substitutions (in haplogroup H). ${ }^{10}$ However, the haplotype still does not explain the differences in disease expression within the same family since all family members carry the same mitochondrial mutation and the same haplogroup. We concluded that common, modifying mtDNA variants like a haplotype could have striking effects on the expression of LHON, at least between families. But this result should be used only with great care for genetic counseling. The mtDNA subhaplogroups have a marked geographic variation and the above described associations may not be important in all LHON populations. The J haplogroup for example is not occurring in the Iranian population and consequently the association with the $J_{1}$ haplogourp is not found in the Iranian LHON patients. Large population studies in other populations are therefore required before haplogroups can possibly be implemented in the genetic counseling of LHON patients.

In order to find a further explanation for the heterogenic expression we studied LHON families that presented with unusual clinical symptoms or with additional signs and symptoms. In these families we screened the entire mtDNA to find out whether the different expression was the result of a rare LHON mutation or of the (concordant) presence of another mtDNA mutation. In the first family a female showed clinical symptoms that were very suggestive of LHON while her brother presented with dystonia in childhood. No primary LHON mutation was found. Subsequent sequencing of the mitochondrial DNA showed a rare pathogenic m.3697G>A mutation in the ND1 gene, which is likely responsible for both 
phenotypes (Chapter 5). However, the difference in clinical presentation between the two siblings could not be explained by this mutation alone and additional (nuclear or environmental) factors are probably responsible for the difference in clinical presentation. In a second family we identified two mitochondrial mutations in a patient with LHON symptoms and additional neurological complaints: a homoplastic m.14484T>C LHON mutation and a heteroplasmic mutation in the tRNA (Ile) gene (Chapter 6). The detection of additional mtDNA mutations explaining associated features in LHON (neurological manifestations or sensorineural hearing loss) or an otherwise remarkable LHON presentation (a very young onset or a particular severe course) has recently been described by others as well.1-12

It is remarkable that there are now several reports on LHON families with a presumably very rare combination of a LHON mutation and an additional mtDNA mutation. Is the presence of an additional mtDNA mutation just coincidence or is there a causal relationship? First of all, reactive oxygen species (ROS) are a natural by-product of the OXPHOS system. But pathogenic mtDNA mutations involving complex I genes are causing a significant increase in the ROS production specifically when the activity of complex 1 is impaired. This enhanced ROS production was also demonstrated in cybrids cell lines with one of the mTDNA LHON point mutation. ${ }^{13}$ Even if cells are equipped with a number of antioxidants defense systems to neutralize the ROS production, some ROS still do evade these systems and are able to influence membranes, proteins, and DNA. The physical proximity of the mIDNA near the inner mitochondrial membrane where ROS are produced, leads to oxidative damage and production of mtDNA mutations. ${ }^{14}$ This consequently result in further decrease and defects of oxidative phosphorylation leading to further production of ROS and thus establishing a vicious circle of oxidative stress, energetic decline and further mtDNA damage. It has been even suggested that ROS overproduction represent a common step in the induction of clinical phenotypes that are associated with mtDNA point mutations. ${ }^{15}$ The role of ROS in mtDNA damage is agedependent and results in significantly higher levels of mtDNA damage in post-mitotic tissues than in nuclear DNA. Recent and more sensitive laboratory techniques were able to detect this age-related accumulation of point mutations and this supports the hypothesis of a general decline in mitochondrial function with age. ${ }^{16}$ ROS induced mtDNA mutations could also happen in the oocyte and it is not unlikely that this occurs more often in carriers of a primary mtDNA mutation, explaining the relatively high frequency of double mutations. Furthermore, increased ROS production could also be due to exogenous or endogenous conditions (e.g. exposure to drugs and/or toxins like smoking ${ }^{17}$ or changing hormonal status). Apart from additional mutations, this could also cause irreparable damage leading to apoptotic death of retinal ganglion cells and contribute to the clinical expression of LHON. ${ }^{18}$

A related feature of $L H O N$ is the age specific expression. The peak incidence of the symptoms is in the second or third decade of life. But visual impairment can occur also in young child- 
ren or in patients beyond their fifties. Childhood-onset LHON starting before the age of 10 has a prevalence of only $10 \%$. 'Approximately half of them show an atypical slow progressive or sometimes unilateral onset and have a more favorable prognosis than in adultonset LHON. In one of our own studies we did find this slower onset in children too..$^{19}$ In the majority of the LHON families there is a wide variety in the age of disease onset in the affected cases. Contrary there are a few families with a virtually universal young onset in all affected family members. These families may represent a particular subgroup with the involvement of different modifying factors in the expression of the disease. Recently, we examined nine LHON patients with a particular late onset after the age of 45 years (mean 61.1 years, range $45-74$; unpublished results). It was remarkable that nearly all patients (8/9) active mokers and had a more than average daily alcohol intake (more than 2 units per day). Five had a positive family history of similar affected relatives in the maternal line. The association between smoking and increased disease penetrance within the same LHON family has been reported before and underscores the ROS-hypothesis described above. ${ }^{77}$ In the older LHON individuals, as opposed to non-symptomatic individuals, smoking appears to be the trigger of the clinical symptoms. "It is possible that these patients would have never been diagnosed with LHON if smoking had not disturbed the balance. In the patients with a childhood-onset, smoking and the use of alcohol were not the triggering factors. As far as we know other environmental factor like infection, co-morbidity by other diseases, trauma and vaccinations were not present. Other undetected endo- or exogenous causes may be involved.

A remarkable feature of $L H O N$ is the predisposition for affected male patients. Male mutation carriers have a lifetime risk of $-30-50 \%$ to become affected and females $10-20 \%$. A modifier gene located on the X-chromosome has often been proposed as an explanation for this sex dependent penetrance. This $\mathrm{X}$-linked modifier gene has not been detected yet even if several loci were identified. Other less explored reasons for the male predominance could be hormonal factors (estrogen has been reported to have anti-oxidant properties), anatomic differences, difference in exposure to toxic substances, or trauma that are work or sex-related. The last factors might influence the mtDNA LHON mutation through certain epigenetic mechanisms that have to be identified yet. Epigenetics refers to modifications in gene expression controlled by heritable but potentially reversible changes in DNA methylation and/or chromatin structure. DNA methylation is a post-replication process that is able to influence the gene expression by "switching" a gene on or off. Tissue-specific genes are methylated ("switched off") in all tissues except the tissue where the gene is expressed ("switch on"). An example is the phenomenon of imprinting occurring in about $1 \%$ of the genes that are expressed monoallelically in a parentof-origin fashion. Correspondingly the role of skewed $X$-linked inactivation as an important mechanism in LHON has been ruled out. ${ }^{20,21}$ In normal circumstances, the failing correction for 
maternal imprinting leads to the preferential transmission of grandpaternal chromosomes to their grandchildren. ${ }^{22}$ The inheritance of a partially silenced grandpaternal gene could explain the characteristic penetrance of primary LHON mutations in males. In females the inheritance of such a grandpaternal gene together with normal female random inactivation pattern could explain the reduced penetrance in women.

A comparable situation is the skewed transmission of the mutated alleles in the long-OT syndrome rather to daughter (55\%) than to sons ( $45 \%){ }^{23}$ This positive selection of the mutated allele can already take place during gametogenesis or during the postfertilization processes. Moreover, male carriers of the long-QT syndrome are possibly already eliminated be eliminated before birth could. ${ }^{23}$ This skewed transmission could explain the excess of female patients with autosomal dominant long-OT syndrome and underlines that mechanisms other than an increased penetrance of a mutation might result in a female predominance. ${ }^{23}$ In the LHON population however, we observed no distorted transmission of grandpaternal alleles comparable to the control populations. There was no difference in the frequency of grandpaternal alleles between affected and unaffected male offspring or between affected and unaffected female offspring. ${ }^{24}$

In conclusion, subphenotypes of LHON exist and can at least partly be explained by additional mutations in the mtDNA or by different haplotypes. Furthermore, intrinsic and environmental factors like oxidative stress may play a role especially in the age at onset. It has not yet been possible to define a specific, possible genetically homogeneous subgroup that would ease the identification of nuclear genetic factors, although the group of young patients might be of interest to achieve this. Unfortunately there are no families with a universally young onset in all involved family members, so a complete homogenous subgroup is virtually never present.

\section{Nuclear modifier genes}

So far nuclear modifier genes have been searched for by linkage-analysis in large families, often focusing on the $X$-chromosome because of the male predominance of LHON. The earliest attempts failed because too widely spaced and not sufficiently informative polymorphic markers were used. ${ }^{25-27}$ In addition, most studies were limited in size and therefore lacking enough power to exclude a substantial portion of the $X$ chromosome. ${ }^{28,29}$ Also, the disease model is not easy to describe. However, segregation analyses did confirm the presence of a X-linked susceptibility locus.$^{30}$ Later studies, using exclusion mapping, were based on an $X$-linked recessive model, although this cannot explain the segregation pattern in all LHON pedigrees. ${ }^{31}$

There are branches in large LHON families with high penetrance rates while in other branches the penetrance is close to zero. ${ }^{8} \mathrm{~A}$ possible explanation is the presence of a modifier gene in the high penetrance branches, which is absent in the low penetrance branches. 
The existence of large LHON pedigrees with more than 10 generations makes it unlikely that this nuclear modifier is inherited continuously together with the LHON mutation for so many generations. We hypothesized that the fathers of LHON patients carry a certain genetic variant that is common in the general population and in this way is introduced into the family. The occurrence of a common factor, together with the mitochondrial LHON mutation from the mother, could explain that LHON symptoms start seemingly suddenly in their offspring. The extinction of the symptoms in consecutive generations then occurs, when this common factor segregates out of the family. In order to identify such a paternal factor we performed nonparametric linkage (NPL) analysis in 6 Finnish families. The Finnish are a geographically isolated population, narrowing down the number of potentially involved risk alleles. We identified a X-chromosomal haplotype located in Xp11 (bounded by markers DXS8090 and DXS1068). The effect of this haplotype appears to explain the variable penetrance and sex bias in these families. ${ }^{24}$ The lifetime risk for developing a visual defect seems to be determined, at least in certain families, by this haplotype. The effect of the haplotype is independent of the mtDNA genetic background and appears to explain the variable penetrance and gender bias that is specific for LHON. However, until now sequencing of candidate genes in this Xp11 region did not result in the detection of mutations (Hudson and Chinnery, unpublished results). The NDUFB11 (ESSS) gene was one of the candidate genes for LHON because of its localization in the Xp11.3 region, its function in complex I assembly, the expression in the eye and the age related expression. Nevertheless, we did not find sequence variations in the NDUFB11 gene that influenced the expression in Dutch and Finnish LHON patients (unpublished data). Others recently excluded the NDUFB11 gene as a modifier gene in LHON too..$^{32}$ We considered another gene on the Xchromosome, the apoptosis-inducing factor (AIF). It is a good candidate for a LHON modifier because it induces apoptosis, it is confined to the mitochondrial intermembrane space and is translocated to the nucleus when apoptosis is induced. However, this gene is located in the Xq25-26 region, a locus without evidence of linkage. The gene was also excluded as a candidate modifier in LHON. (personal communication Hudson and Chinnery)

In Maastricht we further concentrated on families with a possible autosomal locus in the high-penetrant branches, assuming that this would be due to the same genetic risk factor. We performed a complete genome scan in a family with 11 affected persons. This resulted in the identification of several regions on different chromosomes with a possible location of a modifying factor. In these regions many candidate genes are present and the still unsolved discussion is what the definition of a good candidate is. Such a gene has to be expressed in the affected tissue, but it is not necessarily a mitochondrial gene, making the list of genes to be screened way too long. More families have to be screened to limit the number and size of the candidate regions and subsequently the number of genes. 


\section{Biochemical solutions?}

Although genome wide linkage studies confirmed the role of multiple nuclear-encoded modifier genes in the phenotypical expression of LHON and support was found for the linkages of several modifier loci, no mutations in these modifier genes have yet been identified. So presumably, this approach is not as successful in rare and complicated disorder like LHON compared to Mendelian inherited disorders. The genetic models that were used in the linkage calculations may not have been correct and more complex than assumed. Exploring the mitochondrial dysfunction at the biochemical level could be a valuable different approach for several reasons. Firstly the identification of a biochemical phenotype in families could help in locating a genetic factor, as this may not suffer from reduced penetrance as the clinical phenotype. If consistent biochemical abnormalities are found, also alternative approaches such as complementation studies can be applied to identify the target genetic modifier factor. The chromosome fragment able to complement the biochemical defect most likely carries the nuclear factor that we look for. Subsequently, this region can be narrowed down. Secondly, knowing the nature of the biochemical defects could be useful in predicting the severity, the prognosis or in the identification of nonmanifesting carriers.

All primary LHON mutations are located in genes that encode a subunit of complex I.Therefore a defect in the oxidative phosphorylation, in particular in complex I, is expected. So far, reports on enzyme defects in LHON patients have been controversial. First of all, all LHON mutations do induce a severe complex I-dependent defect in ATP production. This can result in energy failure in the retinal cells. The retinal ganglion cells are in particular vulnerable to energy production failure because of the high energy demands. In particular the unmyelinated part of the retinal ganglion cell axons, before they enter the lamina cribrosa, requires huge amounts of proper functioning mitochondria. Simultaneously, a defect in ATP production results in the generation of more free radicals than normal in mitochondria. It is postulated that the observed mitochondrial dysfunction causes retinal ganglion cell death through an apoptotic pathway. ${ }^{33}$ However, the defect in the ATP production does not lead to a reduced total ATP cellular content, indicating that there are compensatory mechanisms present. ${ }^{34}$ Secondly, enzyme studies in LHON consistently showed a $60-80 \%$ reduction of electron transport activity of complex I only in the m.3460G>A mutation, but not in the other two primary LHON mutations.33.35.36 Mitochondria with the m.11778G $>\mathrm{A}$ and $m .3460 G>A$, and in a lesser extend the m.14484T $>C$ mutation have a decreased sensitivity to rotenone. ${ }^{37}$ The latter suggests a defect in the interaction between complex 1 and the substrates of $\mathrm{COQ}$ (electron transporter of complex I). ${ }^{38,39}$ All 3 LHON mutations interfere with the interaction between complex I and the ubiquinone substrate (CoQ10) and hence the ubisemiquinone intermediates have a reduced stability. The consequences 
of a complex I dysfunction can therefore result in: a disturbed respiratory function, a defect in proton pumping through complex l, affected energy conservation (ATP) and unstable ubisemiquinone radicals which dismutate rapidly and an increase ROS production. ${ }^{34}$

The new and relatively simple biochemical test that we developed to measure the complex I activity in circulating lymphocytes of LHON patients and controls is hardly invasive and is not influenced by the process of cell culturing and resulted in reliable and reproducible results (Chapter 8).The average decrease of complex I activity of $60 \%$ in m.3460G>A/ ND1 carriers, but not for the other mutations, are consistent with previous studies (Chapter 9). We detected a slightly improved enzymatic activity of complex I per unit citrate synthase (CS) in the mitochondria with the m.11778A>G/ND4 and m.14484T>C/ND6 mutation. Such an increase can result in the increased generation of reactive oxygen species (ROS). $4^{\circ}$ The CS levels per mg protein were found to be increased significantly in the unaffected m.11778G $>A$ and $m .14484 T>C$ carriers. (Table 1) $C S$ is a parameter that reflects the quantity of the mitochondria per cell. When the mitochondrial function is insufficient, to a certain degree, the number of mitochondria can increase in order to compensate for the functional defect, and the CS concentration will increase. An increase of CS is therefore indicating a defective mitochondrial function. The increase in the number of mitochondria in individuals that remained unaffected suggests that they were able to compensate for the qualitative defect in the mitochondria and this could explain why they remained symptom free. Those with normal CS levels may be more at risk to develop LHON. In a similar way an increase in the relative mIDNA content has been reported in NAION (non-arteritic anterior ischemic optic neuropathy) patients with a mitochondrial respiratory chain defect. This was also suggested to indicate a response to oxidative stress..$^{40}$ In addition, the number of mitochondria correlates with the activity of myelin turnover too.41 There is evidence that the pathophysiology of LHON is determined by hypo- or demyelinisation of the axons of the retinal ganglion cells. Viable axons can be remyelinated, which probably is a factor in the spontaneous recovery described in LHON even years after onset. One may speculate that an increased number of mitochondria protects or restores insufficient myelinated axonal fibres as is seen in LHON. 
Table 1

Biochemical effect of LHON mutation and affected status of patients (Chapter 6)

\begin{tabular}{|l|l|l|}
\hline Mutation and affected status & CS mU/mg prot & Cl mU/U CS \\
\hline 3460 & & \\
Affected & $\uparrow$ & $\downarrow$ \\
Unaffected & $\uparrow$ & $\downarrow$ \\
& & \\
11778 & $\leftrightarrow$ & $\leftrightarrow / \uparrow$ \\
Affected & $\leftrightarrow$ & $\leftrightarrow$ \\
Unaffected & $\uparrow$ & $\leftrightarrow / \uparrow$ \\
14484 & & $\leftrightarrow$ \\
Affected & $\leftrightarrow$ & $\leftrightarrow$ \\
Unaffected & $\leftrightarrow$ & $\leftrightarrow$ \\
\hline
\end{tabular}

The m.346oG>A mutation behaved differently. All mutation carriers, independent of their affection status, showed a reduction of the complex I activity per unit CS. Both the unaffected and affected $m .3460 G>A$ mutation carriers had also an increased CS levels (mg prot) that is an indication of a compensatory increase of the number of mitochondria. Clearly, this compensation did not result in a normalization of the $\mathrm{Cl}$ activity. This might be related to the position of the m.3460G>A mutation in complex $I$, at the site of CoO binding that is different for the other two LHON mutations. We showed that it is possible to measure the complex l activity in circulating lymphocytes but it is not likely that a modifier gene that determines the clinical outcome of the defect in complex I could be detected on the basis of the present biochemical assay in the m.3460G>A mutation carriers. There was no difference between the affected and unaffected $\mathrm{m} .3460 \mathrm{G}>\mathrm{A}$ patients. The reduction of complex $\mathrm{I}$ is in these cases apparently independent from the nuclear background. In the m.11778G $>A$ and $m .14484 T>C$ mutation carriers this is different. In these latter two groups the primary LHON mutation causes a slightly increased activity of complex I. In addition, the number of mitochondria correlates with the activity of myelin turnover too. ${ }^{4}$ Further studies that focus on ATP production differences between affected and unaffected and the resulting free radical production can be a next step in studying the biochemical consequences of a LHON mutation. These activities can also be evaluated in circulating lympohocytes. By studying other functions of complex I and substances that might harm the mitochondria, the effect of neuro-protective substances could be evaluated too. 


\section{Conclusion and future perspectives}

The gathering of LHON families presented in this manuscript resulted in de identification of additional mtDNA mutations, and in some families an mtDNA-haplotype located on the $X$-chromosome that influences the expression of the disease. The results also suggested that there have to be other modifier genes that are not X-linked given the fact that not all LHON families had involvement of an X-linked factor. The modifier or modifiers involved in LHON are probably heterogenic. Possibly there are several different modifying genes involved, each confining a small risk of disease. These can be identified by large association studies but, since LHON is such a rare disease and the large number of patients required ${ }^{16}$ for association studies are unavailable, this approach may not be successful. The critical importance of study size in genetic association studies was demonstrated in the recent identification of five novel breast cancer susceptibility loci explaining some of the variation in breast cancer risk to be due to common alleles. The combination of susceptibility alleles together with other risk factors may become sufficiently predictive to be important clinically. ${ }^{16}$ In addition, phenocopies of LHON, although not very common and incomplete penetrance make it difficult to deduce the carrier status of a nuclear disease allele from the disease status in a LHON patient. Even within a family a different combination of these genes could influence the affected status. Taken together this makes it very difficult to identify the genetic factors influencing the LHON phenotype.

When we started with his study there were no proper animal studies for mitochondrial dis. orders. During the last years an adeno-associated viral vector was introduced in mice making it possible to estimate the effect of an artificially induced oxidative injury to the optic nerve. ${ }^{42}$ This resulted in an increased cellular superoxide, a reduced mitochondrial membrane potential and apoptotic cell death and loss of axons and myelin in the optic nerve and retinal ganglion cells similar as in LHON patients. ${ }^{42}$ These finding again underscore the importance of free radicals in the pathogenesis. In a similar way a human ND4 gene mutation was introduced in mice resulting in the same biochemical and histopathological findings in optic nerve and ganglion cells as seen in LHON. This mouse model provides new opportunities in unravelling the pathogenesis and future testing of gene therapy. ${ }^{43} \mathrm{An}$ attempt was made to rescue the optic nerve degeneration by the restoration of respiration by introducing a human mitochondrial superoxide dismutase ( $\mathrm{SOD}_{2}$ ) gene that reduced apoptosis and degeneration of optic nerve fibres. ${ }^{43}$ Although genetic linkage analysis resulted in the identification of a risk haplotype, it did not result in the finding of a genetic modifier. The combined information with more advanced animal models and biochemical evaluation will hopefully result in solving the pathogenic mechanism of LHON. 


\section{References}

1. Barboni P, Savini G, Valentino ML, et al. Leber's hereditary optic neuropathy with childhood onset. Invest Ophthalmol Vis Sci. 2006;47:5303-5309.

2. Bower SP, Hawley I, Mackey DA. Cardiac arrhythmia and Leber's hereditary optic neuropathy. Lancet. 1992;339:1427-1428.

3. Nikoskelainen EK, Savontaus ML, Huoponen K, Antila K, Hartiala J. Pre-excitation syndrome in Leber's hereditary optic neuropathy. Lancet. 1994;344:857-858.

4. Finsterer J, Stollberger C, Kopsa W, Jaksch M. Wolff-Parkinson-White syndrome and isolated left ventricular abnormal trabeculation as a manifestation of Leber's hereditary optic neuropathy. Can J Cardiol. 2001;17:464-466.

5. Finsterer J, Stollberger C, Michaela J. Familial left ventricular hypertrabeculation in two blind brothers. Cardiovasc Pathol. 2002;11:146-148.

6. Finsterer J, Stollberger C, Prainer C, Hochwarter A. Lone noncompaction in Leber's hereditary optic neuropathy. Acta Cardiol. 2004;59:187-190.

7. Sorajja P, Sweeney MG, Chalmers R, et al. Cardiac abnormalities in patients with Leber's hereditary optic neuropathy. Heart. 2003;89:791-792.

8. Howell N, Herrnstadt C, Shults C, Mackey DA. Low penetrance of the 14484 LHON mutation when it arises in a non-haplogroup J mtDNA background. Am J Med Genet. 2003;119A:147-151.

9. Carelli V, Achilli A, Valentino ML, et al. Haplogroup effects and recombination of mitochondrial DNA: novel clues from the analysis of Leber hereditary optic neuropathy pedigrees. Am J Hum Genet. 2006;78:564-574.

10. Dudkina NV, Eubel H, Keegstra W, Boekema EJ, Braun HP. Structure of a mitochondrial supercomplex formed by respiratory-chain complexes I and III. Proc NatI Acad Sci USA. 2005;102:3225-3229.

11. Wei QP, Zhou $X$, Yang $L$, et al. The coexistence of mitochondrial ND6 T14484C and $12 \mathrm{~S}$ rRNA A1555G mutations in a Chinese family with Leber's hereditary optic neuropathy and hearing loss. Biochem Biophys Res Commun. 2007;357:910-916.

12. Qu J, Li R, Zhou X, et al. Cosegregation of the ND4 G11696A mutation with the LHONassociated ND4 G11778A mutation in a four generation Chinese family. Mitochondrion. 2007;7:140-146.

13. Beretta S, Mattavelli L, Sala G, et al. Leber hereditary optic neuropathy mtDNA mutations disrupt glutamate transport in cybrid cell lines. Brain. 2004;127:2183-2192.

14. Gonzalo R, Garcia-Arumi E, Llige D, et al. Free radicals-mediated damage in transmitochondrial cells harboring the $T 14487 \mathrm{C}$ mutation in the ND6 gene of mtDNA. FEBS Lett. 2005;579:6909-6913. 
15. Lenaz G, Baracca A, Carelli V, et al. Bioenergetics of mitochondrial diseases associated with mtDNA mutations. Biochim Biophys Acta. 2004;1658:89-94.

16. Easton DF, Pooley KA, Dunning AM, et al. Genome-wide association study identifies novel breast cancer susceptibility loci. Nature. 2007;447:1087-1093.

17. Tsao K, Aitken PA, Johns DR. Smoking as an aetiological factor in a pedigree with Leber's hereditary optic neuropathy. Br J Ophthalmol. 1999;83:577-581.

18. Floreani $M$, Napoli $E$, Martinuzzi $A$, et al. Antioxidant defences in cybrids harboring mtDNA mutations associated with Leber's hereditary optic neuropathy. Febs $J$. 2005;272:1124-1135.

19. Spruijt L, Kolbach DN, de Coo RF, et al. Influence of mutation type on clinical expression of Leber hereditary optic neuropathy. Am J Ophthalmol. 2006;141:676-682.

20. Pegoraro $E$, Carelli V, Zeviani $M$, et al. X-inactivation patterns in female Leber's hereditary optic neuropathy patients do not support a strong X-linked determinant. Am J Med Genet. 1996;61:356-362.

21. Oostra RJ, Kemp S, Bolhuis PA, Bleeker-Wagemakers EM. No evidence for 'skewed' inactivation of the $\mathrm{X}$-chromosome as cause of Leber's hereditary optic neuropathy in female carriers. Hum Genet. 1996;97:500-505.

22. Naumova AK, Leppert M, Barker DF, Morgan K, Sapienza C. Parental origin-dependent, male offspring-specific transmission-ratio distortion at loci on the human $X$ chromosome. Am J Hum Genet. 1998;62:1493-1499.

23. Imboden $M$, Swan $H$, Denjoy l, et al. Female predominance and transmission distortion in the long-OT syndrome. N Engl I Med. 2006;355:2744-2751.

24. Hudson G, Keers S, Yu Wai Man P, et al. Identification of an X-chromosomal locus and haplotype modulating the phenotype of a mitochondrial DNA disorder. Am J Hum Genet. 2005;77:1086-1091.

25. Vilkki J, Ott J, Savontaus ML, Aula P, Nikoskelainen EK. Optic atrophy in Leber hereditary optic neuroretinopathy is probably determined by an X-chromosomal gene closely linked to DXS7. Am J Hum Genet. 1991;48:486-491.

26. Carvalho MR, Muller B, Rotzer $E$, et al. Leber's hereditary optic neuroretinopathy and the X-chromosomal susceptibility factor: no linkage to DXs7. Hum Hered. 1992;42:316-320.

27. Sweeney MG, Davis MB, Lashwood A, et al. Evidence against an X-linked locus close to DXS7 determining visual loss susceptibility in British and Italian families with Leber hereditary optic neuropathy. Am J Hum Genet. 1992;51:741-748.

28. Juvonen V, Vilkki J, Aula P, Nikoskelainen E, Savontaus ML. Reevaluation of the linkage of an optic atrophy susceptibility gene to X-chromosomal markers in Finnish families with Leber hereditary optic neuroretinopathy (LHON). Am J Hum Genet. 1993:53:289-292. 
29. Chalmers RM, Davis MB, Sweeney MG, Wood NW, Harding AE. Evidence against an Xlinked visual loss susceptibility locus in Leber hereditary optic neuropathy. Am J Hum Genet. 1996;59:103-108.

30. Bu X, Yang HY, Shohat M, Rotter JI. Two-locus mitochondrial and nuclear gene models for mitochondrial disorders. Genet Epidemiol. 1992;9:27-44.

31. Mackey D. Blindness in offspring of women blinded by Leber's hereditary optic neuropathy. Lancet. 1993;341:1020-1021.

32. Petruzzella V, Tessa A, Torraco A, et al. The NDUFB11 gene is not a modifier in Leber hereditary optic neuropathy. Biochem Biophys Res Commun. 2007;355:181-187.

33. Carelli V, Ross-Cisneros FN, Sadun AA. Mitochondrial dysfunction as a cause of optic neuropathies. Prog Retin Eye Res. 2004;23:53-89.

34. Baracca A, Solaini G, Sgarbi G, et al. Severe impairment of complex 1-driven adenosine triphosphate synthesis in leber hereditary optic neuropathy cybrids. Arch Neurol. 2005;62:730-736.

35. Brown MD, Trounce IA, Jun AS, Allen JC, Wallace DC. Functional analysis of lymphoblast and cybrid mitochondria containing the 3460,11778 , or 14484 Leber's hereditary optic neuropathy mitochondrial DNA mutation. J Biol Chem. 2000;275:39831-39836.

36. Howell N. LHON and other optic nerve atrophies: the mitochondrial connection. Dev Ophthalmol. 2003;37:94-108.

37. Degli Esposti M, Carelli V, Ghelli A, et al. Functional alterations of the mitochondrially encoded ND4 subunit associated with Leber's hereditary optic neuropathy. FEBS Lett. 1994;352:375-379.

38. Ghelli A, Degli Esposti M, Carelli V, Lenaz G. Changes in mitochondrial complex I activity and coenzyme $\mathrm{Q}$ binding site in Leber's hereditary optic neuropathy (LHON). Mol Aspects Med. 1997;18 Suppl:S263-267.

39. Carelli V, Ghelli A, Bucchi L, et al. Biochemical features of mtDNA 14484 (ND6/M64V) point mutation associated with Leber's hereditary optic neuropathy. Ann Neurol. 1999:45:320-328.

40. Abu-Amero KK, Bosley TM. Increased relative mitochondrial DNA content in leucocytes of patients with NAION. BrJ Ophthalmol. 2006;90:823-825.

41. Ludwin S. The Axon: Structure, function and Pathophysiology. Oxford, UK: Oxford University Press, 1995:412-437

42. Qi X, Lewin AS, Hauswirth WW, Guy J. Suppression of complex I gene expression induces optic neuropathy. Ann Neurol. 2003;53:198-205.

43. Oi X, Sun L, Hauswirth WW, Lewin AS, Guy J. Use of mitochondrial antioxidant defenses for rescue of cells with a Leber hereditary optic neuropathy-causing mutation. Arch Ophthalmol. 2007;125:268-272. 


\section{Summary \\ \&}

Samenvatting

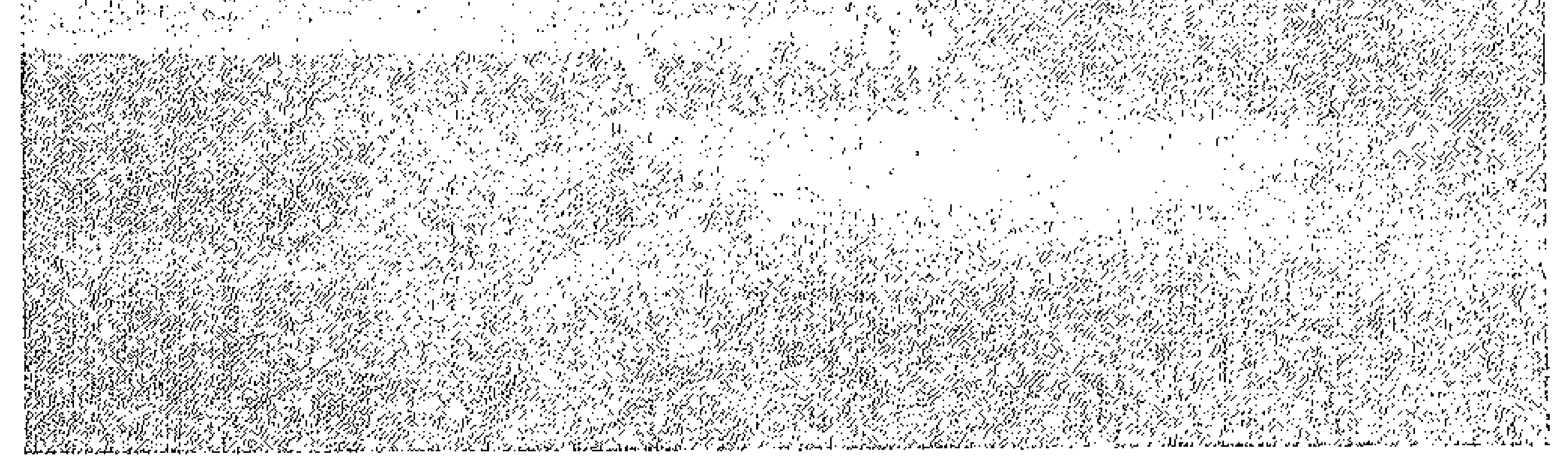




\section{Summary}

Leber's hereditary optic neuropathy (LHON) is a mitochondrial-inherited disorder that characteristically presents with a (sub) acute painless, impaired vision in previous healthy persons predominantly in the second and third decade of life. The penetrance of the disease is not complete. Males are for a yet unexplained reason predominantly affected. It becomes more and more clear that the clinical expression is more variable than was initially thought. The exact disease mechanism and genetic factors of influence on the expression are in spite of many years of research still unknown.

In this thesis we describe diverse approaches to study the pathogenesis of Leber's Hereditary Optic Neuropathy (LHON). In chapter 1 a general introduction of the function, structure and biochemical processes of mitochondria in general are explained and the general aspects of LHON are summarized in chapter 2.

Patient characteristics in a large group of LHON patients were studied retrospectively (chapter 3). The m.14484T>A mutation is a milder mutation with a higher chance for recovery. We found a higher recovery rate in $\mathrm{m} .11778 \mathrm{~A}>G$ mutation carriers than was reported before. There is a slower onset of symptoms in m.11778A>C mutation carriers and children. The recovery that takes place does not occur before one year and not after four years after the initial onset of symptoms.

Visual impairment is usually the sole symptom of LHON. Rarely extra ocular complaints like cardiac symptoms (hypertrophic cardiopmyopathy, preexcitation defects) have been described. In chapter 4 we studied prospectively if cardiac symptoms are more often present in LHON mutation carriers than in the normal population and if structural screening for this is warranted. In a group of LHON mutation carriers, both affected and unaffected, we found the same prevalence of cardiac defects as in the general population suggesting that previous studies were biased. But supplementary studies are required before we can conclude that specific cardiac surveillance is not necessary in LHON patients.

It is clear that the mtDNA LHON mutation alone is not sufficient to explain the phenotype and additional factors are very likely involved. Although genome wide linkage studies confirmed the role of multiple nuclear-encoded modifier genes in the phenotypical expression of LHON, no mutations in these modifier genes have yet been identified. So presumably, this approach is not successful in a rare and complicated disorder as LHON is. The genetic 
models that were used in the linkage calculations may not have been correct and more complex than assumed. Exploring the mitochondrial dysfunction at the biochemical level could be a valuable different approach. In chapter 5 we describe a relatively new method to measure complex I activity in circulating lymphocytes and show that this assay is relatively easy, noninvasive and that the results are reproducible.

We applied this method in a large group of LHON patients in chapter 6 and showed a defect in the complex I activity in affected and unaffected $m \cdot 3460 \mathrm{G}>\mathrm{A}$ mutation carriers that was not present in the other LHON mutations. Defects in the respiratory chain complexes can lead to reactive oxygen species (ROS) overproduction and consequently to cell damage. The slightly higher complex 1 activity in the affected m.11778G $>\mathrm{A}$ and $\mathrm{m} .14484 \mathrm{~T}>\mathrm{C}$ mutation carriers could indeed point into that direction. An increased citrate synthase (CS) activity was detected in all unaffected LHON patients, indicating an increase in the number of mitochondria and a possible compensation mechanism. In affected m.11778G $>\mathrm{A}$ and m.14484 $>C$ mutation carriers it might be possible to recognize a biochemical phenotype, because of the presence of an increased activity of the first respiratory chain enzyme complex.

In order to find a further explanation for the heterogenic expression of LHON we studied families that presented with unusual clinical symptoms or with additional signs and symptoms. In these families we screened the entire mtDNA to find out if the different expression was the result of a rare LHON mutation or of the (concordant) presence of another mtDNA mutation. In a m.14484T>C mutation carrier with LHON, encephalomyopathy and deafness a second mtDNA mutation in the tRNA lle m.4269A>G gene was detected explaining the extra-ocular symptoms better than the m.14484T $>C$ alone (chapter 7 ).

In Chapter 8 a new mutation in the ND1 gene was reported in a family with LHON in one, and childhood onset dystonia in the other sibling. A rare m.3697G $>A / N D 1$ mutation was detected as well as an isolated complex I deficiency. The mutation caused in this family a very diverse clinical phenotype in two siblings. The clinical characteristics in them were similar as in other LHON/dystonia families, but were never reported in patients with a ND1 mutation.

The incomplete penetrance of LHON can be explained by an interaction of the primary LHON mutation with additional genetic factors. The m.11778G $>A$ and m.14484T>C LHON mutation have been present both more often in combination with a specific mtDNA genetic haplotype. In a large study we showed that there was a higher risk of visual impairment 
with a J haplotype ( $\mathrm{J}_{2}$ for the $\mathrm{m} .11778 \mathrm{G}>\mathrm{A}$ and $\mathrm{J}_{1}$ for the m.14484 $\mathrm{T}>\mathrm{C}$ mutation). When a m.11778G $>A$ mutation and $\mathrm{H}$ haplotype were present the risk of visual impairment was reduced. These findings can be possibly explained by certain substitutions in the MTCYB gene indicating that small and normal genetic polymorphisms can have a significant effect on the expression of apparent monogenic disorders. (chapter 9 ).

Since nuclear genes are capable of influencing the phenotype of a mitochondrial disorder and males are more often affected in LHON we have been searching for a X-chromosomal haplotype. We identified a risk haplotype that could explain the variable penetrance and male predominance in the majority of the LHON families. However, how exactly this influences the phenotype is not yet clear. (chapter 10). Not all LHON families had this X-linked risk haplotype indicating that there do exist other autosomal modifying genes. Although a risk haplotype was found, the gene could not be identified so far. 


\section{Samenvatting}

Leber's hereditaire optic neuropathy (LHON) is een mitochondriaal overervende ziekte die karakteristiek presenteert met een (sub)acute slechtziendheid bij tot dan toe gezonde personen. De klachten ontstaan meestal op jong volwassenen leeftijd. De penetrantie van de ziekte is niet compleet en mannen zijn vaker aangedaan dan vrouwen. De reden hiervoor is nog niet bekend. Het wordt steeds duidelijker dat de klinische expressie van LHON variabeler is dan aanvankelijk gedacht. In dit proefschrift hebben we met behulp van verschillende benaderingsmethoden de pathogenese van LHON verder onderzocht. Van deze ziekte zijn zowel het exacte ziekte mechanisme als de genetische factoren van invloed op de expressie nog niet bekend.

In hoofdstuk 1 wordt een algemene inleiding over de functie, structuur, betrokken genen en biochemische functies van mitochondriën gegeven. Hoofdstuk 2 geeft een meer specifiek overzicht van de verschillende klinische en genetische kenmerken van LHON.

In hoofdstuk 3 beschrijven we retrospectief de relatie tussen de genetische en klinische kenmerken van een grote groep LHON patiënten. De m.14484T $>C$ mutatie is relatief mild omdat er een grotere kans is op herstel. Maar ook de m.11778 $>\mathrm{G}$ mutatiedragers hebben een grotere kans op herstel dan tot nu toe in de literatuur werd beschreven. Het verloop van de klachten is minder acuut bij kinderen en bij volwassen m.11778>G mutatiedragers. Gewoonlijk begint het herstel niet eerder dan 1 jaar, en niet later dan 4 jaar, nadat de eerste symptomen van de ziekte zijn ontstaan.

Meestal is slechtziendheid het enige symptoom van LHON. Zelden hebben patiënten ook extraoculair klachten zoals cardiale klachten (hypertrofe cardiomyopathie, pre-excitatie stoornissen). Omdat de meeste studies slechts een casus of specifieke familie bestudeerden hebben wij bij een groep individuele LHON patiënten prospectief onderzocht of cardiale klachten deel uit maken van het klinische spectrum van LHON (hoofdstuk 4). In een groep dragers van een primaire LHON mutatie, zowel symptomatische als niet symptomatische patiënten, werden cardiale afwijkingen met een zelfde prevalentie gevonden als in de algemene populatie. Dit suggereert dat in eerdere studies mogelijk teveel geselecteerd is op het voorkomen van cardiale afwijkingen, maar dat aanvullende studies nodig zijn vooraleer we kunnen concluderen dat specifieke cardiale controles bij LHON patiënten al dan niet nodig zijn. 
Het is duidelijk dat een mtONA LHON mutatie alleen onvoldoende is om te verkaren waar. om iemand LHON klachten krijgt. Niet alle mutatiedragers ontwikkelen immers kiachten Zeer waarschinnlijk zijn er andere additionele factoren die bepalen of iemand symptoma. tisch wordt. Dit kunnen omgevingsfactoren of (epi)genetische factoren zijn. Hoewel lin kage studies hebben bevestigd dat er zeer warschijnlijk multipele nucleair-gecodeerde modificerende genen een rol spelen in de expressie van het LHON fenotype, werd tot nu toe geen mutatie in een van deze genen ontdekt. Linkage in fen complexe en zeldzame aandoeningen zoals LHON is mogelijk niet de beste methode om deze genen aan te tonen Als alternatieve benadering hebben wij gezocht naar een biochemisch fenotype. Indien deze kan worden aangetoond dan kan via complementatie studies een dergelijk modificerend gen mogelijk wel worden geidentificeerd. In hoofdstuk 5 ontwikkelden we een methode waarmee verschillende biochernische metabolieter konden worden gemeten in circulerende witte bloed cellen. Deze methode kan verricht worden op een kleine hoeveelheid bloed waardoor het weinig invasief is. Daarnaast is de methode relatief eenvoudig uit te voeren en zijn de resultaten reproduceerbaar.

Deze biochemische methode hebben we vervolgens toegepast op LHON patiënten met een van de drie primaire mutaties verdeeld over symptomatische en niet-symptomatische mutatie dragers (hoofdstuk 6). Onverwacht vonden we een verhoogde activiteit van complex 1 in symptomatische m.11778G $>A$ en m.14484T $>C$ mutatie dragers. Defecten in de ademhalingsketen zouden kunnen resulteren in een averproductie van vrije radicalen en vervolgens voor celschade zorgen. De verhoogde citraat synthase (CS) activiteit welke werd gevonden bij niet-symptomatische LHON mutatie dragers is toe te schrijven aan een toename in het aantal mitochondriën. Dit zou een compensatie mechanisme kunnen zijn voor een defect in complex l. Juist in deze mutatiedragers kan het mogelijk zijn een modificerend gen aan te tonen op de basis van onze methode.

Klinisch patiënten onderzoek leerde ons dat de presentatie van LHON variabeler dan gedacht is. Het verschil in expressie zou verklaard kunnen worden door een zeldzame LHON mutatie of een simultaan voorkomende mtDNA mutatie. We hebben daarom in een aan aantal families met een ongewone klinische presentatie het complete mtDNA onderzocht op mutaties (hoofdstuk 7 ). Een patiënt met een bekende m.14484T $>C$ mutatie had naast LHON symptomen ook nog een progressieve encefalomyopathie en doofheid. De bijkomende m.4269A>G mutatie in het tRNA lle gen verklaart deze additionele symptomen beter dan de $\mathrm{m} .14484 \mathrm{~T}>\mathrm{A}$ mutatie alleen.

In hoofdstuk 8 beschrijven we een tweede familie waarin een vrouw met klassieke LHON 
klachten geen van de tien meest voorkomende LHON mtDNA mutaties had. Zij had een broer met een ernstige dystonie welke was begonnen op de jonge kinderleeftijd. Bij hen werd een nieuwe zeldzame m.3697G>A/ND1 mtDNA mutatie gevonden en een geisoleerd complex I deficiëntie. In deze familie veroorzaakte dit een zeer divers klinisch beeld, verschillend tussen een broer en een zus.

De incomplete penetrantie van LHON kan mede verklaard worden door de interactie van de primaire mutatie met bijkomende genetische factoren. De m.11778G $>$ A en m.14484T $>C$ LHON mutaties worden beide vaak aangetoond in combinatie met een specifiek mtDNA genetisch haplotype. In een grote studie toonden we aan dat het risico op slechtziendheid groter is met een J haplotype ( $\mathrm{J} 2$ voor de m.11778G $>$ A en J1 voor de m.14484T>C mutatie). Indien de $m .11778 \mathrm{G}>\mathrm{A}$ mutatie met een $\mathrm{H}$ haplotype voorkomt is de kans op slechtziendheid juist kleiner. Waarschijnlijk wordt dit verklaard door bepaalde substituties in het MTCYB gen. Dit bewijst dat kleine en in feite normale genetische varianten een opmerkelijk effect hebben op de expressie van een schijnbaar monogeen overervende mtDNA aandoening (hoofdstuk 9).

Omdat bepaalde nucleaire genen het fenotype van een mitochondriale aandoening modificeren en er meer mannen dan vrouwen symptomatisch worden hebben we in eerste instantie gezocht naar een X-chromosomaal haplotype. We identificeerden een risico haplotype op het $X$-chromosoom die de variabele penetrantie en predominante van de ziekte bij mannen verklaart in een meerderheid van de LHON families. De reden dat deze sequentie variatie van invloed is op het fenotype is echter nog niet duidelijk (hoofdstuk 10). Het $X$-linked risico haplotype kon echter niet in alle LHON families worden geïdentificeerd. Dit betekent dat er ook nog autosomale modificerende genen zouden bestaan. Hoewel we een risico haplotype konden identificeren kon het exacte modificerende gen niet worden aangetoond. 


\section{Dankwoord}

Mijn dankwoord is letterlijk het laatste "loodje" ter afronding van dit proefschrift. Allereerst vloeit die dankbaarheid voort uit een enorme opluchting dat het werk erop zit! Maar uiteraard ben ik ook een aantal mensen dankbaar die dit werk mede mogelijk hebben gemaakt.

Het is op zijn plaats om mijn copromotoren Dr. H.J. Smeets en Dr.C.E.M. de Die-Smulders als eerste te bedanken. Beste Bert, zonder jouw vertrouwen in mij als (arts)onderzoeker en de aanstelling die je mogelijk maakte aan de Universiteit Maastricht nadat ik de opleiding tot Klinisch Geneticus had afgerond, zou dit proefschrift letterlijk niet afgemaakt zijn. Hoewel ik eerder een klinisch "artsonderzoeker" was dan de basiswetenschapper, die jij bent, is het toch gelukt om samen dit proefschrift voor elkaar te krijgen.

Beste Christine, van jou heb ik helder en georganiseerd leren werken, iets wat me nu in het dagelijkse werk nog veel profijt oplevert. Jouw kritiek op mijn speciale vorm van "slordigheids dyslexie" hebben me alert gemaakt en ik ben je zeer erkentelijk voor de goede suggesties, snelle correcties en vooral zeer positieve aanmoedigingen tijdens mijn promotietraject.

Mijn promotor, Prof dr. C.T.R.M. Schrander-Stumpel, beste Connie. Ik ben je erkentelijk voor een gedegen en zeer brede opleiding tot klinisch geneticus. Om daarna een promotie voor elkaar te krijgen, hoewel ik eigenlijk al ergens anders aan het werk was, was een hele uitdaging. Fijn dat je er in deze laatste fase bij wilt zijn.

Dr. I.F.M. de Coo, beste René. Jij bent een door en door geroutineerde mitochondriën specialist. De vele ritjes naar Rotterdam, de LOA-dagen en Leber patiënten die we samen zagen zijn een leuke herinnering. Jij bent een échte dokter en voor mij een voorbeeld hoe een dokter, zelfs in een academisch ziekenhuis, zeer nauw betrokken is bij zijn patiënten.

In één adem wil ik Dr. Wim Sluiter noemen die mij de kneepjes van het erg ingewikkelde vak biochemie leerde en hierin een ware onderwijzer bleek. Je positieve instelling hielp mij ook om toch weer meer data te gaan verzamelen ondanks het vele werk.

Elly de Wit, jij hebt mij de praktische zaken in het lab geleerd en het was altijd gezellig bij een beker Caffiato! Kees Schoonderwoerd en Jasper Scholte, ook betrokken bij de RoMa meetings en onze gedeelde interesse in de mitochondriën. Ten slotte wens ik Alex Korsten, die het LHON-stokje in Rotterdam over heeft genomen, veel succes, wijsheid en inspiratie. toe. 
Mijn lieve paranimf Hermiene, ik vind het heel fijn dat je me ook weer vandaag wilt bijstaan, zoals al eerder bij belangrijke gebeurtenissen in mijn leven. Jouw vriendschap is erg belangrijk voor me en ik hoop dat we nog vele meiden uitjes mogen beleven.

Mijn andere paranimf en collega, beste Carlo, heel fijn dat je me vandaag wil bijstaan zoals je ook als collega en vriend (samen met Liedewij) altijd klaar voor mij staat. Dank je wel.

Francis van der Lubbe, lieve Francis. Wat heb je weer iets moois voor me gemaakt. Dank je voor al het werk dat je aan het proefschrift hebt gehad, maar ook al vele malen vaker op het werk in Maastricht.

Hannes Wallrafen, fotograaf van de prachtige foto "de boom" op de voorkant van dit boekje. De dreiging van de donkere lucht, gelijk aan de ziekte, is symbolisch voor de veranderingen die Leber in een leven teweeg brengt. Dank je wel dat ik de foto mag gebruiken.

Belangrijk voor dit proefschrift waren mijn contacten met de LOA patiëntenvereniging. Voorzitter Ton Hulskramer en alle betrokken mensen en patiënten met dikwijls indrukwekkende verhalen over deze onbegrepen ziekte, bedankt!

Dear Patrick Chinnery, thank you very much for the great cooperation with your research group. Thanks for sharing the large projects.

Prof. Niermeijer voor het meeschrijven aan mijn introductie en alle andere medeauteurs van de artikelen.

Dinanda Kolbach, niet alleen medeauteur die mij epidemiologische kennis bijbracht maar ook leerde doorzetten met de data die ik had en dat dat best al meer was dan ik in eerste instantie dacht.

De collega's van de Klinische Genetica Maastricht, medeopleiders waar ik de kneepjes van het vak van heb geleerd Dominique en Ute. Kamergenoot en medeassistent Yvonne en daarna Maaike, Susanne, Wendy en Meijke. Het secretariaat Petra, Juliette, Elke, Jolanda, Margriet, Yvette, Liesbeth met wie ik ook veel gezellige praatjes kon maken tussen de werkzaamheden door.

De collega's van mijn "tweede baan" aan de Universiteit Maastricht, in het bijzonder Mike, Alexandra en Rien.

Stimulerend voor mijn welzijn in Nijmegen zijn mijn nieuwe collega's in Nijmegen van de afdeling Klinische Genetica geweest. De relaxte sfeer en teamgeest zorgde dat ik voldoende ruimte in mijn hoofd over had om dit proefschrift naast de "gewone" werkzaamheden 
af te maken. Lieve Yvette, je bent meer dan een P.A. Ineke, bedankt voor de niet werkgerelateerde sfeer op de kamer. Staf, secretariaat, consulenten, MW, assistenten; allemaal bedankt! Na de promotie (net iets later) ben ik weer volledig beschikbaar.

Ten slotte mijn familie en vrienden. Als kind al was ik bezig met de stambomen. Toen had ik nog niet eens door dat er ook een beroep bestond dat zich bezig hield met stambomen. lk denk hier nog vaak aan terug als ik aan het puzzelen ben tijdens mijn werk. De weekenden en avonden waarin het werk van deze promotie werd verricht zullen nu ook weer ingevuld worden met andere interesses. En de dagen dat het stralen mooi weer was en ik me afvroeg wat ik in hemelsnaam achter mijn computer aan het doen was, en vooral WAAROM, zal ik waarschijnlijk dan ook dubbel genietend doorbrengen.

Lieve papa en mama, die door mij aan het schrikken waren gebracht door het afzakken naar de HAVO, om vervolgens te blijven zitten. Het is nu toch goed gekomen, niet?

Mijn lieve Rob, die gelukkig niet onder de indruk is van ambities en carrière maar er juist apentrots op is. Jij bent er altijd als ik je nodig heb en ik ben blij met alle steun rondom mijn promotie. Jij bent mijn rustpuntje..... en soms ook onrustpuntje waardoor ons leven prachtig in balans is. Na dit wel erg hectische jaar met een handvol aan "life-time-events" gaan we nu van onze (bijna) twee kindjes, huis en wat rustiger (?) werk genieten, ok? Veel liefs.

Liesbeth 


\section{Curriculum Vitae}

Liesbeth Spruijt werd geboren op 18 juli 1970 te Amersfoort. Na de HAVO en het VWO, die werden afgerond in 1990 op het van der Puttlyceum te Eindhoven, studeerde zij geneeskunde aan de Universiteit van Antwerpen vanwege uitloting in Nederland. De wetenschap stage van een half jaar werd verricht op de afdeling Kindergeneeskunde van het Universitair ziekenhuis van Bologna (Italië) waar het onderzoek "De invloed van prenatale diagnostiek op het voorkomen van Down syndroom" werd verricht. De geneeskundeopleiding werd in 1997 afgerond "met onderscheiding".

In 1998 werkte ze als arts-assistent niet in opleiding (AGNIO) Neonatologie op de Neonatale Intensive Care Unit (NICU) van het toenmalige Sint Joseph Ziekenhuis te Veldhoven. In 1999 werd een jaar onderzoek verricht naar mitochondriële aandoeningen op de afdeling Biochemical Genetics, UCSD (San Diego, USA) van Prof. W.L. Nyhan. Dit werd mogelijk gemaakt door het Ter Meulen Fonds van de Koninklijke Nederlandse Academie voor Wetenschappen. In 2000/2001 werden "stap 1 en 2" van het Amerikaans Arts examen (USMLE) gehaald.

Na terugkomst in Nederland, aanvankelijk als AGNIO, startte de opleiding tot Klinisch Geneticus in 2001 (opleider Prof. dr Schrander-Stumpel). Tijdens deze opleiding begon zij met het onderzoek naar LHON. Na afronding van de opleiding tot Klinisch Geneticus op 31 december 2004 verhuisde zij naar Nijmegen en werkte in 2005 en 2006 parttime als arts-onderzoeker aan de Universiteit van Maastricht op de afdeling Genetica en Celbiologie waar het LHON onderzoek met Dr. H.J. Smeets werd voortgezet. Sinds 1 januari 2006 is zij werkzaam als Klinisch Geneticus in het Universitair Medisch Centrum Sint Radboud te Nijmegen. Ze is getrouwd met Robert van Maanen en samen hebben zij een dochter Alice. 


\section{Publications}

1. L. Spruijt, M. de Kleine, L. Verhoef. Het perinataal voorkomen van Haemophilus influenzae. Tijdschrift Sint Joseph Ziekenhuis, Veldhoven, 1998.

2. L. Spruijt, M van der Blij-Philipsen, J. Engelen, C. Schrander-Stumpel. An adult patient with a distal 149 deletion: clinical report and literature review. Genetic Counseling $2000,11,335-340$.

3. L. Spruijt, B. Barshop, R. Naviaux, K. McGowan, W. Nyhan, G. Sheean, R. Haas. Decline in nerve conduction parameters during administration of dichloroacetate. Muscle and Nerve, 2001, 24, 916-924.

4. L. Spruijt, K Devriendt, J. Offermans, S. Bulstra, C. Schrander-Stumpel. VATER- tibia aplasia association: report on two patients. Clin Dysmorph; 2002, 11: 283-287.

5. J. Edmonds, D Kirse, D Kearns, R Deutsch, L. Spruijt, R. Naviaux. The otolaryngological manifestations of mitochondrial disease and the risk of neurodegeneration with infection. Arch Otolaryngol Head Neck Surg, 2002, 128: 355-362.

6. N. Howell, R. Oostra, P. Bolhuis, L. Spruijt, L. Clarke, D. Mackey, C. Preston, C. Herrnstadt. Sequence analysis of the mitochondrial genomes from Dutch LHON pedigrees. Am J Hum Genet. 2003, 72: 1460-1469.

7. L. Spruijt, J. Engelen, I. Bruinen-Smeijsters, J. Albrechts, J Schrander, C. Schrander-Stumpel. A patient with a de novo 15q24926.1 interstitial deletion, developmental delay, mild dysmorphism, and very blue irises. Am J Med Genet. 2004; 129A(3):312-315.

8. M. Zeegers, F. van Poppel, L. Spruijt, R. Vlietinck, H. Ostrer. Founder mutations among the Dutch. Eur J Hum Genet, 2004, 12: 591-600.

9. L. Spruijt, J. Fryns, J. Engelen, M. Alofs, J. Abrechts, J. Hanekom, C. Schrander-Stumpel. A patient with a de novo 11q24.24qter deletion with features of Jacobsen Syndrome. Genetic Counseling, 2004, 15: 1-7. 
10. C. Schrander-Stumpel, L. Spruijt, H. van der Vlught, T. Defloor, L. Curfs, J. Schrander. Kabuki syndrome: clinical data in 20 patients, literature review and further guidelines for preventive management. Am J Med Genet. 2005 Jan 22; 132A(3):234-243.

11. A. van Steensel, L. Spruijt, I. van der Burgt, R. Bladergroen, M. Vermeer, P. Steijlen, M. van Geel. A 2-bp deletion in the GJA1 gene is associated with oculo-dento-digital dysplasia with palmoplantar keratoderma. Am J Med Genet. 2005 Jan 15; 132A(2):171-174.

12. L. Spruijt, P.Verdyck, W.van Hul, W.Wuyts, C. de Die-Smulders. A new mutation in the MSX2 gene in a family with foramina parietalia permagna (FPP). Am J Med Genet. $2005 ; 139 A(1): 45-47$.

13. G. Hudson, S.M. Keers, Y.W.P. Man, P. Griffiths, K. Huoponen, M-L Savontaus, E. Nikoskelainen, M. Zeviani, F. Carrara, R. Horvath, V. Karcagi, L. Spruijt, I.F.M. de Coo, H.J.M. Smeets, P.F. Chinnery. Identification of an X-chromosomal locus and Haplotype modulating the phenotype of a mtDNA disorder. Am J Hum Genet 2005, 17:1086-1091.

14. L. Spruijt, J. Hoogendijk, A.T.M. Hendrickx, G. I.F. de Coo, P.A. Doevendans, PTVM. de Jong, H. Kroes, H.J.M. Smeets. Additional mitochondrial DNA mutations may explain extra-ocular involvement in LHON. Am J Med Genet, 2006, 140(13): 1478-1481.

15. L. Spruijt, L. Hoefsloot, G. van Schaijk, D van de Waardenburg, B Kremer, C. de Die-Smulders. EYA1 mutation presenting in a newborn with tracheamalacia, retrognathia and pectus excavatum. Am J Med Genet 2006, 140 (12):1343-1345.

16. L. Spruijt, D. Kolbach, R. de Coo, A. Plomp, N Bauer, H. Smeets, C. de Die-Smulders. Influence of mutation type on clinical expression of Leber hereditary optic neuropathy. Am J Ophthalmol 2006 141:676-82.

17. M.J. Blok* / L. Spruijt*, I F M de Coo, K Schoonderwoerd, A. Hendrickx, H.J. Smeets. Mutations in the ND5 subunit of complex I of the mtDNA are a frequent cause of OXPHOS disease. J Med Genet 2007 Apr; 44(4): e74.

18. L. Spruijt. Leber Hereditary Optic Neuropathy. Encyclopedia of Life Science. Wiley and Sons, United Kingdom. DOI: npg.els.0005541. Online: june 2007 
19. L. Spruijt, H.J. Smeets, A. Hendrickx, M.W. Bettink-Remijer, A. Maat-Kievit, K.C. Schoonderwoerd, W. Sluiter, I. F. de Coo, R.O. Hintzen. A novel MELAS-associated NDi mutation causing LHON and spastic dystonia. Arch Neurol; 2007 Jun;64(6):890-893.

20. G. Hudson, V. Carelli, L. Spruijt, M. Gerards, C. Mowbray, A. Achilli, A. Pyle, J. Elson, N. Howell, C. La Morgia, M.L.Valentino, K. Huoponen, M. Savontaus, E. Nikoskelainen, A.A. Sadun, S.R. Salomao, R. Belfort Jr, P. Griffiths, P. Man, I.F de Coo, R. Horvath, M. Zeviani, H.J. Smeets, A. Torroni, P.F. Chinnery. Increase penetrance of LHON with a J background. Am J Hum Genet. 2007, 81(2):228-233

21. E. de Wit, L. Spruijt, K. Schoonderwoerd, H.Smeets, R de Coo, W Sluiter. A new sensitive spectrophotometric assay to detect respiratory chain complex I deficiency in blood lymphocytes. J Immunol Methods, 2007, 326(1-2):76-82.

22. E. van Os, H. Niemarkt, M. Verreusel, V. Bok, L. Spruijt. Twee patiënten met congenitale aniridie; Wanneer bestaat de noodzaak tot screening op Wilms tumoren? NTVG, in press, 2007

23. A. Nemes, I.F. de Coo, L. Spruijt, H.J. Smeets, P.F. Chinnery, O.I. Soliman, M.L. Geleijnse, F.J. ten Kate. Is there alteration in aortic stiffness in Leber`s hereditary optic neuropathy? Eur J Ophthalmol in press, 2007. 